\title{
Measurements of Heat and Combustion Products in Reduced-Scale Ventilation-Limited Compartment Fires
}

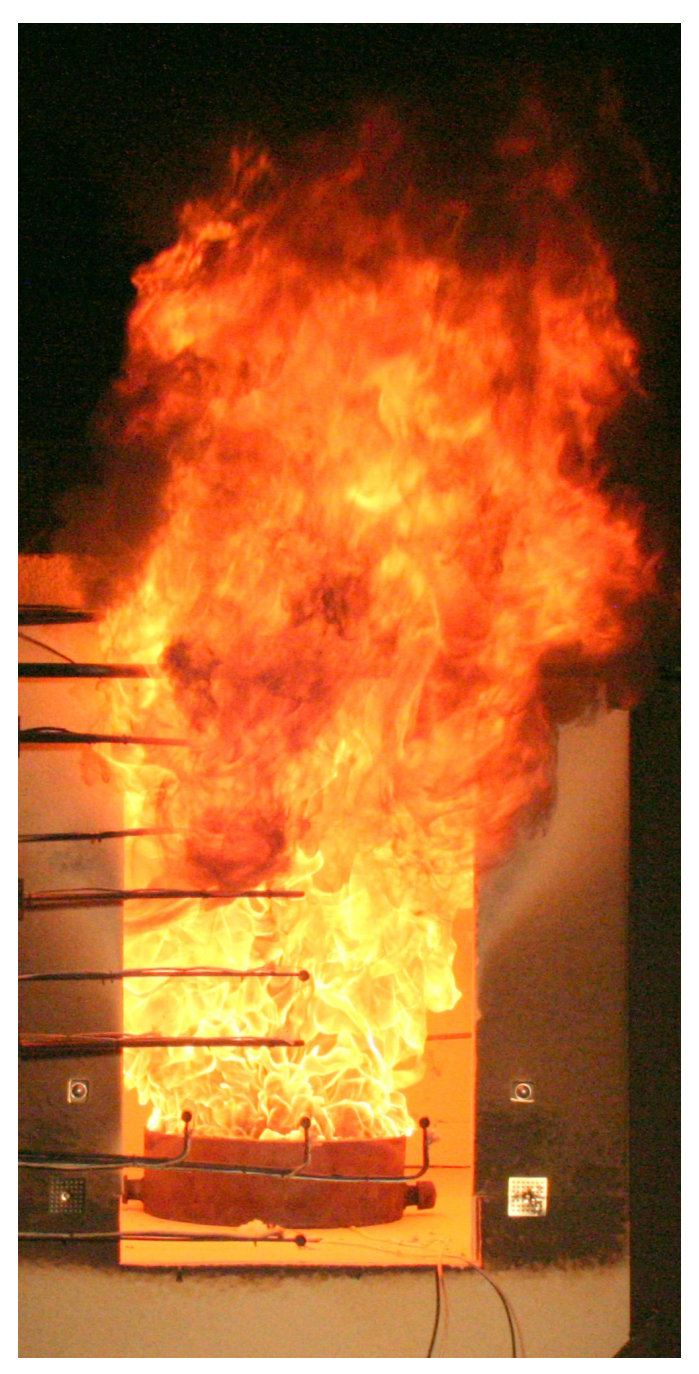

Matthew Bundy

Anthony Hamins

Erik L. Johnsson

Sung Chan Kim

Gwon Hyun Ko

David B. Lenhert

U.S. Department of Commerce

Technology Administration

Building and Fire Research Laboratory

National Institute of Standards and Technology

Gaithersburg, MD 20899 


\title{
NIST Technical Note 1483
}

\section{Measurements of Heat and Combustion Products in Reduced-Scale Ventilation-Limited Compartment Fires}

\author{
Matthew Bundy \\ Anthony Hamins \\ Erik L. Johnsson \\ Sung Chan Kim \\ Gwon Hyun Ko \\ David B. Lenhert
}

U.S. Department of Commerce Technology Administration Building and Fire Research Laboratory

National Institute of Standards and Technology Gaithersburg, MD 20899

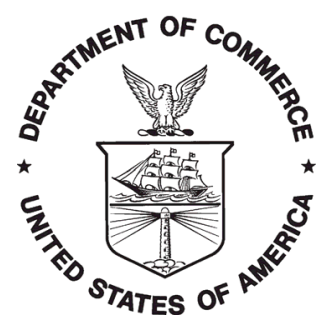

U.S Department of Commerce Carlos M. Gutierrez, Secretary Technology Administration Robert Cresanti, Under Secretary of Commerce for Technology National Institute of Standards and Technology William Jeffery, Director 
Disclaimer:

Certain commercial equipment, instruments, or materials are identified in this document. Such identification does not imply recommendation or endorsement by the National Institute of Standards and Technology, nor does it imply that the products identified are necessarily the best available for the purpose.

National Institute of Standards and Technology Technical Note 1483

Natl. Inst. Stand. Technol. Tech. Note 1483, 147 pages (July 2007)

CODEN: NSPUE2 


\section{Table of Contents}

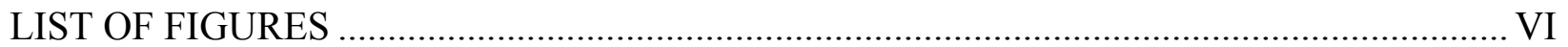

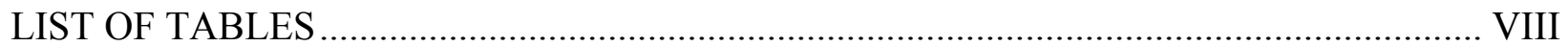

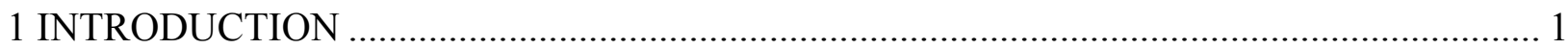

1.1 Background and Relationship to Current Research ............................................................. 2

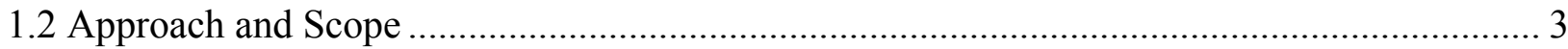

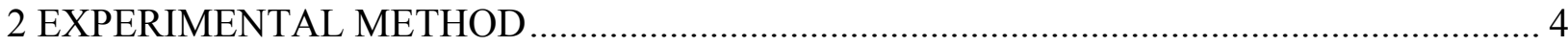

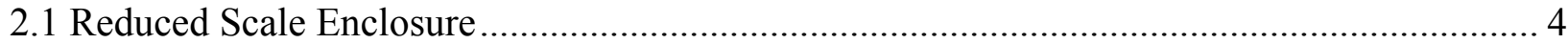

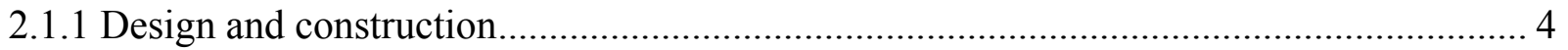

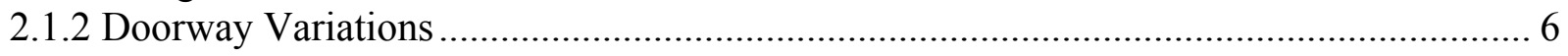

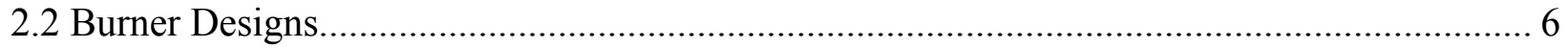

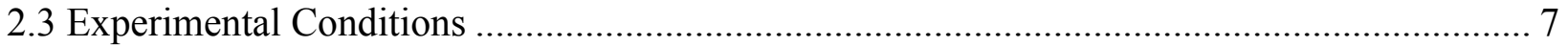

2.4 Measurement Locations ............................................................................................ 8

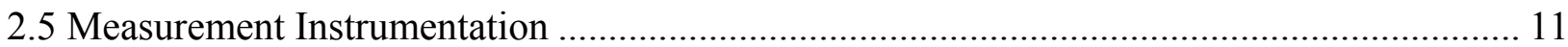

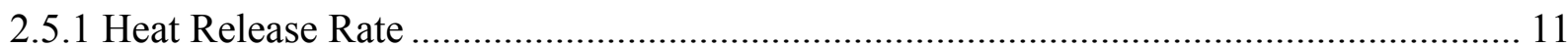

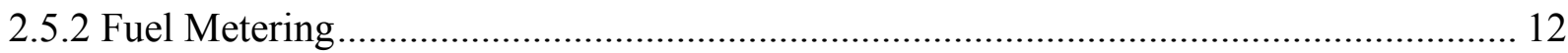

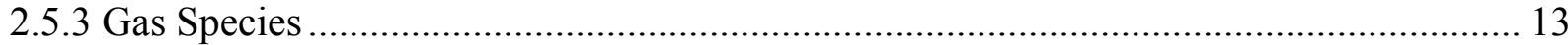

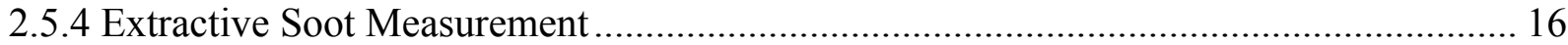

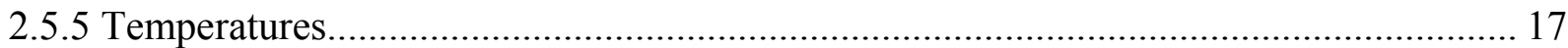

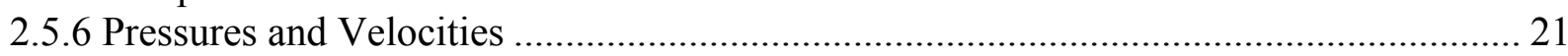

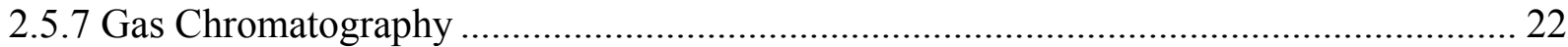

2.5.8 Optical Extinction Soot Measurements …………....................................................... 24

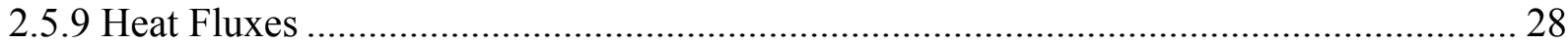

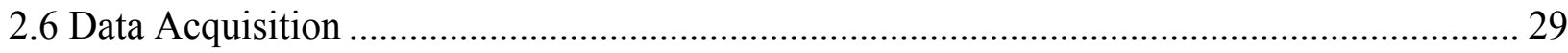

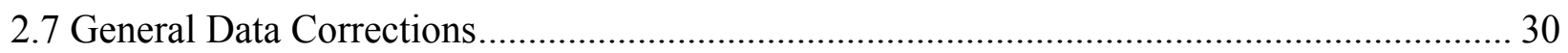

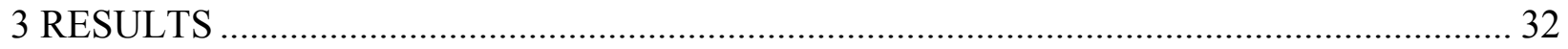

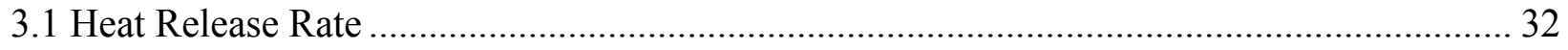

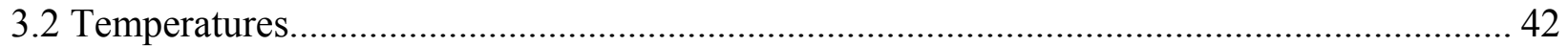

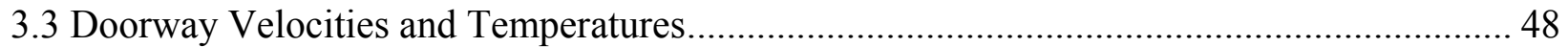

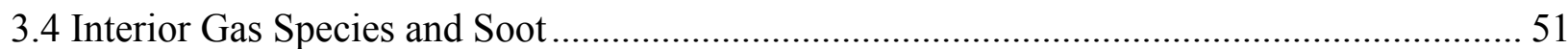

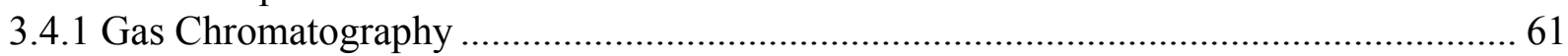

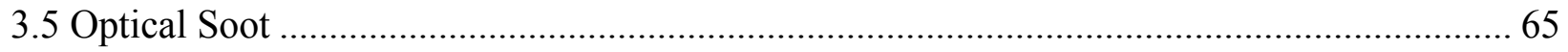

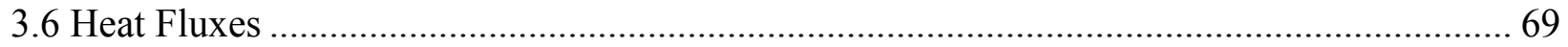

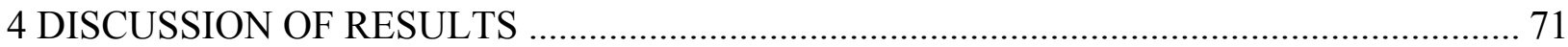




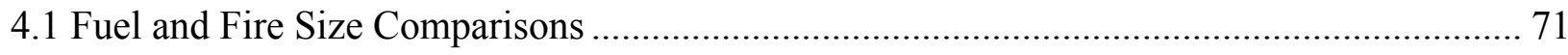

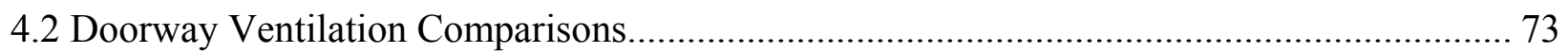

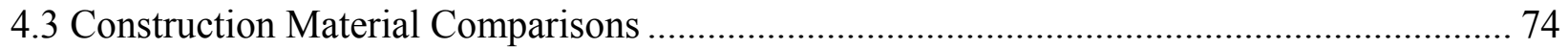

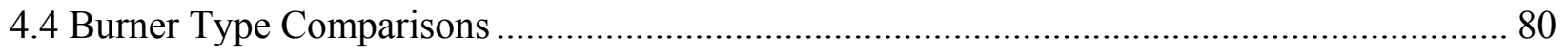

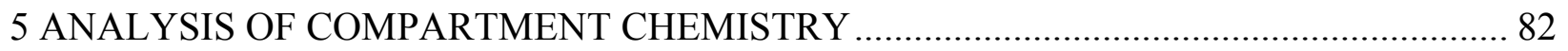

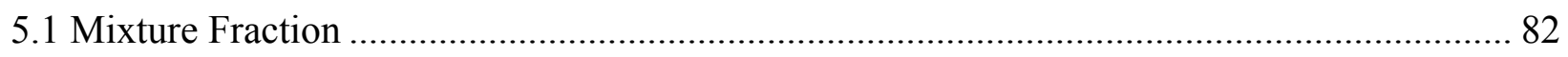

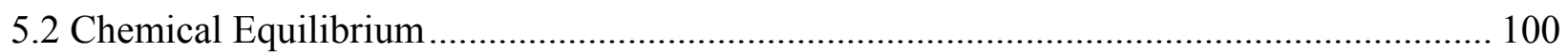

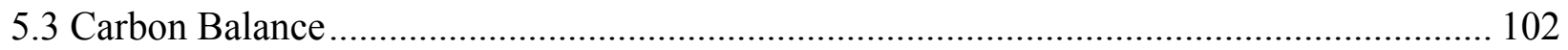

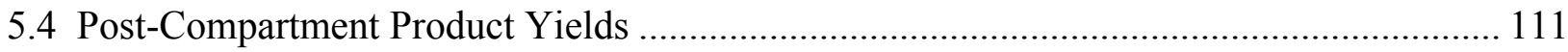

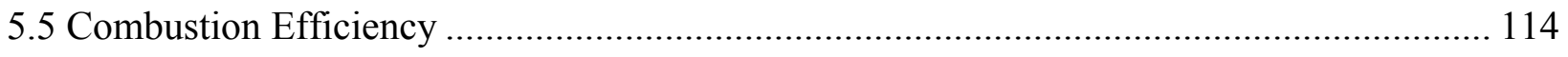

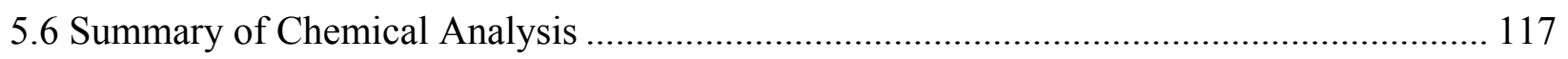

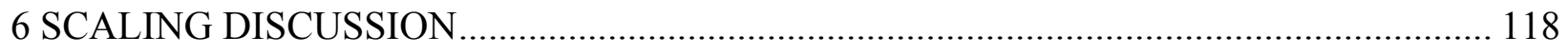

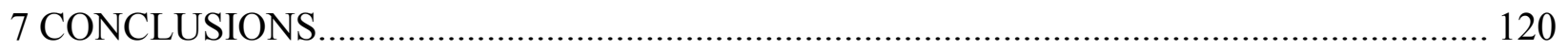

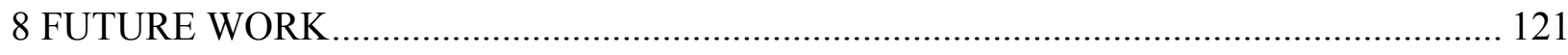

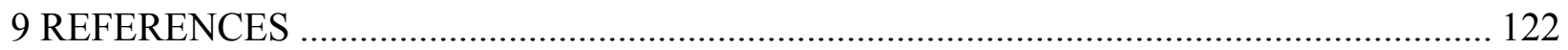

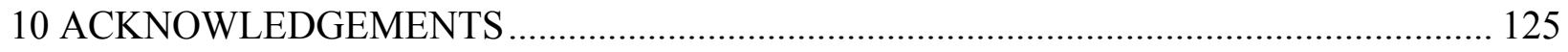

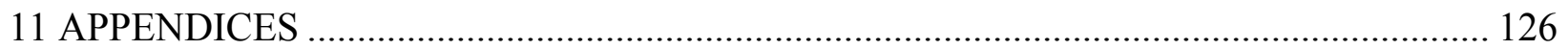

A. Analysis of Thermocouple Temperature Measurement ................................................. 126

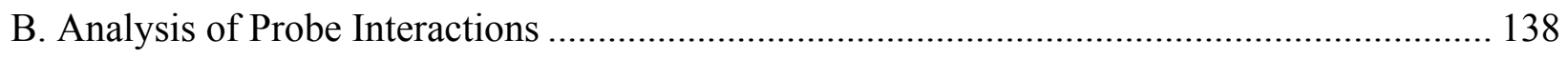

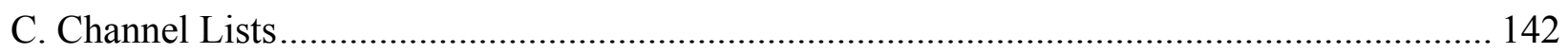

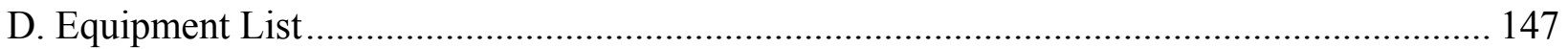




\section{List of Figures}

Figure 1. Perspective views of the Reduced Scale Enclosure and upper layer gas sampling probes drawn to scale. Dimensions are given with respect to interior walls.

Figure 2. Dimensional drawing of burners used in the RSE experiments. Burners D and E were similar to Burner F, but the diameters were $22 \mathrm{~cm}$ and $40 \mathrm{~cm}$, respectively.

Figure 3. Photograph of extractive sampling probes and aspirated thermocouple at the front sample location (photo taken with rear wall removed).

Figure 4. Isometric view of Reduced Scale Enclosure showing the relative position of doorway measurement probes.

Figure 5. Isometric semi-transparent view of the RSE interior measurement probe locations and burner. ......................................................... 10

Figure 6. Schematic drawing of $3 \mathrm{~m}$ hood and exhaust stack instrumented for calorimetry and light extinction measurements......................... 12

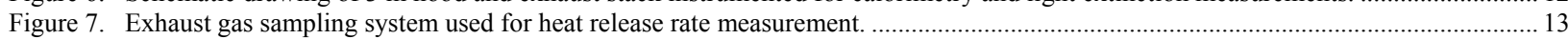

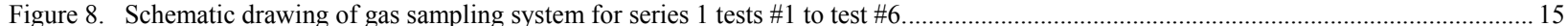

Figure 9. Schematic drawing of gas sampling system for series 2 (test $\# 6.5$ to test $\# 16$ ). .......................................................................... 15

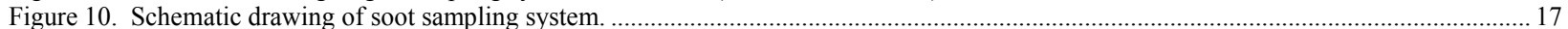

Figure 11. Detailed drawing of aspirated thermocouple using NACA design [34] ...................................................................................... 18

Figure 12. Schematic drawing of aspirated thermocouple measurement hardware ................................................................................ 19

Figure 13. Type $\mathrm{K}$ thermocouple on compartment floor surface near a $6 \mathrm{~mm}$ diameter total heat flux gauge....................................................20

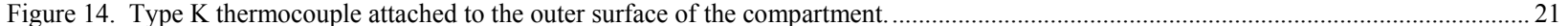

Figure 15. Schematic of the optical extinction measurement apparatus used during test \#6. ........................................................................... 27

Figure 16. Schematic of the optical extinction measurement apparatus used during test \#13 and test \#14 including a blow-up of the circled

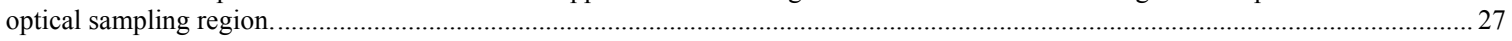

Figure 17. Heat release rate results for natural gas test \#3 using Burner A.

Figure 19. Heat release rate results for methanol test $\# 12$ using spray burner $\mathrm{C}$................................................................................... 35

Figure 21. Heat release rate results for polystyrene test \#16. A heptane spray was used to ignite $6 \mathrm{~kg}$ of polystyrene pellets............................... 36

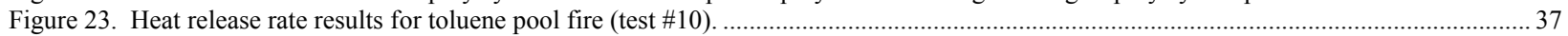

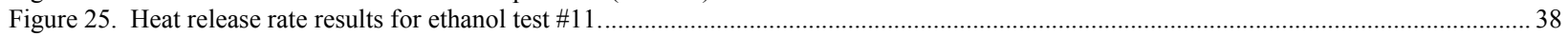

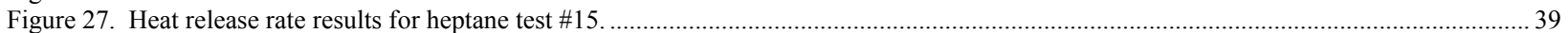

Figure 29. Steady state heat release rate results. Dashed line represents ideal or complete burning. ................................................................. 40

Figure 30. Gas temperature measurement results for 4 positions inside RSE. Natural gas test \#3....................................................................43

Figure 31. Gas temperature measurements at two front interior locations inside RSE during the heptane spray fire (test \# 15) . .......................... 44

Figure 32. Steady state average temperature measurements at interior locations for repeated natural gas fires (tests \#1, \#2, \#3). The lines in

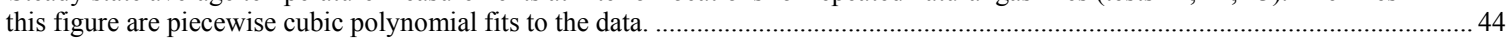

Figure 33. Steady state average temperature results from aspirated thermocouple measurement at front gas sampling location......................... 45

Figure 34 Steady state average temperature results from aspirated thermocouple measurement at rear gas sampling location........................... 45

Figure 35. Comparison of doorway centerline temperatures measured using aspirated and bare bead thermocouple at the same position.

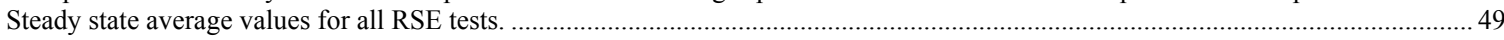

Figure 36. Steady state doorway temperature measurements for natural gas test \#3, HRR=265 kW. Error bars in this figure are 2 standard deviations.

Figure 37. Doorway centerline velocity profiles for natural gas fire (test $\# 3$ )

Figure 38. Doorway centerline velocity profiles for heptane spray fire (test $\# 15)$. ....................................................................................5 50

Figure 39. Transient gas volume fractions and soot mass fractions for heptane test \#15........................................................................ 52

Figure 40. Transient gas volume fractions and soot mass fractions for polystyrene test \#16 ...................................................................5 53

Figure 41. Steady state gas and soot species results for natural gas full door tests \#1, \#2,\#3, and \#65. The lines in this figure are piecewise cubic polynomial fits to the data.

Figure 42. Steady state average oxygen volume fraction measurements at front sample probe location. ..................................................................5

Figure 43. Steady state average oxygen volume fraction measurements at rear sample probe location................................................................ 54

Figure 44. Steady state average carbon dioxide volume fraction measurements at front sample probe location. ................................................. 55

Figure 45. Steady state average carbon dioxide volume fraction measurements at rear sample probe location.....................................................55

Figure 46. Steady state average carbon monoxide volume fraction measurements at front sample probe location. .................................................56

Figure 47. Steady state average carbon monoxide volume fraction measurements at rear sample probe location............................................... 56

Figure 48. Steady state average total hydrocarbon volume fraction measurements at front sample probe location............................................... 57

Figure 49. Steady state average total hydrocarbon volume fraction measurements at rear sample probe location.............................................. 57

Figure 50. Steady state gravimetric soot mass fraction measurements at front sample probe location. ............................................................5 58

Figure 51. Steady state gravimetric soot mass fraction measurements at rear sample probe location............................................................ 58

Figure 52. Comparison of total hydrocarbons measured using the GC and the total hydrocarbon analyzer (THC Front), both expressed on a $\mathrm{CH}_{4}$ basis.

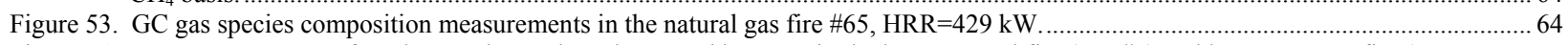

Figure 54 GC measurements of methane, ethyne plus ethene, and benzene in the heptane pool fire (test \#7) and heptane spray fire (test \#15), front gas sample probe...

History of the soot mass concentration during natural gas fire (test \#6). Mean values of the soot mass concentration were determined over the same periods as the gravimetric measurements as indicated by the dotted boxes. The fire heat release rate is also shown

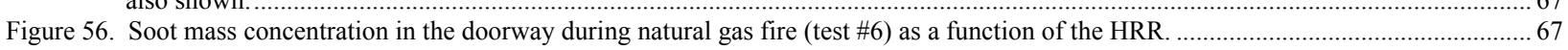

Figure 57. History of the particle mass fraction in the doorway during test $\# 13$, polystyrene burning in the $20 \mathrm{~cm}$ diameter burner. The fire heat release rate is also shown.

Figure 58. History of the soot mass concentration in the doorway during test $\# 14$, polystyrene burning in a $40 \mathrm{~cm}$ diameter burner. The fire heat release rate is also shown.

Figure 59. Total heat flux gauge measurements at two locations on the interior floor of the RSE for test \#15 using the spray burner with heptane fuel. 
Figure 60 Steady state total heat flux measurement at front floor location. Note: Front heat flux gauge was partially blocked by debris for polystyrene test \#16.

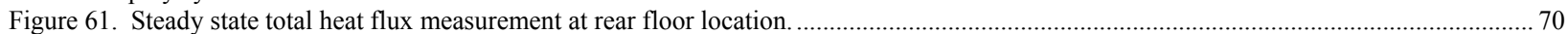

Figure 62. Photograph of soot agglomerate on the water inlet tube of the burner after toluene pool fire (test \#10)........................................ 72

Figure 63 The $\mathrm{CO}$ volume fraction measured in the stack and at the front and rear of the compartment as a function of time during the burning of $6.0 \mathrm{~kg}$ of polystyrene pellets (Test 16). Photographs at various times show the fire appearance through the open

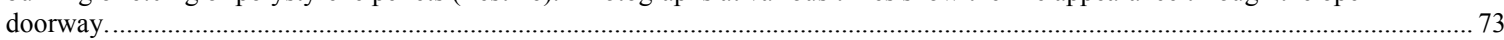

Figure 64. Photo of rear gas sample location and Marinite I construction before test \#2 ................................................................... 77

Figure 65. Photo of rear gas sample location and Marinite I construction after test \#2 with natural gas......................................................... 77

Figure 66. Photo inside enclosure after test \#6 showing Marinite I condition. Large chunks of ceiling fell to the floor during this test............... 78

Figure 67. Photo of rear gas sample location showing Kaowool M-board and furnace pin construction prior to test \#6.5................................ 78

Figure 68. Photo of rear gas sample location after test \#6.5 with natural gas using Kaowool M-Board..................................................... 79

Figure 69. Photo of enclosure with rear wall removed after test \#10 using toluene. Notice melted stainless steel furnace pins and bowed Mboard wall but very little cracking of walls

Figure 70. Photo of rear lower aspirated probe (TR24A) after test \#16 with polystyrene. Stainless steel furnace pins melted and dripped along the wall.

Figure 71 The equivalence ratio as a function of mixture fraction for nonpremixed flames burning methane and n-heptane. ............................. 86
Figure 72 The mass fraction vs. the mixture fraction calculated by the single-parameter mixture fraction model.

Figure 73 Mass fractions of front and rear compartment gas species as a function of mixture fraction for the natural gas fire tests \#1-\#3, and \#6: (a) transient measurements and (b) time-averaged measurements during the period when the HRR was quasi-steady.................... 89

Figure 74 Mass fractions of front and rear compartment gas species as a function of mixture fraction for the heptane fire tests \#4, \#5, \#7 and \#15: (a) transient measurements and (b) time-averaged measurements during the period when the HRR was quasi-steady........... 92

Figure 75 Mass fractions of front and rear compartment gas species as a function of mixture fraction for the toluene fire test \#10: (a) transient measurements and (b) time-averaged measurements during the period when the HRR was quasi-steady........................... 93

Figure 76 Mass fractions of front and rear compartment gas species as a function of mixture fraction for polystyrene fire tests \#13, \#14, and \#16: (a) transient measurements and (b) time-averaged measurements during the period when the HRR was quasi-steady................. 94

Figure 77 Mass fractions of front and rear compartment gas species as a function of mixture fraction (with soot included) for the timeaveraged measurements when the HRR was quasi-steady in the experiments burning (a) heptane, (b) toluene, and (c) polystyrene.

Figure 78 Comparison of mixture fractions calculated with and without soot using the time-averaged species measurements when the HRR was quasi-steady in the experiments burning (a) heptane, (b) toluene, and (c) polystyrene......................................................... 96

Figure 79 Transient values of (a) $Y_{\mathrm{CO}_{2}}$ and (b) $Y_{\mathrm{CO}}$ in the front and rear of the compartment as a function of the mixture fraction (without soot) with symbols colored to represent the local temperature for the heptane fire tests $\# 4, \# 5$, and \#7 ...........................................97

Figure 80 Mass fractions of front and rear compartment gas species as a function of mixture fraction for methanol fire tests \#8 and \#12: (a) transient measurements and (b) time-averaged measurements during the period when the HRR was quasi-steady............................. 98

Figure 81 Mass fractions of front and rear compartment gas species as a function of mixture fraction for ethanol tests \#9 and \#11: (a) transient measurements and (b) time-averaged measurements during the period when the HRR was quasi-steady............................. 99

Figure 82 Comparison between the equilibrium calculations and the time-averaged species mass fractions measured in the front and rear of the compartment as a function of the mixture fraction during the period when the HRR was quasi-steady in the natural gas fire tests \#1-\#3, and \#6.

Figure 83 The $\mathrm{CO}$ and soot yields as a function of the local equivalence ratio for the time-averaged measurements during the period when

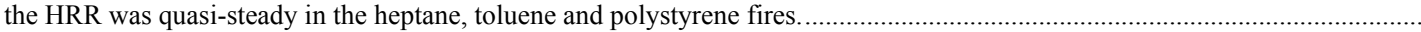

Figure 84. The values of $F_{C O}$ and $F_{\text {Soot }}$ as a function of the local equivalence ratio during the period when the HRR was quasi-steady in the

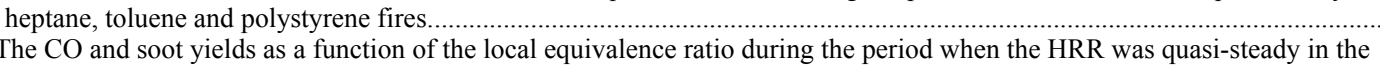
natural gas and ethanol fires

The $\mathrm{CO}$ yield as a function of the soot yield during the period when the HRR was quasi-steady in the heptane, toluene and polystyrene fires. Also shown is a line representing the results of Koylu [46]......................................................................... 108

Figure 87. The ratio of the CO to soot yield as a function of the local equivalence ration during the period when the HRR was quasi-steady in the heptane, toluene and polystyrene fires. Best fit lines to the data and a line representing the results of Koylu [46] are also shown.

Figure 88 The CO yield as a function of the soot yield for the same data shown in Fig. 85 during the period when the HRR was quasi-

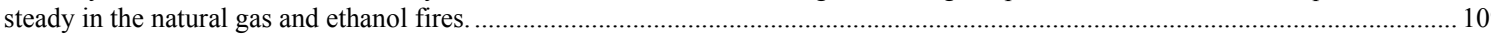

Figure 89 The ratio of the $\mathrm{CO}$ to soot yield as a function of the local equivalence ration for the same data shown in Fig. 85 during the period when the HRR was quasi-steady in the natural gas and ethanol fires. ....................................................................... 109

Figure 90 The $\mathrm{CO}_{2}$ yield in the exhaust stack as a function of the fire heat release rate during the periods when the HRR was quasi-steady

Figure 91. The CO yield in the exhaust stack as a function of the fire heat release rate during the periods when the HRR was quasi-steady

Figure 92. The soot yield in the exhaust stack as a function of the fire heat release rate during the periods when the HRR was quasi-steady

Figure 93. The total hydrocarbon yield in the exhaust stack as a function of the fire heat release rate during the periods when the HRR was

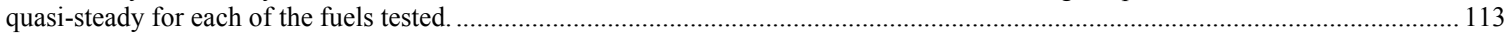

Figure 94. The combustion efficiency in the exhaust stack as a function of the fire HRR.............................................................. 115

Figure 95. The local combustion efficiency at the rear and front compartment sampling locations as a function of the fire heat release rate during the periods when the HRR was quasi-steady for three fuels.

Figure 96. The local combustion efficiency at the rear and front compartment sampling locations as a function of the oxygen volume fraction during the periods when the HRR was quasi-steady in the heptane fire. 


\section{List of Tables}

Table 1. List of test numbers and key experimental conditions......................................................................... 8

Table 2. Location of measurement probes inside of the enclosure. .......................................................................... 10

Table 3. Location of measurement probes in the enclosure doorway........................................................................11

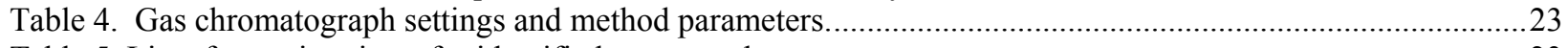

Table 5. List of retention times for identified compounds.................................................................................23

Table 6. Components used in the optical extinction measurements. .......................................................................26

Table 7. Tests in which optical light extinction measurements were conducted. .....................................................26

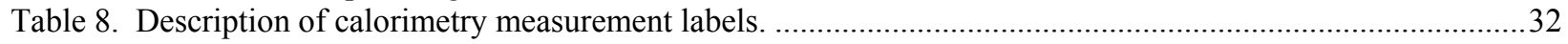

Table 9. Composition (volume fraction \%) and heating values of natural gas used in RSE tests..............................33

Table 10. Summary of time averaged steady-state results of HRR and exhaust stack species measurements. ..........41

Table 11. Description of interior gas temperature measurement labels.................................................................42

Table 12. Steady state rear gas temperatures and total heat flux to the floor inside the RSE. .................................46

Table 13. Steady state front gas temperatures and total heat flux to the floor inside the RSE..................................47

Table 14. Description of interior gas species and soot measurement labels. ..........................................................51

Table 15. Summary of steady state rear gas and soot sample probe measurements. ...............................................59

Table 16. Summary of steady state front gas and soot sample probe measurements................................................60

Table 17. Summary of GC sample results. Values in bold were identified as trace species. Blank spaces

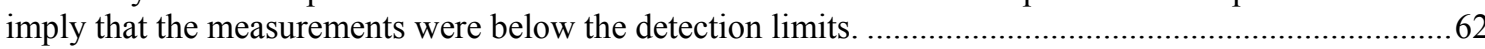

Table 18. Summary of GC measurement uncertainty analysis results. Blank spaces imply that the

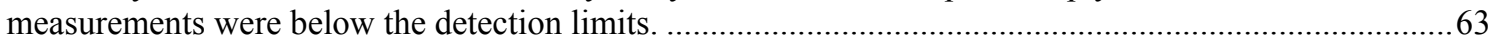

Table 19. Soot measurements during narrow doorway natural gas fire (test \#6) ......................................................66

Table 20. Description of interior total heat flux measurement labels..................................................................69

Table 21. Comparison of thermal, physical and construction properties of wall lining materials..............................76

Table 22. Stoichiometric value of the mixture fraction $\left(Z_{s t}\right)$ for different fuels.....................................................8

Table 23. Average fractional soot, $\mathrm{CO}$ and $\mathrm{CO} /$ Soot ratio at the front and rear compartment measurement locations.

Table 24. Time-averaged yields of soot, $\mathrm{CO}$, and the ratio $\left(\mathrm{y}_{\mathrm{CO}} / \mathrm{y}_{\mathrm{s}}\right)$ at the front and rear compartment measurement locations and in the exhaust stack for all fuel types.

Table 25. List of non-dimensional scaling parameters for compartment fires and the range of values examined in this study. 


\section{Introduction}

A series of new reduced-scale compartment fire experiments were conducted, which included local measurements of temperature and species composition. The measurements are unique to the compartment fire literature. By design, the experiments provided a comprehensive and quantitative assessment of major and minor carbonaceous gaseous species and soot at two locations in the upper layer of fire in a $2 / 5$ scale International Organization for Standards (ISO) 9705 room. The enclosure defined in the international standard ISO 9705 "Full-scale room test for surface products" [1] is an important structure in which to conduct fire research. Many dozens of research projects and journal articles have focused on this enclosure and the standard describing its use. It is a common reference point for studies of many fire-related phenomena as well as fire modeling efforts.

While some previous studies have considered the mixture fraction to analyze experimental compartment fire data, few have considered minor hydrocarbon species and none have considered soot. In tandem, accurate measurements of temperature at these same locations allowed analysis of thermal effects on species concentrations. A wide range of fuel types were considered, including aliphatic hydrocarbons (natural gas and heptane), aromatic hydrocarbons (toluene and polystyrene) and alcohols (methanol and ethanol).

Field models, such as the National Institute of Standards and Technology (NIST) Fire Dynamics Simulator (FDS) [2], are widely used by fire protection engineers to predict fire growth and smoke transport for practical engineering applications. Field models numerically solve the conservation equations of mass, momentum and energy that govern low-speed, thermally-driven flows with an emphasis on smoke and heat transport from fires. All field models have strengths and weaknesses. Among the various assumptions used in the development of previous versions of FDS, all chemical species were tied to the mixture fraction state relations. A single mixture fraction variable cannot be used for the prediction of carbon monoxide and soot, and the yield of these species was prescribed in FDS 4, rather than predicted. In fact, the yield of these species is usually not constant, but a complex function of their time-temperature history. In practice, an engineer using FDS 4 would choose combustion product yields directly from literature values for well-ventilated burning, using data from a bench-scale apparatus [3]. Using this approach, the carbon monoxide $(\mathrm{CO})$ volume fraction for pool fire burning in an under-ventilated compartment can be underestimated by as much as a factor of ten. A new version of FDS (version 5) is currently being tested which implements a predictive model of $\mathrm{CO}$ production.

The experimental results provided in this report are the first step of a long-term NIST project to generate the data necessary to test our understanding of fire phenomena in enclosures and to guide the development and validation of field models by providing high quality experimental data. The experimental plan was designed in cooperation with developers of the NIST FDS model to assure that the measurements would be of maximum value. Advanced development of FDS and other field models is extremely important, since it will lead to improved accuracy in the prediction of underventilated burning, typical of fire conditions that occur in structures.

Improving models for under-ventilated burning will foster improved prediction of important life safety and fire dynamic phenomena, including fire spread, backdraft, flashover, and egress (involving the presence of toxic gases and smoke), which are critically important for application of fire models for fire safety. In summary, the main objective of this project is to provide an 
improved understanding of the physics, chemistry, and structure of underventilated compartment fires, and to provide experimental measurements to guide the development of fire chemistry submodels.

\subsection{Background and Relationship to Current Research}

Experimental research on enclosure fires has been on-going in fire research laboratories and academic institutions over the last 50 years. The motivation has varied from applied investigations studying particular fire scenarios to more fundamental work with the goal of understanding toxic species production behavior in fires. Some of the fundamental research that tried to ascertain ventilation and upper-layer effects on enclosure fire chemistry was conducted in well-controlled hoods. Sometimes, the main objectives of this research was to generally develop and validate fire models or particular structural fire simulations, while much of the research was conducted to acquire a better understanding of complex enclosure fire dynamics with a focus on chemical and thermal conditions. This section provides an overview of some of the recent research efforts in enclosure fires and highlights some of the more pertinent experimental work.

Research conducted at Harvard University and the California Institute of Technology in the 1980s explored fires burning under an exhaust hood (false ceiling) to simulate the layer effect of an enclosure fire, e.g. $[4,5]$. The relative distance of the fire below the hood was adjusted to vary the entrainment of air into the plume before it entered the upper layer. These experiments focused on underventilated burning, pathways for air to enter the upper layer, and the validity of the concept of "global equivalence ratio" (GER) which is the fuel-to-air mass ratio normalized by the mass ratio required for stoichiometric burning. Some recent modeling work by Cleary and Kent [6], has also focused on experimental data from hoods. In a recent study, Brohez et al. explored the use of a bench-scale calorimeter to measure fire properties of materials burning in underventilated conditions $[7,8]$.

Research at NIST by Bryner et al. further explored the global equivalence ratio concept and carbon monoxide production in a reduced $(2 / 5)$ scale enclosure with natural gas as the principal fuel [9]. The results showed that the upper layer in enclosure fires is not homogeneous, and that $\mathrm{CO}$ can be produced in greater quantities than predicted by the GER concept, depending on temperatures and flow patterns developed within an enclosure. The current effort is meant to overlap some of the conditions explored by Bryner et al. and to repeat and fill gaps in the data. Pitts expanded the work to full-scale and other fuels such as heptane and wood. It was established that wood pyrolysis in the upper layer of an enclosure fire can produce high concentrations of $\mathrm{CO}$ directly without further oxidation to $\mathrm{CO}_{2}$ [10]. A subsequent study by Lattimer confirmed and expanded on this research [11].

Researchers at Virginia Tech investigated fires in a reduced-scale enclosure that directed the air inflow through slots in the floor connected to a duct where instrumentation was used to quantify air entrainment [12]. Several fuels were studied, and this configuration produced results consistent with GER predictions due to the more distinct, less dynamic nature of the gas layer structure. Later work used a more typical enclosure design and focused on transport of gas species outside the doorway and how it was affected by doorway geometry, soffit design, and hallway configuration [13]. More recently, Gann et al [14] conducted research on transport of 
toxic species in a full-scale enclosure with a corridor. These data were analyzed by Hirschler [15]. Researchers in Sweden conducted a study [16] of underventilated fires in an ISO 9705 room with a window vent of varying height. Several polymer fuel types were included in this study and measurements of local equivalence ratio and toxic gas species were performed.

Pitts [17] provides a comprehensive review of the application of the GER concept to predict CO concentration in building fires, using data from the Harvard and Cal Tech hood experiments $[3,4]$, the Virginia Tech enclosure studies [11], and the NIST reduced-scale enclosure experiments $[8,9]$. Several CO formation mechanisms were identified, which were substantiated by detailed chemical kinetic modeling. While the GER concept is of limited utility for predicting the local $\mathrm{CO}$ concentration, important aspects of enclosure fire dynamics and chemistry are highlighted in this paper.

Several recent experimental studies $[18,19,20]$ have used very small scale enclosures $\left(0.21 \mathrm{~m}^{3}\right.$, $0.06 \mathrm{~m}^{3}$, and $0.05 \mathrm{~m}^{3}$, respectively) while investigating underventilated burning of propane and heptane fires. These bench-scale studies described the structure and dynamics of underventilated burning including extinction, flame projection and flame stability. Another recent study [21,22] has used an intermediate-scale enclosure similar to that used for this paper, but a roof vent was added as well.

Recently, NIST has conducted a number of high-profile case studies in which realistic-scale mock-ups of actual fire scenarios were recreated with the ultimate goal of improving building codes and standards. These studies included the World Trade Center disaster investigation [23], the Rhode Island Station nightclub fire [24], and the Chicago Cook County Administration Building fire investigation [25]. The compartment fires in all of these studies burned real furnishings and became underventilated as the fire evolved. In addition, a series of large-scale compartment fire experiments were conducted to simulate an over-ventilated fire in a nuclear power plant cable room [26] to provide data for fire model validation.

\subsection{Approach and Scope}

The series of experiments reported on here was conducted in a reduced scale (2/5 ISO 9705 room) enclosure (RSE). The experiments repeated and extended a part of the work of Bryner and coworkers [9]. Similar to Bryner's experiments, natural gas served as a fuel; the burning of heptane, toluene, methanol, ethanol, and polystyrene was also investigated. In most experiments, the fuel was controlled and metered by flow valves or pumped into a pool burner or spray nozzle. Experiments were run to near-steady conditions. Multiple fire sizes were run consecutively to decrease the time required to approach steady-state. Ventilation was varied during some experiments by modifying the door opening. Two types of enclosure lining materials were investigated and compared.

Temperature and species composition measurements were made at many of the same nominal locations as studied previously by Bryner [9]. Measurements included $\mathrm{CO}, \mathrm{CO}_{2}$, temperature, heat fluxes, and dynamic pressures (used to obtain velocities). One emphasis of this series was to develop techniques for the measurement of hydrocarbons and soot. Hydrocarbons were measured with Flame Ionization Detector (FID) total hydrocarbon analyzers and gas chromatography (GC). The GC measurements were used to independently validate the total 
hydrocarbon measurements and to allow accurate determination of carbon mass distribution. The quantification of hydrocarbon species was needed to describe the chemical structure of underventilated fires. Soot samples were extracted from within the enclosure and measured gravimetrically. Optical soot measurements were performed at the doorway.

The fuels included in this test series were selected to cover a wide range of combustion properties and to simulate fuels encountered in actual building fires. Gases, liquids and solids were selected for testing to cover a wide range of physical properties. Realistic materials represent complex multi-component fuels. In this study, all of the fuels selected were homogeneous single component fuels to simplify the analysis and attempt to find generalizable trends in the results. Real materials are often oxygenated. This includes many types of commodity materials including nylon (e.g., carpet), cellulose (e.g. paper and building products), polyester (e.g., fabric), epoxy (e.g., adhesives), polymethylmethacrylate (PMMA), and POM (polyoxometalate). In this study, alcohols were selected as a surrogate to represent the compartment fire chemistry in the burning of oxygenated fuels.

In a real compartment fire, fuel sources are physically distributed throughout the compartment. In this study, a single location for the fuel was used to simplify the analysis of the experimental results for the purpose of model validation. Multiple fuel locations would have led to uncertainty in the specification of the location of the heat source, which is a critical boundary condition in a CFD fire calculation and, therefore, crucial information for model validation.

In a real compartment fire, heat feedback and natural ventilation give rise to important aspects of the structure and dynamics of the fire, such as the temperature field and the spatial distribution of combustion products. This study deliberately set out to investigate representative fire conditions at two key locations in the upper layer of the compartment, which were selected based on a series of CFD fire modeling calculations. The upper layer locations were selected to provide two distinct conditions in the upper layer, one relatively close to the natural ventilation flow of fresh air through the doorway and the other relatively far from the doorway, on the far side of the fire source. The design calculations confirmed that these locations would provide a range of local conditions in terms of the combustion species equivalence ratio and the temperature that would be useful for the construction of a database for model development and validation. To enhance the range of conditions investigated and in an attempt to seek information on the relationship between the combustion products and generalizable local flame conditions, a broad range of fire heat release rates and a number of very different fuel types were selected for study. At the same time, the effect of compartment ventilation was changed to induce a range of mixing and compartment fire conditions.

\section{Experimental Method}

\subsection{Reduced Scale Enclosure}

\subsubsection{Design and construction}

Experiments were conducted using an enclosure, shown in Fig. 1, that is roughly a 2/5 scale replicate of the ISO 9705 room [1]. The steel frame for this enclosure was used extensively in the early 1990s to study carbon monoxide production in compartment fires. A detailed 
description of the design and construction of the Reduced Scale Enclosure (RSE) can be found in the original NIST report [9]. The original report described the "as designed" internal dimensions of the enclosure as $98 \mathrm{~cm}$ wide $\times 98 \mathrm{~cm}$ tall $\times 146 \mathrm{~cm}$ deep, however for this report, the "as constructed" internal dimensions were measured as $95 \mathrm{~cm}$ wide $\times 98 \mathrm{~cm}$ tall $\times 142 \mathrm{~cm}$ deep, with a pre-burn uncertainty of less than $1 \mathrm{~cm}$ on each dimension. The uncertainty in the internal dimensions increased as more fire experiments were conducted, e.g., during and after some of the fire tests, the walls were observed to deform in local areas by as much as $10 \mathrm{~cm}$.
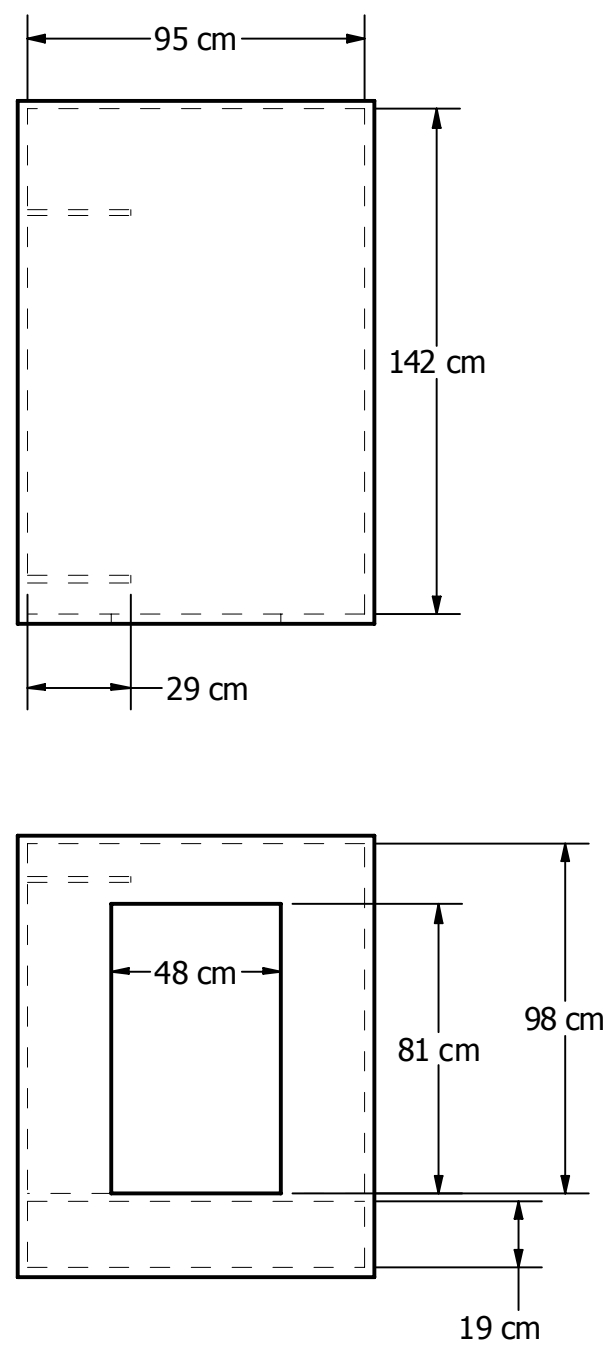
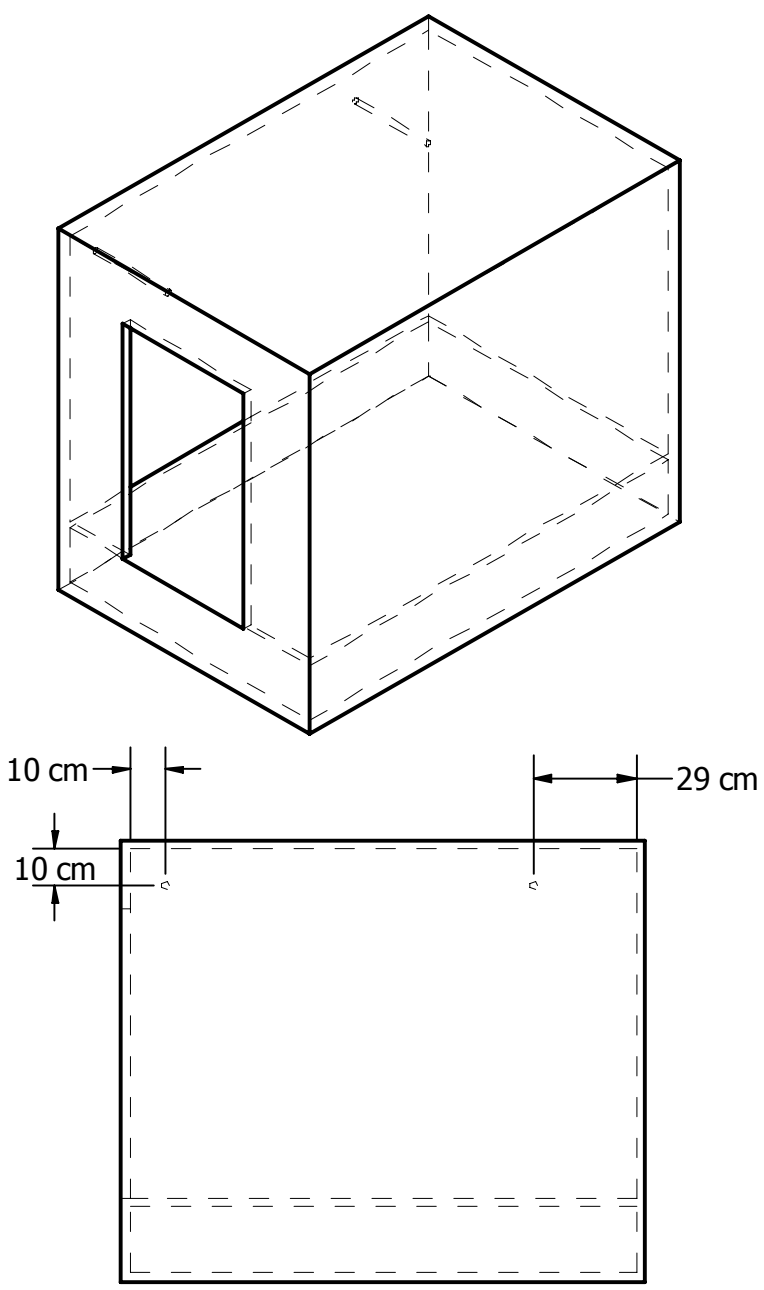

Figure 1. Perspective views of the Reduced Scale Enclosure and upper layer gas sampling probes drawn to scale. Dimensions are given with respect to interior walls.

The steel frame of the enclosure was lined with 2 layers of $1.27 \mathrm{~cm}$ thick insulation board. For the first six tests, a calcium silicate board (Marinite I) was used. For all other tests a rigid self supporting ceramic fiber (alumina and silica) board (Kaowool M-board) was used. The location of the retention bolts for the Marinite board were the same as the original test series [9]. Because the M-board sheet size was $122 \mathrm{~cm} \times 91 \mathrm{~cm}$, a single board would not span the length of the enclosure and joint seams were present. Stainless steel furnace pins were used to secure the M-board in both the original bolt locations (six retention points per wall and ceiling) and near the 
seams. The performance of the two different lining materials is discussed in Sec. 4.3. A comparison of the fire tests using the different lining materials showed no significant effect on the gas temperature and species measurements.

\subsubsection{Doorway Variations}

The standard doorway geometry (shown in Fig. 1) was $81 \mathrm{~cm}$ tall $\times 48 \mathrm{~cm}$ wide and centered horizontally on the $95 \mathrm{~cm}$ front wall. The bottom of the door was aligned with the inside floor. The inside floor was $43 \mathrm{~cm}$ above the laboratory floor. This configuration was used for all but two of the tests described here. The narrow door tests (listed in Table 1) were test \#5 and test \#6. The narrow doorway geometry was $81 \mathrm{~cm}$ tall $\times 24 \mathrm{~cm}$ wide.

\subsection{Burner Designs}

Four different burner designs, shown in Fig. 2, were used in this test series to accommodate the different fuels. A $13 \mathrm{~cm}$ square gravel-filled burner (Burner A) was used for the first three tests using natural gas. The area of this burner matched the area of the round burner used in the original test series [9]. The rim of the burner was $15 \mathrm{~cm}$ above the floor. Natural gas was delivered to the burner by a $1.3 \mathrm{~cm}$ tube that was fed through the floor and wrapped with Kaowool blanket insulation. The insulation nearly filled the space below the burner. The square geometry of burners A and B was chosen to match the rectangular grid used in FDS simulations.

A $25 \mathrm{~cm}$ square liquid cooled burner (Burner B) was used for both natural gas and liquid fuels. The burner was designed to have a pool surface area that increased with the depth of the pool. The maximum depth of the pool was $6.5 \mathrm{~cm}$ and the burner walls were at a 24 degree angle with respect to the horizontal plane. This feature allows for different size steady pool fires with a single burner. Burner B was designed with a $2.5 \mathrm{~cm}$ vertical rim to prevent fuel from spilling out of the burner. This burner was filled with gravel for some tests with natural gas. Like burner A, the height of the rim was $15 \mathrm{~cm}$ from the floor and fuel was delivered by an insulated tube through the floor.

A water-cooled downward spray burner (Burner C) was used for liquid fuels in tests \#11, \#12 and \#15. The nozzle was located $20 \mathrm{~cm}$ above the base of a $40 \mathrm{~cm}$ diameter round catch pan with a $12.5 \mathrm{~cm}$ rim. The spray was delivered using a 90 degree full-cone medium atomization (droplet diameter $\approx 250 \mu \mathrm{m}$ ) nozzle with a $1.40 \mathrm{~mm}$ orifice. The fuel delivery tube was fed through a hole in the ceiling and wrapped with Kaowool insulation of approximately $3 \mathrm{~cm}$ thickness.

Polystyrene pellets were burned using round pans $22 \mathrm{~cm}, 40 \mathrm{~cm}$ and $60 \mathrm{~cm}$ in diameter (Burners $\mathrm{D}, \mathrm{E}$ and $\mathrm{F}$ respectively). Each of the burners was centered on the floor. The pan size was increased for this fuel in order to reach under-ventilated conditions. A description of the test conditions including burner type can be found in Table 1. 


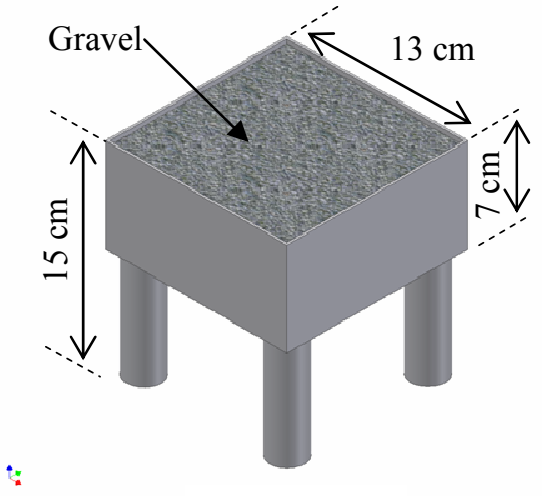

Burner A

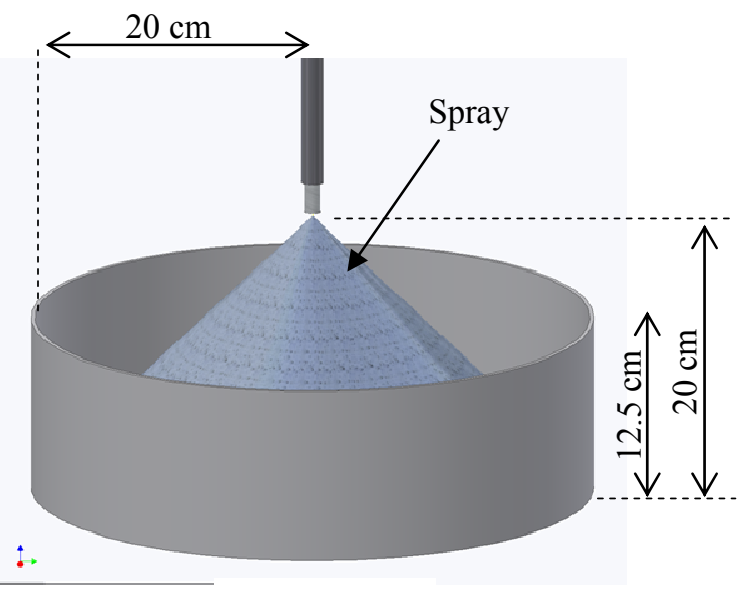

$\underline{\text { Burner C }}$

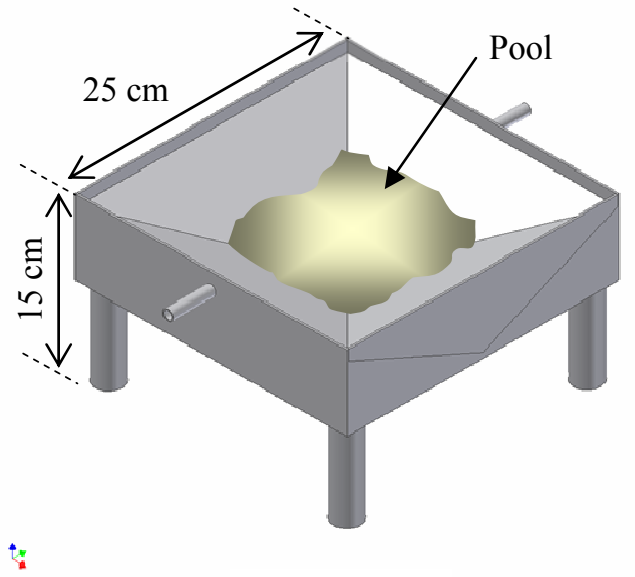

$\underline{\text { Burner B }}$

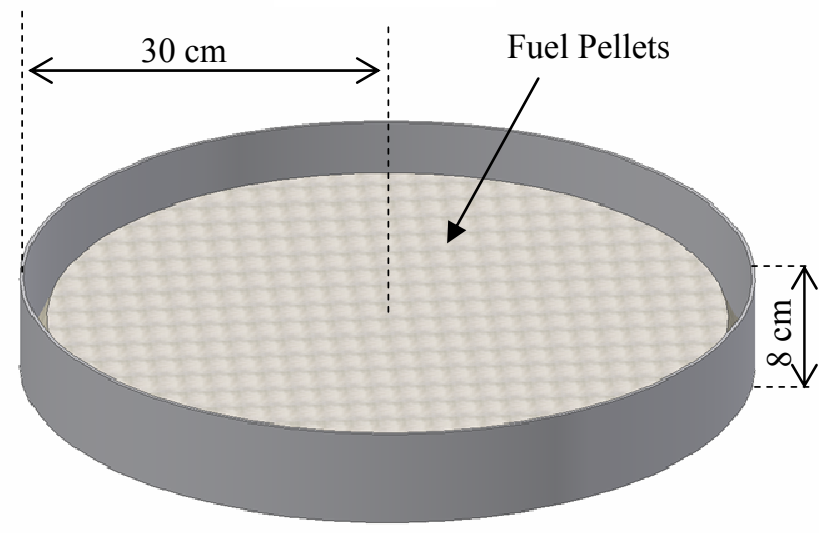

Burner F

Figure 2. Dimensional drawing of burners used in the RSE experiments. Burners D and E were similar to Burner F, but the diameters were $22 \mathrm{~cm}$ and $40 \mathrm{~cm}$, respectively.

\subsection{Experimental Conditions}

Experiments were conducted during two separate series. The test number (\#), series and controlled test parameters are listed in Table 1. The two main differences between the series 1 and series 2 were the wall lining material (see Sec. 2.1.1) and the gas sample conditioning systems (see Sec. 2.5.3).

The fuels included in this test series are listed in Table 1 and included gases, liquids and solids at ambient temperature. The composition of natural gas used for these tests is described in Sec. 3.1. The heptane fuel was a blend of heptane isomers. The fuel referred to as ethanol was actually a blend of $90 \%$ ethanol and $10 \%$ methanol by volume. The polystyrene fuel was clear granulated ( $2.5 \mathrm{~g} / 100$ granules) Dow Styron 666D general purpose resin with a manufacturer reported average molecular mass of $230.8 \mathrm{~kg} / \mathrm{mol}$. 
Table 1. List of test numbers and key experimental conditions.

\begin{tabular}{|c|c|l|l|c|c|c|}
\hline Test \# & Series & \multicolumn{1}{|c|}{ Fuel } & $\begin{array}{c}\text { Heat Release Rates* } \\
(\mathbf{k W})\end{array}$ & $\begin{array}{c}\text { Door } \\
\text { Vent }\end{array}$ & Burner & $\begin{array}{c}\text { Wall } \\
\text { Material }\end{array}$ \\
\hline 1 & 1 & Natural Gas & $75,190,75$ & Full & A & Marinite I \\
\hline 2 & 1 & Natural Gas & $255,395,180,115,50$ & Full & A & Marinite I \\
\hline 3 & 1 & Natural Gas & $265,410,180,115,75$ & Full & A & Marinite I \\
\hline 4 & 1 & Heptane & $155,270,375$ & Full & B & Marinite I \\
\hline 5 & 1 & Heptane & 140,220 & Narrow & B & Marinite I \\
\hline 6 & 1 & Natural Gas & $75,175,270,420,80$ & Narrow & B & Marinite I \\
\hline 6.5 & 2 & Natural Gas & $95,425,270,180,85$ & Full & B & M board \\
\hline 7 & 2 & Heptane & $150,245,340$ & Full & B & M-board \\
\hline 8 & 2 & Methanol & 15 & Full & B & M-board \\
\hline 9 & 2 & Ethanol & 20 & Full & B & M-board \\
\hline 10 & 2 & Toluene & $50,140,200,295,340$ & Full & B & M-board \\
\hline 11 & 2 & Ethanol & $80,145,265,335$ & Full & C & M-board \\
\hline 12 & 2 & Methanol & $70,140,240,305$ & Full & C & M-board \\
\hline 13 & 2 & Polystyrene & 15 & Full & D & M-board \\
\hline 14 & 2 & Polystyrene & 70 & Full & E & M-board \\
\hline 15 & 2 & Heptane & $90,160,225,300,375,85$ & Full & C & M-board \\
\hline 16 & 2 & Polystyrene & 360,310 & Full & F & M-board \\
\hline * Nominal pseudo steady state heat release rate values from calorimetry measurements \\
\hline \multicolumn{7}{|l}{} \\
\hline
\end{tabular}

\subsection{Measurement Locations}

Temperature, species volume fraction, soot mass fraction and velocity measurements were conducted at various locations in the compartment doorway and interior. A photograph of the front gas, soot, and temperature measurement probes is shown in Fig. 3. The sample probe for the gravimetric soot measurement is seen on the right of the image, and the aspirated thermocouple protrudes down through the ceiling. Figure 4 and Fig. 5 show the relative positions (drawn to scale) of the measurement probes in the doorway and inside the enclosure respectively. The reference point used to describe the positions within the enclosure is annotated in Fig. 5.

The measurement locations inside the RSE are listed in Table 2 and the locations in the doorway are listed in Table 3. The column heading (data label) corresponding to these measurements locations are also listed in the measurement location tables. These data labels are referenced in the tables and figures in Section 3. A complete list of data column headings can be found in Appendix C. 


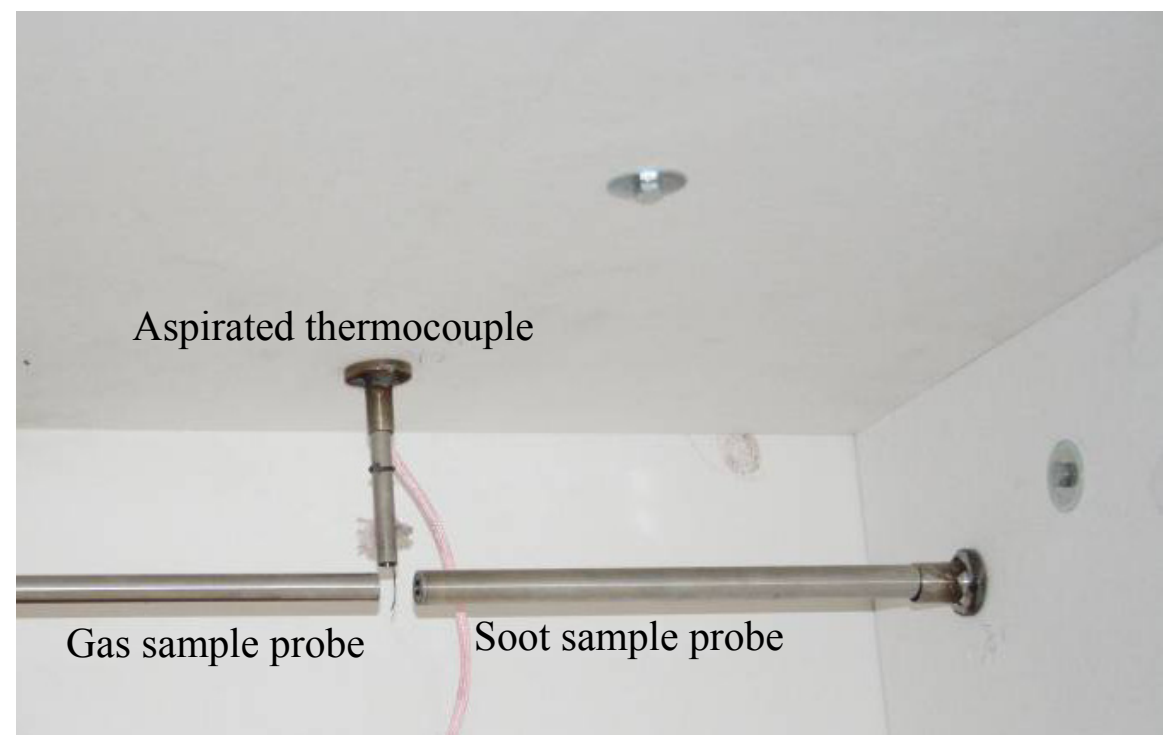

Figure 3. Photograph of extractive sampling probes and aspirated thermocouple at the front sample location (photo taken with rear wall removed).

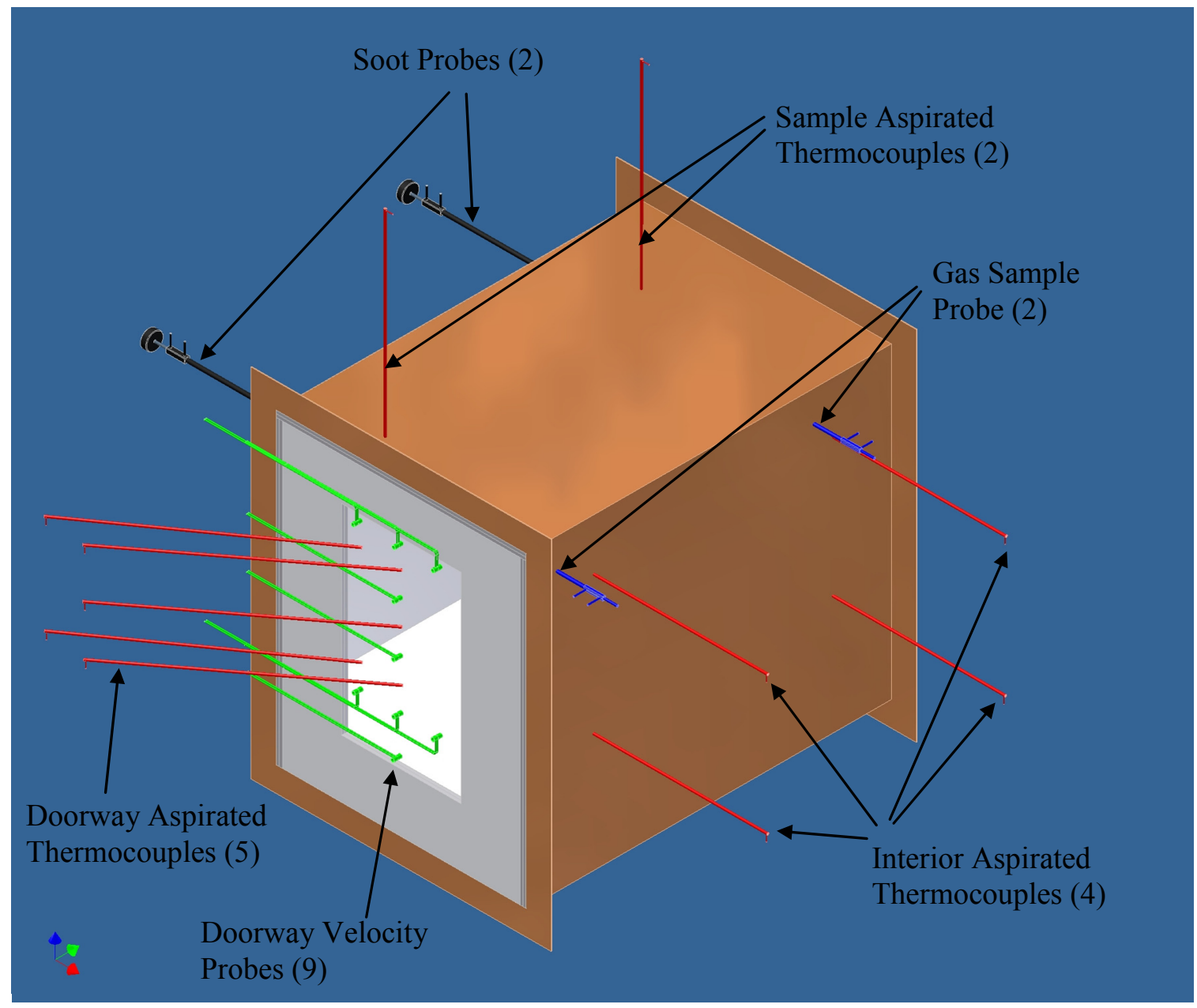

Figure 4. Isometric view of Reduced Scale Enclosure showing the relative position of doorway measurement probes. 


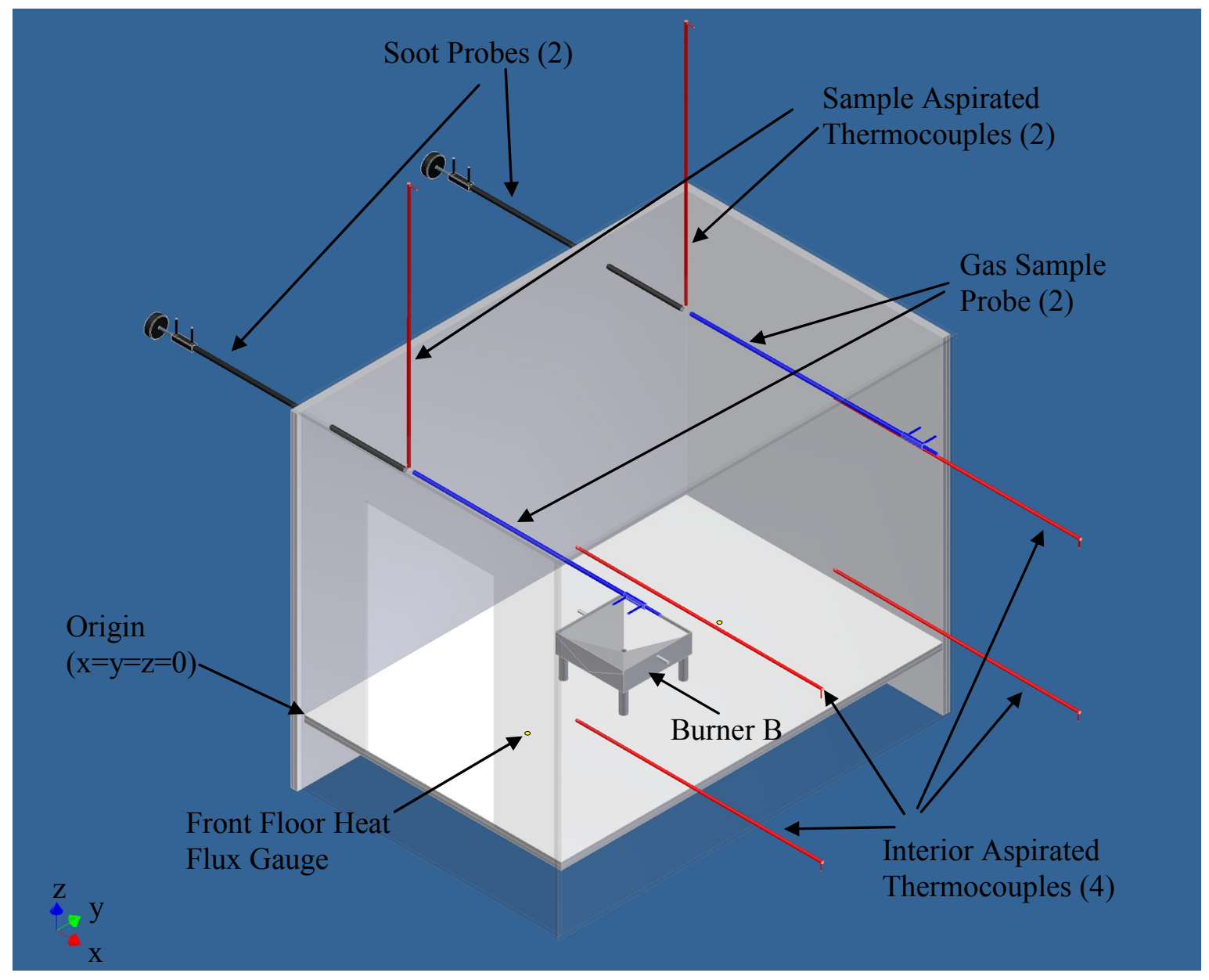

Figure 5. Isometric semi-transparent view of the RSE interior measurement probe locations and burner.

Table 2. Location of measurement probes inside of the enclosure.

\begin{tabular}{|l|l|c|c|c|}
\hline \multicolumn{1}{|c|}{ Probe Description } & Data Label & x (cm) & y (cm) & z (cm) \\
\hline Gas Sample Rear & 1 O2Rear & 29 & 113 & 88 \\
\hline Gas Sample Front & 7 O2Front & 29 & 10 & 88 \\
\hline Gravimetric Soot Sample Rear & 6 SootRear & 29 & 113 & 88 \\
\hline Gravimetric Soot Sample Front & 11 SootRear & 29 & 10 & 88 \\
\hline Aspirated Thermocouple & 15 TRSampA & 29 & 113 & 88 \\
\hline Aspirated Thermocouple & 16 TFSampA & 29 & 10 & 88 \\
\hline Aspirated Thermocouple & 17 TR24A & 75 & 122 & 24 \\
\hline Aspirated Thermocouple & 18 TR80A & 75 & 122 & 80 \\
\hline Aspirated Thermocouple & 19 TF24A & 75 & 20 & 24 \\
\hline Aspirated Thermocouple & 20 TF80A & 75 & 20 & 80 \\
\hline Total Heat Flux Gauge Rear & 12 HFR & 48 & 106 & 0 \\
\hline Total Heat Flux Gauge Front & 13 HFF & 48 & 35 & 0 \\
\hline Bare Bead Thermocouple & 21 TFloorR & 49 & 106 & 0 \\
\hline Bare Bead Thermocouple & 22 TFloorF & 49 & 35 & 0 \\
\hline Bare Bead Thermocouple & 23 TCeilF & 31 & 11 & 98 \\
\hline
\end{tabular}


Table 3. Location of measurement probes in the enclosure doorway.

\begin{tabular}{|l|l|c|c|c|}
\hline \multicolumn{1}{|c|}{ Probe Description } & Data Label & $\mathbf{x ~ ( c m ) ~}$ & $\mathbf{y ~ ( c m ) ~}$ & $\mathbf{z}(\mathbf{c m})$ \\
\hline Aspirated Thermocouple & 31 TC70CA & 48 & -5 & 70 \\
\hline Aspirated Thermocouple & 29 TC70LA & 32 & -5 & 70 \\
\hline Aspirated Thermocouple & 36 TC50CA & 48 & -5 & 50 \\
\hline Aspirated Thermocouple & 39 TC30CA & 48 & -5 & 30 \\
\hline Aspirated Thermocouple & 33 TC30LA & 32 & -5 & 30 \\
\hline Bi-Directional Velocity Probe & 45 VD79L & 32 & -5 & 79 \\
\hline Bi-Directional Velocity Probe & 46 VD79C & 48 & -5 & 79 \\
\hline Bi-Directional Velocity Probe & 47 VD79R & 64 & -5 & 79 \\
\hline Bi-Directional Velocity Probe & 48 VD60C & 48 & -5 & 60 \\
\hline Bi-Directional Velocity Probe & 49 VD40C & 48 & -5 & 40 \\
\hline Bi-Directional Velocity Probe & 50 VD20L & 32 & -5 & 20 \\
\hline Bi-Directional Velocity Probe & 51 VD20C & 48 & -5 & 20 \\
\hline Bi-Directional Velocity Probe & 52 VD20R & 64 & -5 & 20 \\
\hline Bi-Directional Velocity Probe & 53 VD5C & 48 & -5 & 5 \\
\hline
\end{tabular}

\subsection{Measurement Instrumentation \\ 2.5.1 Heat Release Rate}

Heat Release Rate (HRR) measurements were conducted using the $3 \mathrm{~m} \times 3 \mathrm{~m}$ calorimeter at the NIST Large Fire Research Laboratory (LFRL). The HRR measurement was based on the oxygen consumption calorimetry principle first proposed by Huggett [27]. This method assumes that a known amount of heat is released for each gram of oxygen consumed by a fire. The measurement of exhaust flow velocity and gas volume fractions $\left(\mathrm{O}_{2}, \mathrm{CO}_{2}\right.$ and $\left.\mathrm{CO}\right)$ were used to determine the HRR based on the formulation derived by Parker [28]. A detailed description of the methodology used for this measurement can be found in a previous report [29]. The experimental apparatus for the current measurements has been modified since the earlier report was written. In 2005, the $3 \mathrm{~m} \times 3 \mathrm{~m}$ square hood was installed in the LFRL. A schematic drawing of the $3 \mathrm{~m}$ hood is shown in Fig. 6 . The exhaust flow rate, optical soot and extractive gas measurements were performed in a vertical section of the $48.3 \mathrm{~cm}$ diameter duct. A bidirectional probe located $9 \mathrm{~cm}$ from the edge of the duct was used to measure the exhaust flow velocity. Because of the non-uniform shape of the velocity profile, a flow calibration coefficient was used in the HRR calculation. The flow coefficient was determined using natural gas calibration performed before and after the test series. The flow calibration coefficients $\pm 2 \sigma$ for these tests ranged from $0.85 \pm 0.04$ to $0.90 \pm 0.05$.

The exhaust gas was sampled through a perforated tube across the duct downstream of the velocity probe. Figure 7 shows the exhaust gas sampling system. The main difference between this system and the one previously reported [29] is the method for removing water from the gas sample. The current system uses a Nafion dryer instead of a dry ice cold trap. Nafion is a copolymer of tetrafluoroethylene (Teflon) and perfluoro-3,6-dioxa-4-methyl-7-octene-sulfonic acid. A dew point meter was added to monitor the efficiency of the gas dryer. The dew point temperature meter measures the change in electrical impedance of a hygroscopic conductive polymer in the range of $-80{ }^{\circ} \mathrm{C}$ to $20{ }^{\circ} \mathrm{C}$. The delay time from the gas sample tube to the analyzers was $20 \mathrm{~s}$. Measurements of exhaust soot and total hydrocarbons were performed, but 
were not included in the HRR calculation because in most cases they have negligible effect. The combined expanded relative uncertainty of the HRR measurements reported here was $14 \%$, based on a propagation of uncertainty analysis [29]. The exhaust mass flow rate was the largest component of uncertainty in the HRR measurement. A list of commercial equipment used for all of the measurements described in this report can be found in Appendix D.

\subsubsection{Fuel Metering}

Two different fuel delivery systems were used to control and measure the flow rate of fuel to the burners. The natural gas tests used a positive displacement flow meter with a standard relative uncertainty of $1 \%$ to measure the fuel volume flow rate. Combined with measurements of the fuel temperature, pressure, and ideal heat of combustion, the ideal natural gas burner heat release rate was determined with a combined expanded uncertainty of $2.4 \%$. A gas chromatograph was used to measure the composition of the natural gas [30]. The net ideal heating value of the natural gas was determined using the composition measurements [31].

The liquid fuel delivery rate was measured using a dual rotor turbine flow meter with a manufacturer's stated uncertainty of $0.1 \%$ in the range from $0.06 \mathrm{~L} / \mathrm{min}$ to $11 \mathrm{~L} / \mathrm{min}$. Although the liquid fuel volume flow rate was accurately measured, the fuel mass burning rate was not directly measured. In some cases, the amount of fuel (depth of liquid pool) in the burners was observed to vary with time, even though the fuel delivery rate was constant. Once the fuel delivery was stopped, the burnout of existing fuel could take several minutes.

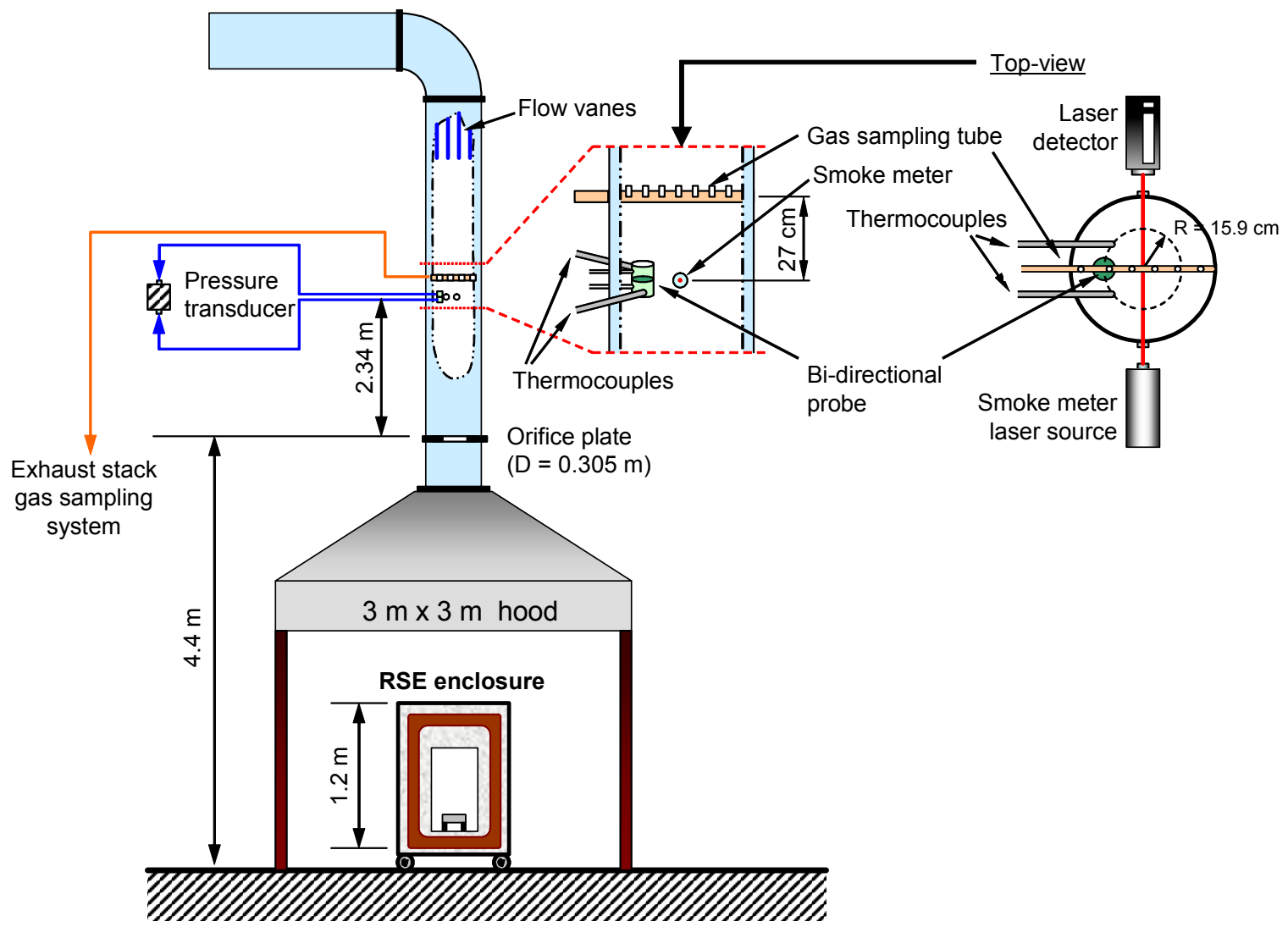

Figure 6. Schematic drawing of $3 \mathrm{~m}$ hood and exhaust stack instrumented for calorimetry and light extinction measurements. 


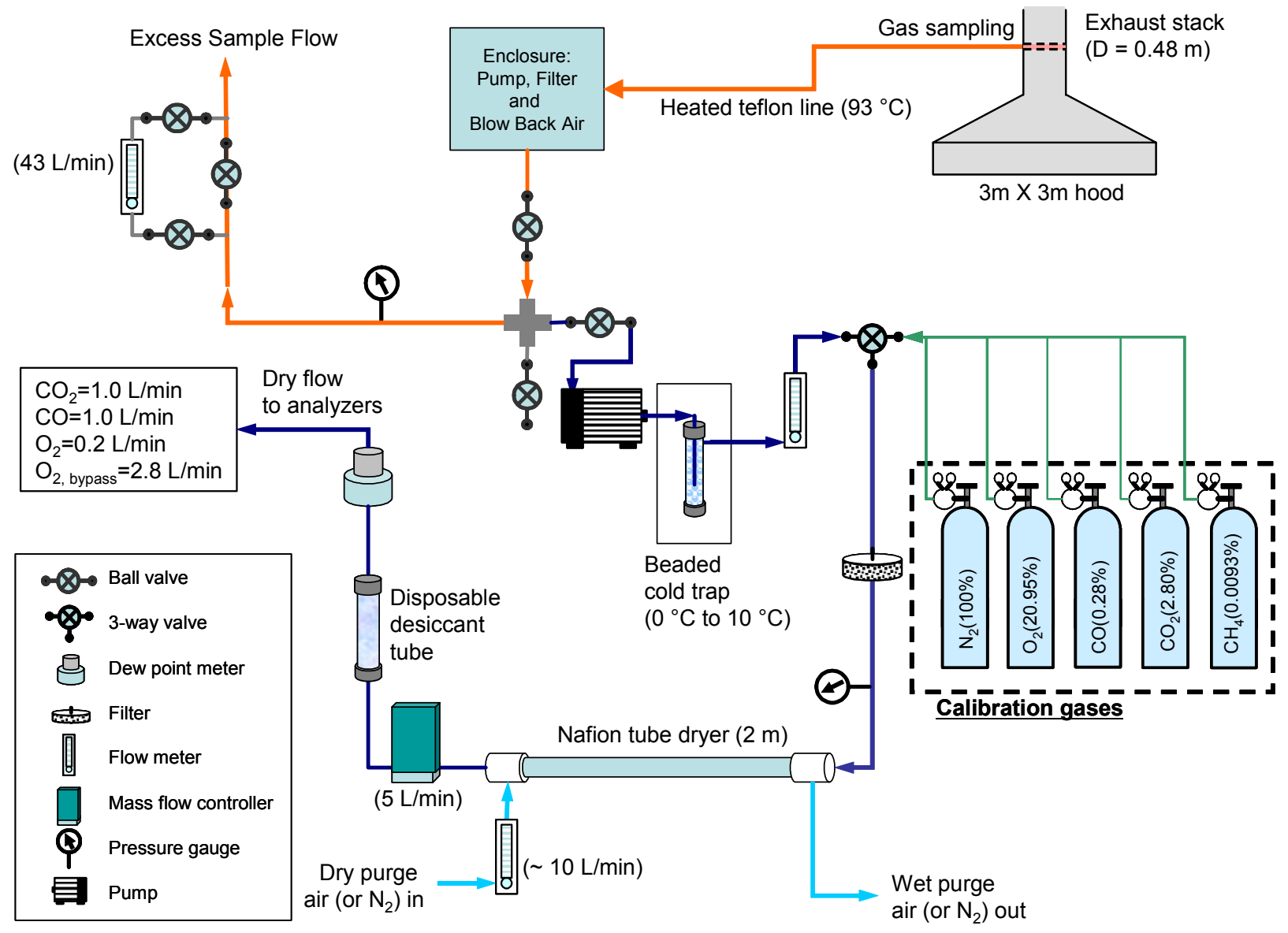

Figure 7. Exhaust gas sampling system used for heat release rate measurement.

\subsubsection{Gas Species}

Gas species were continuously measured at two locations (front and rear) inside the RSE during each of the tests. Oxygen was measured using paramagnetic analyzers. The $10 \%$ to $90 \%$ response time $\left(\mathrm{t}_{10-90}\right)$ of the oxygen analyzer was less than $12 \mathrm{~s}$. Carbon monoxide and carbon dioxide were measured using non-dispersive infrared (NDIR) analyzers. The $\mathrm{t}_{10-90}$ response time for the $\mathrm{CO}_{2} / \mathrm{CO}$ analyzers was less than $5 \mathrm{~s}$. Total hydrocarbons were measured using two flame ionization detectors (FID) having a $t_{10-90}$ response time of less than $1 \mathrm{~s}$.. A gas chromatograph (GC) was used intermittently during some of the tests at the front gas sampling location. The cycle time on the GC measurements was 20 min to $30 \mathrm{~min}$. The dried sample gas dew point temperature was measured using a thin polymer sensor. Soot and temperature were also measured at these two locations (see Sec. 2.5.4 and Sec. 2.5.5).

The two total hydrocarbon analyzers used in these experiments were designed to measure high volume fractions of hydrocarbons. The analyzers were factory calibrated for up to $50 \%$ volume fraction of hydrocarbons as methane and were capable of measuring even higher concentrations. The primary span gas used for these tests was $20 \%$ volume fractions of methane with a balance of nitrogen. A span gas of $1 \%$ methane was also used to periodically check the linearity of the detector. The FID burner fuel used was $40 \%$ hydrogen and $60 \%$ nitrogen on a volumetric basis. 
Each hydrocarbon analyzer had an internal filter to prevent soot from accumulating in the plumbing and internal sample pump which could lead to less sensitivity due to hydrocarbon contamination and also deterioration of some components of the instrument. It was later determined that additional external filtration of soot was necessary to protect the analyzer and enable a sufficient time period for sampling soot-laden flows. The external filter could be replaced much more frequently and easily than the internal filter.

Two liquid cooled probes were used to sample gas inside the enclosure at the front and rear locations. The $1 \mathrm{~m}$ long probes were constructed of 3 concentric stainless steel (type 304) tubes. Liquid coolant was forced through the inner shell and returned through the outer shell. This design allowed the cooling fluid to condition the entire length of the probe. The inner tube was lined with glass to reduce catalytic reactions. The inner diameter of the sample probe was $4.0 \mathrm{~mm}$. Two different gas sample configurations were used during the tests described here. For both configurations the front and rear gas sample systems were identical, except the GC measurement was conducted only at the front sample location.

The first configuration (series 1 in Table 1), shown in Fig. 8, used a re-circulated temperature controlled bath of $50 \%$ (by volume) ethylene glycol and $50 \%$ water to cool the gas sample probes. The sample was drawn through a $3 \mathrm{~m}$ stainless steel sample line heated to $120^{\circ} \mathrm{C}$ before the sample stream was split. Immediately after the heated line, $3 \mathrm{~L} / \mathrm{min}$ of the sample went through a heated filter to the total hydrocarbon analyzer. The bypass stream of the total hydrocarbon analyzer was connected to the inlet of the gas chromatograph (not shown in Fig. 8).

A two-stage water trap and filter was used to remove moisture and soot particles from the sample path going to the $\mathrm{O}_{2}, \mathrm{CO}_{2}$ and $\mathrm{CO}$ analyzers. The sample first passed through a filtered glass trap cooled in a wet ice bath and then passed through a beaded glass trap cooled with dry ice. The sample pump was located downstream of the drying traps. The gas analyzers were connected in parallel so the total flow rate to the rack gas was $2.3 \mathrm{~L} / \mathrm{min}$. A 5 way ball valve was connected to each analyzer to switch between the gas sample, zero calibration gas and span calibration gas. The zero and span gas volume fractions are shown in Fig. 8. A dew point transducer was connected to the sample gas line prior to the oxygen analyzer. The oxygen analyzer had separate inlet ports for zero and span gases. The expanded $(\mathrm{k}=2)$ relative uncertainty of each of the span gas volume fractions was $\pm 1 \%$.

A number of problems were encountered with the first sampling configuration. The coolant bath for the gas probes could not maintain a steady probe temperature. A vapor lock was formed in one of the probes and the loss of cooling caused the probe to melt and fail. The glass traps became clogged with ice after a period of time (creating a loss of sample flow) and there were intermittent leaks into the sample line through the trap seals. The internal filter in the total hydrocarbon analyzer became clogged with soot during some of the tests. After several tests, the gas sampling system was redesigned for improved performance. The redesigned gas sampling system (series 2 in Table 1) is shown in Fig. 9. 


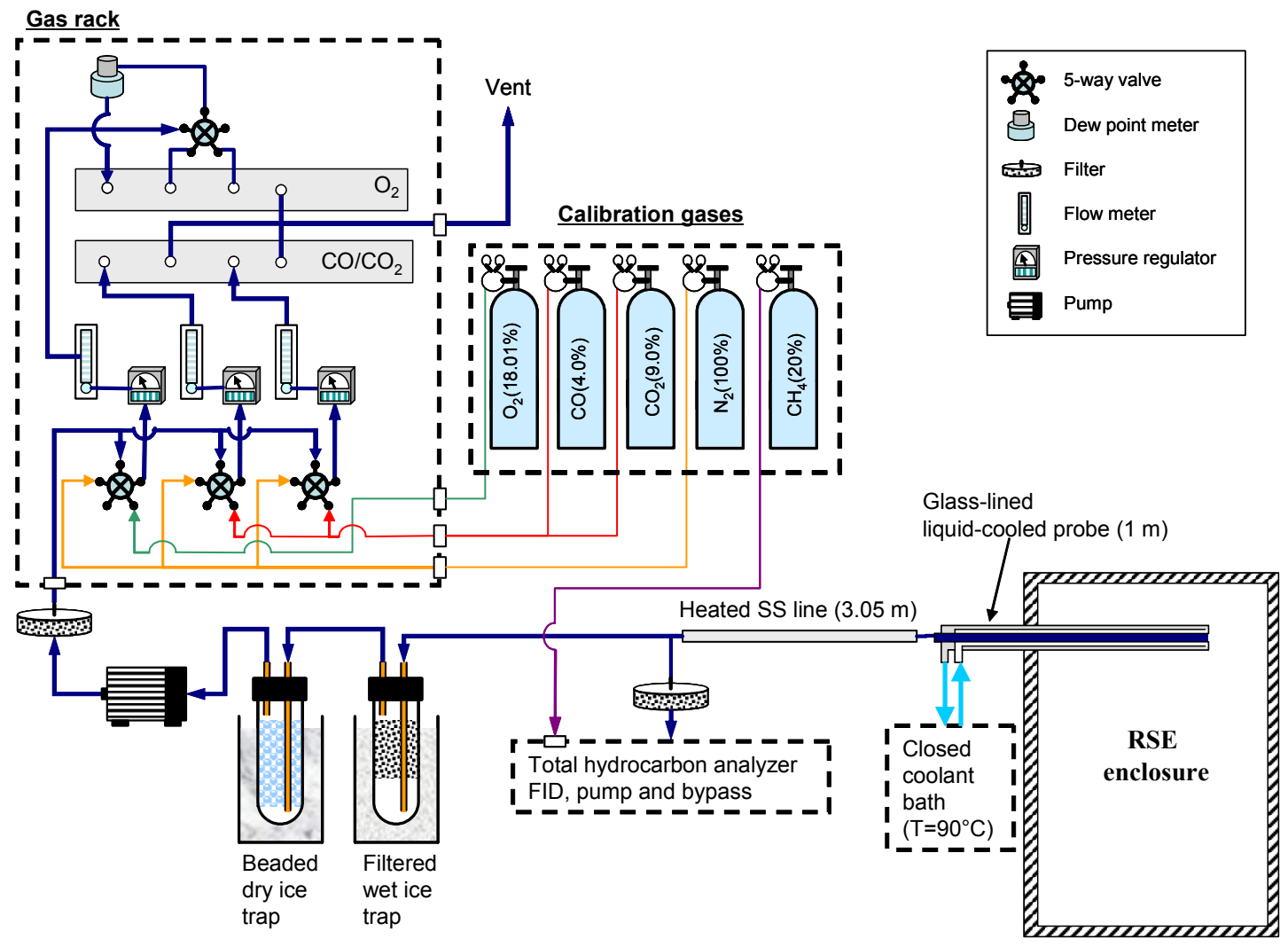

Figure 8. Schematic drawing of gas sampling system for series 1 tests \#1 to test \#6.

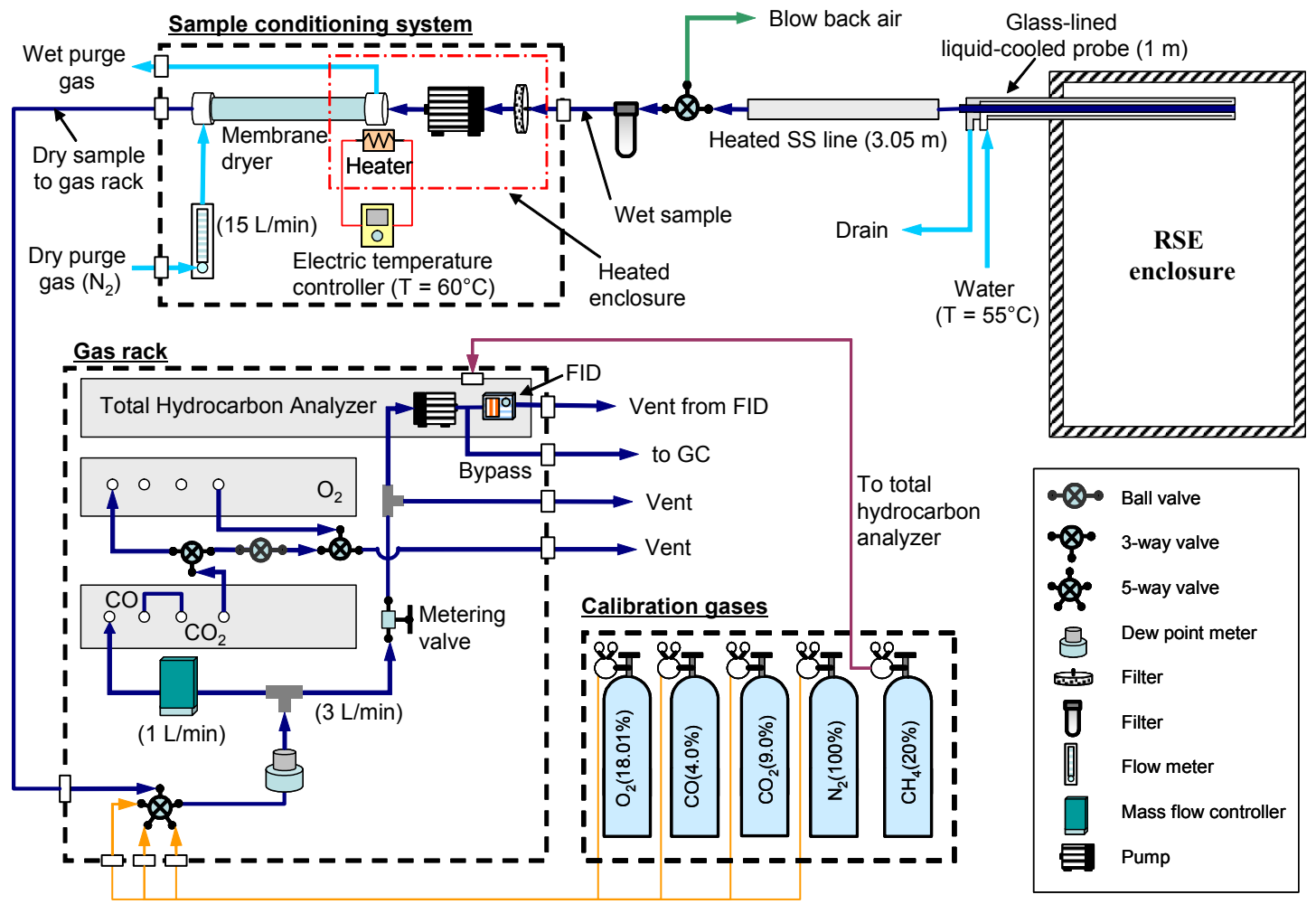

Figure 9. Schematic drawing of gas sampling system for series 2 (test \#6.5 to test \#16). 
The sample probes shown in Figs. 3-5, 8, and 9 were cooled using house water heated to $55^{\circ} \mathrm{C}$ at a flow rate of $1 \mathrm{~L} / \mathrm{min}$. The total hydrocarbon analyzers were placed in the gas racks with the other analyzers. The cold traps were replaced with a membrane type dryer. A bundle of Nafion tubes were purged with dry nitrogen to selectively remove moisture from the sample stream. The Nafion conditioner has no effect on most of the gas species of interest, however, polar organic compounds (i.e. ketones and alcohols) are trapped by the dryer. A large area filter was added between the heated line and gas dryer. Because the external filters and transfer lines after the gas dryer were not heated, there was a potential loss of high molecular mass hydrocarbons due to condensation. Due to limitations in the flow capacity of the dryer, the gas analyzers were connected in series. A mass flow controller set to $1 \mathrm{~L} / \mathrm{min}$ was used to control the flow through the $\mathrm{O}_{2} / \mathrm{CO}_{2} / \mathrm{CO}$ analyzers. The flow to the hydrocarbon analyzer was split prior to the mass flow controller. A needle valve was used to set the total flow to $3 \mathrm{~L} / \mathrm{min}$ (only a small fraction of this passed through the FID). The bypass flow from the hydrocarbon analyzer was connected to the injection port of the GC.

\subsubsection{Extractive Soot Measurement}

A gravimetric sampling system (shown in Fig. 10) was used to measure soot mass fractions at the two sample locations within the enclosure. The design of the soot probe was similar to the gas sampling probes except the inner diameter of the sample tube was $6.4 \mathrm{~mm}$. The soot sampling probes were conditioned with $65^{\circ} \mathrm{C}$ water flowing at $1.0 \mathrm{~L} / \mathrm{min}$. A three way solenoid valve was used to rapidly switch from the bypass to sample flow. A sample gas mass flow rate of 2.75 standard L/min $\left(\mathrm{N}_{2} @ 0{ }^{\circ} \mathrm{C}, 101.3 \mathrm{kPa}\right)$ was drawn through the collection filter for a period of $60 \mathrm{~s}$ to $300 \mathrm{~s}$. The collection filter was a $47 \mathrm{~mm}$ round Zeflour membrane filter with an aerosol retention efficiency of $99.99 \%$ for $2 \mu \mathrm{m}$ sized particles. A gas correction factor was applied to the mass flow rate measurement to account for the gas composition in the enclosure. The amount of time for sampling was determined by monitoring the pressure drop across the filter to ensure an optimal amount of filter loading.

The collection filters (shown at the base of the probes in Fig. 10 below) and probe cleaning pads were conditioned in a desiccant drier before and after the tests. The conditioned filters were weighed using an analytic mass balance with an expanded uncertainty of $0.12 \mathrm{mg}$. After each soot sampling period, the probe was cleaned twice with gun cleaning pads. The total soot mass collected on both the filter and 2 cleaning pads was used in determining the soot mass fraction. Both the soot mass and sample mass flow rates were measured on a dry basis. For most of the tests conducted in this series between $10 \mathrm{mg}$ and $200 \mathrm{mg}$ of soot was collected during the $1 \mathrm{~min}$ to $5 \mathrm{~min}$ sample time. The extracted gas volume was corrected for the water removed by the method described in Sec. 2.7. The combined expanded relative uncertainty of the soot mass fraction measurement (for mass fraction measurements greater than $0.001 \mathrm{~g} / \mathrm{g}$ ) was in the range of $2 \%$ to $5 \%$ based on a propagation of uncertainty analysis. 


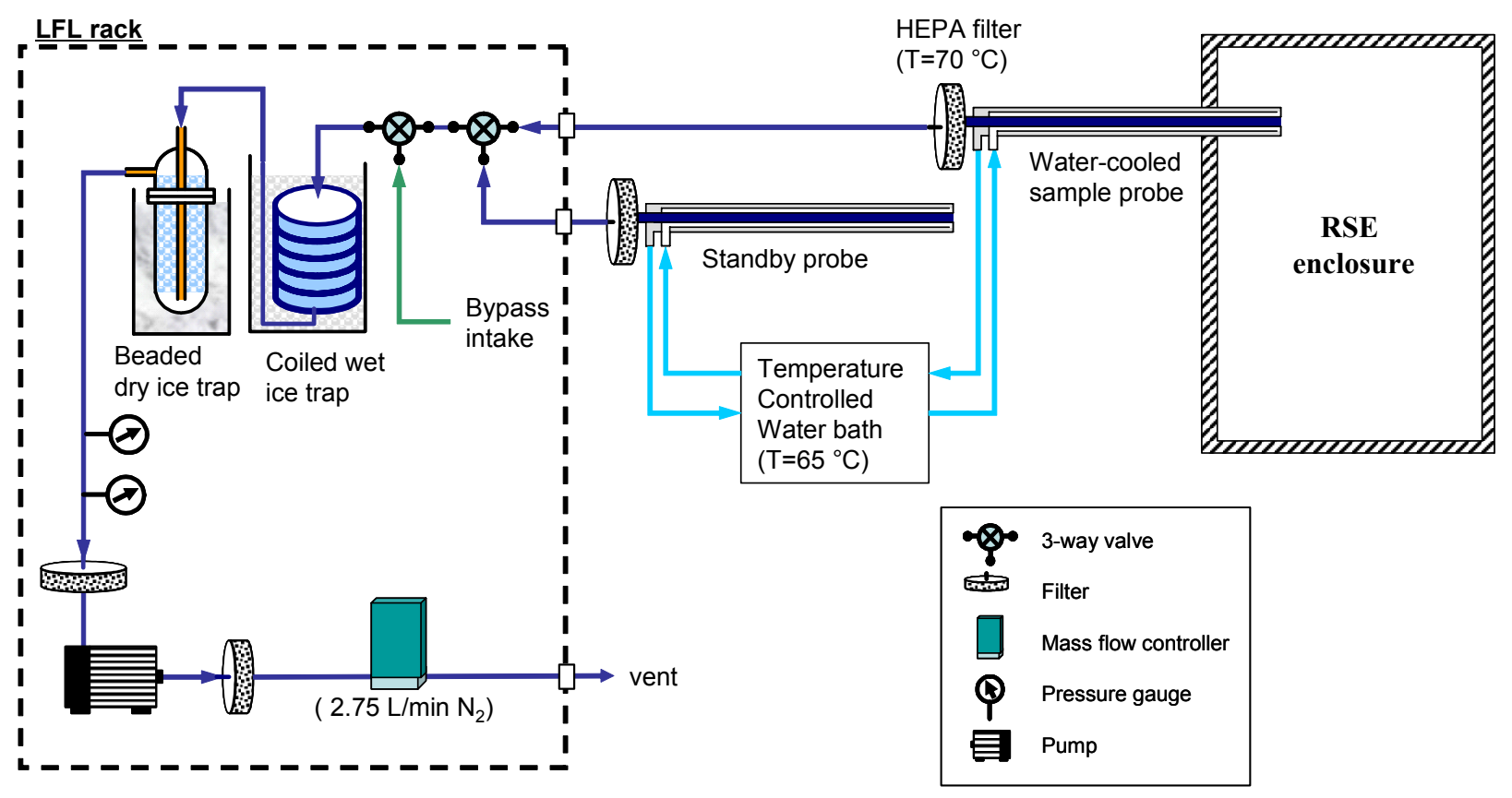

Figure 10. Schematic drawing of soot sampling system.

\subsubsection{Temperatures}

\section{Aspirated thermocouples}

A bare-bead thermocouple situated in a compartment fire typically experiences radiative exchange with walls, hot smoke, flames, and the surrounding environment with the effect that the measured temperature is not the true gas temperature. Accurate correction for these effects is complex, due to temporally and spatially varying local temperatures, velocities, and species. To reduce the effect of energy exchange on temperature measurement accuracy, aspirated thermocouple probes were used in addition to bare-bead thermocouples in this study.

An aspirated thermocouple probe is a bare-bead thermocouple contained within a small cylindrical metal tube through which the sample gas flows. If the flow over the bead is at least $5 \mathrm{~m} / \mathrm{s}$, a more accurate gas temperature measurement may be obtained [32]. According to Blevins [33], higher flows may be required depending on the thermal environment. Aspirated thermocouple probes may be shielded by a single cylindrical tube or by two or more concentric cylindrical tubes. In either case, the flow and thermal conditions and the detailed design of the assembly can impact measurement accuracy. Double-shielded aspirated thermocouple probes based on a design from National Advisory Committee for Aeronautics (NACA) were used in this study [34]. Figure 11 shows a drawing of an end-hole type NACA design aspirated thermocouple probe. Models with the entrance hole perpendicular to the probe axis were also used.

Each aspirated thermocouple was connected to a set of wet-ice and dry-ice traps, a flowmeter, and a pump using $9.5 \mathrm{~mm}$ (3/8 in) outer diameter (OD) copper and polyethylene tubing. A schematic of this is shown in Fig. 12. The gas was filtered and dried with the traps to protect the flowmeters and pumps. Flows were set at $24 \mathrm{~L} / \mathrm{min}$ for each aspirated probe. While the volumetric flows were set at the flow meters to be the same for all probes, since the ice traps 
cooled the hot gases, high temperature compartment gases produced much higher velocities at the bead compared to those produced by low temperature gases. The uniform setting of the cold volumetric flows kept the mass flows consistent across the probes. This velocity difference effect was not completely proportionate to the gas temperature differences since a higher flow would experience a greater pressure drop and flow resistance through the probe and tubing. Due to the large flows pumped through the aspirated thermocouple probes, the resulting temperature represents a volumetric average over a several centimeter diameter region at the end of the probe. For further discussion of the probe and gas interaction see Appendix B of this report.

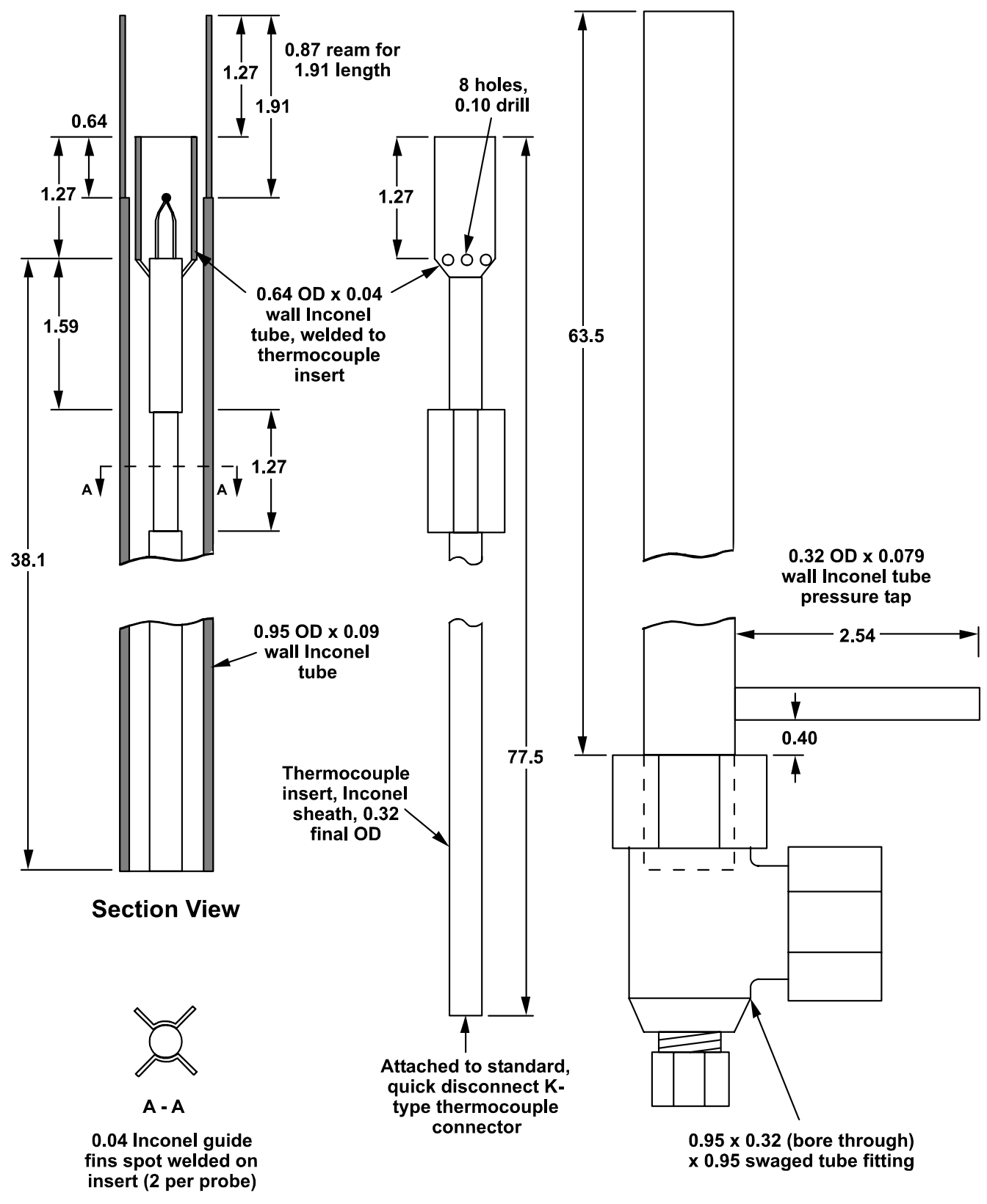

All dimensions in centimeters

Figure 11. Detailed drawing of aspirated thermocouple using NACA design [34]. 
Each aspirated thermocouple probe was attached to the data acquisition system using K-type thermocouple wire and connectors. During each experiment, the flow meters and measured temperatures were monitored. These checks were performed in order to determine if any probe system became clogged so it could be unclogged with high pressure air. The difference in temperature signal between an inoperative probe and a properly flowing probe was obvious. A functioning aspirated thermocouple showed higher frequency temperature fluctuations due to the transient thermal environment and effective convective heat transfer while a non-functioning probe would not show rapidly fluctuating temperatures since the large mass of hot metal of the probe radiating to the bead and lack of convection would dampen any short fluctuations. A probe typically required about 1 min when activated to overcome accumulated heat and reach the true gas temperature.

To evaluate measurement uncertainty and instrument time response, the present study performed a series of detailed flow and heat transfer calculations, focusing on double-shielded aspirated thermocouples and bare-bead thermocouples. A detailed description of the calculations and results can be found in Appendix A.

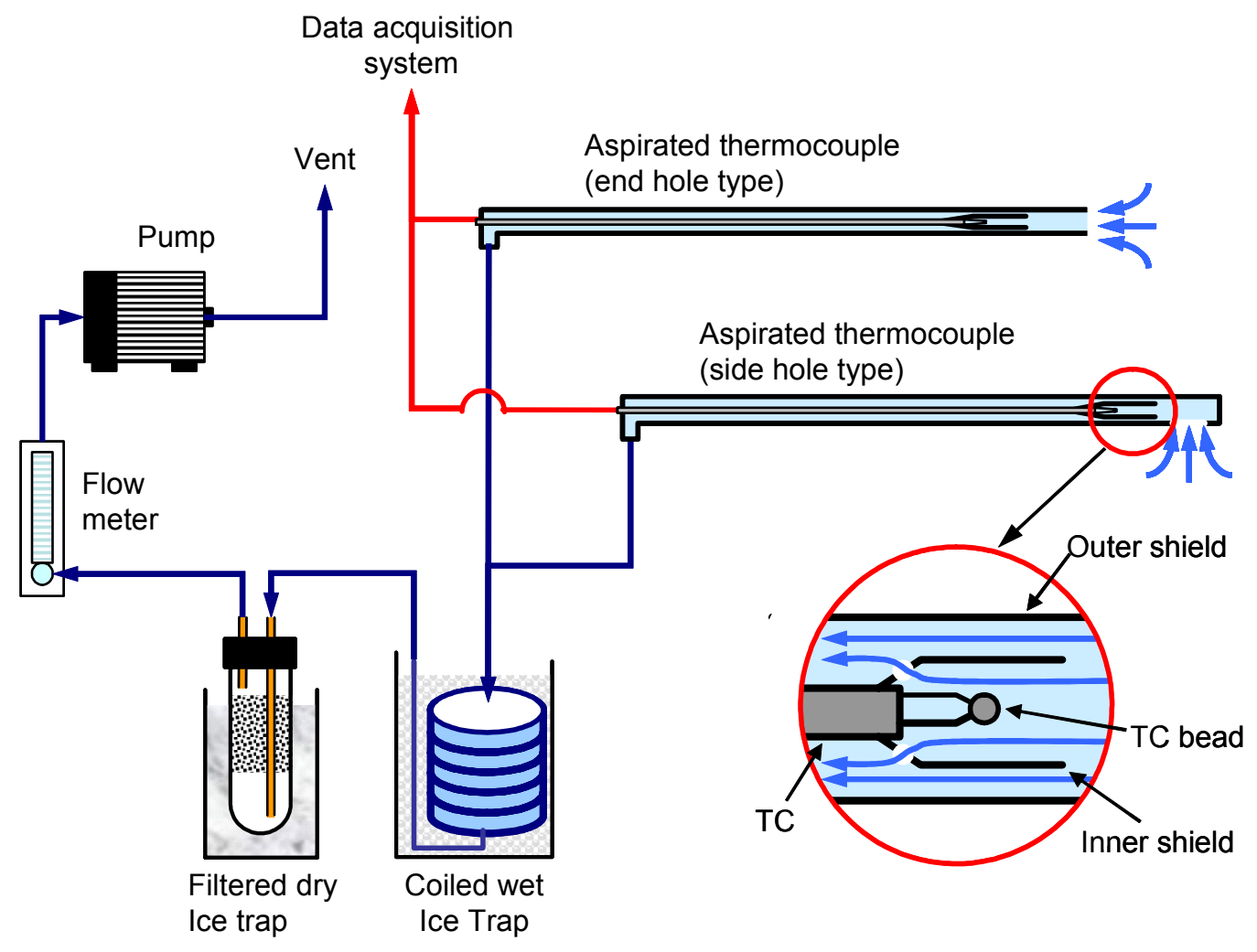

Figure 12. Schematic drawing of aspirated thermocouple measurement hardware.

\section{Bare Bead Thermocouples}

Temperature measurements by thermocouples located on compartment surfaces are required to characterize the thermal environment created by the fire, as well as to provide information for the aspirated thermocouple uncertainty analysis. Surface temperature measurements on the external surfaces of the compartment are needed to check the overall enthalpy balance associated with the 
fire, which is important for validating predictive compartment fire models. Bare bead thermocouples were also used in the doorway adjacent to the bi-directional probes and aspirated thermocouples.

The bare bead thermocouples were created by removing $1 \mathrm{~cm}$ to $2 \mathrm{~cm}$ of silica ceramic yarn insulation from chromel and alumel (type $\mathrm{K}$ ) lead wires and spot welding them together. The thermocouple lead wire diameter was $0.51 \mathrm{~mm}$ (24 gauge). The mean bead diameter was approximately two times the wire diameter.

Bare bead thermocouples were placed on the inside surface of the compartment at three locations: two on the floor and one on the ceiling. Table 2 in Section 2.4 lists the exact locations of the thermocouples, which were positioned on the floor, adjacent to the total heat flux gauges, and on the ceiling, almost directly above the front measurement station (which included the gravimetric soot and aspirated thermocouple probes). Figure 13 shows a 30 gauge Type $\mathrm{K}$ thermocouple on the compartment floor surface, which was held in place by spring loading to maintain its position near a $6 \mathrm{~mm}$ diameter total heat flux gauge. The screw/washer assembly about the thermocouple wire ensured that the thermocouple would not move.

Bare bead thermocouples were also positioned on the external surface of the compartment at one to five locations on the rear wall, depending on the experiment. Figure 14 shows a type $\mathrm{K}$ thermocouple attached to the rear outer surface of the compartment and held in place by a washer/screw arrangement (with the thermocouple spring loaded to maintain its position). The expanded uncertainty associated with a type $\mathrm{K}$ thermocouple is approximately $4.4^{\circ} \mathrm{C}$ [35].

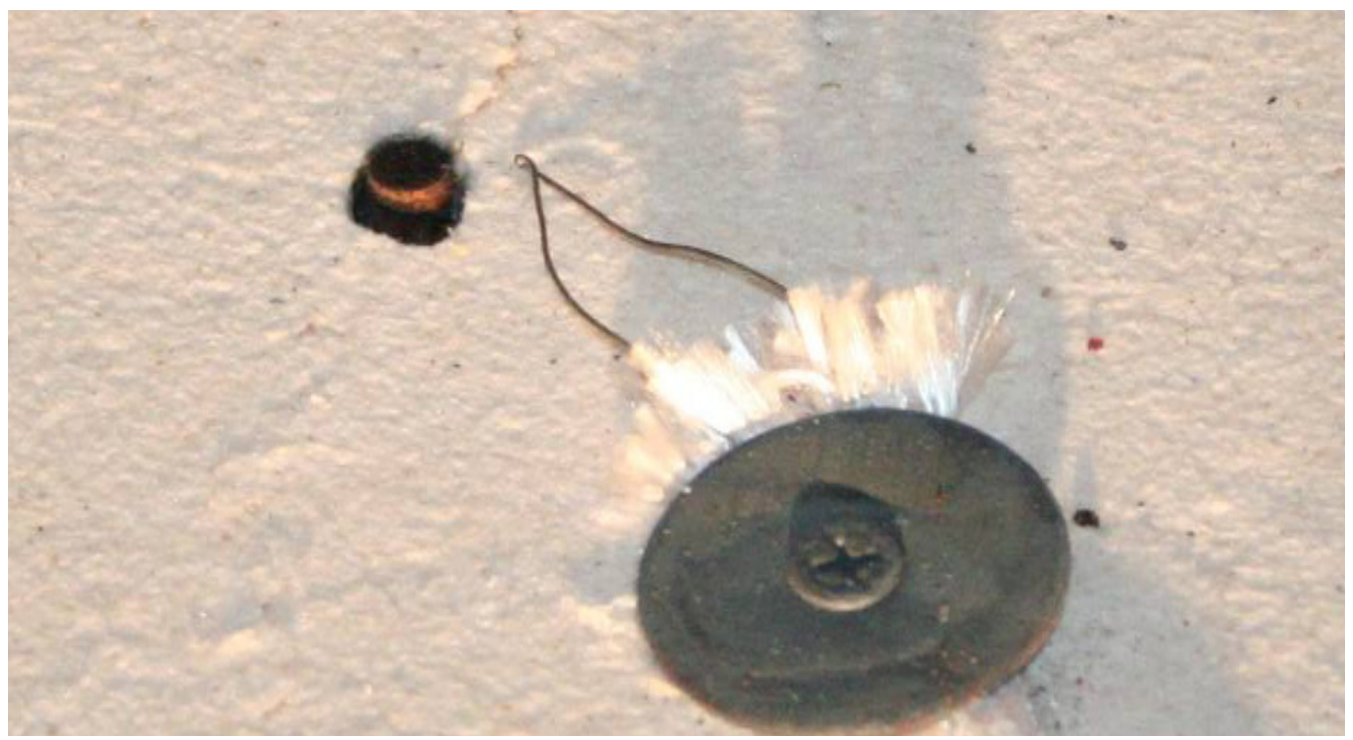

Figure 13. Type $\mathrm{K}$ thermocouple on compartment floor surface near a $6 \mathrm{~mm}$ diameter total heat flux gauge. 


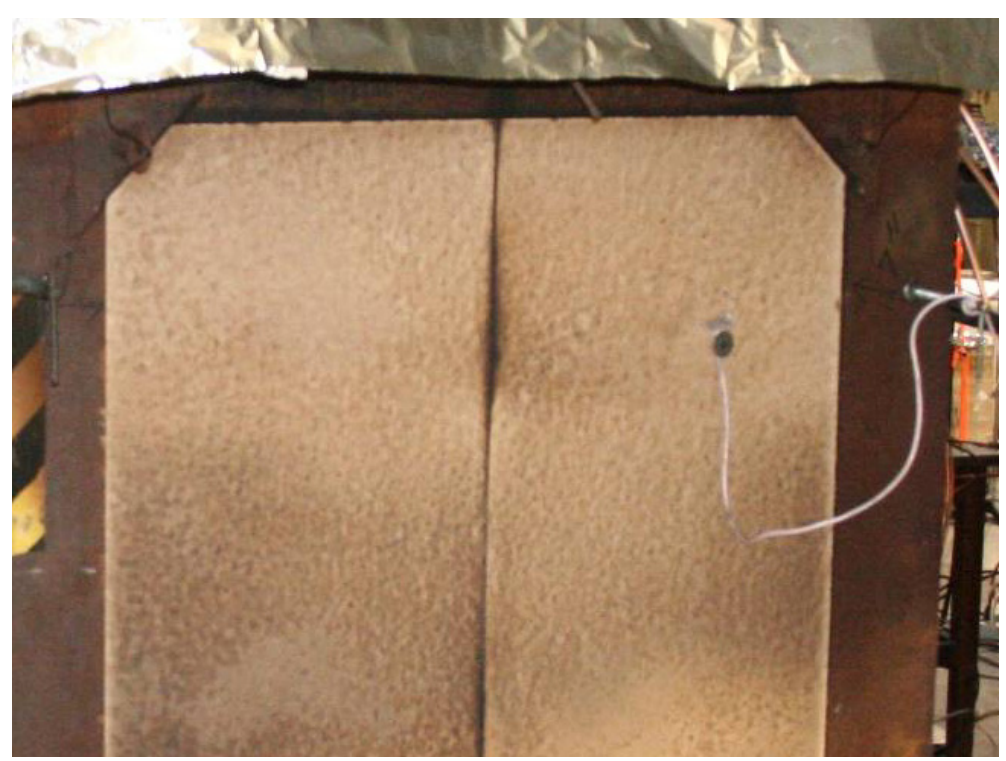

Figure 14. Type $K$ thermocouple attached to the outer surface of the compartment.

\subsubsection{Pressures and Velocities}

Dynamic pressure was measured at 9 locations in the doorway of the enclosure in order to determine velocities in the doorway. The coordinates of the locations are contained in Table 3 and shown in Fig. 4. The differential pressure transducers ( $0 \mathrm{~V}$ to $10 \mathrm{~V}$ output) had a maximum range of $133 \mathrm{~Pa}$. The particular model information is contained in Appendix D. Each pressure transducer was mounted on a board, and the board was attached to one of the support legs of the exhaust hood. Insulating board was also used to shield the transducers from the thermal insult of the fire. Each transducer produced a voltage, $V_{b d p}$, related to the exposed differential pressure by the following equation: $\Delta P_{b d p}=13.332\left(V_{b d p}-V_{b d p \text {, zero }}\right)$, where the pressure difference is in pascals and the voltages are measured in volts. The zero voltage, $V_{b d p, z e r o}$, condition is created when the positive and negative ports of the transducer are connected so there can be no pressure difference between them.

The transducers were connected to $1.3 \mathrm{~cm}$ diameter bi-directional probes [36] with $6.4 \mathrm{~mm}$ diameter copper tubing. Probe leads were routed close to each other so each lead was exposed to the same levels of heating. This installation care minimized differential heating and any resulting non-flow induced pressure differences between the leads.

Bi-directional probes enable the measurement of dynamic pressure which is the difference between the total pressure on the face where flow impinges and the static pressure on the downstream face of the probe. Using Bernoulli's principle and including a calibration factor, velocity, $v$, can be obtained from the dynamic pressure and a local gas temperature through the following relation: $v=C \sqrt{\Delta P_{b d p} T_{b d p}}$ where $\Delta P_{b d p}$ is the measured pressure across the bidirectional probe, $T_{b d p}$ is the temperature (in $\mathrm{K}$ ) of the gases flowing past the probe and $C$ is defined as: $C=\frac{1}{C_{b d p}} \sqrt{\frac{2 R}{P_{r e f} M W_{g a s}}}$. 
The calibration coefficient, $C_{b d p}$, for a bi-directional probe is equal to $1.08 \pm 0.05$ [36] when the local Reynolds number (defined by the probe diameter) is greater than 1000 . $R$ is the ideal gas constant and $M W_{\text {gas }}$ is the molecular mass of the gas.

To generate the velocity from the differential pressure, the temperature near the bi-directional probe is required. Because aspirated thermocouples can intrude on the pressure measurement bare-bead thermocouples were used to measure temperature. See Appendix A for a discussion of the errors associated with this approach. The measured doorway velocities were in the range of $-7 \mathrm{~m} / \mathrm{s}$ (flow out of the enclosure) to $+1.5 \mathrm{~m} / \mathrm{s}$ (into the enclosure). The combined expanded $(\mathrm{k}=2)$ uncertainty in the velocity measurement varied from $\pm 0.5 \mathrm{~m} / \mathrm{s}$ to $\pm 2.3 \mathrm{~m} / \mathrm{s}$. The largest component of uncertainty in this measurement was the variation in the pressure signal.

\subsubsection{Gas Chromatography}

A gas chromatograph was used at discrete times during the RSE tests to identify and quantify the major hydrocarbon species for each fuel and fire size at the front gas sampling location. The majority of the stable intermediate species were identified and quantified with a Hewlett-Packard 5890 gas chromatograph (GC) with flame ionization detector (FID). For chromatographic separation, a Restek Rt-QPLOT column (30 meter, $0.32 \mathrm{~mm}$ ID) was installed in the HP5890. Identification of the unknown species was accomplished by retention time matching. The quantification of the identified compounds was accomplished using the FID. The settings for the HP5890 are specified in Table 4.

In order to identify and quantify the hydrocarbons, gas phase calibration standards were obtained from Scott Specialty Gas. These standards had a reported uncertainty of $\pm 10 \%$ of desired volume fractions. Several other sources of gas standards were available for only retention time matching of unknown compounds. Table 5 documents the retention times for the specific identified compounds.

To quantify the identified compounds, either the calibration curve for the specific identified molecule or a calibration curve of a similar molecule was employed. If the molecular mass of the identified molecule and calibration curve molecule were different, then a correction factor based on the calibration molecule's carbon number divided by the identified molecule's carbon number was used. Employing this technique with two known compounds, the relative uncertainty associated with this correction was approximately $1 \%$ for one carbon atom difference, and approximately $3 \%$ for two carbon atom difference. As a result, all correction factors for unknown compounds were generally limited to a 1 or 2 carbon number difference. 
Table 4. Gas chromatograph settings and method parameters.

\begin{tabular}{|l|l|}
\hline GC Parameters & Setting \\
\hline Inlet Parameters & Constant Pressure Rate \\
\hline Inlet Mode & $124 \mathrm{kPa}$ \\
\hline Inlet Pressure & $250^{\circ} \mathrm{C}$ \\
\hline Inlet Temperature & $2.3 \mathrm{~mL} / \mathrm{min}$ \\
\hline Column Flow & $10: 1$ \\
\hline Split Ratio & $1.0 \mathrm{~mL} / \mathrm{min}$ \\
\hline Septum Purge & \\
\hline \multicolumn{2}{|l|}{ Oven Temperature Parameters } \\
\hline Initial Temperature & $50{ }^{\circ} \mathrm{C}$ \\
\hline Initial Time & $1 \mathrm{~min}$ \\
\hline Ramp \#1 Rate & $15^{\circ} \mathrm{C} / \mathrm{min}$ \\
\hline Ramp \#1 Temperature & $80^{\circ} \mathrm{C}$ \\
\hline Ramp \#1 Hold time & $1 \mathrm{~min}$ \\
\hline Ramp \#2 Rate & $20^{\circ} \mathrm{C} / \mathrm{min}$ \\
\hline Ramp \#2 Temperature & $240^{\circ} \mathrm{C}$ \\
\hline Ramp \#2 Hold time & $5 \mathrm{~min}$ \\
\hline \multicolumn{2}{|l}{} \\
\hline Auxiliary Parameters & \\
\hline Valve Oven Temperature & $125^{\circ} \mathrm{C}$ \\
\hline FID Temperature & $250^{\circ} \mathrm{C}$ \\
\hline \multicolumn{2}{|l}{} \\
\hline Valve Timing Parameters \\
\hline 0.10 min - Valve \#A & $\mathrm{ON} \mathrm{(Sample} \mathrm{Injection)}$ \\
\hline 1.10 min - Valve \#A & $\mathrm{OFF}$ \\
\hline
\end{tabular}

Table 5. List of retention times for identified compounds.

\begin{tabular}{lclc}
\hline Species & $\begin{array}{c}\text { Elution } \\
\text { Time } \\
(\mathbf{m i n})\end{array}$ & Species & $\begin{array}{c}\text { Elution } \\
\text { Time } \\
\text { (min) }\end{array}$ \\
\hline \hline methane & 2.41 & n-butane & 9.27 \\
ethene & 3.60 & 1-butyne & 9.34 \\
ethyne & 3.62 & 2-butyne & 10.22 \\
ethane & 4.07 & 1-pentene & 11.00 \\
propene & 6.58 & n-pentane & 11.17 \\
propane & 6.80 & 1-hexene & 12.79 \\
propyne & 7.12 & n-hexane & 12.93 \\
1-butane & 9.05 & benzene & 13.74 \\
1,3-butadiene & 9.18 & & \\
\hline
\end{tabular}


Analysis of variance (ANOVA) and regression analysis were employed in an effort to determine the errors associated with the quantification of the intermediate combustion species. The result of this analysis was the uncertainty of a single value, $S_{y}$, calculated from the calibration curve. The equations utilized for the analysis are show below:

$$
S_{y}=\frac{s_{\text {regression }}}{\beta} \sqrt{\frac{1}{m}+\frac{1}{N}+\frac{\left(y_{i}-\bar{y}\right)^{2}}{\beta^{2} S_{x x}}}
$$

where,

$$
\begin{aligned}
& S_{\text {regression }}=\sqrt{\frac{\left(S_{y y}\right)-\left(\frac{\left(S_{x y}\right)^{2}}{\left(S_{x y}\right)}\right)}{N-2}} \\
& s_{y y}=\sum y^{2}+\frac{\left(\sum y\right)^{2}}{N} \\
& s_{x y}=\sum x y+\frac{\left(\sum x \sum y\right)}{N} \\
& s_{x x}=\sum x^{2}+\frac{\left(\sum x\right)^{2}}{N}
\end{aligned}
$$

$m=$ number of measurements of the unknown sample

$N=$ number of calibration curve points (typically, 3 )

$y=$ FID area count of calibration species

$x=$ volume fractions of calibration species

$y_{i}=$ FID area count of unknown species

$\beta=$ slope of linear least squares fit to calibration points

The results of this analysis are included in all of the quantification graphs for each of the fuels examined in this program. However, it is important to note that this analysis does not include other sources of errors, such as sample extraction errors, possible decay of the samples prior to analysis, or errors resulting from carbon number correction factors.

\subsubsection{Optical Extinction Soot Measurements}

Two optical configurations were used to measure soot using laser transmission. They are shown schematically in Figure 15 and Figure 16, and the optical components used in both configurations are listed in Table 6. Results are available for Tests 6, 13, and 14 only, mainly because the measurement proved to be very challenging. The method and instrumentation used during Test 6 differed from that of Tests 13 and 14, as the experimental technique was being optimized during the course of this study. Table 7 lists the fuel type used during the tests. The apparatus used in Test \#6 (shown in Fig. 15) consisted of a laser light source, a chopper, a beam splitter, purged tubes, optical lenses and two detectors. A chopper and lock-in amplifier were 
used to minimize the background signal and amplify the original signal. The reference signal of the original laser source was monitored by splitting the laser beam.

Figure 16 shows the apparatus used during tests \#13 and tests \#14. The laser light source was a $9.7 \mathrm{~mW} 657 \mathrm{~nm}$ diode laser (continuous). A spherical lens with a $2.5 \mathrm{~cm}$ diameter and $40 \mathrm{~cm}$ focal length reduced the beam diameter. The optical path-length was defined by two thin ( $1 \mathrm{~mm}$ wall thickness) $2.5 \mathrm{~cm}$ diameter stainless steel tubes that were aligned and separated by a gap of distance $L_{D}$. Each of these tubes was connected to commercially available "stackable lens tubes" that were used to align the laser and detector and to shield the detector from stray light. Low flowing nitrogen gas was used to prevent combustion products, including soot, from entering the tubes. A glass window was attached on the end of the stackable lens tubes to prevent backward flow of the nitrogen purge gas. The detector was a silicon photodiode sensitive from $350 \mathrm{~nm}$ to $1100 \mathrm{~nm}$. On the detector side of the optical assembly, a spherical lens $(2.5 \mathrm{~cm}$ diameter and $1 \mathrm{~m}$ focal length) was positioned in the middle of stackable lens tubes to focus the laser light on the detector and prevent backward flow of the nitrogen purge gas. Several optical components were placed in front of the detector. A band pass filter $( \pm 10 \mathrm{~nm}$ window centered about $650 \mathrm{~nm})$ acted to attenuate radiation other than that from the laser. A diffuser lens was used to expand the laser beam, a standard practice that reduces beam steering effects. To prevent detector saturation, a neutral density filter was used to attenuate the beam.

The position of the optical apparatus used in tests \#13 and \#14 was different from that used in Test 6 . The sampling position was located $1 \mathrm{~cm}$ below the doorway soffit $(80 \mathrm{~cm}$ above the floor) and $1.4 \mathrm{~cm}$ from the plane defining the doorway as shown in Fig. 16. The nominal pathlength $\left(L_{D}\right)$ (the distance between the stainless steel purging tubes) in the optical soot measurement was $11.5 \mathrm{~cm}$. The nitrogen purge flow rate was adjusted to keep combustion products and smoke out of the purge tubes. The purge was measured as $900( \pm 30) \mathrm{cm}^{3} / \mathrm{min}$, equivalent to an average speed of $4 \mathrm{~cm} / \mathrm{s}$ through each of the tubes. The purge flow was estimated to reduce the actual path-length of the optical measurement $(L)$ by approximately $1.0 \mathrm{~cm}$. This value was observed to vary somewhat with fire size, such that the estimated expanded uncertainty of $L_{\mathrm{D}}$ was about $1 \mathrm{~cm}$, corresponding to a relative expanded uncertainty of $9 \%$.

The determination of soot density $\left(m_{s}\right)$ from an optical extinction measurement is based on Bouguer's law, in which the light extinction coefficient $(K)$ is defined in terms of the attenuated intensity $(I)$, and the reference intensity $\left(I_{o}\right)$ of monochromatic light passing through a homogeneous smoke path of distance $(L)$ :

$$
\begin{aligned}
& K=-\frac{\ln \left(I_{o} / I\right)}{L} \\
& m_{s}=\frac{K}{\sigma_{S}}
\end{aligned}
$$

where $\sigma_{s}$ is the mass specific extinction coefficient. The recommended value of $\sigma_{s}$ for flame generated smoke in over-ventilated fires is $8.7 \mathrm{~m}^{2} / \mathrm{g} \pm 5.4 \%$ (standard relative uncertainty). The expanded uncertainty of the $\ln \left(I_{o} / I\right)$ term during a period of 6 min before the fire test was on the order of $0.2 \%$. The laser drift, which was about $5 \%$, dominated the uncertainty in the baseline. 
The expanded combined uncertainty of the soot volume fraction is computed as the square root of the sum of the individual standard uncertainties $\left[\mathrm{u}\left(\mathrm{x}_{\mathrm{i}}\right)\right]$ associated with each of the terms that influence the soot mass measurement. The combined uncertainty of the optical soot density measurement is calculated as follows:

$$
U_{m_{s}}=2 \sqrt{\left(\frac{\partial m_{s}}{\partial \ln \left(I_{o} / I\right)}\right)^{2} u\left(\ln \left(I_{o} / I\right)^{2}+\left(\frac{\partial m_{s}}{\partial L}\right)^{2} u(L)^{2}+\left(\frac{\partial m_{s}}{\partial \sigma_{s}}\right)^{2} u\left(\sigma_{s}\right)^{2}\right.}
$$

An estimate of the combined relative expanded uncertainty was about $20 \%$, for both experimental configurations.

Table 6. Components used in the optical extinction measurements.

\begin{tabular}{|l|c|c|}
\hline Component & Test 6 & Tests 13 and 14 \\
\hline \hline Spherical lens before detector & Present & Present \\
\hline Spherical lens after laser & Not Present & Present \\
\hline Beam splitter & Present & Not Present \\
\hline Neutral density filter & Not Present & Present \\
\hline Reference detector & Present & Not Present \\
\hline Aperture in the detector part & Not Present & Present \\
\hline Lock-in amplifier & Present & Not Present \\
\hline Probe separation distance $\left(L_{D}\right)$ & $>24$ cm $(\approx 6 \mathrm{~m})$ & $11.5 \mathrm{~cm} \pm 0.1 \mathrm{~cm}$ \\
\hline Probe location & $\begin{array}{c}5 \mathrm{~cm} \text { below door soffit; } \\
\text { Across entire doorway; } \\
1.4 \mathrm{~cm} \text { beyond compartment }\end{array}$ & $\begin{array}{c}1 \mathrm{~cm} \text { below door soffit; } \\
\text { about center of doorway; } \\
1.4 \mathrm{~cm} \text { beyond compartment }\end{array}$ \\
\hline
\end{tabular}

Table 7. Tests in which optical light extinction measurements were conducted.

\begin{tabular}{|l|c|c|c|c|}
\hline Test $^{1}$ & Fuel type & Burner $^{2}$ & Fire size, $Q_{\max }(\mathrm{kW})$ & Path-length, $L(\mathrm{~cm})$ \\
\hline \hline 6 & Natural Gas & B (25 cm square) & 75 to 400 & $24.0 \pm 1.5$ \\
\hline 13 & Polystyrene & D (20 cm round) & 18 & $10.5 \pm 1.0$ \\
\hline 14 & Polystyrene & E (40 cm round) & 80 & $10.5 \pm 1.0$ \\
\hline
\end{tabular}

1. measurements not made in other tests, because the fire adversely affected the detection system.

2. see Fig. 2. 


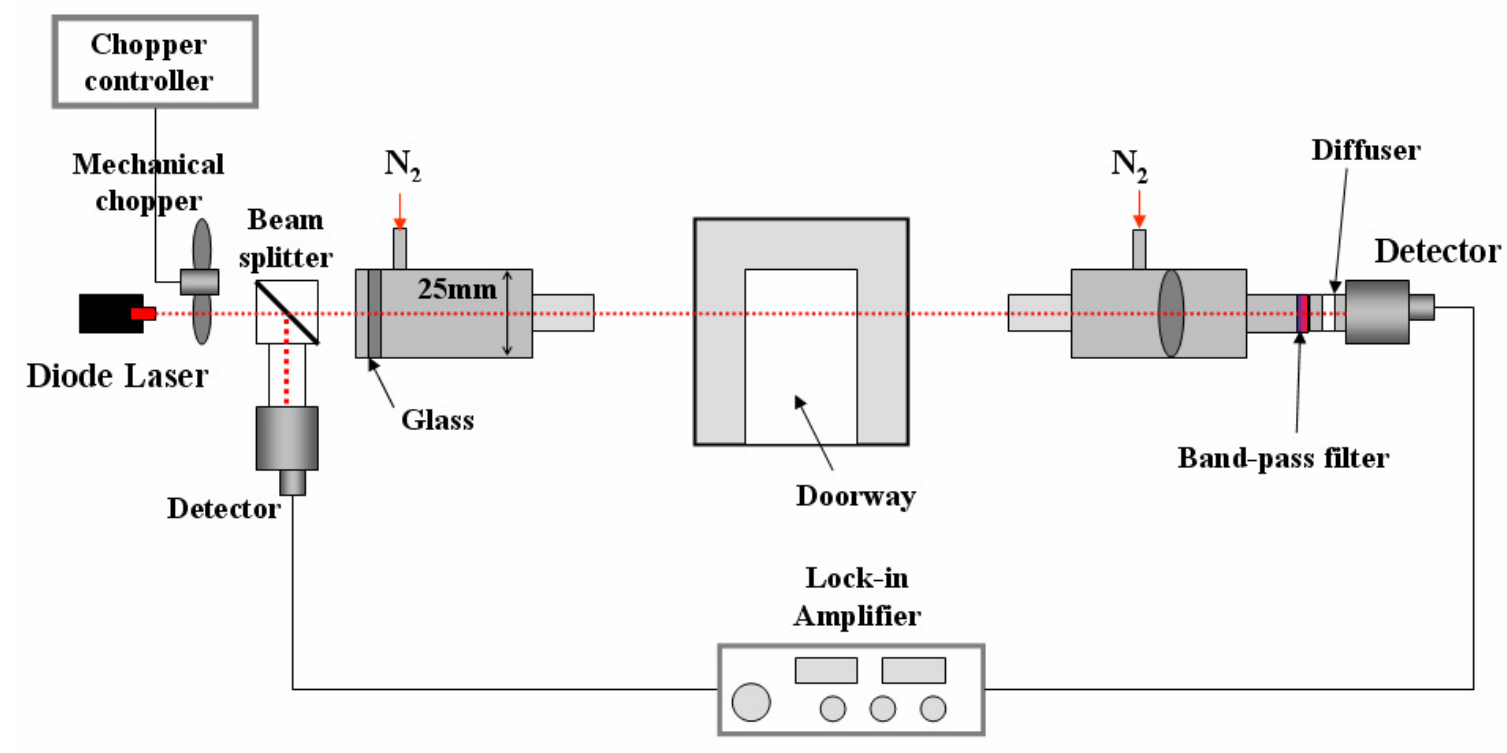

Figure 15. Schematic of the optical extinction measurement apparatus used during test \#6.

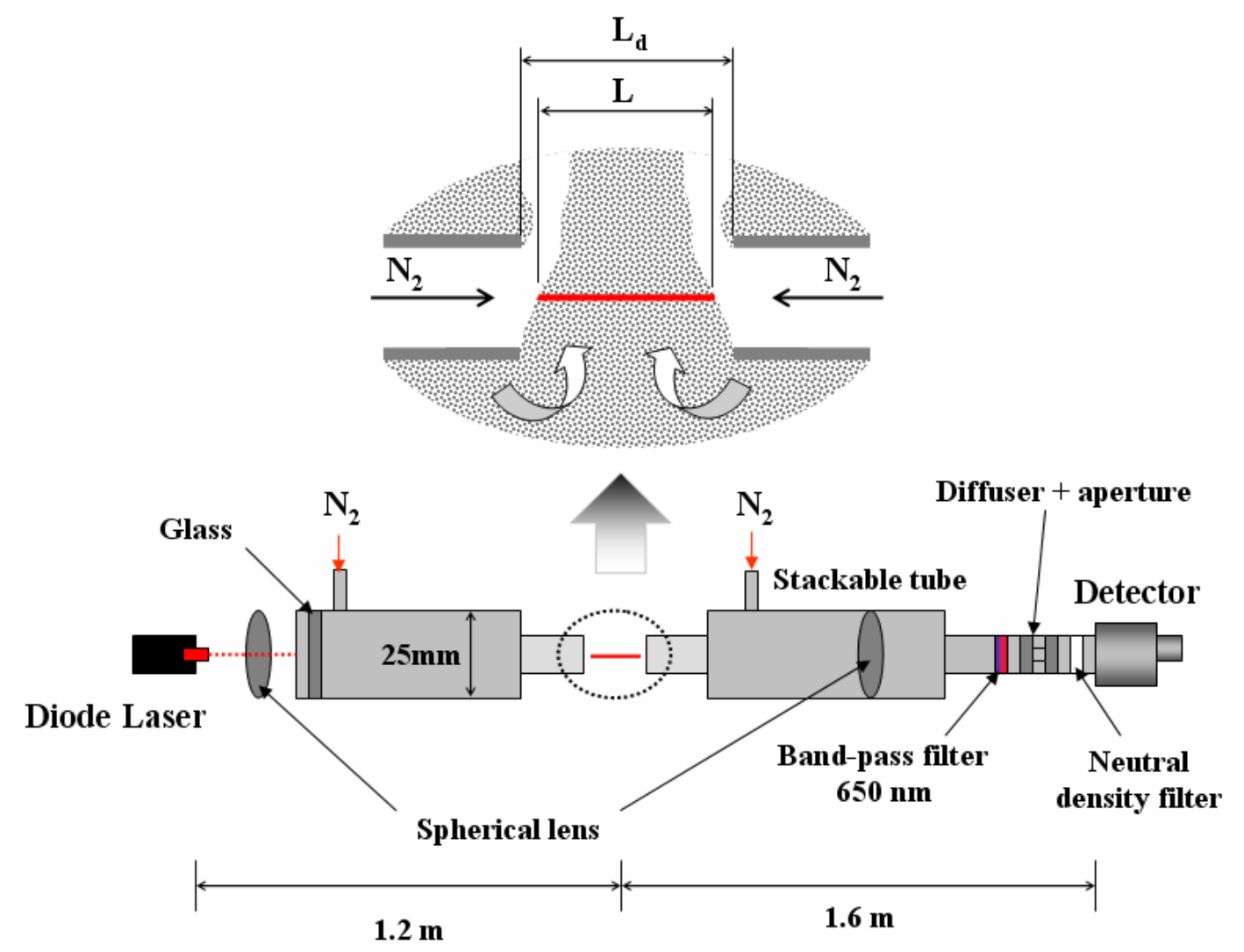

Figure 16. Schematic of the optical extinction measurement apparatus used during test \#13 and test \#14 including a blow-up of the circled optical sampling region. 


\subsubsection{Heat Fluxes}

Total heat flux was measured at two locations during each experiment. The heat flux gauges were $6.4 \mathrm{~mm}$ diameter Schmidt-Boelter type, water cooled gauges with embedded type-K thermocouples. The particular model information is contained in Appendix D. The nominal range for the gauges was $150 \mathrm{~kW} / \mathrm{m}^{2}$. Schmidt-Boelter gauges measure a temperature difference across a thin insulating material using a thermopile to generate a voltage from the small temperature difference. These gauges typically generate voltages much less than $100 \mathrm{mV}$ even for heat fluxes near their maximum range.

Each gauge was inserted in the floor flush with the upper surface and facing vertically upward. The rear gauge was located on the centerline of the enclosure and approximately $3 / 4$ of the way toward the rear from the front. The front gauge was located on the centerline of the enclosure and approximately $1 / 4$ of the way toward the rear from the front. The exact location coordinates for the gauges are listed in Table 2. The condition of the installed gauges was checked periodically. If significant soot accumulated on a gauge, it was brushed off. If a gauge was no longer flush with the surface of the floor, a note was made, but there was no attempt to move the gauge since the gauges were very difficult to access and attempting to do so could have impacted the integrity of the floor.

Heat fluxes as high as $250 \mathrm{~kW} / \mathrm{m}^{2}$ were observed. These heat fluxes are beyond the stated range of the gauges. According to the manufacturer, the calibrations remain linear and valid beyond the stated range as long as the materials do not degrade and change the sensitivity of the gauge. After the first six experiments the heat flux gauges were checked for changes to their calibrations. Each gauge's responsivity was found to remain within $3 \%$ of the factory calibration.

The main sources of uncertainty related to the total heat flux measurements are: the calibration, soot and dust deposition, and shifting of the gauge surface below the floor. These sources will be described and the total uncertainty estimated for the reported measurements. A model of uncertainty for heat flux gauge measurements in fire environments can be found in the study by Bryant et al. [37].

The total heat flux gauge calibration from the manufacturer was used to convert millivolt readings to $\mathrm{kW} / \mathrm{m}^{2}$. This calibration was performed using cooling water at $23{ }^{\circ} \mathrm{C} \pm 3{ }^{\circ} \mathrm{C}$. The cooling water in the Large Fire Laboratory was found to be within the same range. The manufacturer reported a $\pm 3 \%$ expanded uncertainty in the responsivity (the slope in $\mathrm{kW} / \mathrm{m}^{2} / \mathrm{mV}$ ). Calibrations at the NIST facility have varied within the $3 \%$ range of the nominal manufacturer's calibration. A recent round-robin study of heat flux gauge calibration consistency [38] sent the same heat flux gauges to multiple laboratories around the world and found that while several calibrations fell within the $3 \%$ range, if some outlier data were included, then the uncertainty rose to around $8 \%$. For this current project, an uncertainty of $\pm 6 \%$ for gauge calibration was chosen as fairly conservative since the NIST calibration was within the $3 \%$ range in the round-robin study.

While the cooling water was supplied at approximately $23{ }^{\circ} \mathrm{C}$, the fire heated the water such that the gauge temperature typically rose to between $40{ }^{\circ} \mathrm{C}$ and $60^{\circ} \mathrm{C}$, and less frequently to $100{ }^{\circ} \mathrm{C}$. 
For the fires where the water temperatures increased to between $40{ }^{\circ} \mathrm{C}$ and $100{ }^{\circ} \mathrm{C}$, the heat fluxes were on the order of $100 \mathrm{~kW} / \mathrm{m}^{2}$ to $300 \mathrm{~kW} / \mathrm{m}^{2}$ which represent blackbody temperatures in the $950{ }^{\circ} \mathrm{C}$ to $1300{ }^{\circ} \mathrm{C}$ range. The most extreme combination (affecting uncertainty) of cooling water and environment temperature would be a $75^{\circ} \mathrm{C}$ increase in cooling water in a $950{ }^{\circ} \mathrm{C}$ environment. This combination would only have about a $0.5 \%$ effect on the measured heat flux. The effect was determined by calculating the ratio of the $\mathrm{T}^{4}$ difference between $950{ }^{\circ} \mathrm{C}$ and the $25^{\circ} \mathrm{C}$ cooling water with $950{ }^{\circ} \mathrm{C}$ and the $100^{\circ} \mathrm{C}$ cooling water. This is a simplified comparison which assumes everything else is equal, but generates an approximation of the magnitude of the cooling water effect under specified conditions.

Heat flux uncertainty due to soot and dust deposition is difficult to quantify. For many tests, such as those burning methanol, ethanol, and natural gas, there was little to no contact with soot or combustion products. Also, even for the sootier fuels at low heat release rates, the lower layer remained as air with little opportunity for soot-laden gases to contact the gauges. For those experiments with sooty fuels and underventilated conditions ( $>200 \mathrm{~kW} \mathrm{HRR})$, combustion products including soot sometimes impinged on the floor. For these periods of time, it was estimated that the soot coating on the gauge would add an additional uncertainty of $\pm 10 \%$ due to variations in surface emissivity, and soot agglomerates shadowing the surface of the gauge.

The physical shifting of the gauge surface below the floor could have impact on a heat flux measurement if the solid angle viewable by the gauge was significantly diminished. Since the gauge is not sensitive either in calibration or application to radiation at angles close to the plane of the gauge surface due to reflection, and the radiation approaching from the lowest angles is generally from the coolest regions of the enclosure, the gauge would have to be below the surface of the floor by a few millimeters or more for there to be a significant impact on its measurement. Neither gauge was ever observed to be shifted by that amount in the course of testing.

\subsection{Data Acquisition}

Data acquisition (DAQ) for this series of experiments was divided into two systems. One DAQ system was dedicated to fuel flows, oxygen depletion calorimetry, and the constituent measurements required to calculate heat release rate using that method. The other DAQ system was used to record signals from all other measurements. Each DAQ system used National Instruments hardware and was controlled with LabVIEW software. The calorimetry DAQ system has been previously described in detail [29].

For this series of experiments, the channel list contained in Appendix $C$ was used to program the DAQ system. The types of measurements included: gas analyzers, dew point readers, heat flux gauges, pressure transducers, and thermocouples. These measurements were recorded on the DAQ hardware as voltages with 200 samples recorded every second. Each second, the average value for each channel was then converted to meaningful physical units. Two event marking channels were used to note the time of important events such as ignition, fuel flow change, or extinguishment. These event marker channels, which are in both DAQ programs, were especially useful in synchronization of the two data sets. 
The DAQ system for measurements not related to heat release rate, called MIDAS (Modular Insitu Data Acquisition System), had a structure and hardware components that differ from the HRR/fuel DAQ system. The MIDAS system utilized a fiberoptic extension of the computer's PCI bus. A series of fiberoptic cables connected the main computer in the control room to three experiment stations in the main bay of the laboratory. Each station has its own DAQ card, multiplexing hardware, and terminal blocks for voltage or thermocouple inputs. The East MIDAS Station was the station used for this series of experiments.

There were four comma-delimited spreadsheet files produced for each experiment. One file (with the -raw suffix) contained all of the raw voltages and temperatures recorded. A second file (-adj suffix) contained values with converted units calculated from the raw voltages. A third file (-ZS suffix) contained calibration data for each instrument that is calibrated at the beginning of an experiment. Finally, a fourth file (-sd) contained standard deviations for selected instruments based on the 200 raw voltages averaged each second.

The data acquisition hardware had 16 bit precision, with stated accuracies of the data acquisition board and multiplexing module equal to $0.014 \%$ and $0.015 \%$ of the reading. These uncertainties were orders of magnitude lower than those from other sources in all of the measurements reported here.

\subsection{General Data Corrections}

A Matlab script file was created for post-processing all data files generated during the test series. This program was used to make corrections to the data, generate plots, and save results to ASCII text files for archival purposes. The program was also used to compute time averaged values and uncertainties for examining trends in the data. An input file was used to allow batch processing of the raw data files. The input file contained the parameters needed for the heat release calculation (this file was also read by the DAQ program during the data collection process). Additional parameters were added to the end of the standard HRR input file to account for the gravimetric soot measurements and to record the time windows when channels had known missing or corrupted data.

The first step in data reduction was to inspect the data files and lab notebooks for erroneous data resulting from open channels, loss of sample flow, or some other instrument or data acquisition malfunction. Because data were collected on two separate computers, the series were synchronized to a common reference time. The ignition time was marked using a virtual event channel on each computer and defined as time zero for the reduced data. The gas analyzer measurements from inside the RSE and exhaust hood measurements were shifted in time to account for the sample flow transfer (delay) time. There was no adjustment for instrument response time in the data reduction. . The $\mathrm{t}_{10-90}$ response time of the instruments used in this study varied from $1 \mathrm{~s}$ to $12 \mathrm{~s}$.

Corrections to the heat release rate measurements were applied to account for the exhaust flow calibration factor and drift in the oxygen analyzer. The exhaust flow rate data was smoothed over a $10 \mathrm{~s}$ window to reduce noise due to turbulent flow in the duct. This smoothing was of the same order as the response time of the exhaust gas sample oxygen measurement. 
Since the gases sampled from the RSE were dried before entering the detectors, an estimate of the water removed must be made in order to correct the measurements to the in situ wet volume fraction. The general combustion reaction assuming all the fuel is reacted and that the soot can be represented as pure carbon is:

$$
\mathrm{C}_{\mathrm{x}} \mathrm{H}_{\mathrm{y}} \mathrm{O}_{\mathrm{z}}+\mathrm{aO}_{2} \rightarrow \mathrm{bCO}_{2}+\mathrm{cCO}+\mathrm{dCH}_{4}+\mathrm{eC}+\mathrm{fH}_{2} \mathrm{O}
$$

The molecular yield of water can be related to the combustion product yields using the known hydrogen/carbon $(y / x)$ ratio of the fuel:

$$
f=\frac{y}{2 x}(b+c+d+e)-2 d
$$

If the yield of soot is small compared to the other products, the water volume fraction, $\mathrm{X}_{\mathrm{H} 2 \mathrm{O}}$, can be estimated from Eq. 11.

$$
\mathrm{X}_{\mathrm{H}_{2} \mathrm{O}}=\frac{\mathrm{y}}{2 \mathrm{x}}\left(\mathrm{X}_{\mathrm{CO}_{2}, \text { wet }}+\mathrm{X}_{\mathrm{CO} \text {,wet }}\right)
$$

The relationships for wet $\mathrm{CO}_{2}$ and $\mathrm{CO}$ are given by the following:

$$
\begin{aligned}
& \mathrm{X}_{\mathrm{CO}, \text { wet }}=\frac{\mathrm{X}_{\mathrm{CO}, \text { dry }}}{1+\frac{\mathrm{y}}{2 \mathrm{x}}\left(\mathrm{X}_{\mathrm{CO}_{2} \text {,dry }}+\mathrm{X}_{\mathrm{CO}, \text { dry }}\right)} \\
& \mathrm{X}_{\mathrm{CO}_{2} \text {,wet }}=\frac{\mathrm{X}_{\mathrm{CO}_{2} \text {,dry }}}{1+\frac{\mathrm{y}}{2 \mathrm{x}}\left(\mathrm{X}_{\mathrm{CO}_{2} \text {,dry }}+\mathrm{X}_{\mathrm{CO} \text {,dry }}\right)}
\end{aligned}
$$

Other gas volume fraction measurements performed on a dry basis were corrected using the following relationship:

$$
\mathrm{X}_{\text {spec,wet }}=\mathrm{X}_{\text {spec,dry }}\left(1-\mathrm{X}_{\mathrm{H}_{2} \mathrm{O}}\right)
$$

The total hydrocarbons can contribute to the formation of water, however the gas composition measurements confirmed that when total hydrocarbons were present in significant quantities, they were in the form of unburned fuel (methane in the natural gas tests). Unburned fuel does not contribute to the formation of water. Therefore, the resulting relative error in the water volume fraction estimation due to neglecting hydrocarbons was always less than $3 \%$. The error in the water volume fraction estimate due to neglecting soot was as much as $10 \%$ for the highly sooting fuels. However, since the soot measurements were sparse, we chose to report the results on a consistent basis. A more accurate estimate of water volume fraction could be made for the short time windows where soot was collected. Hydrogen gas was not quantified for these tests, but could also affect the estimation of water. 
Unless otherwise noted, all uncertainty results reported here represent the combined expanded (coverage factor $\mathrm{k}=2$ ) uncertainty resulting from a propagation of uncertainty analysis. The uncertainty values are represented by error bars on the steady state average values presented in Sec. 3.

\section{Results}

\subsection{Heat Release Rate}

The heat release rate measurement was used to characterize the size of the fire and also to help determine (along with heat flux data) when the fire conditions had reached steady state. As the fire becomes underventilated burning can take place outside of the enclosure. The HRR measurement represents the total burning inside and outside of the enclosure. Table 8 shows a description of the measurement labels used in the table column headings and figure legends in this section. These labels are identical to the column headings in the reduced data files.

Table 8. Description of calorimetry measurement labels.

\begin{tabular}{|c|c|}
\hline Measurement Label & Description \\
\hline 54 HRRcal & Heat Release Rate from Calorimeter, $\mathrm{kW}$ \\
\hline 55 HRRburner & Heat Release Rate from Burner (gas, pool or spray), $\mathrm{kW}$ \\
\hline 56 StackMFR & Exhaust hood mass flow rate, $\mathrm{kg} / \mathrm{s}$ \\
\hline 57 Tstack & Exhaust hood temperature (near bi-directional probe), ${ }^{\circ} \mathrm{C}$ \\
\hline $58 \mathrm{O} 2$ stack & Exhaust $\mathrm{O}_{2}$ volume fraction (dry) \\
\hline $59 \mathrm{CO} 2$ stack & Exhaust $\mathrm{CO}_{2}$ volume fraction (dry) \\
\hline 60 COstack & Exhaust CO volume fraction (dry) \\
\hline 61 THCstack & Exhaust total hydrocarbons volume fraction (dry) \\
\hline 62 MSstack & Exhaust soot mass concentration (wet), $\mathrm{mg} / \mathrm{m}^{3}$ \\
\hline
\end{tabular}

Figure 17 shows the heat release rate results for one of the natural gas experiments (test \#3). For this test, the measured HRR and enthalpy input match closely indicating that the combustion efficiency was close to 1 . The composition and heating values for the natural gas used during all of the tests is shown in Table 9. The heating value is defined at the standard conditions of $300 \mathrm{~K}$ and $101.3 \mathrm{kPa}$. The propane and nitrogen levels were unusually high on the first test day; however the variation in heating value was less than $1.5 \%$ for all of the tests with natural gas. Figure 18 shows two photographs of test \#3 (natural gas) looking into the doorway at the nominal fire sizes of $75 \mathrm{~kW}$ (left) and $400 \mathrm{~kW}$ (right). The intensity and transparency of the flames provided visual evidence of the lack of soot produced by the fire. The image of the $400 \mathrm{~kW}$ fire clearly shows flames exiting the doorway, indicating the fire is underventilated. The $75 \mathrm{~kW}$ fire in the reduced-scale enclosure would scale up to a $485 \mathrm{~kW}$ fire in the ISO 9705 room, and the $400 \mathrm{~kW}$ fire would correspond to a 2.6 MW fire in the ISO room (see Sec. 6).

The heat release results for the methanol spray fire (burner C) test \#12 are shown in Fig. 19. The dashed line in this figure represents the ideal heat release rate of the fuel based on the delivered fuel flow rate. The liquid fuel height in the catch pan varied during the test, and once the fuel flow was stopped the burnout time was more than $20 \mathrm{~min}$ (see Fig. 19 from $3400 \mathrm{~s}$ to $4900 \mathrm{~s}$ ). This accumulation effect explains why the heat release rate of the fire measured by calorimetry 
was significantly different than the set burner heat release rate. Although the HRR measurement had a larger uncertainty than the fuel flow rate measurement, in some cases it was a more reliable measurement of the actual fuel burning rate. Photographic images of three different methanol fires are shown in Fig. 20. The image on the left shows a $50 \mathrm{~kW}$ methanol pool fire burning outside of the enclosure in a $40 \mathrm{~cm}$ diameter pan prior to test \#12. The middle and right images show methanol spray fires from test $\# 12$ at HRR's of $70 \mathrm{~kW}$ and $300 \mathrm{~kW}$, respectively.

Table 9. Composition (volume fraction \%) and heating values of natural gas used in RSE tests.

\begin{tabular}{|c|c|c|c|c|c|c|c|c|c|c|c|c|}
\hline $\begin{array}{l}\text { Test } \\
\text { Name }\end{array}$ & 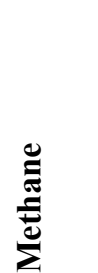 & 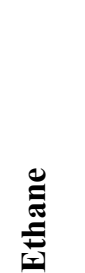 & 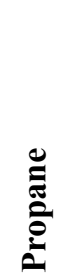 & 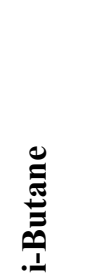 & 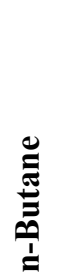 & 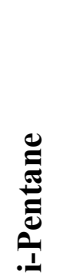 & 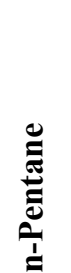 & U & 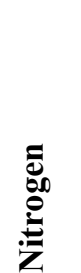 & ชี & 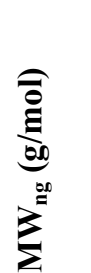 & 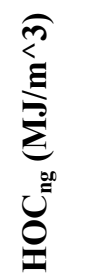 \\
\hline RSE1NG & 86.92 & 3.84 & 3.57 & 0.13 & 0.15 & 0.05 & 0.03 & 0.07 & 4.40 & 0.84 & 18.56 & 34.07 \\
\hline RSE2NG & 93.45 & 3.79 & 0.72 & 0.12 & 0.15 & 0.04 & 0.03 & 0.07 & 0.79 & 0.84 & 17.32 & 33.78 \\
\hline RSE3NG & 93.39 & 3.71 & 0.71 & 0.12 & 0.15 & 0.05 & 0.04 & 0.07 & 0.83 & 0.93 & 17.34 & 33.73 \\
\hline RSE6NG & 93.95 & 3.07 & 0.70 & 0.12 & 0.15 & 0.05 & 0.04 & 0.08 & 0.83 & 1.02 & 17.28 & 33.54 \\
\hline RSE65NG & 93.46 & 3.76 & 0.86 & 0.12 & 0.16 & 0.04 & 0.03 & 0.05 & 0.78 & 0.74 & 17.31 & 33.86 \\
\hline
\end{tabular}

Figure 21 shows the heat release rate results for test \#16 with polystyrene. Six kilograms of polystyrene pellets were ignited using a heptane spray fire which remained on for a period of $30 \mathrm{~s}$. Figure 22 shows images of the fire at two different heat release rates. The left side of the figure shows the fire approximately 6.5 min after ignition when the HRR was $170 \mathrm{~kW}$. Large amounts of black soot can be seen exiting the doorway. The right side of the figure shows the fire 8.5 min after ignition, when the fire size was $340 \mathrm{~kW}$, approaching its peak HRR.

Figure 23 shows the heat release rate results for a toluene pool fire (test \#10). The pool (burner $B$ in Fig. 2) was half-filled with fuel when ignited at $t=0 \mathrm{~s}$. As the thermal environment of the compartment changed, the fuel flow rate and the water flow rate to the liquid-cooled burner were continually adjusted to achieve near-steady burning. Figure 24 shows images of the toluene fires at heat release rates of $60 \mathrm{~kW}$ (left side) and $200 \mathrm{~kW}$ (right side).

The HRR results for the ethanol pool fire (test \#11) are shown in Fig. 25. As with the methanol fire, the discrepancy between the measured HRR and the enthalpy input was primarily due to fuel accumulation in the pool. Images of test \#11 with ethanol are shown in Fig. 26.

The HRR results for the heptane spray fire (test \#15) are shown in Fig. 27. Unlike the tests with alcohol fuels, there was no evidence of fuel accumulation in the burner during test \#15.

Inspection of the HRR curve at approximately $3200 \mathrm{~s}$ after ignition shows that when the fuel delivery was reduced (from $500 \mathrm{~kW}$ to $90 \mathrm{~kW}$ ), there was no lag in the HRR measurement. This suggests that incomplete combustion (rather than accumulation) is responsible for the significant differences in the measured and complete burning rates of the fuel. Images of the $160 \mathrm{~kW}$ and $370 \mathrm{~kW}$ heptane fires are shown in Fig. 28. 


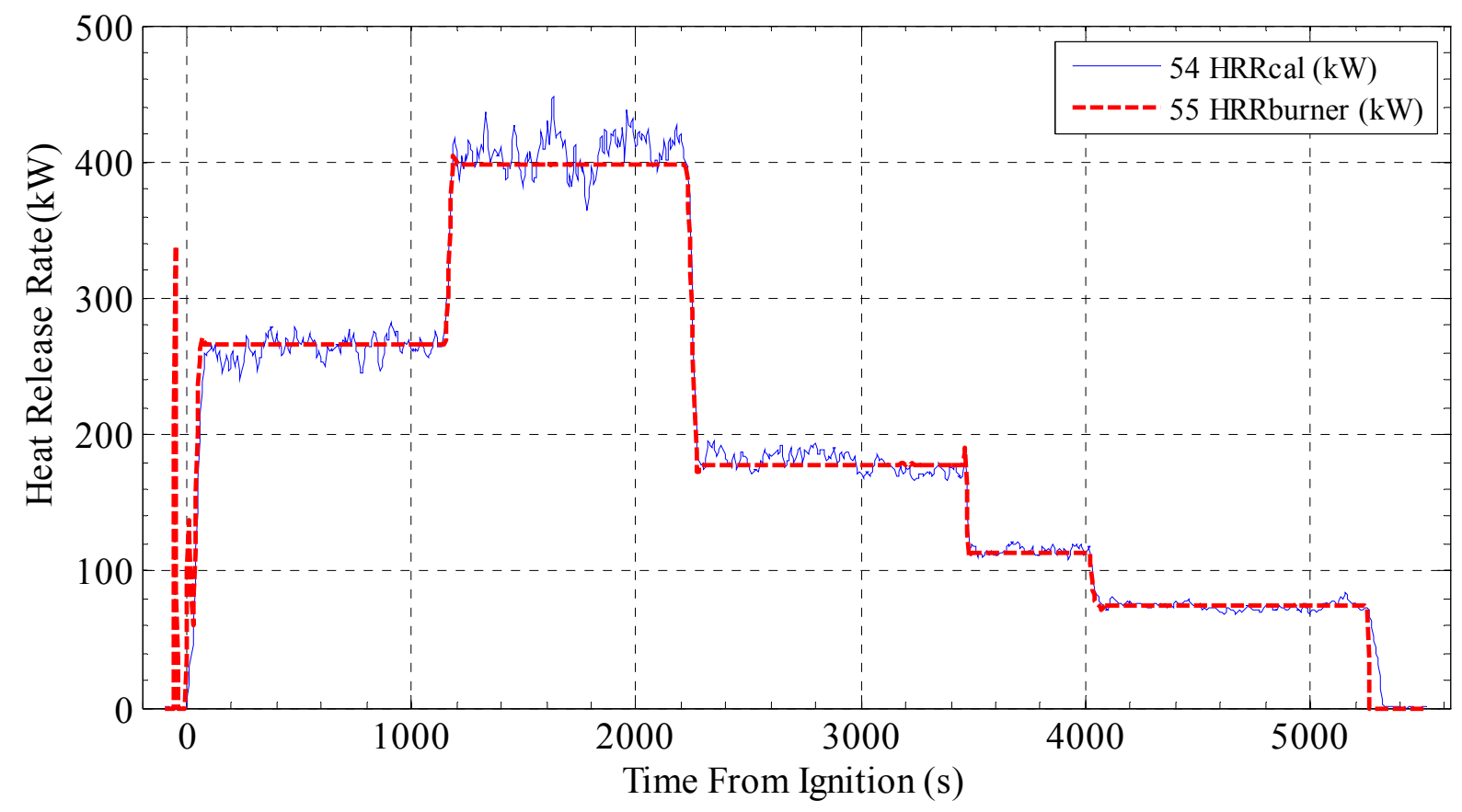

Figure 17. Heat release rate results for natural gas test \#3 using Burner A.
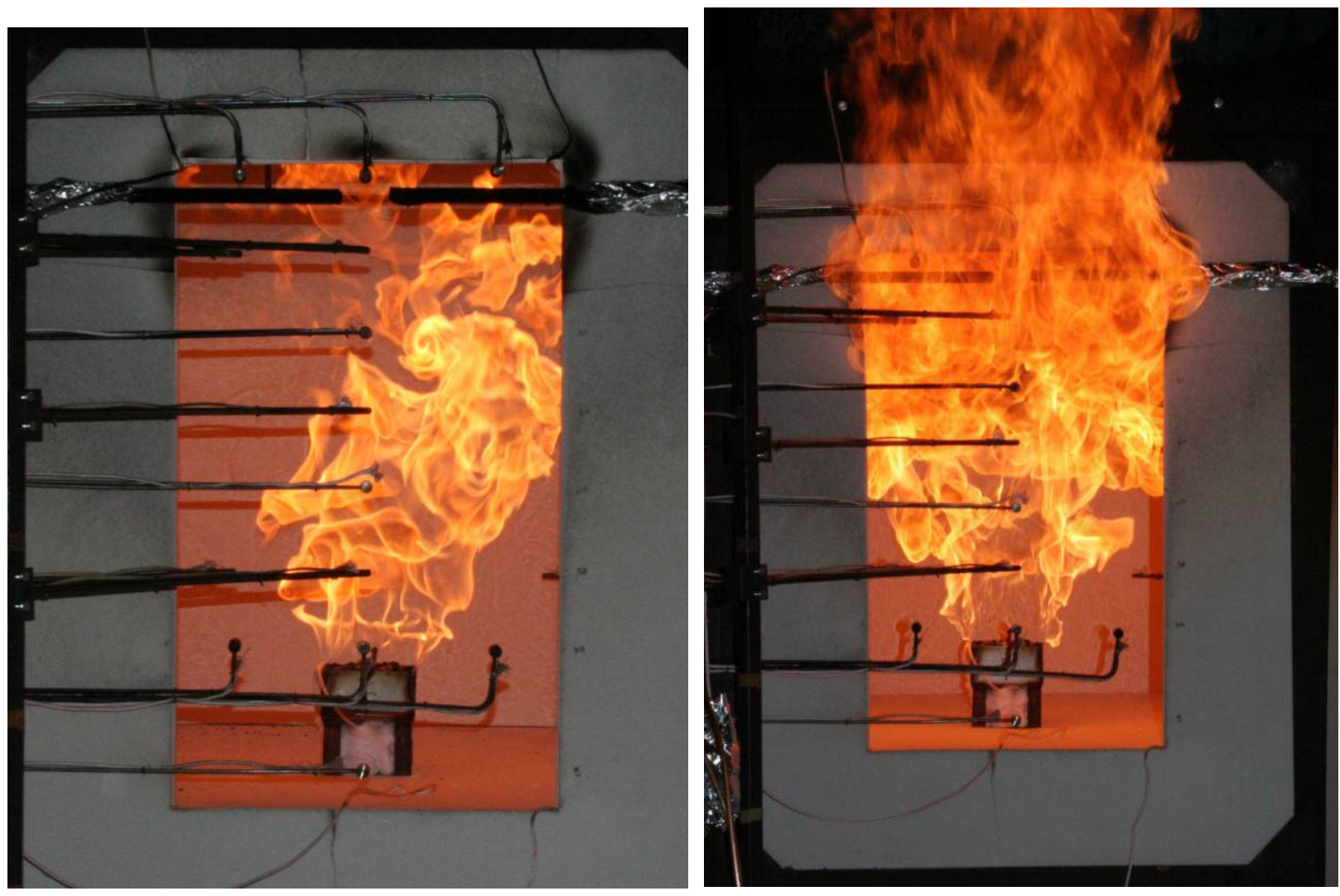

Figure 18. Photograph of test $\# 3$ natural gas, $H R R=75 \mathrm{~kW}$ (left), $H R R=400 \mathrm{~kW}$ (right). 


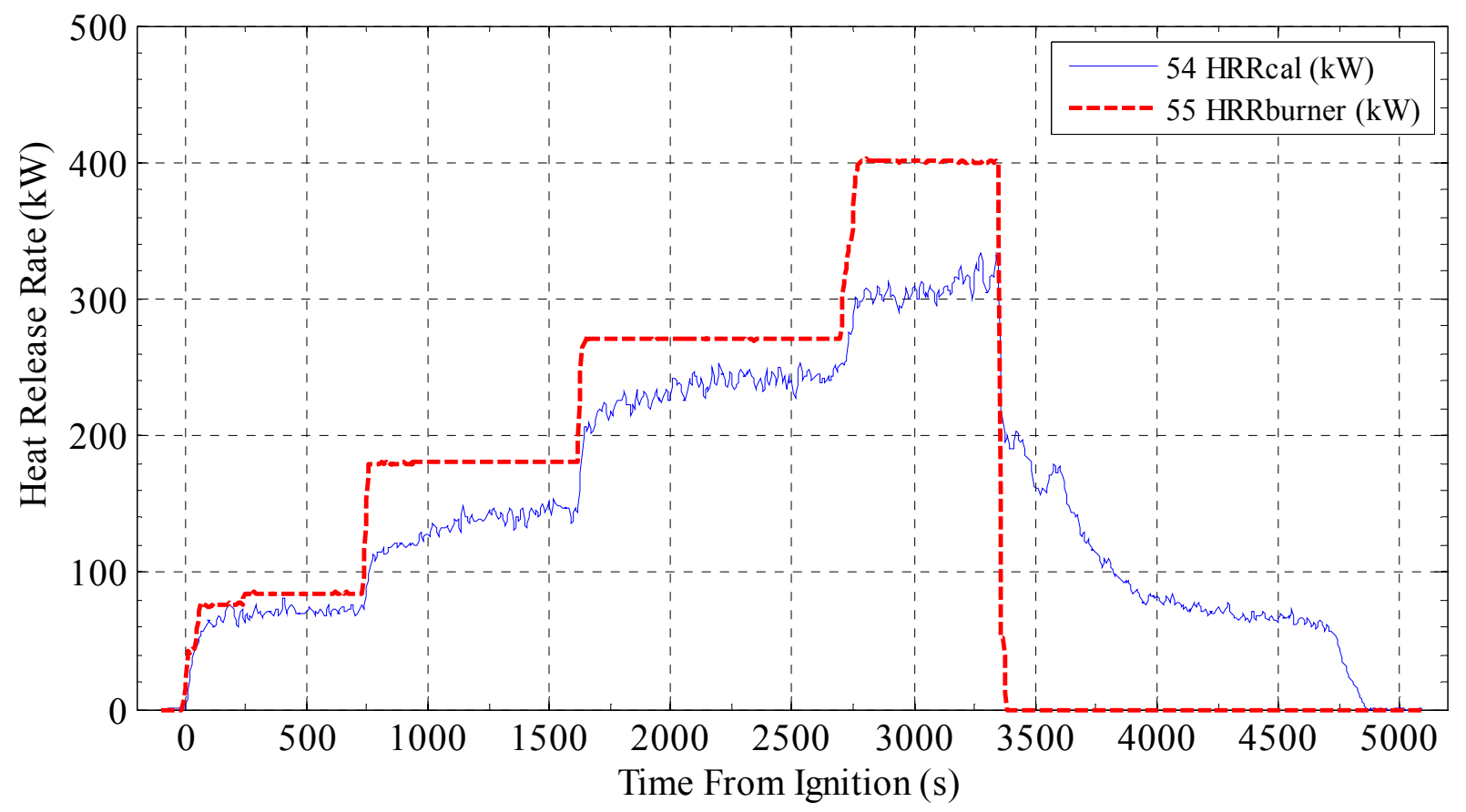

Figure 19. Heat release rate results for methanol test \#12 using spray burner $\mathrm{C}$.
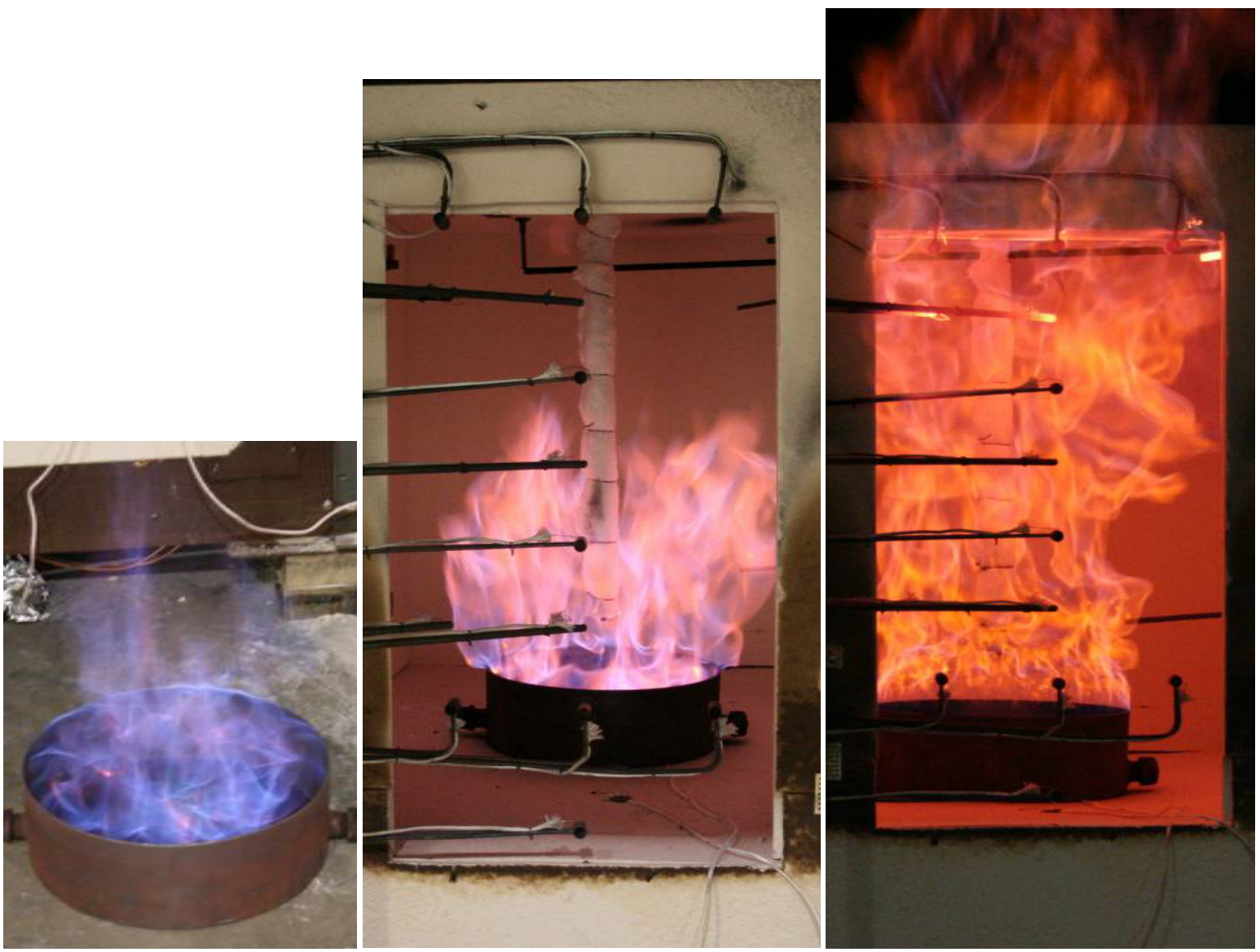

Figure 20. Photographs of methanol test $\# 12$ : Open burn, $H R R=50 \mathrm{~kW}$ (left), $\mathrm{t}=645 \mathrm{~s}$, $\mathrm{HRR}=72 \mathrm{~kW}$ (middle), $\mathrm{t}=2885 \mathrm{~s}, \mathrm{HRR}=305 \mathrm{~kW}$ (right). 


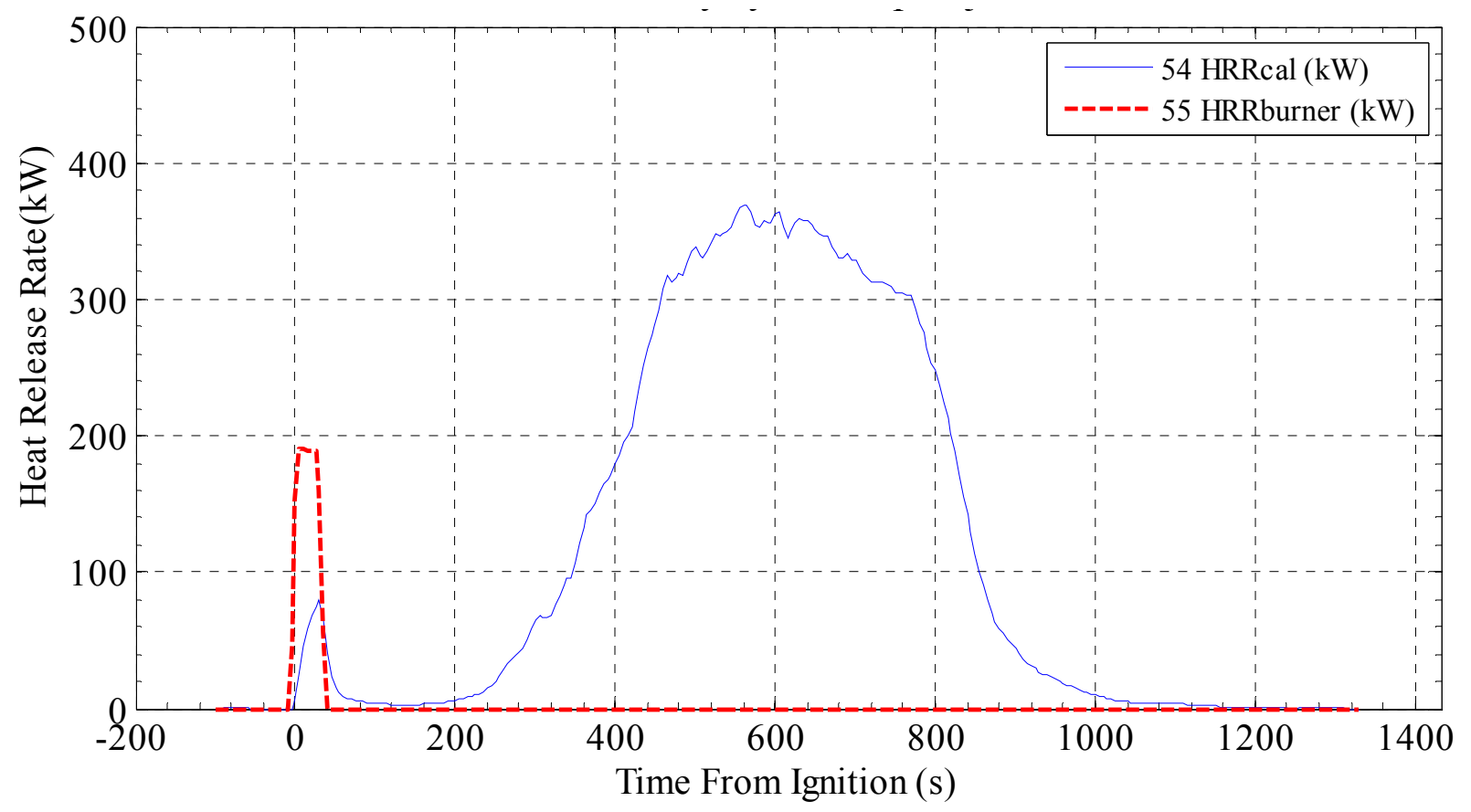

Figure 21. Heat release rate results for polystyrene test \#16. A heptane spray was used to ignite $6 \mathrm{~kg}$ of polystyrene pellets.
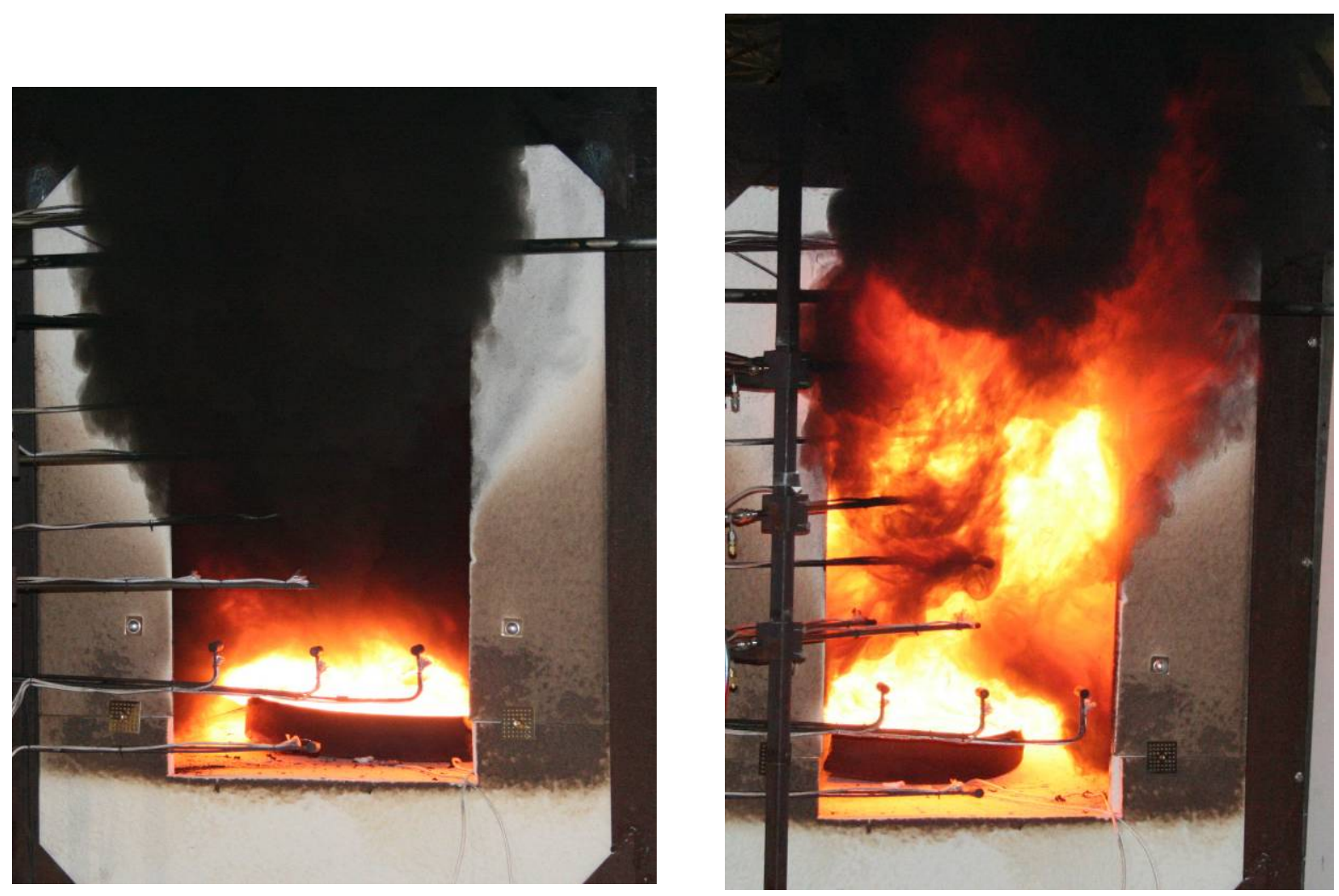

Figure 22. Photographs of polystyrene test $\# 16: t=389 \mathrm{~s}, \mathrm{HRR}=170 \mathrm{~kW}$ (left), $\mathrm{t}=515 \mathrm{~s}, \mathrm{HRR}=340 \mathrm{~kW}$ (right). 


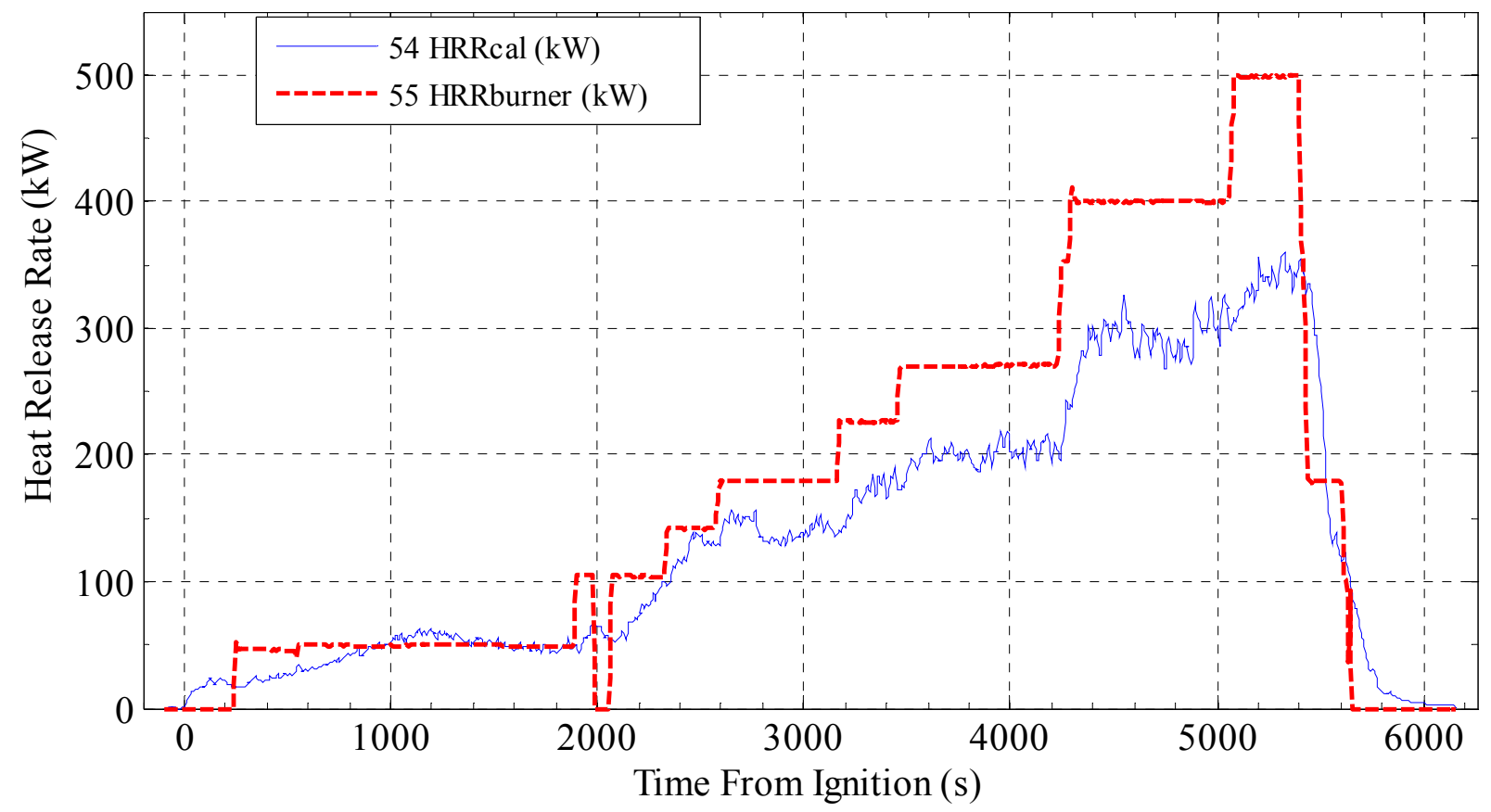

Figure 23. Heat release rate results for toluene pool fire (test \#10).
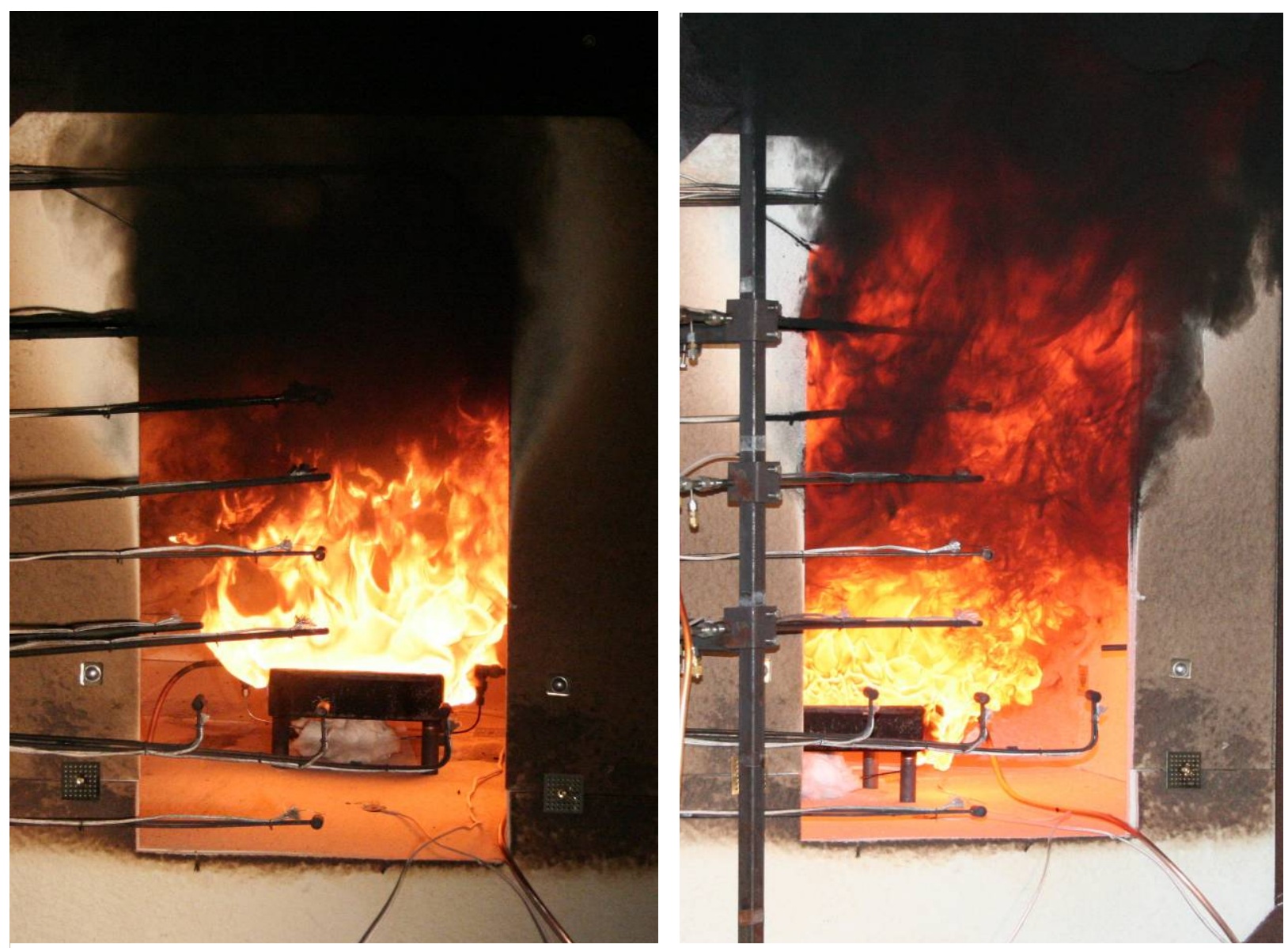

Figure 24. Photographs of toluene pool fire (test $\# 10): t=1279 \mathrm{~s}, \mathrm{HRR}=60 \mathrm{~kW}$ (left), $\mathrm{t}=3843 \mathrm{~s}, \mathrm{HRR}=200 \mathrm{~kW}$ (right). 


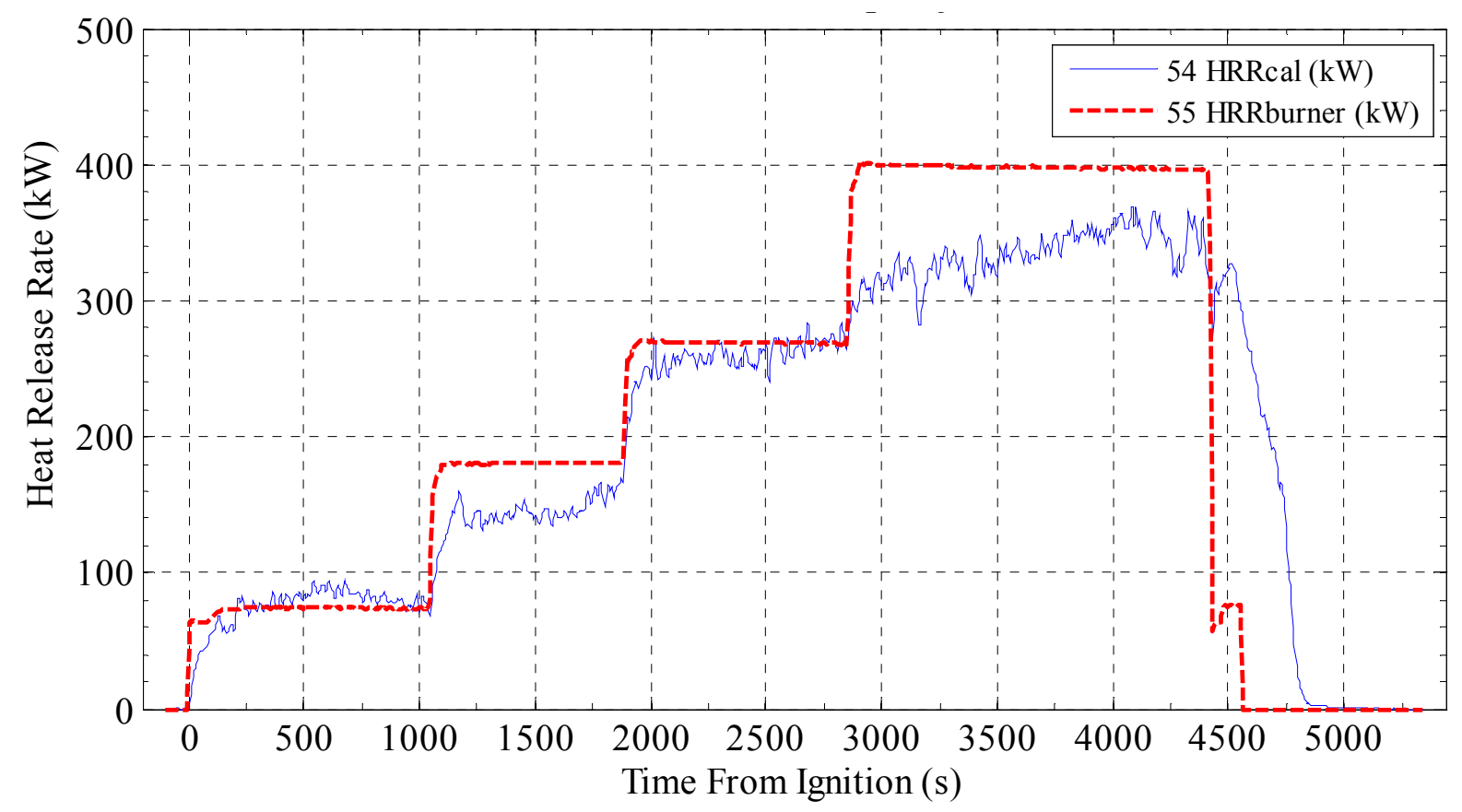

Figure 25. Heat release rate results for ethanol test \#11.
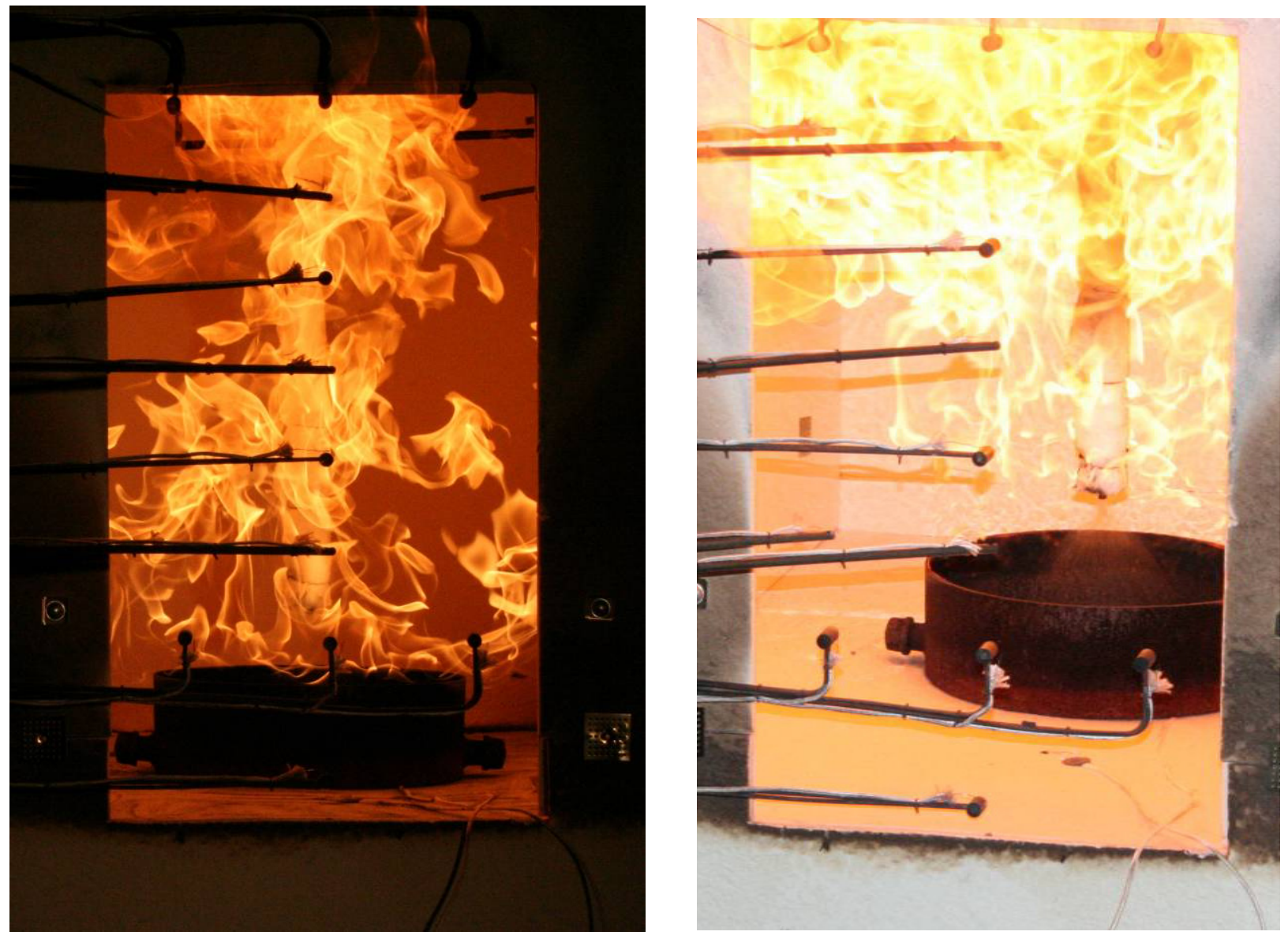

Figure 26. Photographs of ethanol test $\# 11: t=1709 \mathrm{~s}, \mathrm{HRR}=145 \mathrm{~kW}$ (left), $\mathrm{t}=3328 \mathrm{~s}, \mathrm{HRR}=328 \mathrm{~kW}$ (right). 


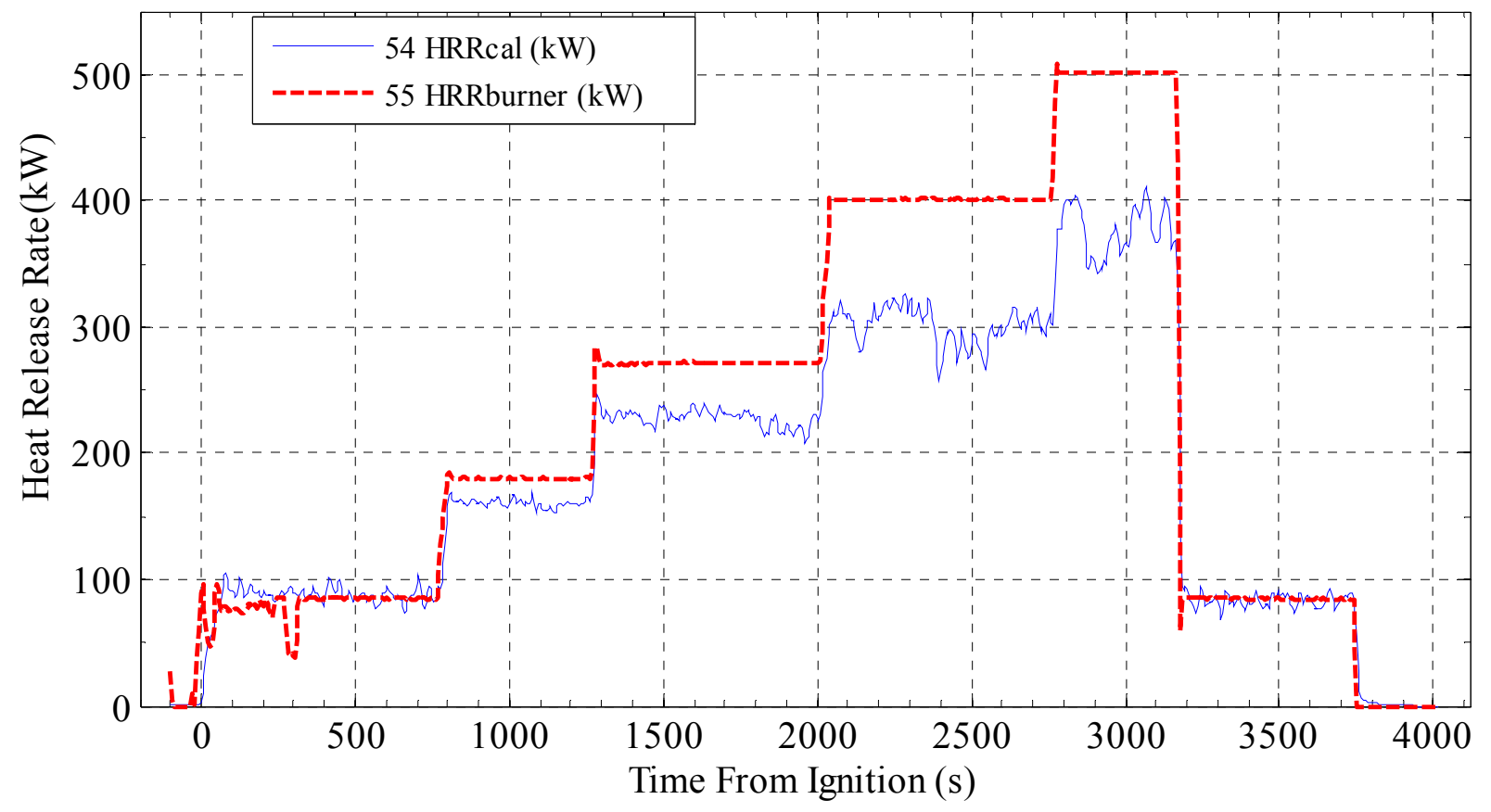

Figure 27. Heat release rate results for heptane test $\# 15$.
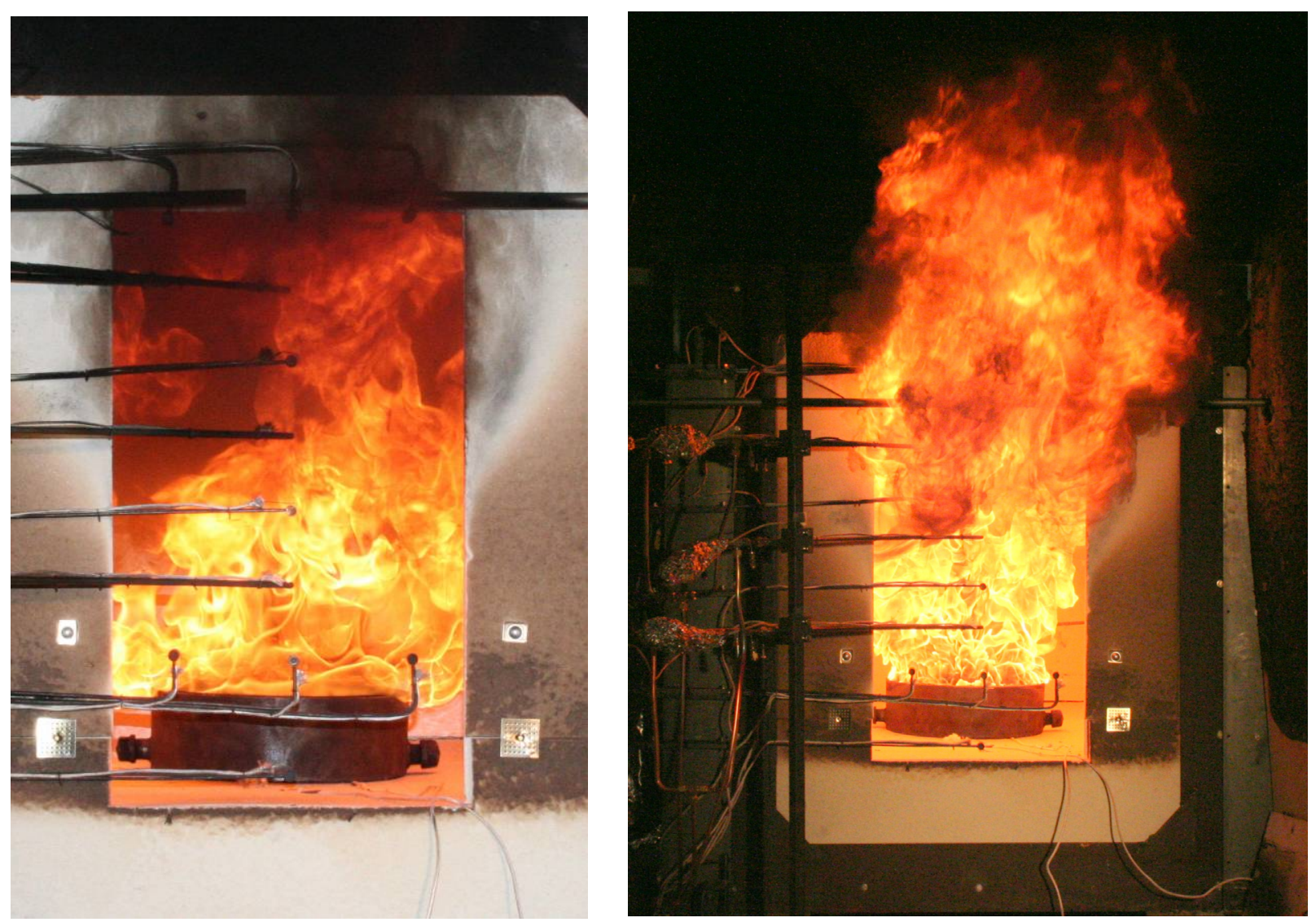

Figure 28. Photographs of heptane test $\# 15: t=1000 \mathrm{~s}, \mathrm{HRR}=160 \mathrm{~kW}$ (left), $\mathrm{t}=2870 \mathrm{~s}, \mathrm{HRR}=370 \mathrm{~kW}$ (right). 
A summary of HRR results is shown in Fig. 29. The measured heat release rate of the fire using oxygen calorimetry is plotted as a function of the ideal heat release rate predicted by the set fuel delivery rate. The dashed line on this plot represents a combustion efficiency of 1 (complete combustion). As expected, the combustion efficiency of the cleaner burning fuels (natural gas, methanol and ethanol) was closer to 1.0 than the highly sooting fuels (toluene and heptane). For most of the fuels, the global combustion efficiency decreased as the fire became more underventilated. Further discussion of the combustion efficiency can be found in Sec. 5.5 of this report. A summary of the time averaged steady-state results of HRR and exhaust stack species measurements is given in Table 10. The averaging period for each row of data in this table is given in the column labeled "SS Window". A description of the remaining columns are given in Table 8. Total hydrocarbons in the exhaust stack were not measured in the exhaust stack during the first set of tests.

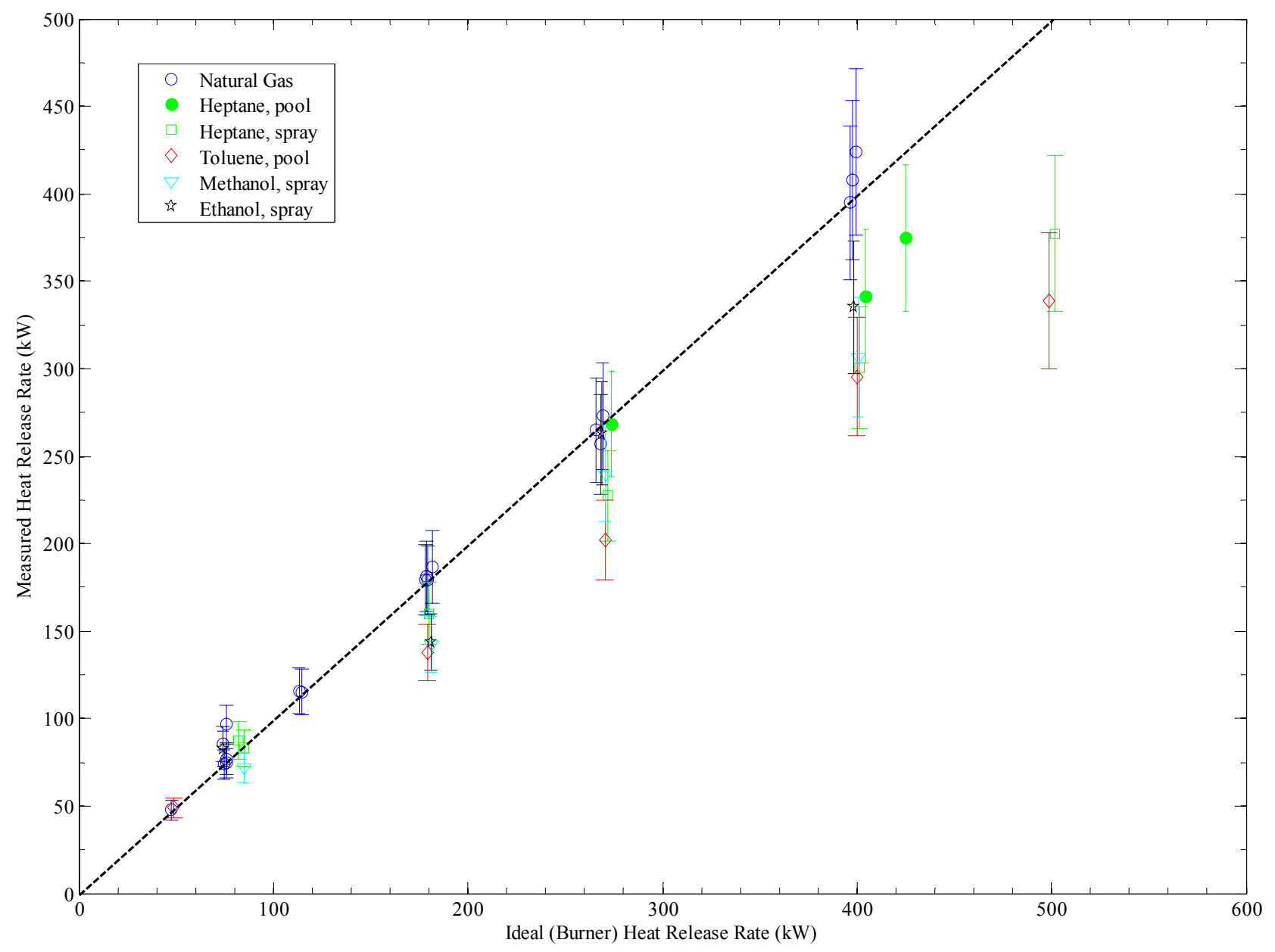

Figure 29. Steady state heat release rate results. Dashed line represents ideal or complete burning. 
Table 10. Summary of time averaged steady-state results of HRR and exhaust stack species measurements.

\begin{tabular}{|c|c|c|c|c|c|c|c|c|c|c|c|c|c|c|c|c|c|}
\hline \multirow[t]{2}{*}{ Test \# } & \multirow[t]{2}{*}{ Fuel } & \multicolumn{2}{|c|}{ SS Window } & \multicolumn{2}{|c|}{$\begin{array}{c}\text { HRRcal } \\
(\mathrm{kW})\end{array}$} & \multicolumn{2}{|c|}{$\begin{array}{c}\text { HRRburner } \\
\text { (kW) }\end{array}$} & \multicolumn{2}{|c|}{$\begin{array}{c}\mathrm{O}_{2} \text { stack } \\
(\mathrm{mol} / \mathrm{mol}) \%\end{array}$} & \multicolumn{2}{|c|}{$\begin{array}{c}\mathrm{CO}_{2} \text { stack } \\
(\mathrm{mol} / \mathrm{mol})^{*} 1 \mathrm{e} 6\end{array}$} & \multicolumn{2}{|c|}{$\begin{array}{c}\text { CO stack } \\
(\mathrm{mol} / \mathrm{mol})^{*} 1 \mathrm{e} 6\end{array}$} & \multicolumn{2}{|c|}{$\begin{array}{c}\text { THC stack } \\
(\mathrm{mol} / \mathrm{mol}) * 1 \mathrm{e} 6\end{array}$} & \multicolumn{2}{|c|}{$\begin{array}{c}\text { MS stack } \\
\left(\mathbf{m g} / \mathbf{m}^{3}\right)\end{array}$} \\
\hline & & start (s) & stop (s) & Mean & $\bar{U}$ & Mean & $U$ & Mean & $U$ & Mean & $U$ & Mean & $U$ & Mean & $U$ & Mean & $U$ \\
\hline \multirow{3}{*}{1} & & 500 & 1924 & 74.6 & 9.1 & 75.7 & 2.4 & 20.75 & 0.21 & 1897 & 98 & 32 & 15 & & & & \\
\hline & Natural Gas & 2220 & 3384 & 186.4 & 22.0 & 181.8 & 5.7 & 20.43 & 0.21 & 3780.0 & 194.4 & 59.2 & 26.5 & & & & \\
\hline & & 3600 & 3944 & 77.0 & 10.0 & 75.9 & 1.7 & 20.74 & 0.21 & 1921.1 & 78.5 & 32.2 & 11.0 & & & & \\
\hline & & 400 & 1594 & 256.9 & 30.3 & 268.1 & 4.6 & 20.14 & 0.20 & 5133.1 & 191.3 & 23.3 & 5.9 & & & & \\
\hline & & 1840 & 3229 & 394.8 & 46.2 & 396.6 & 6.1 & 19.65 & 0.20 & 7939.8 & 203.3 & 31.4 & 5.0 & & & & \\
\hline 2 & Natural Gas & 3500 & 4454 & 179.1 & 21.4 & 179.2 & 3.4 & 20.40 & 0.20 & 3666.0 & 108.9 & 26.2 & 5.5 & & & & \\
\hline & & 4550 & 5004 & 115.3 & 14.3 & 114.7 & 2.5 & 20.59 & 0.21 & 2588.1 & 93.3 & 18.1 & 2.7 & & & & \\
\hline & & 5200 & 5579 & 47.8 & 6.3 & 47.7 & 1.3 & 20.78 & 0.21 & 1487.3 & 70.0 & 23.4 & 5.6 & & & & \\
\hline & & 475 & 1139 & 264.8 & 31.9 & 266.1 & 4.1 & 20.12 & 0.20 & 5213.2 & 138.8 & 20.7 & 8.7 & & & & \\
\hline & & 1300 & 2224 & 407.7 & 49.5 & 397.6 & 6.1 & 19.61 & 0.20 & 8068.6 & 258.7 & 14.9 & 5.0 & & & & \\
\hline 3 & Natural Gas & 2555 & 3449 & 179.4 & 22.0 & 178.1 & 2.9 & 20.39 & 0.20 & 3692.6 & 94.7 & 20.9 & 5.1 & & & & \\
\hline & & 3645 & 4019 & 115.9 & 14.3 & 113.1 & 2.0 & 20.59 & 0.21 & 2576.8 & 110.3 & 9.2 & 2.9 & & & & \\
\hline & & 4390 & 5249 & 73.8 & 9.1 & 74.4 & 1.8 & 20.72 & 0.21 & 1846.6 & 67.3 & 4.0 & 3.2 & & & & \\
\hline & & 1375 & 2149 & 153.3 & \begin{tabular}{|l|}
19.0 \\
\end{tabular} & & & 20.49 & 0.21 & 3761.3 & 208.9 & 67.2 & 21.1 & & & 43.6 & 21.6 \\
\hline 4 & Heptane (pool) & 2850 & 3334 & \begin{tabular}{|l|l|}
268.7 \\
\end{tabular} & 33.0 & 273.9 & 5.3 & 20.14 & 0.21 & 6112.6 & 227.9 & 132.2 & 28.6 & & & 291.9 & 87.3 \\
\hline & & 4090 & 5489 & 374.9 & \begin{tabular}{|l|}
45.3 \\
\end{tabular} & 425.1 & 8.8 & 19.83 & 0.22 & 7456.2 & 480.7 & 230.3 & 77.6 & & & 864.6 & 216.0 \\
\hline 5 & Wh & 1245 & 1799 & 140.5 & \begin{tabular}{|l|}
17.3 \\
\end{tabular} & & & 20.55 & 0.21 & 3245.6 & 169.5 & 40.2 & 16.4 & & & 71.0 & 24.7 \\
\hline 3 & Heptane (pool) & 2340 & 2969 & 221.2 & 27.2 & & & 20.33 & 0.21 & 4304.1 & 168.0 & 152.0 & 43.1 & & & 409.8 & 105.6 \\
\hline & & 660 & 1539 & 73.6 & 9.2 & 75.2 & 1.5 & 20.77 & 0.21 & 1756.1 & 75.2 & 2.1 & 2.4 & & & & \\
\hline & & 2515 & 4179 & \begin{tabular}{|l|l}
173.7 \\
\end{tabular} & 20.2 & 179.3 & 5.1 & 20.48 & 0.21 & 3295.0 & 123.5 & 50.0 & 15.4 & & & & \\
\hline 6 & Natural Gas & 4425 & 4944 & 272.1 & 32.5 & 268.6 & 4.2 & 20.19 & 0.21 & 4922.9 & 164.7 & 21.9 & 3.4 & & & & \\
\hline & & 5090 & 5724 & 417.5 & 49.5 & 399.3 & 9.0 & 19.72 & 0.20 & 7550.3 & 228.9 & 18.8 & 2.7 & & & & \\
\hline & & 6090 & 6549 & 80.5 & 10.1 & 75.0 & 1.6 & 20.76 & 0.21 & 1708.8 & 59.4 & 1.7 & 2.2 & & & & \\
\hline & & 285 & 679 & 96.5 & 11.8 & 76.1 & 8.8 & 20.71 & 0.21 & 2178.2 & 76.6 & 176.6 & 26.9 & 7.2 & 5.1 & & \\
\hline & & 920 & 1204 & 423.9 & 51.9 & 399.4 & 6.1 & 19.64 & 0.20 & 8246.5 & 384.4 & 111.4 & 56.9 & 58.2 & 12.4 & & \\
\hline 6.5 & Natural Gas & 1600 & 2329 & 272.8 & 32.2 & 269.2 & 12.8 & 20.15 & 0.20 & 5170.4 & 118.6 & 45.2 & 13.8 & 20.6 & 9.2 & & \\
\hline & & 2540 & 2804 & 181.3 & 22.3 & 178.7 & 10.8 & 20.45 & 0.21 & 3510.4 & 88.9 & 31.5 & 8.1 & 8.5 & 5.6 & & \\
\hline & & 2980 & 3259 & 85.5 & 10.7 & \begin{tabular}{|l|}
74.1 \\
\end{tabular} & 10.6 & 20.75 & 0.21 & 1842.6 & 107.4 & 55.8 & 19.3 & 4.2 & 5.1 & & \\
\hline & & 1200 & 1669 & 147.7 & 18.6 & & & 20.50 & 0.21 & 3714.7 & 182.5 & 12.4 & 2.9 & 2.2 & 5.1 & 52.0 & 21.9 \\
\hline 7 & Heptane (pool) & 2105 & 2664 & 246.2 & 32.2 & & & 20.15 & 0.22 & 5888.7 & 421.3 & 71.5 & 23.4 & 11.8 & 7.2 & 274.0 & 90.6 \\
\hline & & 3040 & 3709 & 341.4 & 41.1 & 404.5 & 7.4 & 19.83 & 0.21 & 7465.3 & 292.3 & 247.6 & 47.6 & 24.2 & 10.4 & 820.8 & 167.3 \\
\hline 8 & Methanol (pool) & 1439 & 2009 & 17.2 & 2.2 & 22.5 & 71.4 & 20.94 & 0.21 & 825.9 & 58.8 & 0.0 & 2.0 & 1.0 & 5.0 & & \\
\hline 9 & Ethanol (pool) & 1300 & 2019 & 19.3 & 2.4 & 5.8 & 19.6 & 20.94 & 0.21 & 881.6 & 48.3 & 0.0 & 2.0 & 1.0 & 5.0 & & \\
\hline & & 1400 & 1884 & 48.9 & 6.8 & 48.8 & 2.3 & 20.84 & 0.21 & 1623.4 & 156.2 & 70.8 & 37.8 & 42.2 & 6.3 & 115.7 & 32.5 \\
\hline & & 2805 & 3154 & 137.6 & 18.1 & 179.3 & 3.3 & 20.51 & 0.21 & 4151.4 & 255.2 & 95.2 & 10.1 & 9.6 & 5.7 & 306.5 & 56.1 \\
\hline 10 & Toluene (pool) & 3600 & 4224 & 202.2 & 25.0 & 270.4 & 4.6 & 20.26 & 0.21 & 6059.0 & 352.3 & 41.4 & 9.7 & 5.4 & 5.4 & 458.4 & 105.1 \\
\hline & & 4435 & 5044 & 295.4 & 37.6 & 399.9 & 6.3 & 19.93 & 0.21 & 8512.8 & 533.6 & 47.1 & 22.9 & 2.0 & 5.0 & 486.2 & 180.3 \\
\hline & & 5120 & 5394 & 338.8 & 43.5 & 498.7 & 7.8 & 19.93 & 0.29 & 8267.7 & 1495.5 & 107.2 & 38.8 & 1.3 & 5.1 & 682.8 & 217.2 \\
\hline & & 550 & 1039 & 82.5 & 11.4 & 74.0 & 2.0 & 20.72 & 0.21 & 2412.6 & 302.7 & 117.4 & 99.9 & 3.8 & 5.3 & & \\
\hline 11 & Ethon 1 (onme) & 1400 & 1714 & 143.7 & 18.1 & 181.0 & 3.1 & 20.53 & 0.21 & 3805.4 & 141.8 & 12.3 & 11.6 & 2.0 & 5.0 & & \\
\hline 11 & Euranor (spray) & 2175 & 2849 & 263.1 & 32.1 & 268.8 & 4.5 & 20.11 & 0.21 & 6721.1 & 312.7 & 19.6 & 5.2 & 4.5 & 5.2 & & \\
\hline & & 2940 & 4200 & 335.3 & 41.2 & 398.3 & 6.6 & 19.84 & 0.22 & 8531.0 & 728.5 & 54.1 & 7.9 & 19.1 & 6.8 & & \\
\hline & & 300 & 724 & 71.8 & 9.3 & 85.0 & 2.1 & 20.77 & 0.21 & 1977.7 & 106.0 & 0.7 & 2.2 & 1.0 & 5.0 & & \\
\hline 12 & Methan (snrar) & 1145 & 1609 & 142.6 & 17.9 & 181.0 & 3.1 & 20.54 & 0.21 & 3585.3 & 209.5 & 1.5 & 2.3 & 1.0 & 5.0 & & \\
\hline 12 & Metnanor (spray) & 1949 & 2669 & 239.8 & 28.8 & 270.5 & 4.3 & 20.21 & 0.21 & 5890.9 & 376.1 & 35.7 & 7.4 & 1.0 & 5.0 & & \\
\hline & & 2760 & 3299 & 306.5 & 37.1 & 400.6 & 6.6 & 19.96 & 0.21 & 7612.1 & 470.1 & 87.4 & 15.8 & 2.0 & 5.0 & & \\
\hline 13 & Polystyrene & 710 & 1344 & 14.9 & 2.0 & 0.0 & 1.0 & 20.93 & 0.21 & 845.0 & 57.5 & 17.5 & 2.9 & 9.5 & 5.1 & 47.5 & 23.0 \\
\hline 14 & Polystyrene & 870 & 1724 & 67.3 & 8.8 & 0.0 & 1.0 & 20.76 & 0.21 & 2119.2 & 180.2 & 80.3 & 10.6 & 36.6 & 7.2 & 304.3 & 173.6 \\
\hline & & 280 & 759 & 87.7 & 12.2 & 82.0 & 22.8 & 20.69 & 0.21 & 2406.0 & 198.3 & 6.4 & 2.4 & 2.0 & 5.0 & 31.4 & 21.8 \\
\hline & & 950 & 1259 & 160.2 & \begin{tabular}{|l|l|}
19.7 \\
\end{tabular} & 179.8 & 5.9 & 20.43 & 0.21 & 4149.7 & 124.1 & 20.0 & 4.0 & 2.6 & 5.1 & 111.9 & 25.9 \\
\hline 15 & Hentane (snrar) & 1475 & 1999 & 227.3 & 28.1 & 271.8 & 4.4 & 20.20 & 0.20 & 5485.7 & 212.1 & 63.0 & 17.2 & 9.1 & 6.3 & 328.0 & 96.0 \\
\hline 15 & Heptane (spray) & 2200 & 2764 & 300.8 & 39.1 & 401.2 & 6.2 & 19.92 & 0.21 & 6789.6 & 256.9 & 243.8 & 31.6 & 41.1 & 15.8 & 912.8 & 166.1 \\
\hline & & 2790 & 3169 & 377.3 & 50.6 & 501.5 & 7.7 & 19.63 & 0.20 & 8412.1 & 317.1 & 384.1 & 35.9 & 89.4 & 22.5 & 1155.3 & 162.4 \\
\hline & & 3390 & 3734 & 83.3 & 11.9 & \begin{tabular}{|l|}
84.7 \\
\end{tabular} & 5.1 & 20.69 & 0.21 & 2379.4 & 159.0 & 9.7 & 3.3 & 2.0 & 5.0 & 45.1 & 24.9 \\
\hline 16 & Dolycturene & 545 & 649 & 358.1 & 45.7 & 0.0 & 1.0 & 19.73 & 0.20 & 9108.1 & 214.6 & 251.1 & 30.3 & 3.0 & 5.0 & 1258.4 & 228.3 \\
\hline 16 & Polystyrene & 715 & 769 & 308.7 & 40.0 & 0.0 & 1.0 & 19.86 & 0.20 & 8814.7 & 213.8 & 78.2 & 38.4 & 2.0 & 5.0 & 537.1 & 183.6 \\
\hline
\end{tabular}




\subsection{Temperatures}

The time history of the interior gas temperature is shown at 4 locations during the natural gas test (\#3) in Fig. 30. This figure shows the difference in temperature between the front and rear gas sample locations and the temporal variation of temperature in the compartment. Refer to Table 2 and Fig. 4 for exact locations of the temperature probes. The measurement labels for the figures and tables in this section are described in Table 11. The aspirated thermocouple pumps remained on for the duration of this test. The general trend for these tests was higher temperatures in the upper layer at the front sample location than at the rear, however the magnitude of this difference was a function of fuel type and fire size. For all of the natural gas fires, the front and rear gas temperatures in the lower layer of the enclosure $(24 \mathrm{~cm}$ from the floor) were not significantly different. The front to rear variation in lower layer temperature was more pronounced for the other fuels.

Table 11. Description of interior gas temperature measurement labels.

\begin{tabular}{|l|l|}
\hline \multicolumn{1}{|c|}{$\begin{array}{c}\text { Measurement } \\
\text { Label }\end{array}$} & \multicolumn{1}{c|}{ Description } \\
\hline \hline 15 TRSampA (C) & Aspirated thermocouple at rear sample location $(88 \mathrm{~cm}$ above floor $)$ \\
\hline 16 TFSampA (C) & Aspirated thermocouple at front sample location $(88 \mathrm{~cm}$ above floor $)$ \\
\hline 17 TR24A (C) & Aspirated thermocouple at lower rear location $(24 \mathrm{~cm}$ above floor $)$ \\
\hline 18 TR80A (C) & Aspirated thermocouple at upper rear location $(80 \mathrm{~cm}$ above floor $)$ \\
\hline 19 TF24A (C) & Aspirated thermocouple at lower front location $(24 \mathrm{~cm}$ above floor $)$ \\
\hline 20 TF80A (C) & Aspirated thermocouple at upper front location $(80 \mathrm{~cm}$ above floor $)$ \\
\hline
\end{tabular}

For a number of the tests, the aspiration flow pumps were run intermittently. This was done to observe the effect of the aspiration flow on the temperature and other measurements at nearby locations, as well as to conserve the water traps and filters. It was determined that turning on or off the suction flow to the aspirated thermocouples had no measurable effect on the observed gas species volume fractions. This is an important result since the separation distance between the probes was less than $3 \mathrm{~cm}$. Further analysis of probe interactions can be found in Appendix B. The thermocouple response to cycling the aspiration flow is show in Fig. 31. This figure shows the front aspirated thermocouple measurements at two different heights in the enclosure for test \#15 using heptane and the spray burner. The HRR was approximately $220 \mathrm{~kW}$ during this time window. The upper series in Fig. 31 is the aspirated thermocouple at the front sample location (TFSampA in Table 2), $10 \mathrm{~cm}$ below the ceiling. Because this probe was in a region with high soot mass fraction, the aspiration had little effect on the average temperature results. The faster time response (due to high convective heat transfer while aspirating) increases the measurement variation. The high soot mass fraction caused little difference to the probe's average temperature with and without aspiration because the probe's optical view of any cooler temperature radiative heat sinks was minimal due to soot blockage.

The aspirated temperature probe located inside the front of the enclosure at a height of $24 \mathrm{~cm}$ above the floor (TF24A) is also shown. The measured temperature at this location decreased by more than $500{ }^{\circ} \mathrm{C}$ when the aspiration was applied. This result shows the important application of aspirated thermocouples to the thermal characterization of flashed-over compartment fires. Although differences between bare-beads and aspirated thermocouples are usually much greater 
in the lower layer, the upper layer differences may be as much as $100{ }^{\circ} \mathrm{C}$ to $200{ }^{\circ} \mathrm{C}$ depending, primarily, on a fuel's sooting characteristics.

A detailed analysis of the aspirated thermocouple time response and uncertainty can be found in Appendix A of this report. All of the temperature results reported here represent the temperature of the thermocouple bead, not the true temperature of the gas.

Average temperatures were calculated over pseudo-steady periods for all of the tests.

Temperature measurements collected when the aspiration pumps were off or during a transient period were not included in the averages. A summary of the rear gas temperature measurements with combined expanded uncertainty (U) are listed in Table 12. The front gas temperatures are given in Table 13. The average temperatures are plotted as a function of HRR for the natural gas full-door tests in Fig. 32. These temperature measurements demonstrate the reproducibility of the measurements over a number of different days. Figure 33 and Fig. 34 show the steady temperatures at the front and rear gas sample location for all of the fuels included in this study. In general, the soot producing fires (heptane, toluene, polystyrene) produced hotter gas temperatures inside the enclosure than the cleaner fires (natural gas, alcohols) at the same measured HRR.

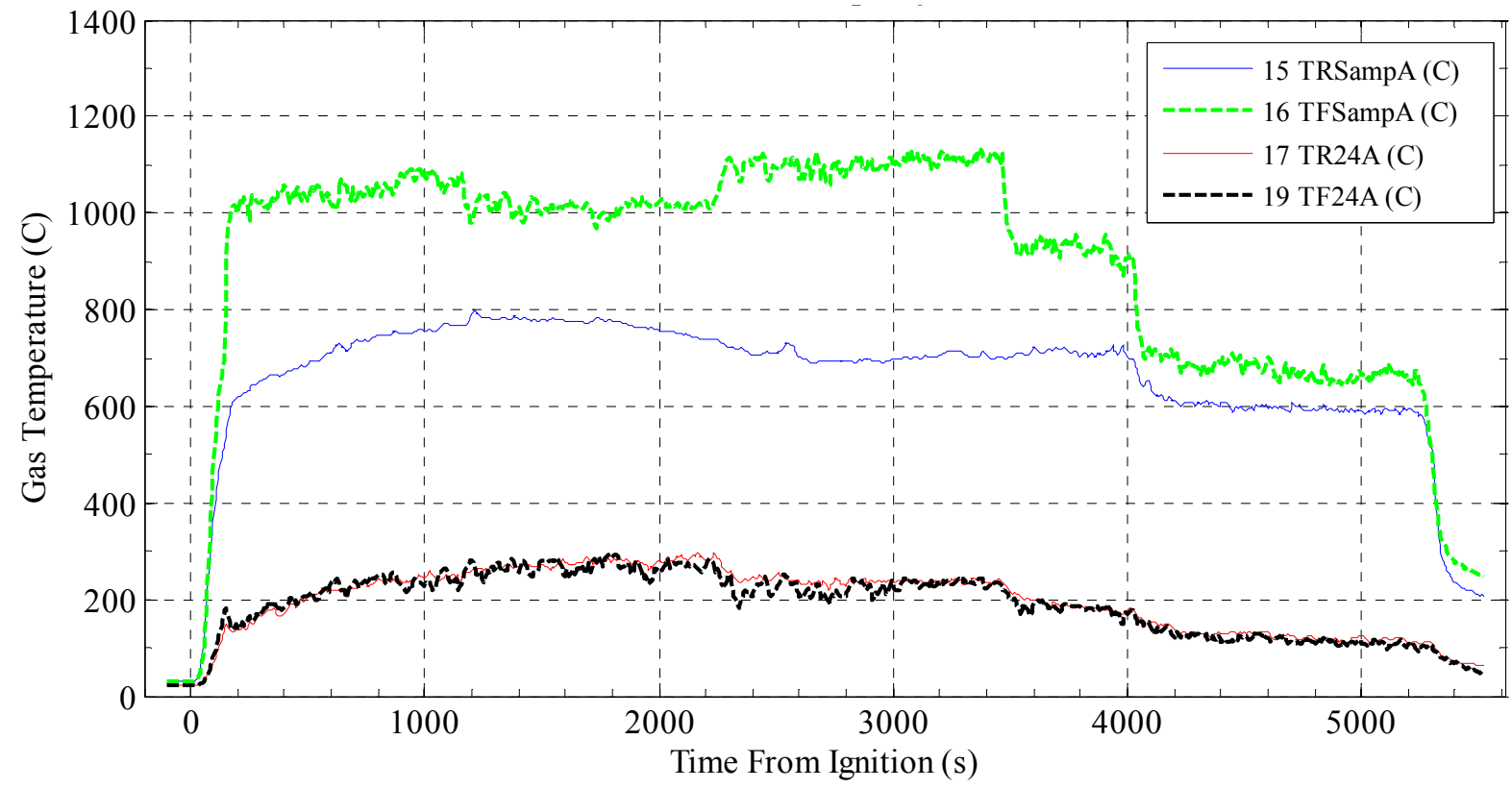

Figure 30. Gas temperature measurement results for 4 positions inside RSE. Natural gas test \#3. 


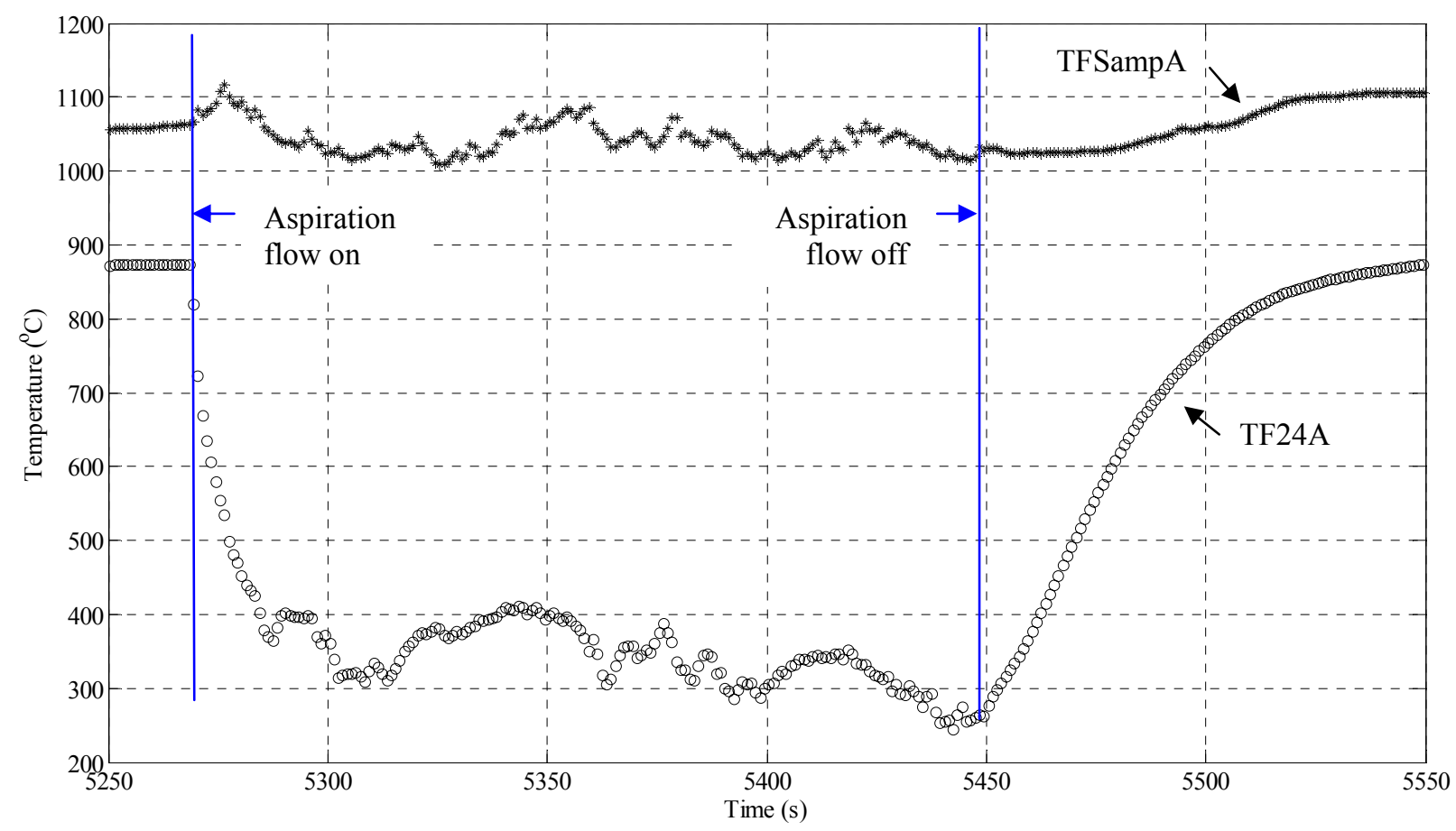

Figure 31. Gas temperature measurements at two front interior locations inside RSE during the heptane spray fire (test \# 15).

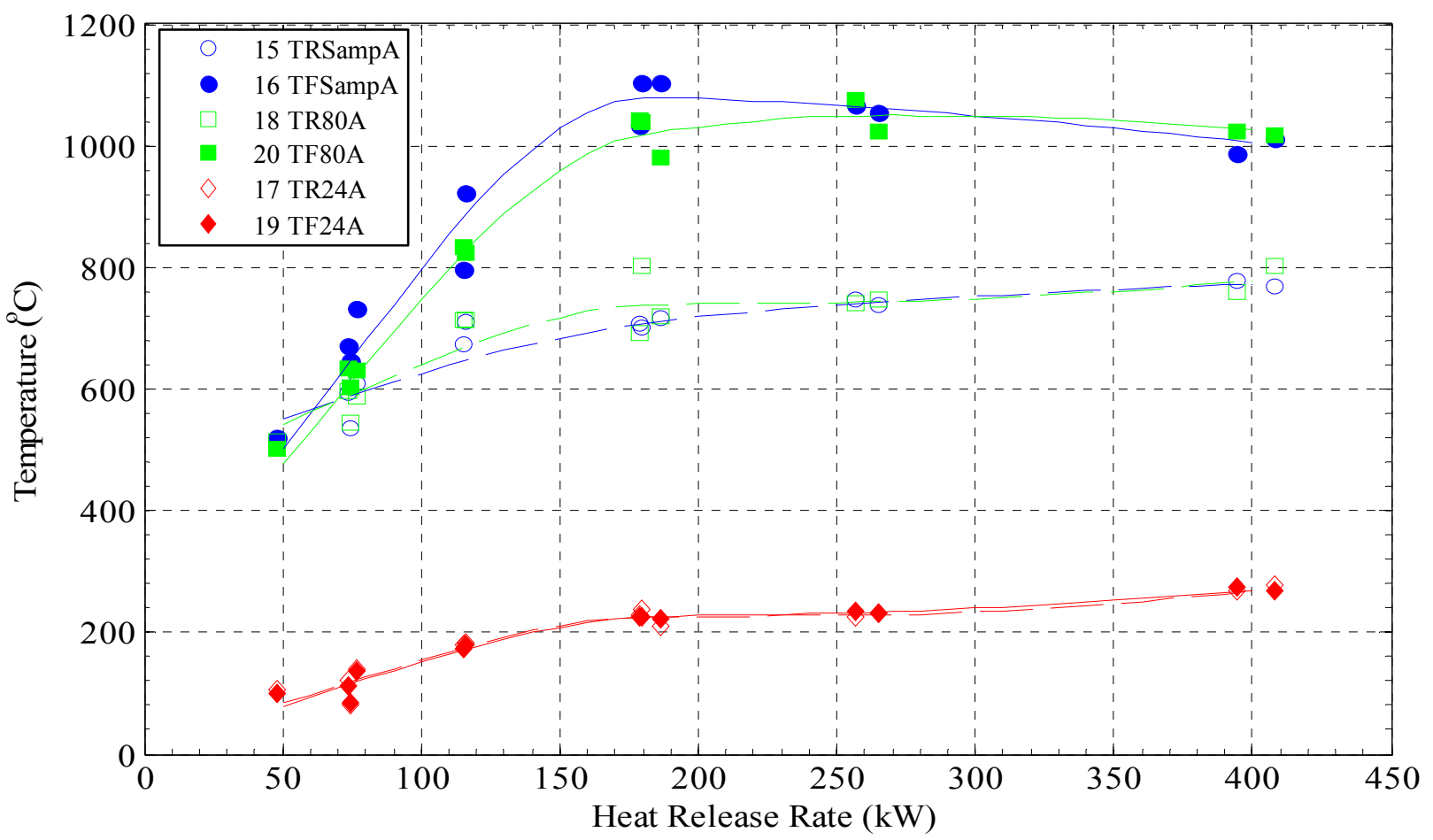

Figure 32. Steady state average temperature measurements at interior locations for repeated natural gas fires (tests \#1,\#2,\#3). The lines in this figure are piecewise cubic polynomial fits to the data. 


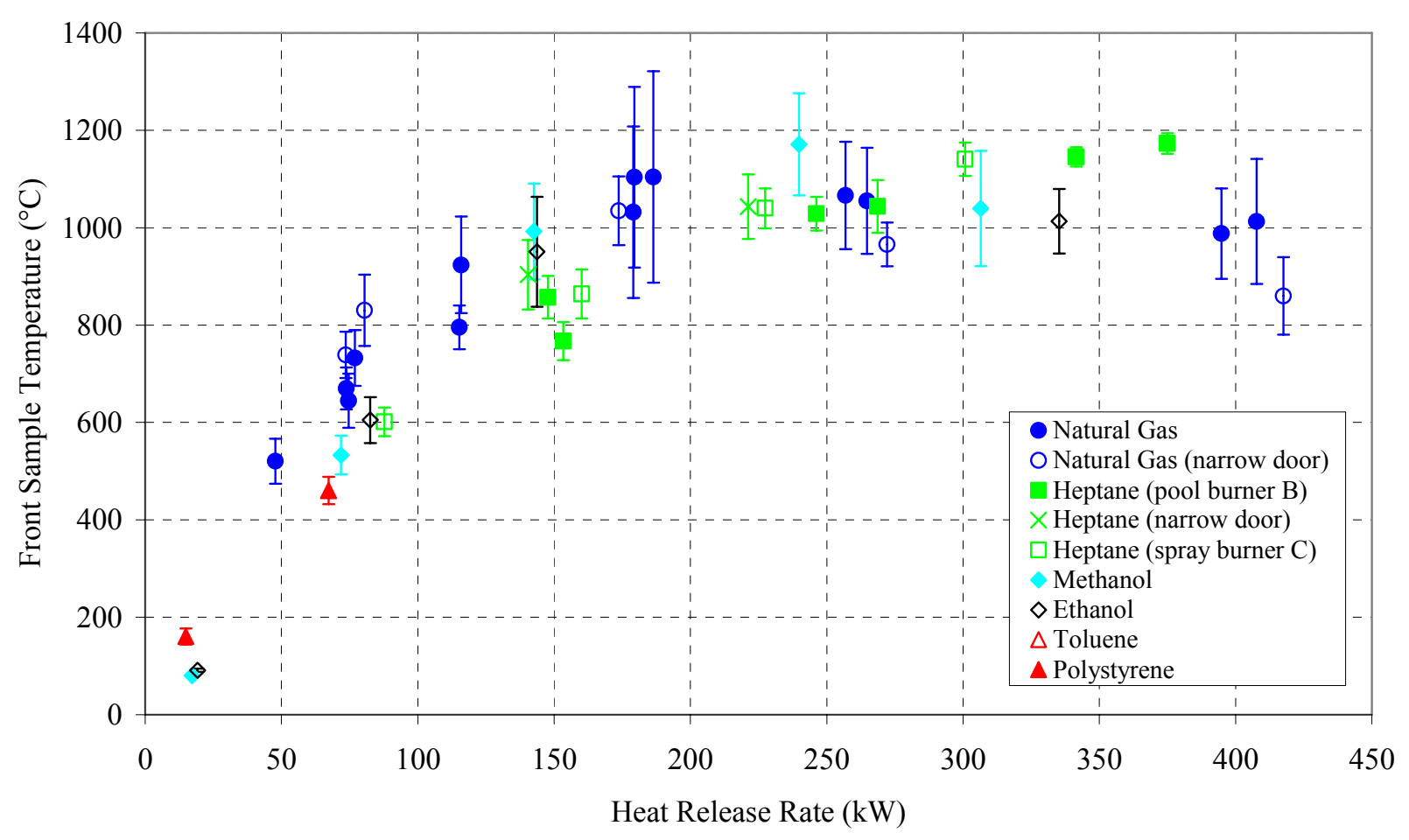

Figure 33. Steady state average temperature results from aspirated thermocouple measurement at front gas sampling location. note: Front sample thermocouple failed during toluene fire (test \#10) and polystyrene fire (test \#16)

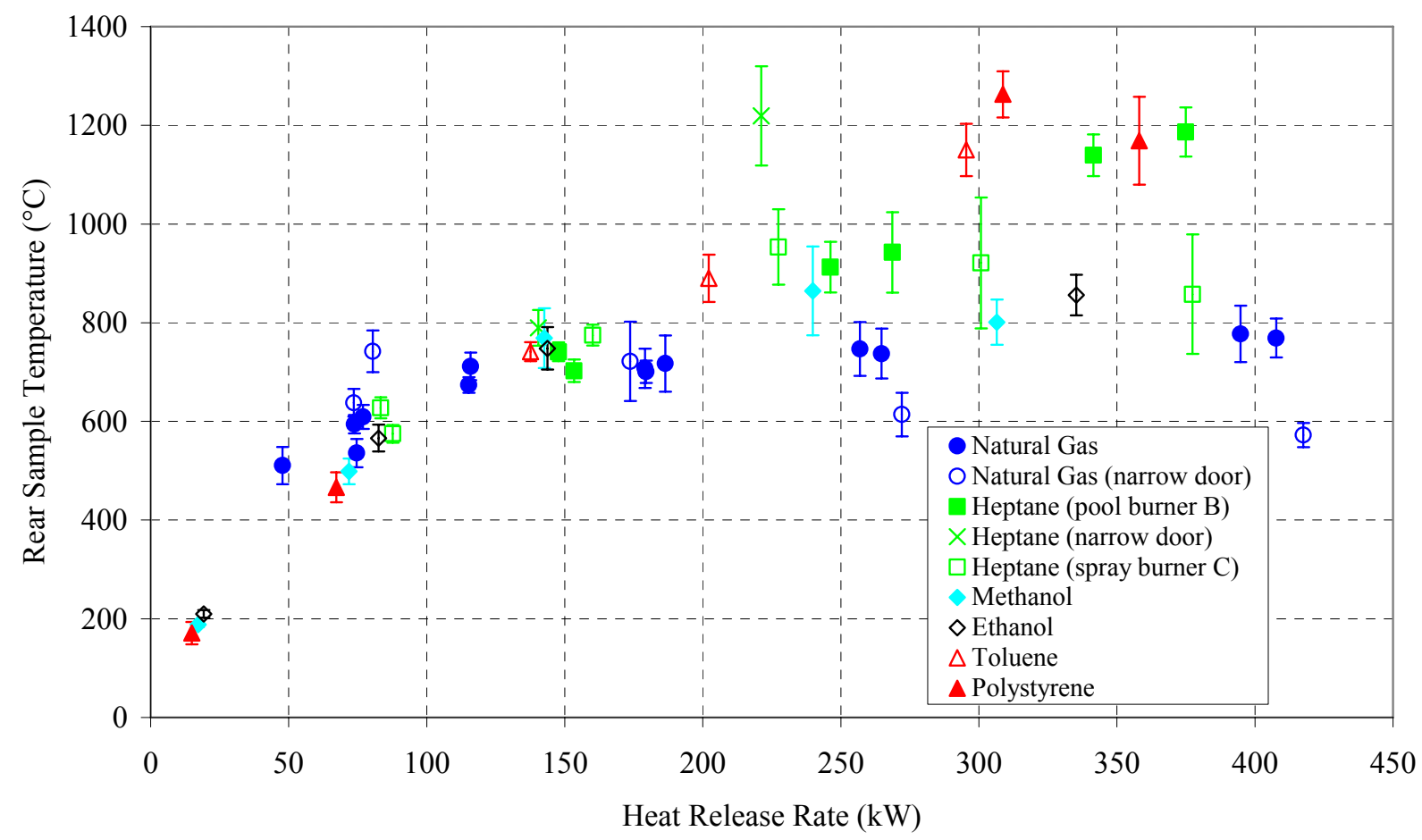

Figure 34 Steady state average temperature results from aspirated thermocouple measurement at rear gas sampling location. 
Table 12. Steady state rear gas temperatures and total heat flux to the floor inside the RSE.

\begin{tabular}{|c|c|c|c|c|c|c|c|c|c|c|c|c|c|}
\hline \multirow[t]{2}{*}{ Test \# } & \multirow[t]{2}{*}{ Fuel } & \multicolumn{2}{|c|}{ SS Window } & \multicolumn{2}{|c|}{$\begin{array}{l}\text { HRR } \\
(\mathrm{kW})\end{array}$} & \multicolumn{2}{|c|}{$\begin{array}{c}\text { HFR } \\
\left(\mathrm{kW} / \mathrm{m}^{2}\right)\end{array}$} & \multicolumn{2}{|c|}{$\begin{array}{c}\text { TRSampA } \\
\text { (C) }\end{array}$} & \multicolumn{2}{|c|}{$\begin{array}{l}\text { TR80A } \\
\text { (C) }\end{array}$} & \multicolumn{2}{|c|}{$\begin{array}{l}\text { TR24A } \\
\text { (C) }\end{array}$} \\
\hline & & start (s) & stop (s) & Mean & $U$ & Mean & $U$ & Mean & $U$ & Mean & $\bar{U}$ & Mean & $U$ \\
\hline \multirow{3}{*}{1} & \multirow{3}{*}{ Natural Gas } & 500 & 1924 & 75 & 11 & 17.1 & 4.1 & 536 & 27 & 546 & 32 & 80 & 28 \\
\hline & & 2220 & 3384 & 186 & 23 & 57.9 & 10.8 & 717 & 53 & 719 & 46 & 211 & 25 \\
\hline & & 3600 & 3944 & 77 & 11 & 30.2 & 3.6 & 609 & 20 & 589 & 29 & 140 & 16 \\
\hline \multirow{5}{*}{2} & \multirow{5}{*}{ Natural Gas } & 400 & 1594 & 257 & 32 & 57.6 & 18.0 & 747 & 58 & 740 & 69 & 225 & 44 \\
\hline & & 1840 & 3229 & 395 & 49 & 75.6 & 6.3 & 777 & 56 & 759 & 37 & 268 & 11 \\
\hline & & 3500 & 4454 & 179 & 23 & 62.2 & 4.6 & 708 & 46 & 691 & 40 & 228 & 11 \\
\hline & & 4550 & 5004 & 115 & 15 & 43.3 & 4.1 & 674 & 11 & 715 & 25 & 178 & 12 \\
\hline & & 5200 & 5579 & 48 & 7 & 18.1 & 2.9 & 511 & 37 & 513 & 19 & 105 & 22 \\
\hline \multirow{5}{*}{3} & & 475 & 1139 & 265 & 33 & 37.8 & 9.0 & 737 & 53 & 747 & 50 & 232 & 30 \\
\hline & & 1300 & 2224 & 408 & 55 & 55.3 & 7.8 & 769 & 34 & 803 & 33 & 277 & 17 \\
\hline & Natural Gas & 2555 & 3449 & 179 & 25 & 50.0 & 3.4 & 701 & 19 & 803 & 48 & 237 & 10 \\
\hline & & 3645 & 4019 & 116 & 14 & 35.3 & 2.8 & 712 & 23 & 715 & 26 & 182 & 14 \\
\hline & & 4390 & 5249 & 74 & 10 & 20.2 & 2.1 & 594 & 16 & 598 & 18 & 121 & 15 \\
\hline & & 1375 & 2149 & 153 & 21 & 52.9 & 7.0 & 703 & 22 & 707 & 26 & 234 & 22 \\
\hline 4 & Heptane (pool) & 2850 & 3334 & 269 & 34 & 96.9 & 44.1 & 942 & 82 & 939 & 61 & 430 & 66 \\
\hline & & 4090 & 5489 & 375 & 54 & 235.0 & 35.4 & 1186 & 50 & 1171 & 43 & 845 & 274 \\
\hline 5 & Hontan (nol) & 1245 & 1799 & 140 & 18 & 67.6 & 9.9 & 789 & 36 & 783 & 33 & 441 & 64 \\
\hline 3 & Heptane (pool) & 2340 & 2969 & 221 & 29 & 220.7 & 34.2 & 1219 & 101 & 1248 & 90 & 1254 & 170 \\
\hline & & 660 & 1539 & 74 & 11 & 24.3 & 4.3 & 638 & 28 & 644 & 30 & 186 & 28 \\
\hline & & 2515 & 4179 & 174 & 22 & 70.6 & 5.9 & 722 & 80 & 781 & 44 & 390 & 23 \\
\hline 6 & Natural Gas & 4425 & 4944 & 272 & 33 & 76.5 & 5.2 & 614 & 44 & 698 & 36 & 418 & 15 \\
\hline & & 5090 & 5724 & 417 & 50 & 73.9 & 4.8 & 572 & 25 & 654 & 28 & 420 & 14 \\
\hline & & 6090 & 6549 & 80 & 11 & 42.8 & 5.0 & 742 & 42 & 738 & 35 & 285 & 22 \\
\hline & & 285 & 679 & 97 & 12 & 23.8 & 3.0 & & & & & & \\
\hline & & 920 & 1204 & 424 & 51 & 83.1 & 12.0 & & & & & & \\
\hline 6.5 & Natural Gas & 1600 & 2329 & 273 & 33 & 87.9 & 7.4 & & & & & & \\
\hline & & 2540 & 2804 & 181 & 22 & 77.4 & 6.9 & & & & & & \\
\hline & & 2980 & 3259 & 85 & 11 & 29.5 & 4.3 & & & & & & \\
\hline & & 1200 & 1669 & 148 & 20 & 54.1 & 6.5 & 741 & 21 & 718 & 16 & 210 & 14 \\
\hline 7 & Heptane (pool) & 2105 & 2664 & 246 & 38 & 133.0 & 41.5 & 913 & 59 & 921 & 54 & 379 & 34 \\
\hline & & 3040 & 3709 & 341 & 43 & 204.8 & 37.0 & 1139 & 45 & 1125 & 32 & 642 & 94 \\
\hline 8 & Methanol (pool) & 1439 & 2009 & 17 & 3 & 2.4 & 0.5 & 188 & 6 & 185 & 8 & 67 & 5 \\
\hline 9 & Ethanol (pool) & 1300 & 2019 & 19 & 3 & 2.7 & 0.4 & 210 & 9 & 203 & 9 & 75 & 5 \\
\hline & & 1400 & 1884 & 49 & 9 & $\overline{14.6}$ & 2.4 & & & & & & \\
\hline & & 2805 & 3154 & 138 & 20 & 65.7 & 7.0 & 741 & 21 & 763 & 21 & 240 & 20 \\
\hline 10 & Toluene (pool) & 3600 & 4224 & 202 & 27 & 116.1 & 15.7 & 890 & 53 & 919 & 45 & 354 & 36 \\
\hline & & 4435 & 5044 & 295 & 43 & 257.4 & 37.3 & 1150 & 58 & 1254 & 56 & 970 & 89 \\
\hline & & 5120 & 5394 & 339 & 44 & 336.2 & 42.9 & & & & & & \\
\hline & & 550 & 1039 & 83 & 15 & 19.9 & 2.5 & 566 & 26 & 546 & 20 & 126 & 6 \\
\hline & & 1400 & 1714 & 144 & 18 & 44.6 & 5.0 & 748 & 44 & 729 & 36 & 221 & 15 \\
\hline 11 & Ethanol (spray) & 2175 & 2849 & 263 & 34 & 80.5 & 8.1 & & & 848 & 44 & 307 & 13 \\
\hline & & 2940 & 4200 & 335 & 51 & 80.9 & 5.9 & 856 & 45 & & & 305 & 10 \\
\hline & & 300 & 724 & 72 & 10 & 13.4 & 2.4 & 499 & 26 & 490 & 27 & 94 & 11 \\
\hline 12 & Methonol (snroy) & 1145 & 1609 & 143 & 19 & 39.5 & 5.7 & 769 & 64 & 736 & 51 & 192 & 20 \\
\hline 12 & Methanol (spray) & 1949 & 2669 & 240 & 30 & 62.4 & 4.3 & 864 & 95 & 842 & 105 & 259 & 13 \\
\hline & & 2760 & 3299 & 306 & 38 & 61.1 & 4.2 & 801 & 50 & 803 & 45 & 260 & 13 \\
\hline 13 & Polystyrene & 710 & 1344 & 15 & 3 & 3.5 & 0.9 & 171 & 23 & 183 & 26 & 112 & 19 \\
\hline 14 & Polystyrene & 870 & 1724 & 67 & 12 & 23.6 & 5.1 & 467 & 30 & 467 & 26 & 130 & 13 \\
\hline & & 280 & 759 & 88 & 16 & 30.8 & 6.5 & 575 & 18 & 571 & 15 & 155 & 7 \\
\hline & & 950 & 1259 & 160 & 19 & 76.9 & 8.0 & 775 & 27 & 784 & 21 & 325 & 14 \\
\hline & & 1475 & 1999 & 227 & 30 & 134.3 & 19.2 & 954 & 83 & 999 & 106 & 497 & 85 \\
\hline 15 & Heptane (spray) & 2200 & 2764 & 301 & \begin{tabular}{|l}
46 \\
\end{tabular} & 143.0 & 20.5 & 921 & 140 & 1005 & 137 & 468 & 42 \\
\hline & & 2790 & 3169 & 377 & 58 & 135.7 & 11.8 & 858 & 129 & 901 & 127 & 452 & 27 \\
\hline & & 3390 & 3734 & 83 & 15 & 46.7 & 11.0 & 627 & 22 & 628 & 17 & 219 & 22 \\
\hline 16 & & 545 & 649 & 358 & 42 & 104.2 & 20.5 & 1169 & 84 & 1240 & 130 & 1256 & 137 \\
\hline 16 & Polystyrene & 715 & 769 & 309 & 35 & 169.9 & 17.5 & 1263 & 36 & 1160 & 45 & & \\
\hline
\end{tabular}


Table 13. Steady state front gas temperatures and total heat flux to the floor inside the RSE.

\begin{tabular}{|c|c|c|c|c|c|c|c|c|c|c|c|c|c|}
\hline \multirow[t]{2}{*}{ Test \# } & \multirow[t]{2}{*}{ Fuel } & \multicolumn{2}{|c|}{ SS Window } & \multicolumn{2}{|c|}{$\begin{array}{l}\text { HRR } \\
(\mathrm{kW})\end{array}$} & \multicolumn{2}{|c|}{$\begin{array}{c}\text { HFF } \\
(\mathrm{kW} / \mathrm{m} 2)\end{array}$} & \multicolumn{2}{|c|}{\begin{tabular}{|c} 
TFSampA \\
(C)
\end{tabular}} & \multicolumn{2}{|c|}{$\begin{array}{c}\text { TF80A } \\
\text { (C) }\end{array}$} & \multicolumn{2}{|c|}{$\begin{array}{c}\text { TF24A } \\
\text { (C) }\end{array}$} \\
\hline & & start (s) & stop (s) & Mean & $U$ & Mean & $U$ & Mean & $U$ & Mean & $U$ & Mean & $U$ \\
\hline \multirow{3}{*}{1} & \multirow{3}{*}{ Natural Gas } & 500 & 1924 & 75 & 11 & 19.7 & 4.6 & 645 & 53 & 604 & 48 & 85 & 35 \\
\hline & & 2220 & 3384 & 186 & 23 & 69.4 & 10.1 & 1104 & 206 & 979 & 136 & 223 & 21 \\
\hline & & 3600 & 3944 & 77 & 11 & 28.0 & 6.2 & 733 & 53 & 631 & 34 & 137 & 20 \\
\hline \multirow{5}{*}{2} & \multirow{5}{*}{ Natural Gas } & 400 & 1594 & 257 & 32 & 80.6 & 16.2 & 1066 & 101 & 1075 & 108 & 235 & 38 \\
\hline & & 1840 & 3229 & 395 & 49 & 94.8 & 7.6 & 988 & 84 & 1025 & 110 & 274 & 23 \\
\hline & & 3500 & 4454 & 179 & 23 & 79.6 & 5.7 & 1032 & 173 & 1043 & 85 & 226 & 23 \\
\hline & & 4550 & 5004 & 115 & 15 & 52.7 & 5.2 & 796 & 39 & 832 & 61 & 173 & 17 \\
\hline & & 5200 & 5579 & 48 & 7 & 20.5 & 3.2 & 520 & 46 & 503 & 23 & 101 & 21 \\
\hline \multirow{5}{*}{3} & & 475 & 1139 & 265 & 33 & 80.6 & 12.8 & 1055 & 99 & 1024 & 80 & 232 & 32 \\
\hline & & 1300 & 2224 & 408 & 55 & 95.8 & 7.8 & 1013 & 119 & 1016 & 140 & 269 & 27 \\
\hline & Natural Gas & 2555 & 3449 & 179 & 25 & 80.4 & 5.7 & 1104 & 175 & 1038 & 142 & 226 & 28 \\
\hline & & 3645 & 4019 & 116 & 14 & 52.8 & 4.2 & 924 & 91 & 823 & 62 & 179 & 19 \\
\hline & & 4390 & 5249 & 74 & 10 & 28.3 & 3.0 & 670 & 40 & 633 & 27 & 113 & 16 \\
\hline & & 1375 & 2149 & 153 & 21 & 51.3 & 5.1 & 767 & 39 & 847 & 44 & 284 & 12 \\
\hline 4 & Heptane (pool) & 2850 & 3334 & 269 & 34 & 98.4 & 11.8 & 1044 & 54 & 1090 & 77 & 468 & 58 \\
\hline & & 4090 & 5489 & 375 & 54 & 168.1 & 21.9 & 1173 & 21 & 1210 & 33 & 677 & 97 \\
\hline & & 1245 & 1799 & 140 & 18 & 80.8 & 12.0 & 903 & 71 & 991 & 70 & 569 & 63 \\
\hline 5 & Heptane (pool) & 2340 & 2969 & 221 & 29 & 119.2 & 16.5 & 1043 & 66 & 1149 & 50 & 1037 & 144 \\
\hline & & 660 & 1539 & 74 & 11 & 9.8 & \begin{tabular}{|l|}
1.6 \\
\end{tabular} & 739 & 48 & 714 & 44 & 210 & 30 \\
\hline & & 2515 & 4179 & 174 & 22 & 43.2 & 7.6 & 1035 & 71 & 1032 & 84 & 423 & 14 \\
\hline 6 & Natural Gas & 4425 & 4944 & 272 & 33 & 51.5 & 3.6 & 966 & 45 & 978 & 45 & 456 & 14 \\
\hline & & 5090 & 5724 & 417 & 50 & 50.2 & 3.3 & 860 & 79 & 829 & 63 & 450 & 10 \\
\hline & & 6090 & 6549 & 80 & 11 & 28.9 & 4.1 & 830 & 73 & 804 & 43 & 302 & 24 \\
\hline & & 285 & 679 & 97 & 12 & 24.7 & 2.7 & & & & & & \\
\hline & & 920 & 1204 & 424 & 51 & 88.8 & 8.9 & & & & & & \\
\hline 6.5 & Natural Gas & 1600 & 2329 & 273 & 33 & 90.9 & 6.6 & & & & & & \\
\hline & & 2540 & 2804 & 181 & 22 & 77.2 & 5.5 & & & & & & \\
\hline & & 2980 & 3259 & 85 & \begin{tabular}{|l|}
11 \\
\end{tabular} & 29.1 & 3.8 & & & & & & \\
\hline & & 1200 & 1669 & 148 & 20 & 57.8 & 6.4 & 857 & 39 & 831 & 28 & 276 & 19 \\
\hline 7 & Heptane (pool) & 2105 & 2664 & 246 & 38 & 118.5 & 12.2 & 1029 & 35 & 1091 & 41 & 423 & 40 \\
\hline & & 3040 & 3709 & 341 & 43 & 166.7 & 13.4 & 1145 & 22 & 1230 & 56 & 594 & 63 \\
\hline 8 & Methanol (pool) & 1439 & 2009 & 17 & 3 & 2.2 & 0.4 & \begin{tabular}{|l|}
80 \\
\end{tabular} & 5 & 181 & 8 & 62 & 5 \\
\hline 9 & Ethanol (pool) & 1300 & 2019 & 19 & 3 & 2.6 & 0.4 & 91 & 6 & 198 & 8 & 76 & 6 \\
\hline & & 1400 & 1884 & 49 & 9 & 13.6 & 2.4 & & & & & & \\
\hline & & 2805 & 3154 & 138 & 20 & 59.2 & 6.6 & & & 859 & 27 & 297 & 24 \\
\hline 10 & Toluene (pool) & 3600 & 4224 & 202 & 27 & 101.9 & 10.3 & & & 1067 & 54 & 421 & 50 \\
\hline & & 4435 & 5044 & 295 & 43 & 174.8 & 17.1 & & & 1241 & 38 & 643 & 75 \\
\hline & & 5120 & 5394 & 339 & 44 & 210.0 & 22.2 & & & & & & \\
\hline & & 550 & 1039 & 83 & 15 & 17.6 & 3.3 & 605 & 46 & 541 & 27 & 134 & 11 \\
\hline 11 & & 1400 & 1714 & 144 & 18 & 45.3 & 5.9 & 951 & 108 & 851 & 70 & 224 & 39 \\
\hline 11 & Ethanol (spray) & 2175 & 2849 & 263 & 34 & 86.8 & 8.9 & & & 1085 & 77 & 308 & 23 \\
\hline & & 2940 & 4200 & 335 & 51 & 82.3 & 6.4 & 1013 & 59 & & & 288 & 25 \\
\hline & & 300 & 724 & 72 & 10 & 11.7 & 2.6 & 533 & 40 & 493 & 41 & 100 & 14 \\
\hline & & 1145 & 1609 & 143 & 19 & 40.0 & 5.9 & 993 & 95 & 850 & 109 & 200 & 22 \\
\hline 12 & Methanol (spray) & 1949 & 2669 & 240 & 30 & 64.9 & 4.9 & 1171 & 94 & 1134 & 109 & 252 & 32 \\
\hline & & 2760 & 3299 & 306 & 38 & 61.5 & 4.1 & 1040 & 113 & 1144 & 122 & 244 & 33 \\
\hline 13 & Polystyrene & 710 & 1344 & 15 & 3 & 2.3 & 0.6 & 161 & 17 & 167 & 21 & 88 & 17 \\
\hline 14 & Polystyrene & 870 & 1724 & 67 & 12 & 17.2 & 4.5 & 460 & 28 & 454 & 26 & 139 & 19 \\
\hline & & 280 & 759 & 88 & 16 & 26.1 & 7.1 & 601 & 29 & 569 & 26 & 157 & 11 \\
\hline & & 950 & 1259 & 160 & 19 & 74.2 & 8.9 & 864 & 50 & 870 & 22 & 309 & 21 \\
\hline & & 1475 & 1999 & 227 & 30 & 128.5 & 13.7 & 1040 & 47 & 1121 & 43 & 346 & 71 \\
\hline 15 & Heptane (spray) & 2200 & 2764 & 301 & 46 & 145.0 & 12.8 & 1140 & 38 & 1197 & 44 & 382 & 95 \\
\hline & & 2790 & 3169 & 377 & 58 & 144.0 & 11.7 & & & 1169 & 36 & 405 & 81 \\
\hline & & 3390 & 3734 & 83 & 15 & 38.2 & 8.4 & & & 629 & 21 & 161 & 57 \\
\hline 16 & & 545 & 649 & 358 & 42 & 71.2 & 14.7 & & & 1195 & 56 & 968 & 111 \\
\hline 10 & & 715 & 769 & 309 & 35 & 90.7 & 6.7 & & & 1244 & 29 & 947 & 64 \\
\hline
\end{tabular}




\subsection{Doorway Velocities and Temperatures}

Doorway velocity measurements were performed in order to establish the ventilation conditions of the compartment fires. Velocity probes and thermocouples were placed at five different heights in the doorway. Aspirated thermocouples and bare bead thermocouples were placed half-way between the velocity probes at three different heights to get a first order estimate of the error in temperature with the bare bead thermocouples due to radiation. See Fig. 4 and Table 3 for exact locations of the doorway probes.

Figure 35 compares the bare bead and aspirated thermocouple temperature measurements at three different heights in the doorway for all 17 fire tests. The results show that at heights of $50 \mathrm{~cm}$ and $70 \mathrm{~cm}$ in the doorway the bare bead temperate measurements agree reasonably well with the aspirated temperature measurements. This was because these points were above the neutral plane where the velocities were relatively high and the large opacity of the hot gases in the upper layer reduced the radiation losses. However, at $30 \mathrm{~cm}$, the temperature probes are below the neutral plane where the velocity is lower and the gas is optically thin cool room air. This thermocouple is exposed to radiation from the hot upper layer resulting in a significant overestimate of the gas temperature. The results of this analysis are that the error in velocity due to using the bare-bead temperature is less than $10 \%$ above the neutral plane and less than $30 \%$ below the neutral plane. Figure 36 show the doorway temperature measurements (not corrected for radiation) for a steady natural gas fire at $265 \mathrm{~kW}$ during test \#3. The error bars in this figure represent twice the standard deviation of the measurement and does not include uncertainty due to radiation.

The steady state velocity profiles along the vertical centerline of the doorway for test \#3 using natural gas are shown in Fig. 37. As expected, the magnitude of the velocity measurement increases and the location of the neutral plane moves downward as the fire size increases. Figure 38 shows the steady doorway velocity profiles for test \#15 using the heptane spray burner. The lines shown in both of these figures are drawn to highlight trends in the data and do not represent a physical model.

The mass flow rate of air into the enclosure is often used to define a global equivalence ratio. This value can be found by integrating the product of velocity and density over the area below the neutral plane. Although this calculation was attempted, the uncertainty in velocity, temperature, and location of neutral plane (due to sparse data) prevented a meaningful determination of mass flow rate. Future work is planned to better quantify the doorway mass flow. 


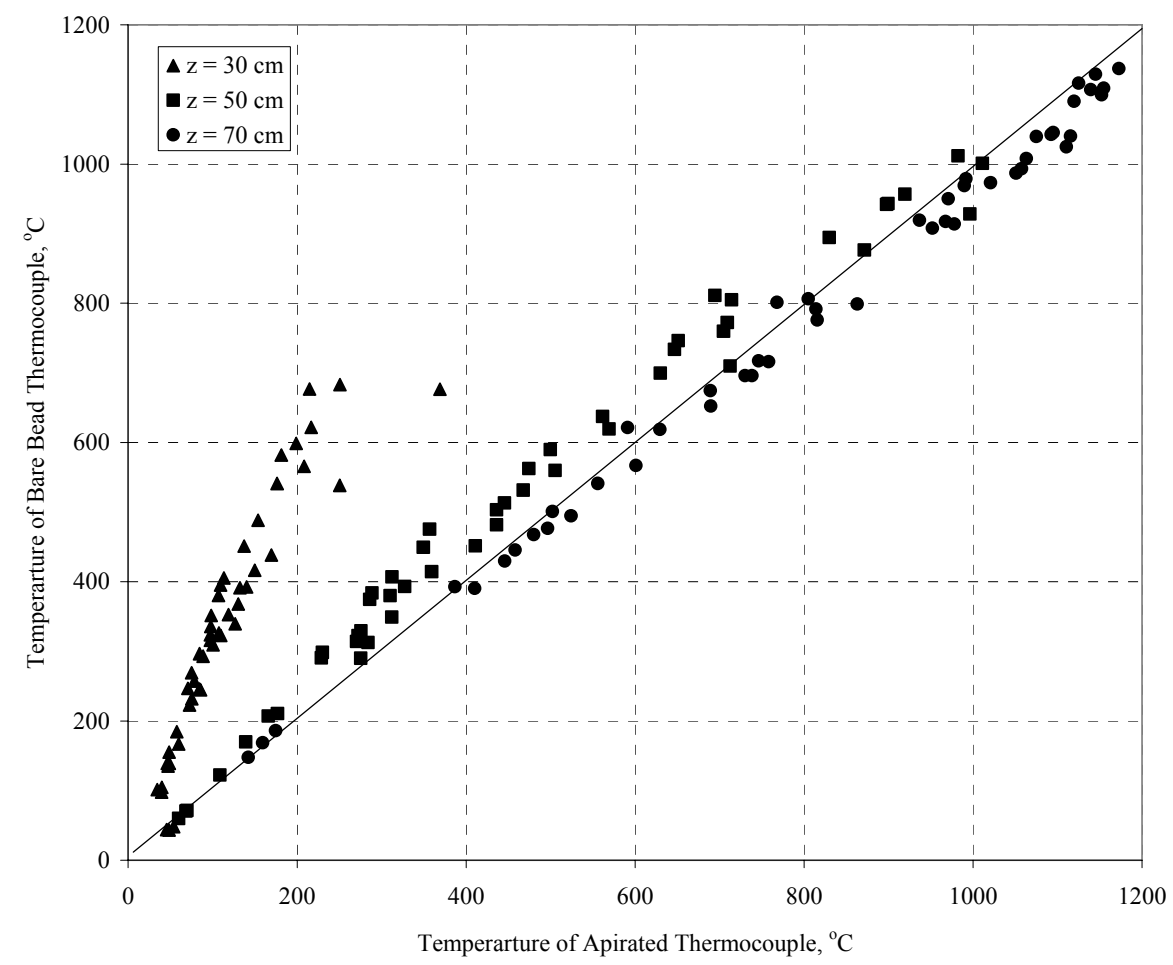

Figure 35. Comparison of doorway centerline temperatures measured using aspirated and bare bead thermocouple at the same position. Steady state average values for all RSE tests.

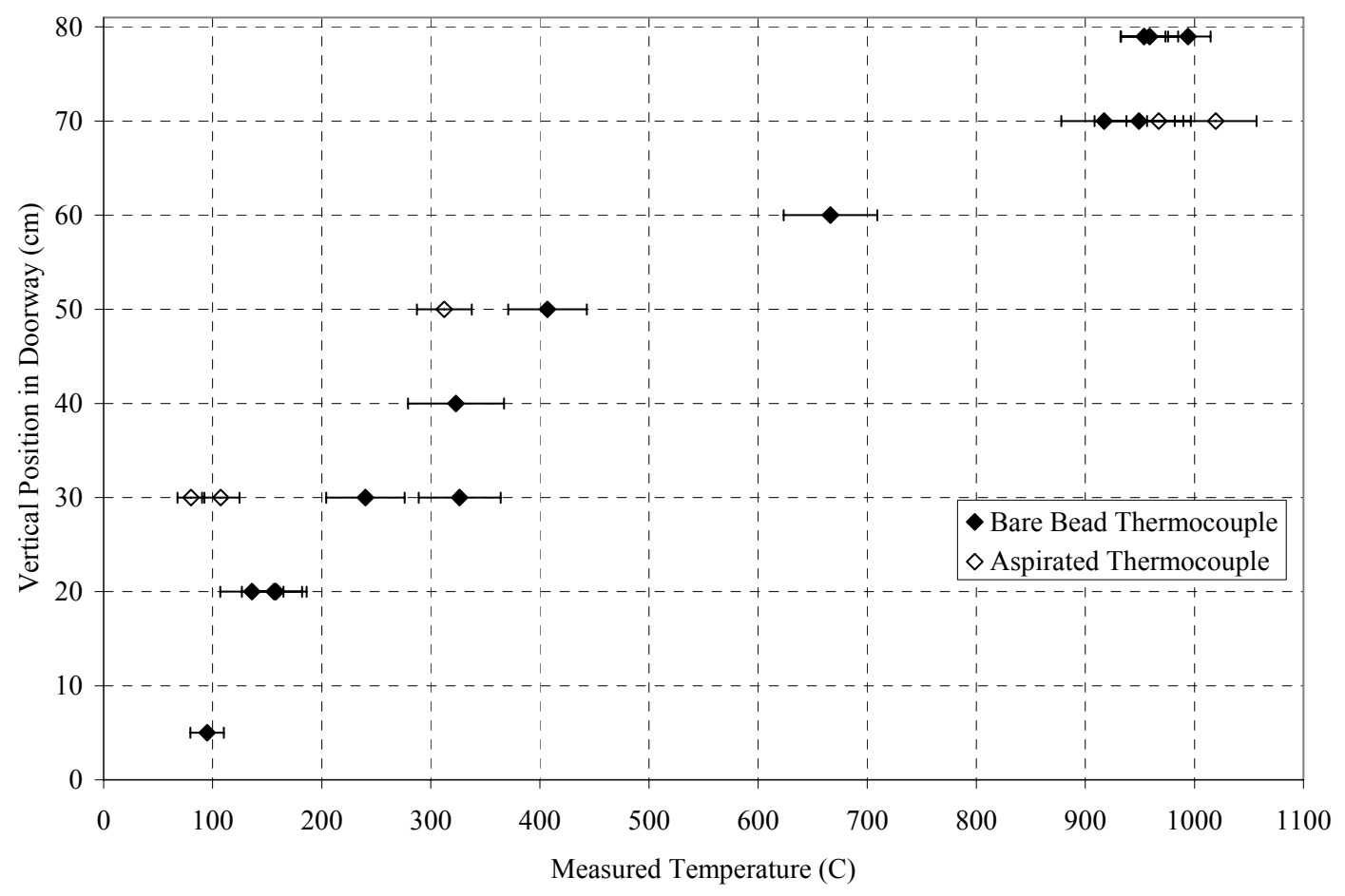

Figure 36. Steady state doorway temperature measurements for natural gas test \#3, $\mathrm{HRR}=265 \mathrm{~kW}$. Error bars in this figure are 2 standard deviations. 


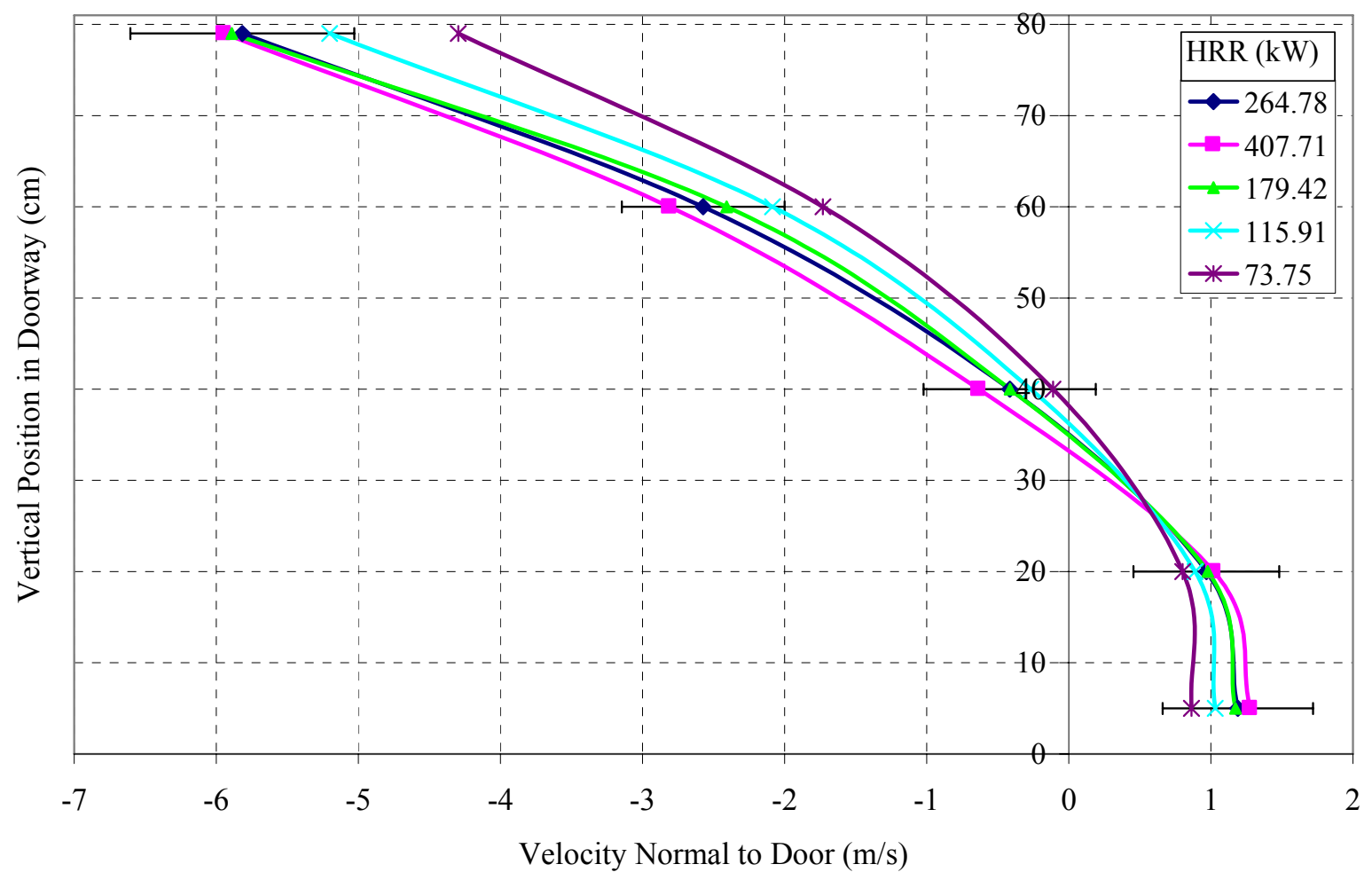

Figure 37. Doorway centerline velocity profiles for natural gas fire (test \#3).

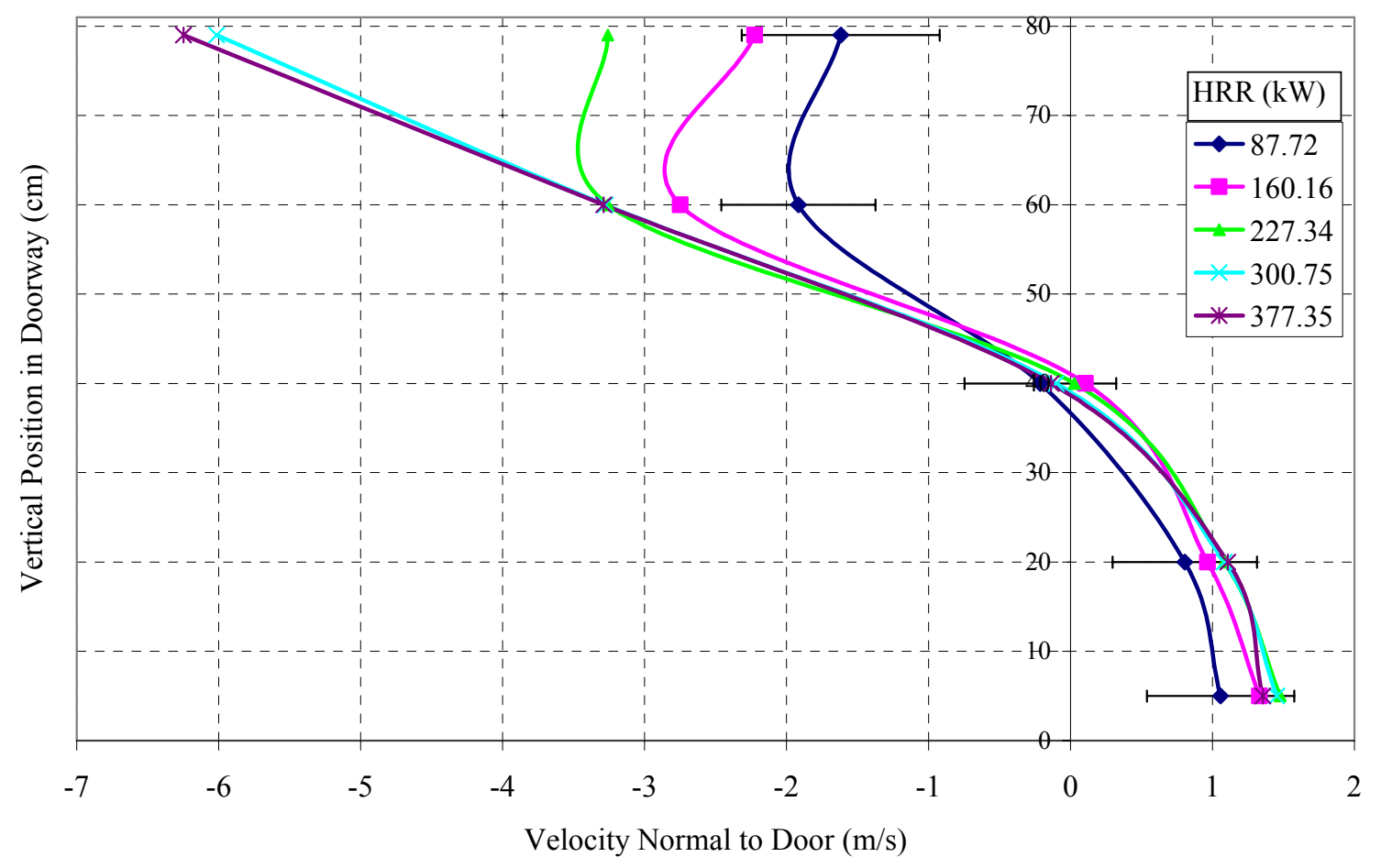

Figure 38. Doorway centerline velocity profiles for heptane spray fire (test \#15). 


\subsection{Interior Gas Species and Soot}

The measurement labels for the figures and tables in this section are described in Table 14. The time history of the gas and soot species measurements at the front and rear probe locations for the heptane spray fire (test \#15) is shown in Fig. 39. The mean measured HRR value over a given steady time window is annotated on this figure. Several observations of this plot are noteworthy. When the fire was underventilated (between $2000 \mathrm{~s}$ and $3000 \mathrm{~s}$ ) there was a mirroring of the random temporal variations in the $\mathrm{CO}$ and $\mathrm{CO}_{2}$ volume fractions. Also evident in Fig. 39 was a strong positive correlation between $\mathrm{CO}$ and total hydrocarbons. The measured gas species volume fractions became less uniform (front to back) as the fire size increased. The uniformity of the upper gas layer was dependant on fire size and fuel type. The transient gas volume fractions and soot mass fractions for polystyrene (test \#16) are shown in Fig. 40. Very high soot mass fractions (nearly $11 \%$ at the front sample location) were observed during this test. The total hydrocarbons measured less than $0.1 \%$ for the entire test. This was a surprising result since the oxygen in the upper layer was completely depleted and flames were observed exiting the doorway (see photograph in Fig. 22). More work is needed to understand this result.

Table 14. Description of interior gas species and soot measurement labels.

\begin{tabular}{|l|l|}
\hline \multicolumn{1}{|c|}{ Measurement Label } & \multicolumn{1}{c|}{ Description } \\
\hline 2 O2Rear & Rear $\mathrm{O}_{2}$ volume fraction corrected for water (wet) \\
\hline 3 CO2Rear & Rear $\mathrm{CO}_{2}$ volume fraction corrected for water (wet) \\
\hline 4 CORear & Rear $\mathrm{CO}$ volume fraction corrected for water (wet) \\
\hline 5 THCRear & Rear Total Hydrocarbons volume fraction corrected for water (wet) \\
\hline 6 SootRear & Rear Soot Mass fraction corrected for water (wet) \\
\hline 7 O2Front & Front $\mathrm{O}_{2}$ volume fraction corrected for water (wet) \\
\hline 8 CO2Front & Front $\mathrm{CO}_{2}$ volume fraction corrected for water (wet) \\
\hline 9 COFront & Front $\mathrm{CO}$ volume fraction corrected for water (wet) \\
\hline 10 THCFront & Front Total Hydrocarbons volume fraction corrected for water (wet) \\
\hline 11 SootFront & Front Soot Mass fraction $(\mathrm{g} / \mathrm{g}$ ), corrected for water (wet) \\
\hline
\end{tabular}

Figure 41 shows the time averaged species volume fractions as a function of heat release rate for all of the natural gas tests with the full-door configuration (tests \#1, \#2,\#3 and \#6.5). The trend lines are included in this figure to help visualize general trends in the data, but do not have a theoretical basis. The figure demonstrates the excellent reproducibility of the gas species measurements and lack of sensitivity of the results to the two different wall lining materials and burners (see Table 1) used in this study.

Figure 42 shows the oxygen volume fraction at the front sample location as a function of heat release rate for the six different fuel types included in this study. Oxygen was depleted for fires larger than about $280 \mathrm{~kW}$. There was some small difference for the various fuel types, with the natural gas fires exhibiting oxygen depletion for slightly smaller values (about $260 \mathrm{~kW}$ ). The rear sample oxygen measurements are summarized in Fig. 43. For the natural gas fires, the oxygen was depleted in the rear of the enclosure at a lower HRR $(\approx 180 \mathrm{~kW})$ than in the front $(\approx 250 \mathrm{~kW})$, however this result could not be generalized for all fuels. For example, the toluene and heptane fires displayed significant amounts oxygen at the rear sample location at HRR's where oxygen was completely depleted at the front sample location. This was an unexpected 
result since flames were observed exiting the doorway (see right side of Fig. 28); however it was not inconsistent with the other species measurements that showed locally lean conditions at the upper rear sample location. In addition, preliminary FDS modeling results showed a similar structure in the compartment. The condition at which oxygen is depleted inside of the compartment is a critical point in the characterization of compartment fire chemistry, indicating when the fire becomes underventilated. In terms of the global equivalence ratio (GER) concept (see Section 1.1 of this report), it is the point at which the GER value is equal to 1.0. Based on the results shown in Figure 42, oxygen depletion could be expected in an ISO 9705 enclosure at about $1800 \mathrm{~kW}$, based on the ventilation scaling relation given in Table 25.

Figure 44 through Fig. 51 shows the steady gas and soot sample results for all of the different fuels at the front and rear locations. The steady state carbon monoxide results are summarized in Fig. 46 (front) and Fig. 47 (rear). As expected, the measured CO values were significantly increased after the fire reached a ventilation limited regime (as indicted by depleted oxygen at the sample locations). The results of the total hydrocarbon volume fraction measurements are shown in Fig. 48 and Fig. 49. Figure 50 and Fig. 51 show the results of the gravimetric soot mass fraction measurements. The species volume fraction results are examined further in Sec. 5 of this report.

The time averaged values for all of the gas and soot species volume fractions are listed in Table 15 and Table 16 for the front and rear sample locations, respectively. The values listed in these tables were used to generate the plots shown in Fig. 41 through Fig. 51. The combined expanded uncertainties listed in these tables represent the absolute percentage (not relative to the mean fractional value).

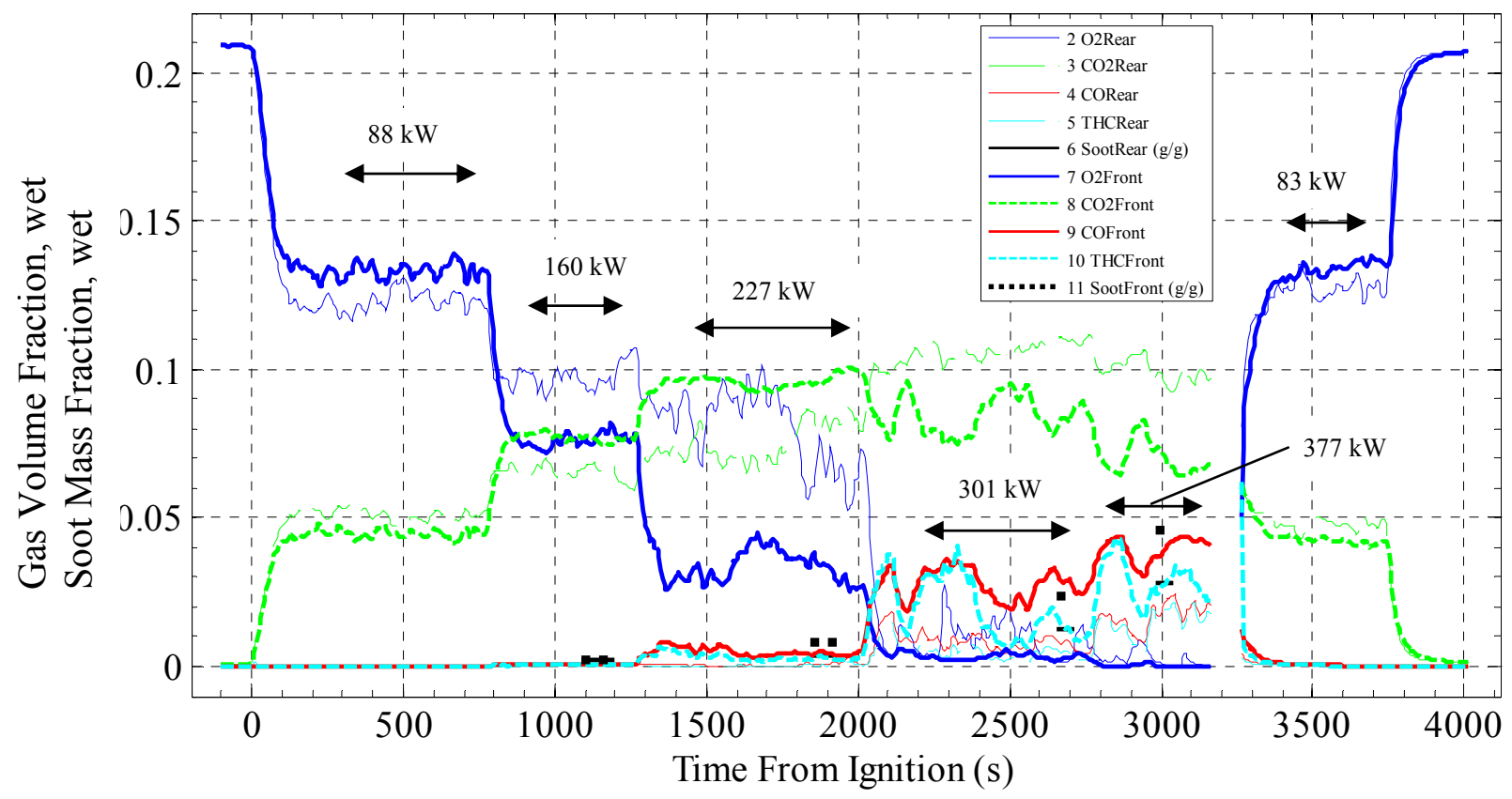

Figure 39. Transient gas volume fractions and soot mass fractions for heptane test \#15. 


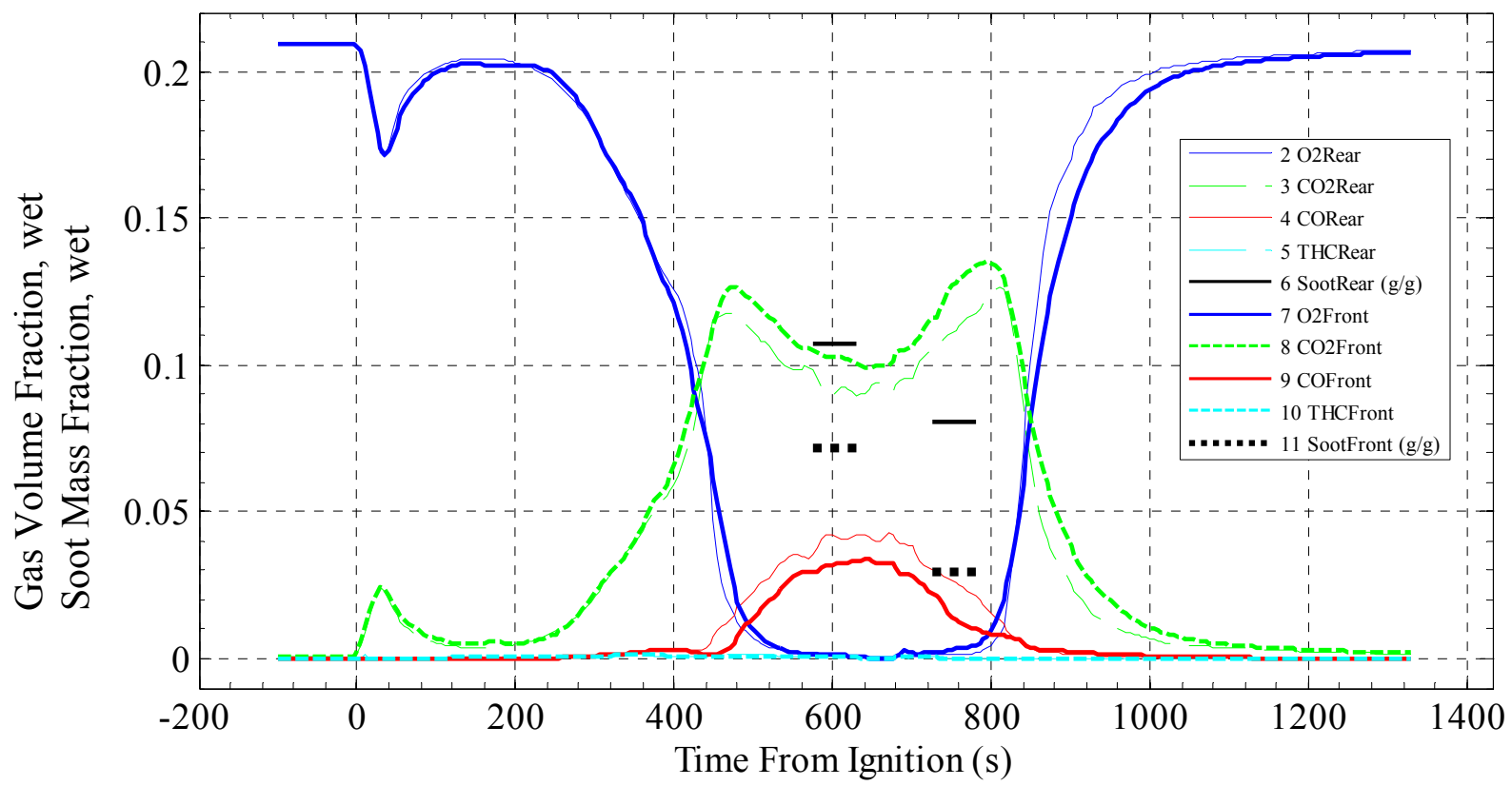

Figure 40. Transient gas volume fractions and soot mass fractions for polystyrene test \#16.

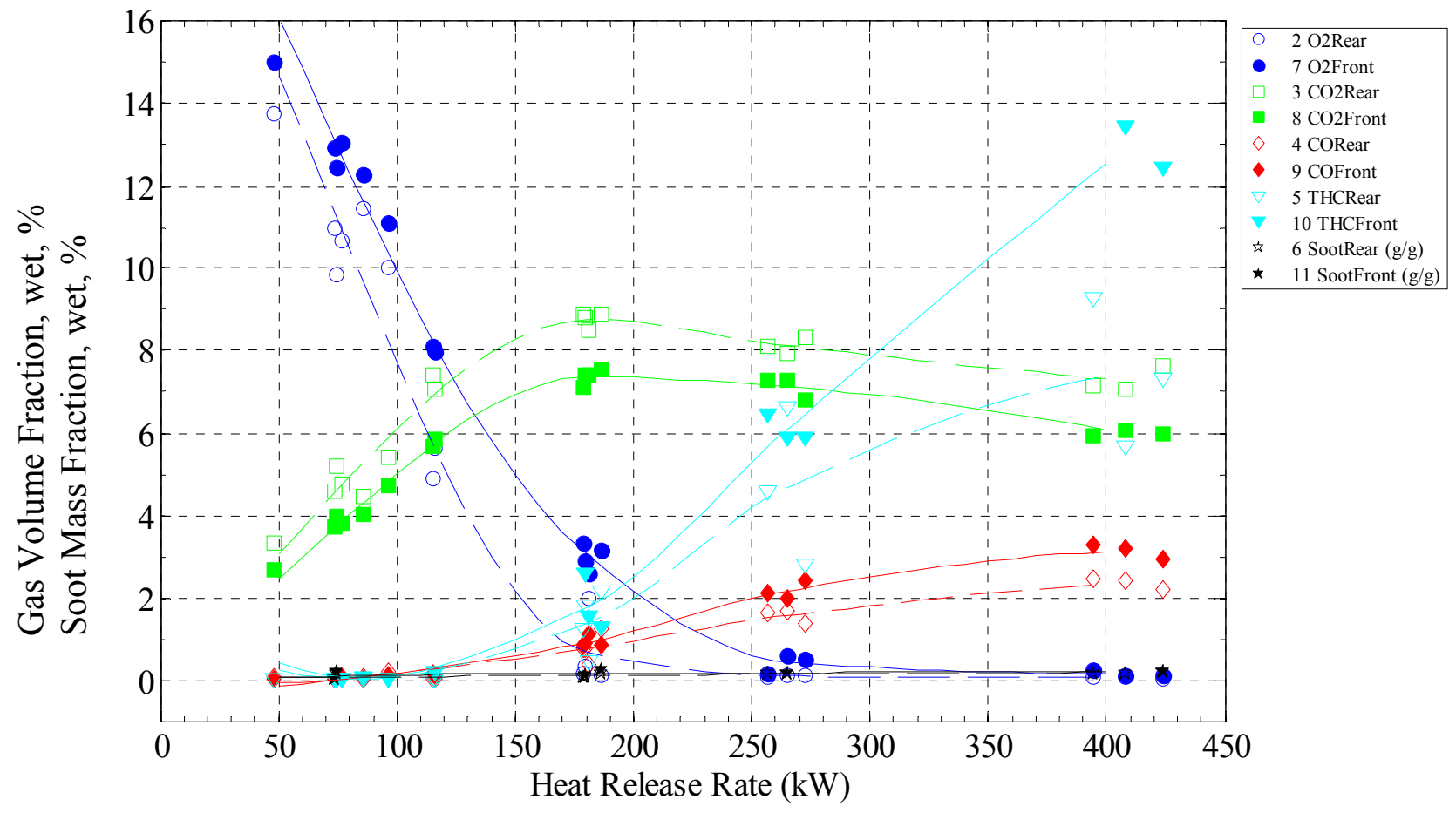

Figure 41. Steady state gas and soot species results for natural gas full door tests \#1, \#2, \#3, and \#65. The lines in this figure are piecewise cubic polynomial fits to the data. 


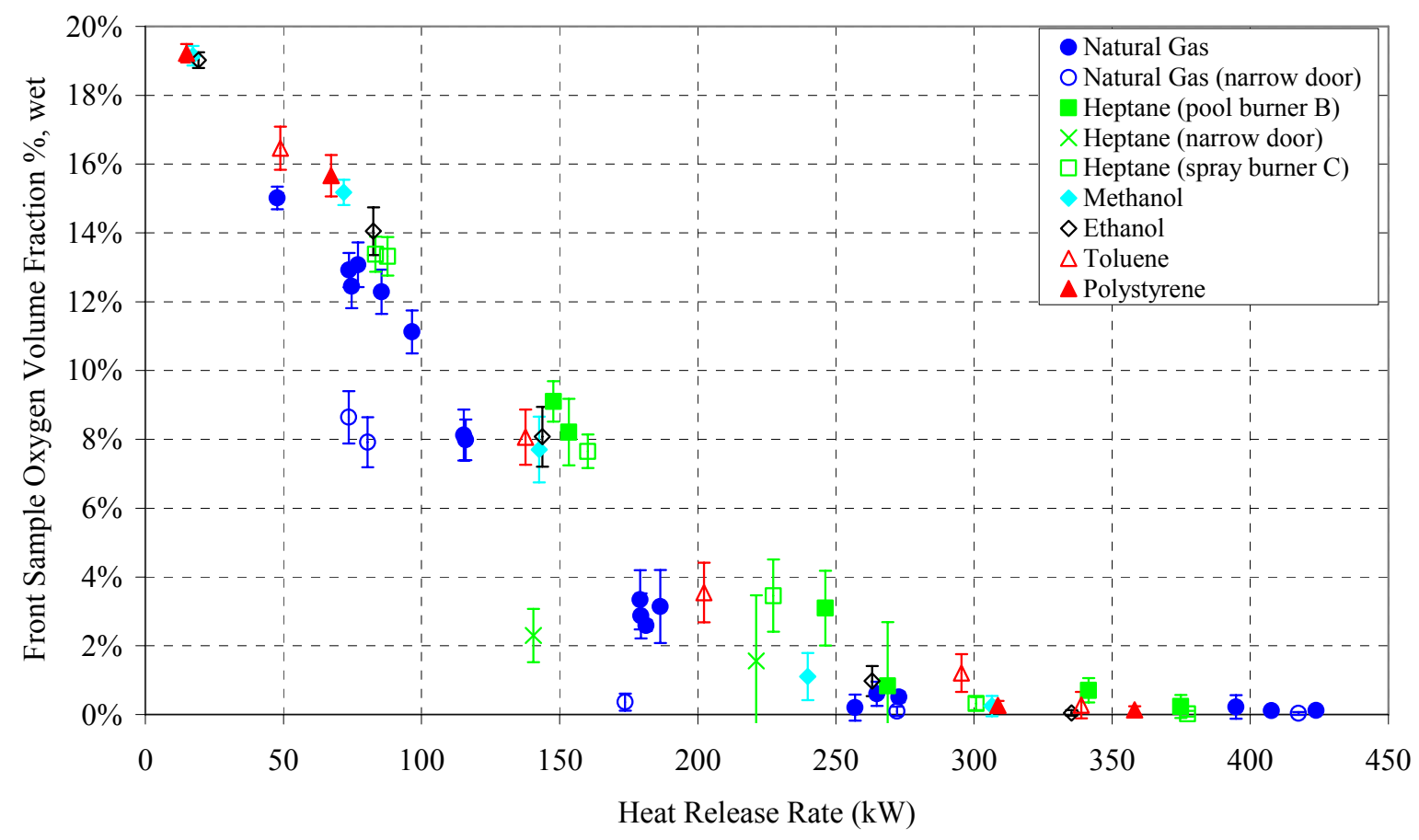

Figure 42. Steady state average oxygen volume fraction measurements at front sample probe location.

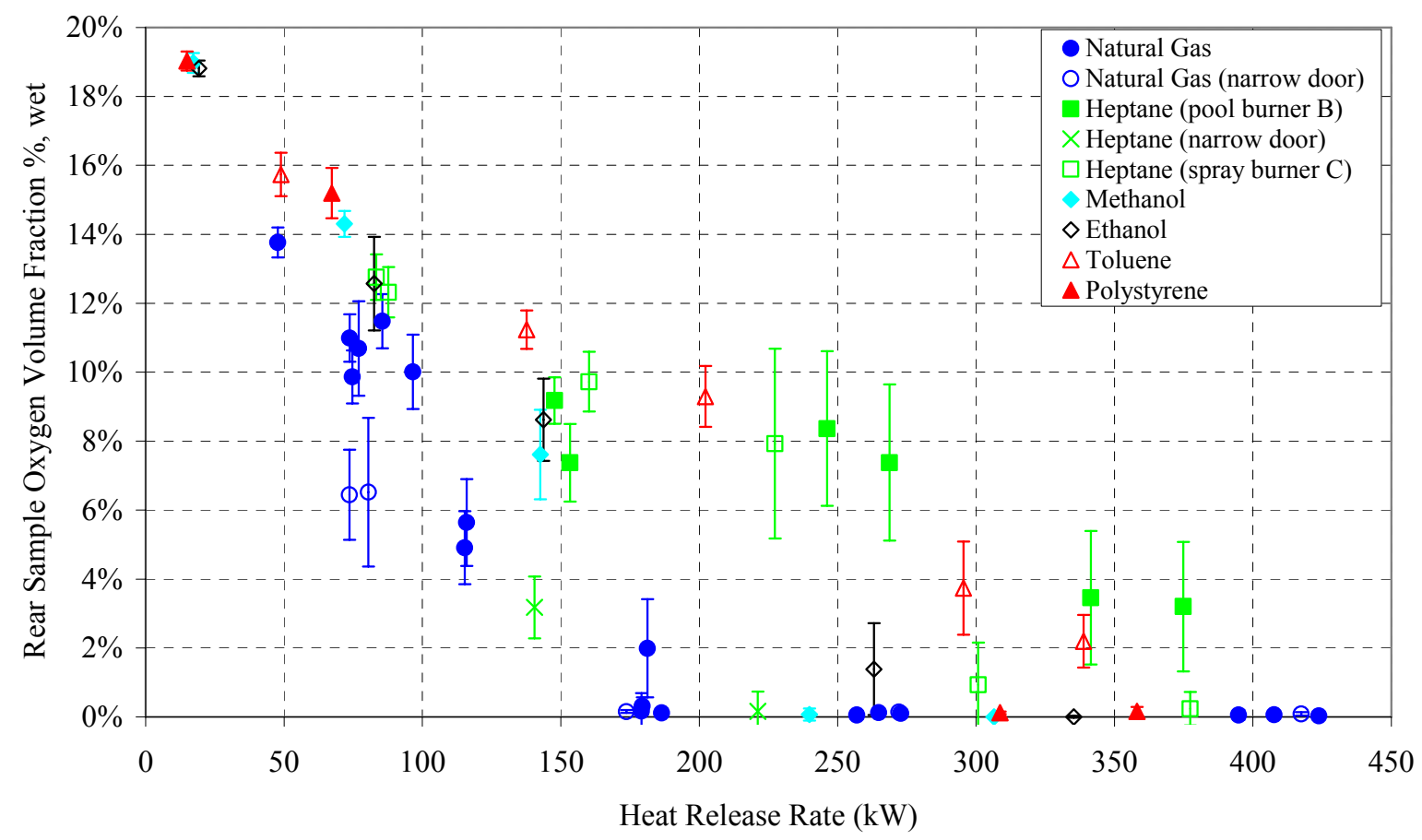

Figure 43. Steady state average oxygen volume fraction measurements at rear sample probe location. 


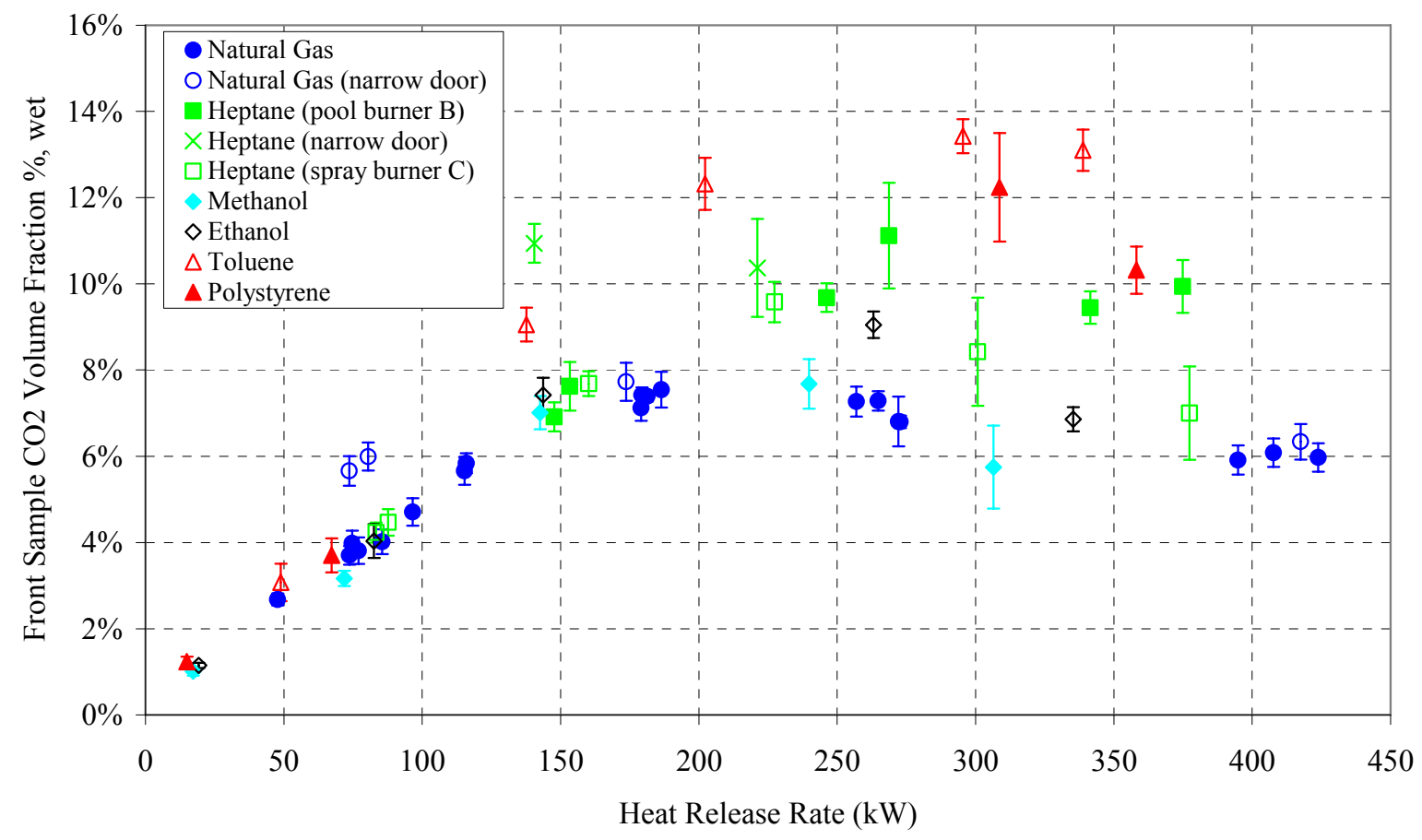

Figure 44. Steady state average carbon dioxide volume fraction measurements at front sample probe location.

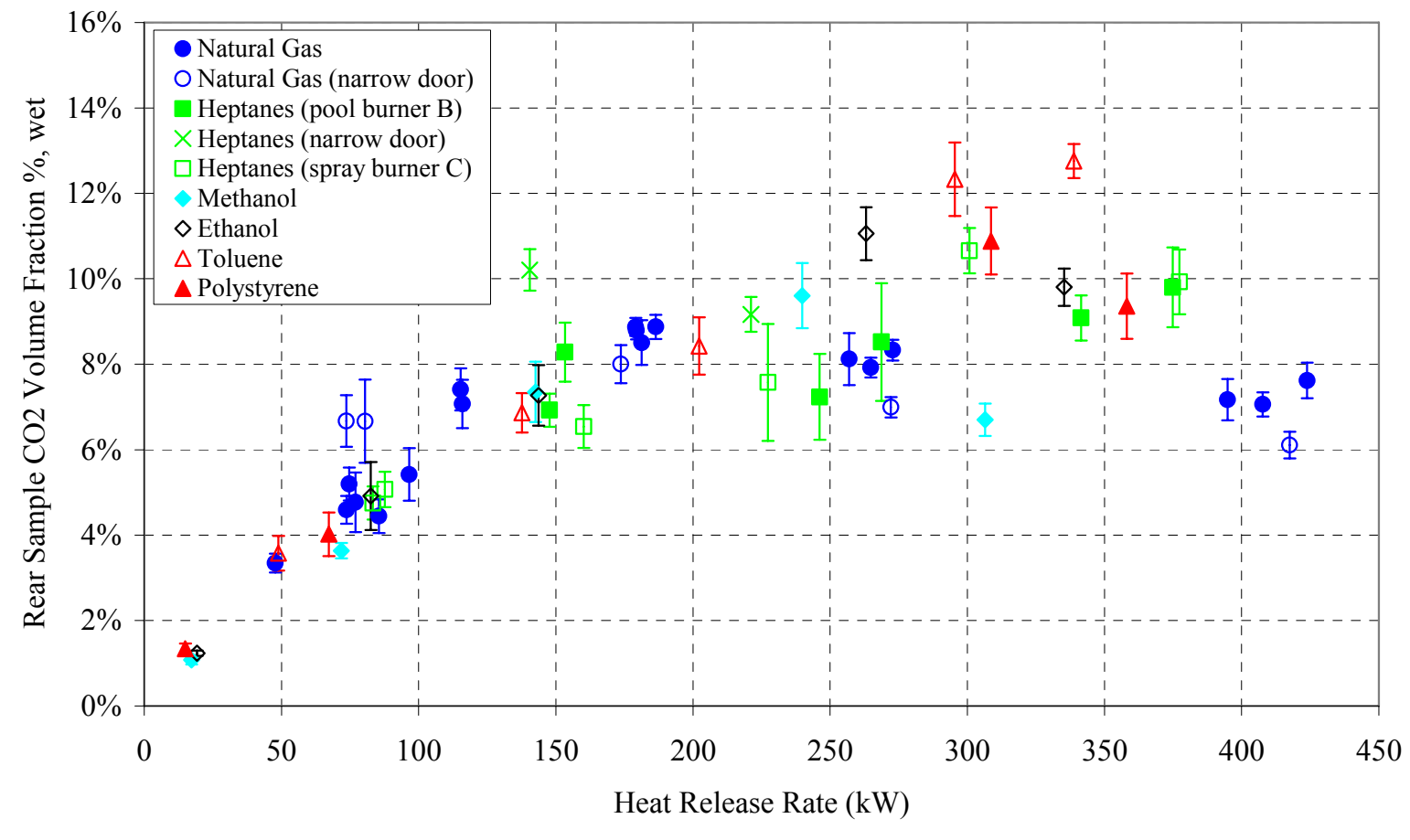

Figure 45. Steady state average carbon dioxide volume fraction measurements at rear sample probe location. 


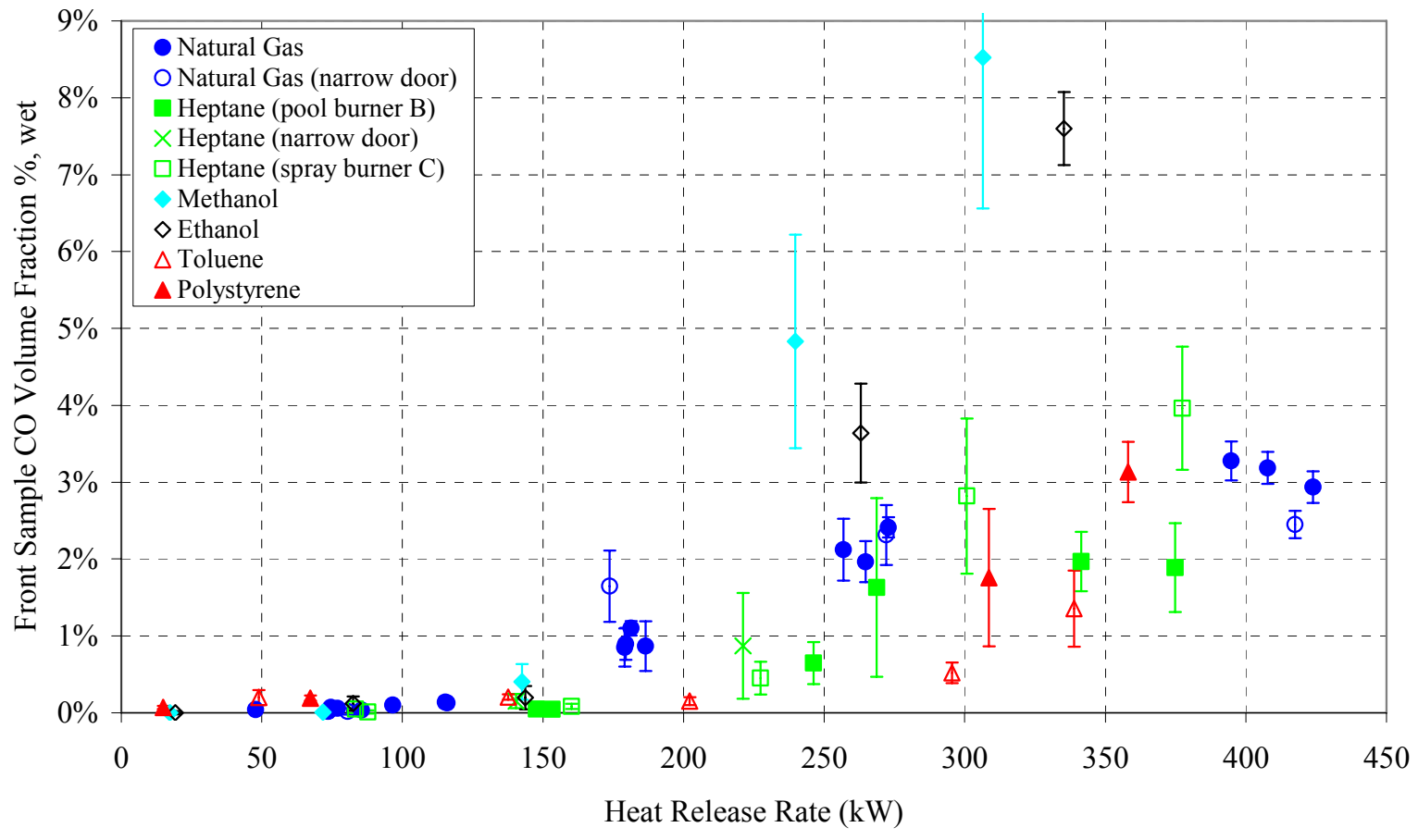

Figure 46. Steady state average carbon monoxide volume fraction measurements at front sample probe location.

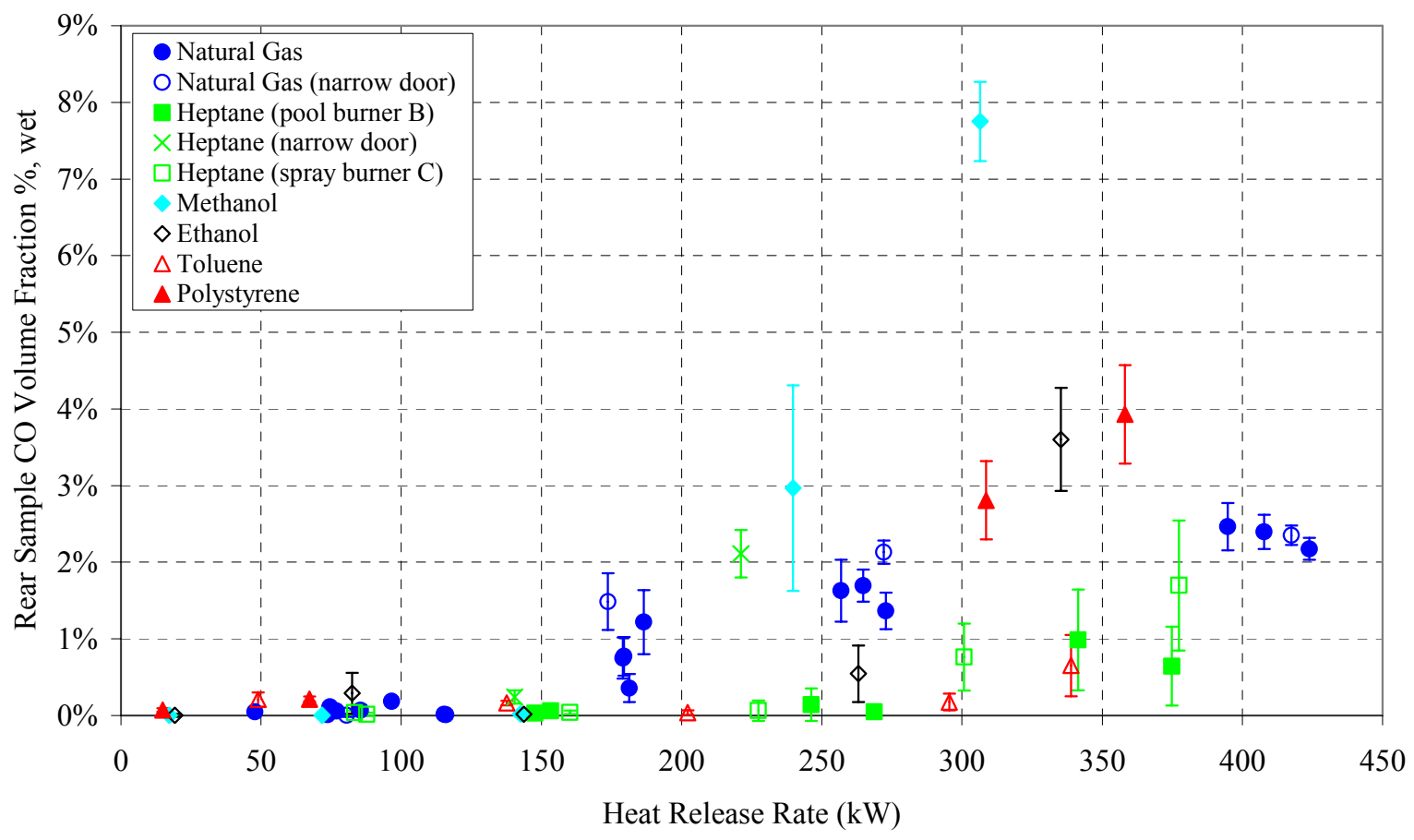

Figure 47. Steady state average carbon monoxide volume fraction measurements at rear sample probe location. 


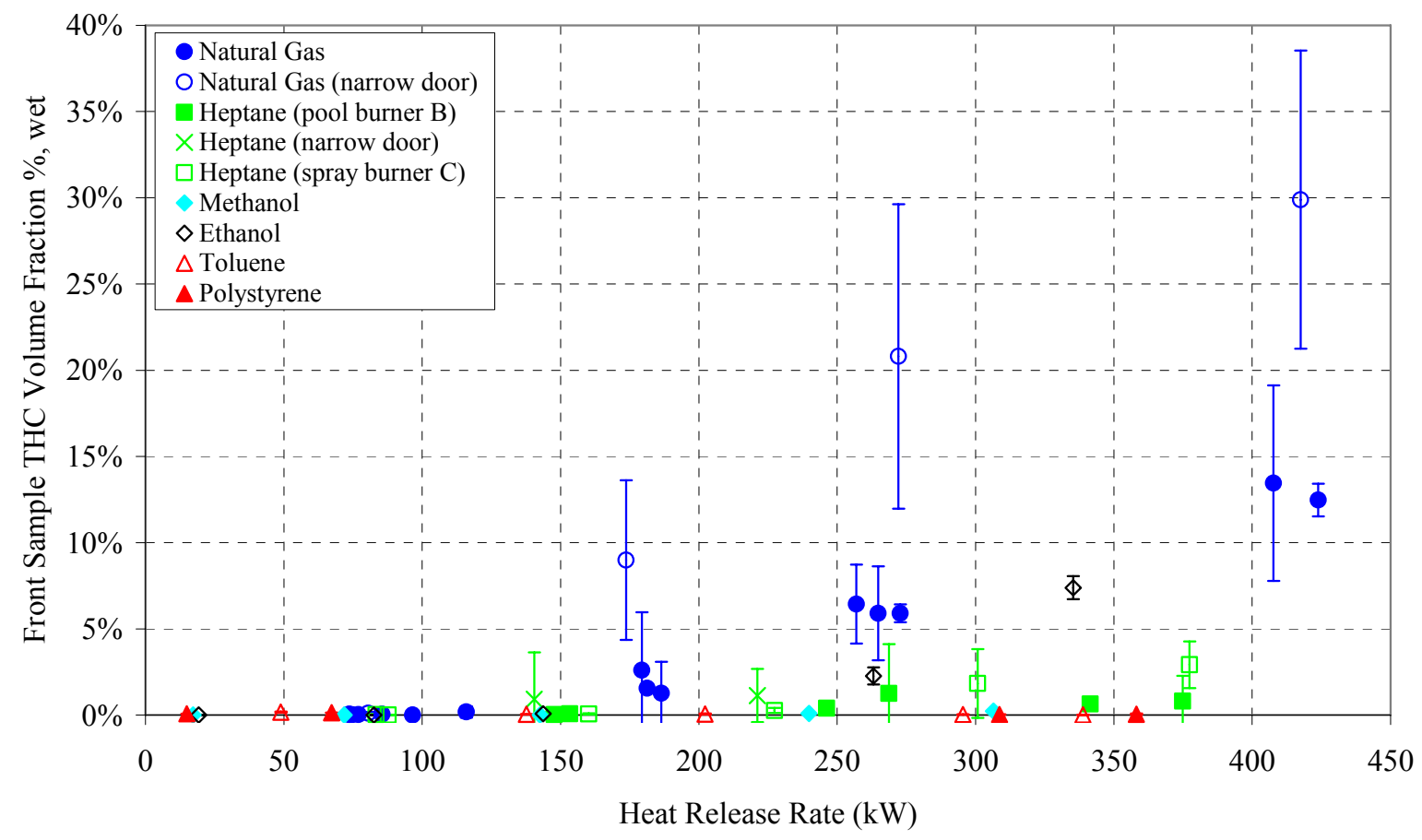

Figure 48. Steady state average total hydrocarbon volume fraction measurements at front sample probe location.

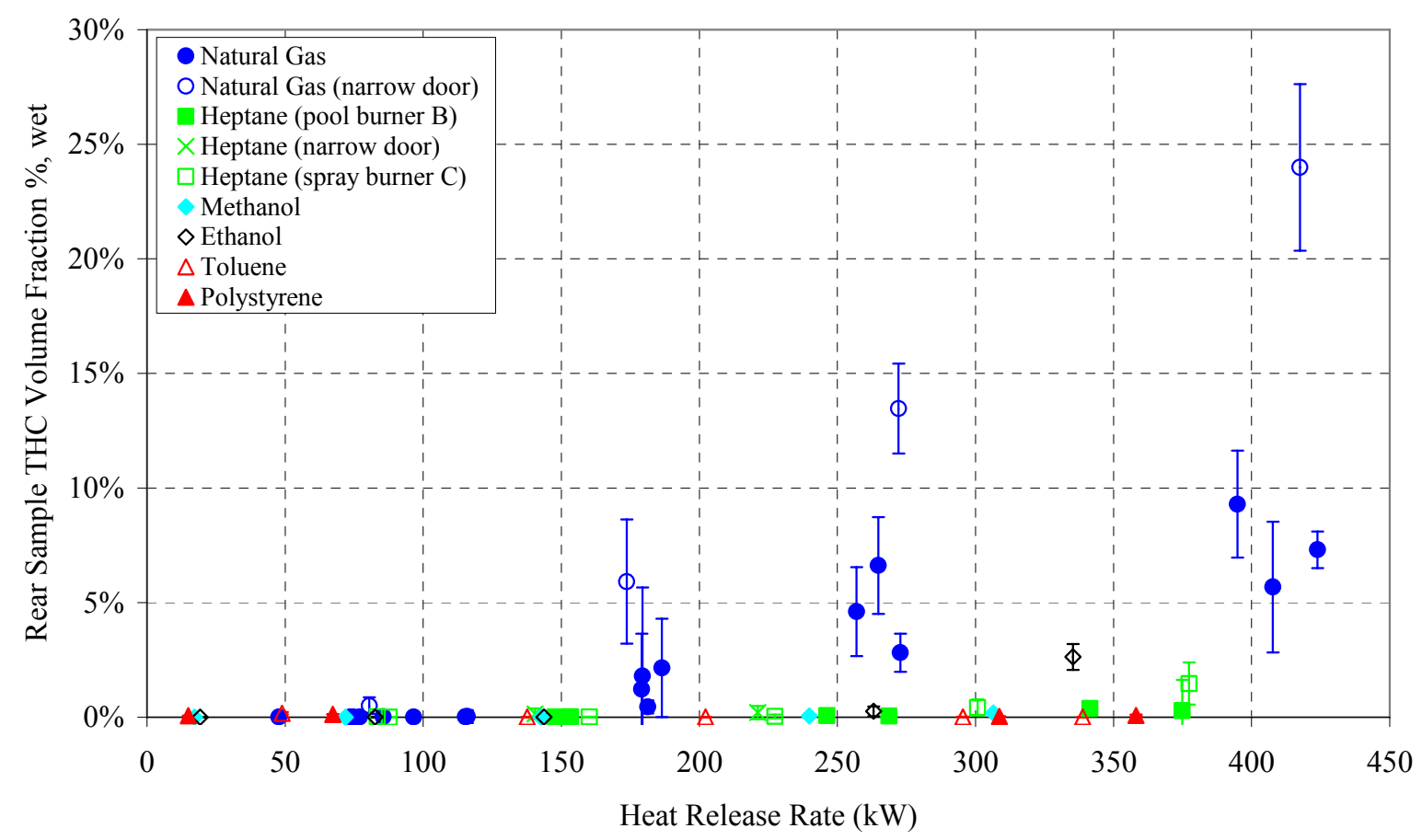

Figure 49. Steady state average total hydrocarbon volume fraction measurements at rear sample probe location. 


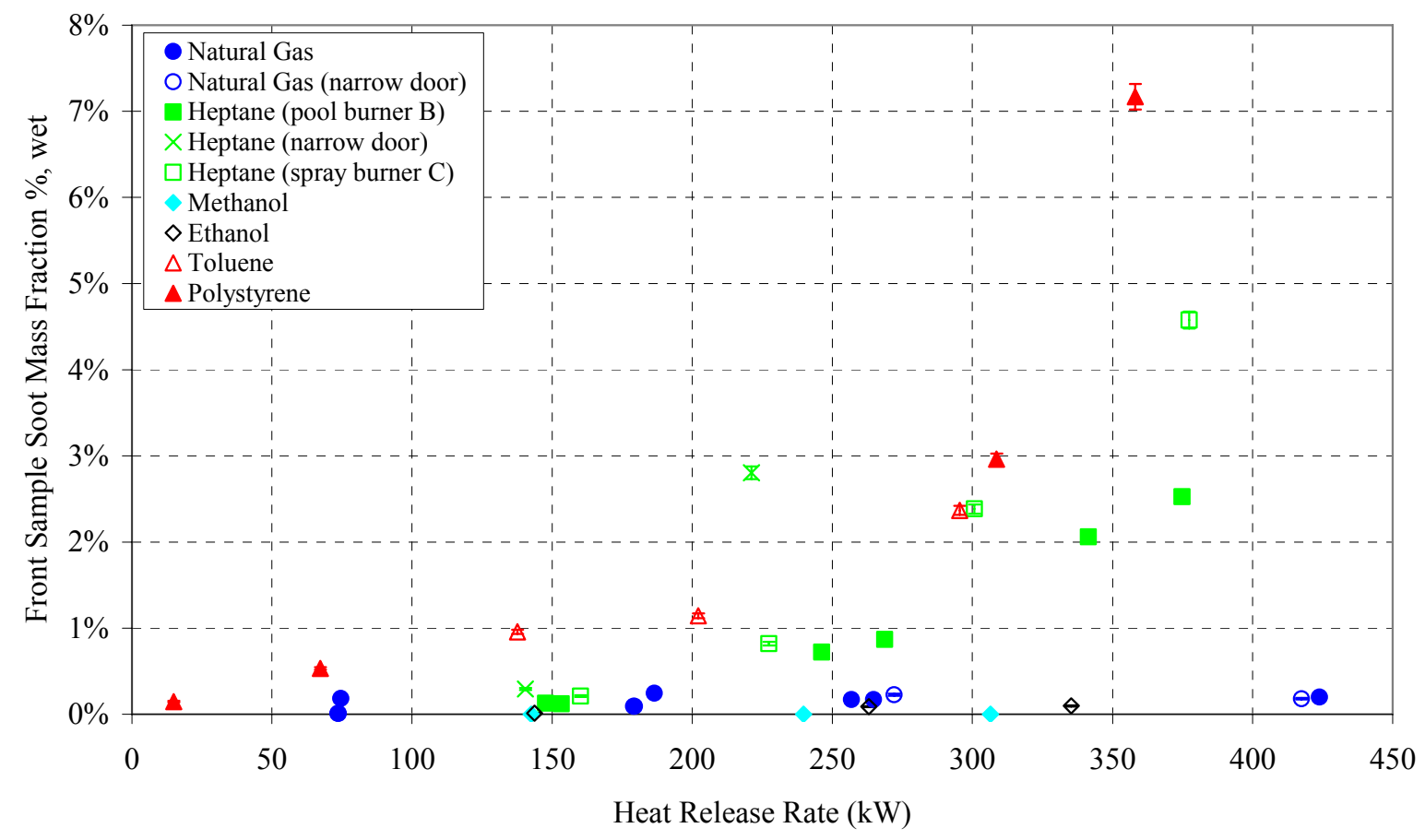

Figure 50. Steady state gravimetric soot mass fraction measurements at front sample probe location.

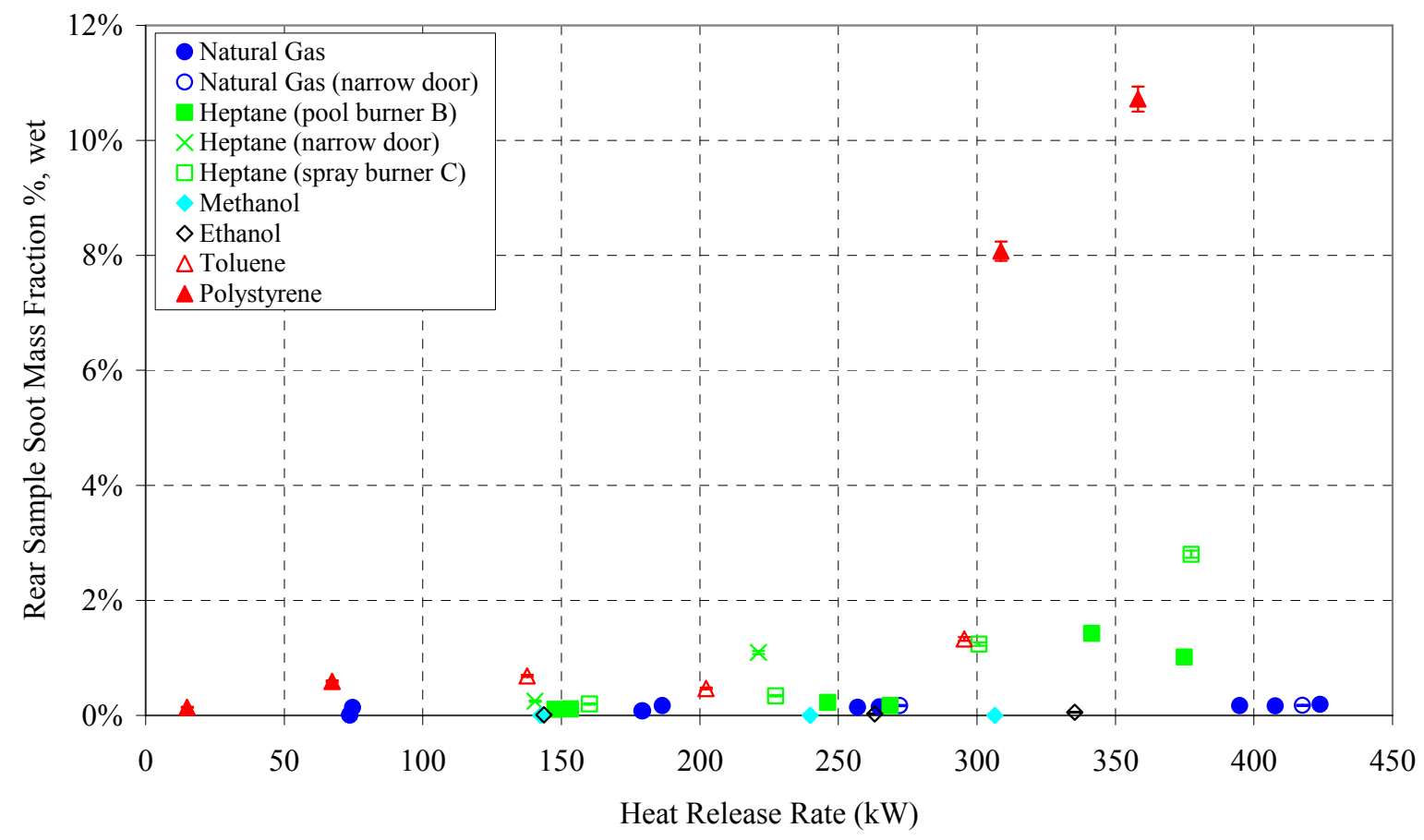

Figure 51. Steady state gravimetric soot mass fraction measurements at rear sample probe location. 
Table 15. Summary of steady state rear gas and soot sample probe measurements.

\begin{tabular}{|c|c|c|c|c|c|c|c|c|c|c|c|c|c|c|c|}
\hline \multirow[t]{2}{*}{ Test \# } & \multirow[t]{2}{*}{ Fuel } & \multicolumn{2}{|c|}{ SS Window } & \multicolumn{2}{|c|}{$\begin{array}{l}\text { HRR } \\
(k W)\end{array}$} & \multicolumn{2}{|c|}{$\begin{array}{c}\mathrm{O}_{2} \text { Rear } \\
(\%)\end{array}$} & \multicolumn{2}{|c|}{$\begin{array}{c}\mathrm{CO}_{2} \operatorname{Rear} \\
(\%)\end{array}$} & \multicolumn{2}{|c|}{$\begin{array}{c}\text { CO Rear } \\
(\%)\end{array}$} & \multicolumn{2}{|c|}{$\begin{array}{c}\text { THC Rear } \\
(\%)\end{array}$} & \multicolumn{2}{|c|}{$\begin{array}{c}\text { Soot Rear } \\
\text { g/g }(\%)\end{array}$} \\
\hline & & start (s) & stop (s) & Mean & $U$ & Mean & $\bar{U}$ & Mean & $\bar{U}$ & Mean & $\bar{U}$ & Mean & $\bar{U}$ & Mean & $U$ \\
\hline \multirow{3}{*}{1} & \multirow{3}{*}{ Natural Gas } & 500 & 1924 & 75 & 11 & 9.86 & 0.77 & 5.20 & 0.38 & 0.11 & 0.04 & 0.01 & 0.01 & 0.14 & 0.01 \\
\hline & & 2220 & 3384 & 186 & 23 & 0.12 & 0.12 & 8.88 & 0.28 & 1.22 & 0.42 & 2.16 & 2.14 & 0.17 & 0.01 \\
\hline & & 3600 & 3944 & 77 & 11 & 10.69 & 1.37 & 4.77 & 0.70 & 0.06 & 0.03 & 0.01 & 0.01 & & \\
\hline \multirow{5}{*}{2} & & 400 & 1594 & 257 & 32 & 0.05 & 0.12 & 8.12 & 0.61 & 1.63 & 0.40 & 4.60 & 1.94 & 0.14 & 0.01 \\
\hline & & 1840 & 3229 & 395 & 49 & 0.06 & 0.15 & 7.17 & 0.48 & 2.47 & 0.31 & 9.30 & 2.33 & 0.17 & 0.01 \\
\hline & Natural Gas & 3500 & 4454 & 179 & 23 & 0.17 & 0.52 & 8.87 & 0.20 & 0.75 & 0.27 & 1.23 & 2.42 & 0.08 & 0.01 \\
\hline & & 4550 & 5004 & 115 & 15 & 4.91 & 1.06 & 7.41 & 0.49 & 0.02 & 0.02 & 0.02 & 0.04 & & \\
\hline & & 5200 & 5579 & 48 & 7 & 13.76 & 0.43 & 3.34 & 0.22 & 0.05 & 0.03 & 0.01 & 0.01 & & \\
\hline & & 475 & 1139 & 265 & 33 & 0.12 & 0.10 & 7.93 & 0.22 & 1.69 & 0.21 & 6.62 & 2.11 & 0.15 & 0.01 \\
\hline & & 1300 & 2224 & 408 & 55 & 0.06 & 0.10 & 7.06 & 0.28 & 2.40 & 0.22 & 5.68 & 2.85 & 0.17 & 0.01 \\
\hline 3 & Natural Gas & 2555 & 3449 & 179 & 25 & 0.31 & 0.25 & 8.79 & 0.20 & 0.77 & 0.25 & 1.80 & 3.87 & 0.08 & 0.01 \\
\hline & & 3645 & 4019 & 116 & 14 & 5.64 & 1.26 & 7.07 & 0.56 & 0.01 & 0.03 & 0.03 & 0.28 & & \\
\hline & & 4390 & 5249 & 74 & 10 & 10.99 & 0.69 & 4.59 & 0.32 & 0.01 & 0.02 & 0.00 & 0.01 & 0.01 & 0.01 \\
\hline & & 1375 & 2149 & 153 & 21 & 7.37 & 1.13 & 8.28 & 0.69 & 0.06 & 0.04 & 0.02 & 0.12 & 0.11 & 0.01 \\
\hline 4 & Heptane (pool) & 2850 & 3334 & 269 & 34 & 7.38 & 2.26 & 8.52 & 1.38 & 0.05 & 0.07 & 0.05 & 0.13 & 0.17 & 0.01 \\
\hline & & 4090 & 5489 & 375 & 54 & 3.20 & 1.87 & 9.80 & 0.93 & 0.64 & 0.51 & 0.29 & 1.34 & 1.01 & 0.02 \\
\hline & & 1245 & 1799 & 140 & 18 & 3.18 & 0.90 & 10.21 & 0.48 & 0.24 & 0.09 & 0.15 & 0.24 & 0.25 & 0.01 \\
\hline 5 & Heptane (pool) & 2340 & 2969 & 221 & 29 & 0.16 & 0.57 & 9.17 & 0.40 & 2.11 & 0.31 & 0.21 & 0.29 & 1.09 & 0.02 \\
\hline & & 660 & 1539 & 74 & 11 & 6.44 & 1.31 & 6.67 & 0.60 & 0.02 & 0.03 & 0.02 & 0.19 & 0.01 & 0.01 \\
\hline & & 2515 & 4179 & 174 & 22 & 0.16 & 0.04 & 8.00 & 0.44 & 1.49 & 0.37 & 5.92 & 2.71 & & \\
\hline 6 & Natural Gas & 4425 & 4944 & 272 & 33 & 0.14 & 0.04 & 7.00 & 0.23 & 2.13 & 0.15 & 13.47 & 1.96 & 0.17 & 0.01 \\
\hline & & 5090 & 5724 & 417 & 50 & 0.09 & 0.05 & 6.11 & 0.31 & 2.35 & 0.12 & 23.99 & 3.63 & 0.17 & 0.01 \\
\hline & & 6090 & 6549 & 80 & 11 & 6.52 & 2.16 & 6.67 & 0.97 & 0.00 & 0.02 & 0.51 & 0.36 & & \\
\hline & & 285 & 679 & 97 & 12 & 10.01 & 1.08 & 5.42 & 0.61 & 0.19 & 0.06 & 0.01 & 0.09 & & \\
\hline & & 920 & 1204 & 424 & 51 & 0.03 & 0.04 & 7.62 & 0.41 & 2.17 & 0.14 & 7.31 & 0.80 & 0.19 & 0.01 \\
\hline 6.5 & Natural Gas & 1600 & 2329 & 273 & 33 & 0.10 & 0.13 & 8.33 & 0.23 & 1.37 & 0.24 & 2.82 & 0.83 & & \\
\hline & & 2540 & 2804 & 181 & 22 & 1.99 & 1.42 & 8.51 & 0.52 & 0.36 & 0.18 & 0.46 & 0.28 & & \\
\hline & & 2980 & 3259 & 85 & 11 & 11.48 & 0.78 & 4.44 & 0.39 & 0.07 & 0.07 & 0.02 & 0.01 & & \\
\hline & & 1200 & 1669 & 148 & 20 & 9.18 & 0.67 & 6.92 & 0.38 & 0.03 & 0.02 & 0.01 & 0.08 & 0.11 & 0.01 \\
\hline 7 & Heptane (pool) & 2105 & 2664 & 246 & 38 & 8.36 & 2.24 & 7.24 & 1.00 & 0.14 & 0.21 & 0.07 & 0.10 & 0.23 & 0.01 \\
\hline & & 3040 & 3709 & 341 & 43 & 3.46 & 1.94 & 9.08 & 0.53 & 0.99 & 0.66 & 0.38 & 0.27 & 1.42 & 0.03 \\
\hline 8 & Methanol (pool) & 1439 & 2009 & 17 & 3 & 18.97 & 0.27 & 1.08 & 0.10 & 0.00 & 0.02 & 0.00 & 0.01 & & \\
\hline 9 & Ethanol (pool) & 1300 & 2019 & 19 & 3 & 18.82 & 0.21 & 1.23 & 0.06 & 0.00 & 0.02 & 0.00 & 0.01 & & \\
\hline & & 1400 & 1884 & 49 & 9 & 15.74 & 0.63 & 3.58 & 0.41 & 0.21 & 0.09 & 0.18 & 0.05 & & \\
\hline & & 2805 & 3154 & 138 & 20 & 11.24 & 0.55 & 6.86 & 0.46 & 0.16 & 0.03 & 0.01 & 0.01 & 0.69 & 0.01 \\
\hline 10 & Toluene (pool) & 3600 & 4224 & 202 & 27 & 9.30 & 0.88 & 8.43 & 0.67 & 0.04 & 0.03 & 0.01 & 0.01 & 0.47 & 0.01 \\
\hline & & 4435 & 5044 & 295 & 43 & 3.74 & 1.35 & 12.33 & 0.86 & 0.18 & 0.11 & 0.01 & 0.01 & 1.33 & 0.03 \\
\hline & & 5120 & 5394 & 339 & 44 & 2.19 & 0.76 & 12.76 & 0.39 & 0.65 & 0.40 & 0.01 & 0.01 & & \\
\hline & & 550 & 1039 & 83 & 15 & 12.57 & 1.35 & 4.92 & 0.79 & 0.29 & 0.27 & 0.01 & 0.01 & & \\
\hline & & 1400 & 1714 & 144 & 18 & 8.62 & 1.19 & 7.27 & 0.71 & 0.02 & 0.03 & 0.01 & 0.13 & 0.01 & 0.01 \\
\hline 11 & Ethanol & 2175 & 2849 & 263 & 34 & 1.39 & 1.34 & 11.06 & 0.62 & 0.55 & 0.37 & 0.26 & 0.21 & 0.03 & 0.01 \\
\hline & & 2940 & 4200 & 335 & 51 & 0.00 & 0.03 & 9.80 & 0.43 & 3.60 & 0.67 & 2.64 & 0.57 & 0.05 & 0.01 \\
\hline & & 300 & 724 & 72 & 10 & 14.30 & 0.37 & 3.63 & 0.18 & 0.00 & 0.02 & 0.00 & 0.01 & & \\
\hline & Motbon ( snroy) & 1145 & 1609 & 143 & 19 & 7.61 & 1.30 & 7.35 & 0.70 & 0.02 & 0.03 & 0.00 & 0.01 & 0.00 & 0.01 \\
\hline 12 & Methanol (spray) & 1949 & 2669 & 240 & 30 & 0.07 & 0.18 & 9.61 & 0.76 & 2.97 & 1.34 & 0.05 & 0.03 & 0.00 & 0.01 \\
\hline & & 2760 & 3299 & 306 & 38 & 0.00 & 0.02 & 6.70 & 0.38 & 7.75 & 0.51 & 0.18 & 0.02 & 0.00 & 0.01 \\
\hline 13 & Polystyrene & 710 & 1344 & 15 & 3 & 19.03 & 0.26 & 1.34 & 0.12 & 0.07 & 0.02 & 0.07 & 0.01 & 0.14 & 0.01 \\
\hline 14 & Polystyrene & 870 & 1724 & 67 & 12 & 15.20 & 0.72 & 4.02 & 0.51 & 0.21 & 0.03 & 0.12 & 0.01 & 0.59 & 0.01 \\
\hline & & 280 & 759 & 88 & 16 & 12.32 & 0.73 & 5.07 & 0.41 & 0.02 & 0.02 & 0.00 & 0.01 & & \\
\hline & & 950 & 1259 & 160 & 19 & 9.72 & 0.87 & 6.54 & 0.50 & 0.04 & 0.02 & 0.01 & 0.01 & 0.20 & 0.01 \\
\hline & & 1475 & 1999 & 227 & 30 & 7.93 & 2.75 & 7.57 & 1.37 & 0.06 & 0.13 & 0.03 & 0.08 & 0.34 & 0.01 \\
\hline 15 & Heptane (spray) & 2200 & 2764 & 301 & 46 & 0.93 & 1.22 & 10.66 & 0.52 & 0.76 & 0.44 & 0.43 & 0.35 & 1.24 & 0.03 \\
\hline & & 2790 & 3169 & 377 & 58 & 0.24 & 0.49 & 9.93 & 0.76 & 1.70 & 0.85 & 1.47 & 0.92 & 2.80 & 0.06 \\
\hline & & 3390 & 3734 & 83 & 15 & 12.76 & 0.66 & 4.75 & 0.38 & 0.04 & 0.03 & 0.03 & 0.01 & & \\
\hline & & 545 & 649 & 358 & 42 & 0.16 & 0.13 & 9.36 & 0.76 & 3.93 & 0.64 & 0.08 & 0.04 & 10.72 & 0.21 \\
\hline & Polystyrene & 715 & 769 & 309 & 35 & 0.12 & 0.03 & 10.89 & 0.79 & 2.81 & 0.51 & 0.04 & 0.01 & 8.07 & 0.16 \\
\hline
\end{tabular}


Table 16. Summary of steady state front gas and soot sample probe measurements.

\begin{tabular}{|c|c|c|c|c|c|c|c|c|c|c|c|c|c|c|c|}
\hline \multirow[t]{2}{*}{ Test \# } & \multirow[t]{2}{*}{ Fuel } & \multicolumn{2}{|c|}{ SS Window } & \multicolumn{2}{|c|}{$\begin{array}{l}\text { HRR } \\
(\mathrm{kW})\end{array}$} & \multicolumn{2}{|c|}{$\begin{array}{c}\mathrm{U}_{2} \text { Rear } \\
(\%)\end{array}$} & \multicolumn{2}{|c|}{$\begin{array}{c}\mathrm{CO}_{2} \text { Rear } \\
(\%)\end{array}$} & \multicolumn{2}{|c|}{$\begin{array}{c}\text { CO Rear } \\
(\%)\end{array}$} & \multicolumn{2}{|c|}{$\begin{array}{c}\text { THC Rear } \\
(\%)\end{array}$} & \multicolumn{2}{|c|}{$\begin{array}{c}\text { Soot Rear } \\
\text { g/g (\%) }\end{array}$} \\
\hline & & start (s) & stop (s) & Mean & $U$ & Mean & $\bar{U}$ & Mean & $U$ & $\overline{M e a n}$ & 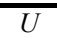 & $\overline{M e a n}$ & $U$ & Mean & $\bar{U}$ \\
\hline \multirow{3}{*}{1} & \multirow{3}{*}{ Natural Gas } & 500 & 1924 & 75 & 11 & 12.45 & 0.63 & 3.98 & 0.29 & 0.07 & 0.03 & 0.02 & 0.18 & 0.18 & 0.01 \\
\hline & & 2220 & 3384 & 186 & 23 & 3.14 & 1.06 & 7.54 & 0.41 & 0.87 & 0.32 & 1.27 & 1.83 & 0.25 & 0.01 \\
\hline & & 3600 & 3944 & 77 & 11 & 13.07 & 0.65 & 3.81 & 0.30 & 0.06 & 0.03 & 0.03 & 0.28 & & \\
\hline \multirow{5}{*}{2} & & 400 & 1594 & 257 & 32 & 0.20 & 0.38 & 7.27 & 0.35 & 2.12 & 0.40 & 6.44 & 2.29 & 0.17 & 0.01 \\
\hline & & 1840 & 3229 & 395 & 49 & 0.22 & 0.34 & 5.92 & 0.33 & 3.28 & 0.25 & 0.00 & 0.00 & & \\
\hline & Natural Gas & 3500 & 4454 & 179 & 23 & 3.34 & 0.86 & 7.12 & 0.30 & 0.85 & 0.25 & 0.00 & 0.00 & 0.09 & 0.01 \\
\hline & & 4550 & 5004 & 115 & 15 & 8.12 & 0.74 & 5.66 & 0.32 & 0.14 & 0.07 & 0.00 & 0.00 & & \\
\hline & & 5200 & 5579 & 48 & 7 & 15.01 & 0.32 & 2.68 & 0.14 & 0.04 & 0.02 & 0.00 & 0.00 & & \\
\hline & & 475 & 1139 & 265 & 33 & 0.60 & 0.35 & 7.28 & 0.22 & 1.97 & 0.27 & 5.91 & 2.72 & 0.17 & 0.01 \\
\hline & & 1300 & 2224 & 408 & 55 & 0.12 & 0.10 & 6.08 & 0.33 & 3.19 & 0.20 & 13.45 & 5.67 & 0.00 & 0.00 \\
\hline 3 & Natural Gas & 2555 & 3449 & 179 & 25 & 2.87 & 0.65 & 7.42 & 0.17 & 0.90 & 0.21 & 2.59 & 3.37 & 0.09 & 0.01 \\
\hline & & 3645 & 4019 & 116 & 14 & 7.98 & 0.58 & 5.84 & 0.23 & 0.13 & 0.05 & 0.18 & 0.33 & & \\
\hline & & 4390 & 5249 & 74 & 10 & 12.92 & 0.49 & 3.70 & 0.21 & 0.02 & 0.02 & 0.03 & 0.39 & 0.01 & 0.01 \\
\hline & & 1375 & 2149 & 153 & 21 & 8.21 & 0.97 & 7.63 & 0.56 & 0.05 & 0.03 & 0.07 & 0.14 & 0.12 & 0.01 \\
\hline 4 & Heptane (pool) & 2850 & 3334 & 269 & 34 & 0.83 & 1.86 & 11.12 & 1.22 & 1.63 & 1.16 & 1.26 & 2.85 & 0.87 & 0.02 \\
\hline & & 4090 & 5489 & 375 & 54 & 0.23 & 0.34 & 9.94 & 0.61 & 1.89 & 0.58 & 0.82 & 1.46 & 2.52 & 0.05 \\
\hline & & 1245 & 1799 & 140 & 18 & 2.30 & 0.78 & $\overline{10.94}$ & 0.44 & 0.15 & 0.09 & 0.92 & 2.72 & 0.29 & 0.01 \\
\hline 5 & Heptane (pool) & 2340 & 2969 & 221 & 29 & 1.56 & 1.91 & 10.37 & 1.14 & 0.87 & 0.69 & 1.13 & 1.54 & 2.80 & 0.07 \\
\hline & & 660 & 1539 & 74 & 11 & 8.64 & 0.76 & 5.66 & 0.34 & 0.02 & 0.03 & 0.04 & 0.27 & 0.01 & 0.01 \\
\hline & & 2515 & 4179 & 174 & 22 & 0.36 & 0.25 & 7.73 & 0.44 & 1.65 & 0.46 & 8.99 & 4.63 & & \\
\hline 6 & Natural Gas & 4425 & 4944 & 272 & 33 & 0.10 & 0.13 & 6.81 & 0.57 & 2.31 & 0.39 & 20.79 & 8.83 & 0.23 & 0.01 \\
\hline & & 5090 & 5724 & 417 & 50 & 0.04 & 0.04 & 6.34 & 0.41 & 2.45 & 0.18 & 29.89 & 8.65 & 0.18 & 0.01 \\
\hline & & 6090 & 6549 & 80 & 11 & 7.92 & 0.72 & 5.99 & 0.32 & 0.02 & 0.04 & 0.10 & 0.08 & & \\
\hline & & 285 & 679 & 97 & 12 & 11.13 & 0.62 & 4.71 & 0.31 & 0.10 & 0.03 & 0.01 & 0.01 & & \\
\hline & & 920 & 1204 & 424 & 51 & 0.13 & 0.10 & 5.97 & 0.33 & 2.94 & 0.20 & 12.47 & 0.95 & 0.20 & 0.01 \\
\hline 6.5 & Natural Gas & 1600 & 2329 & 273 & 33 & 0.51 & 0.15 & 6.80 & 0.14 & 2.41 & 0.13 & 5.90 & 0.51 & & \\
\hline & & 2540 & 2804 & 181 & 22 & 2.59 & 0.16 & 7.39 & 0.11 & 1.10 & 0.09 & 1.55 & 0.25 & & \\
\hline & & 2980 & 3259 & 85 & 11 & 12.29 & 0.64 & 4.02 & 0.29 & 0.03 & 0.03 & 0.05 & 0.02 & & \\
\hline & & 1200 & 1669 & 148 & 20 & 9.10 & 0.59 & 6.92 & 0.33 & 0.05 & 0.03 & 0.03 & 0.02 & 0.13 & 0.01 \\
\hline 7 & Heptane (pool) & 2105 & 2664 & 246 & 38 & 3.09 & 1.08 & 9.68 & 0.33 & 0.65 & 0.27 & 0.40 & 0.16 & 0.72 & 0.02 \\
\hline & & 3040 & 3709 & 341 & 43 & 0.71 & 0.36 & 9.45 & 0.37 & 1.97 & 0.39 & 0.64 & 0.20 & 2.06 & 0.04 \\
\hline 8 & Methanol (pool) & 1439 & 2009 & 17 & 3 & 19.15 & 0.27 & 1.01 & 0.10 & 0.00 & 0.02 & 0.00 & 0.01 & & \\
\hline 9 & Ethanol (pool) & 1300 & 2019 & 19 & 3 & 19.02 & 0.21 & 1.15 & 0.06 & 0.00 & 0.02 & 0.00 & 0.01 & & \\
\hline & & 1400 & 1884 & 49 & 9 & 16.46 & 0.62 & 3.08 & 0.43 & 0.20 & 0.10 & 0.17 & 0.03 & & \\
\hline & & 2805 & 3154 & 138 & 20 & 8.06 & 0.80 & 9.05 & 0.39 & 0.20 & 0.03 & 0.05 & 0.01 & 0.96 & 0.02 \\
\hline 10 & Toluene (pool) & 3600 & 4224 & 202 & 27 & 3.55 & 0.87 & 12.32 & 0.60 & 0.15 & 0.05 & 0.06 & 0.03 & 1.14 & 0.02 \\
\hline & & 4435 & 5044 & 295 & 43 & 1.21 & 0.55 & 13.43 & 0.39 & 0.52 & 0.13 & 0.03 & 0.02 & 2.37 & 0.05 \\
\hline & & 5120 & 5394 & 339 & 44 & 0.28 & 0.38 & 13.10 & 0.47 & 1.36 & 0.49 & 0.01 & 0.01 & & \\
\hline & & 550 & 1039 & 83 & 15 & 14.05 & 0.69 & 4.03 & 0.39 & 0.12 & 0.09 & 0.01 & 0.01 & & \\
\hline & & 1400 & 1714 & 144 & 18 & 8.07 & 0.86 & 7.42 & 0.40 & 0.20 & 0.15 & 0.08 & 0.08 & 0.01 & 0.01 \\
\hline 11 & Ethanol (spray) & 2175 & 2849 & 263 & 34 & 0.98 & 0.44 & 9.05 & 0.30 & 3.64 & 0.64 & 2.27 & 0.50 & 0.09 & 0.01 \\
\hline & & 2940 & 4200 & 335 & 51 & 0.05 & 0.08 & 6.86 & 0.28 & 7.60 & 0.47 & 7.39 & 0.67 & 0.10 & 0.01 \\
\hline & & 300 & 724 & 72 & 10 & 15.18 & 0.36 & 3.17 & 0.17 & 0.01 & 0.02 & 0.00 & 0.01 & & \\
\hline & & 1145 & 1609 & 143 & 19 & 7.70 & 0.96 & 7.01 & 0.38 & 0.40 & 0.23 & 0.01 & 0.01 & 0.00 & 0.01 \\
\hline 12 & Methanol (spray) & 1949 & 2669 & 240 & 30 & 1.11 & 0.69 & 7.68 & 0.57 & 4.83 & 1.39 & 0.09 & 0.03 & 0.00 & 0.01 \\
\hline & & 2760 & 3299 & 306 & 38 & 0.25 & 0.29 & 5.75 & 0.96 & 8.52 & 1.96 & 0.23 & 0.08 & 0.00 & 0.01 \\
\hline 13 & Polystyrene & 710 & 1344 & 15 & 3 & 19.22 & 0.25 & 1.24 & 0.11 & 0.07 & 0.02 & 0.07 & 0.01 & 0.15 & 0.01 \\
\hline 14 & Polystyrene & 870 & 1724 & 67 & 12 & 15.66 & 0.60 & 3.70 & 0.39 & 0.19 & 0.03 & 0.14 & 0.01 & 0.53 & 0.01 \\
\hline & & 280 & 759 & 88 & 16 & 13.32 & 0.55 & 4.47 & 0.31 & 0.01 & 0.02 & 0.01 & 0.01 & & \\
\hline & & 950 & 1259 & 160 & 19 & 7.65 & 0.48 & 7.69 & 0.28 & 0.08 & 0.03 & 0.06 & 0.04 & 0.21 & 0.01 \\
\hline & & 1475 & 1999 & 227 & 30 & 3.46 & 1.05 & 9.58 & 0.46 & 0.45 & 0.21 & 0.26 & 0.15 & 0.82 & 0.02 \\
\hline 15 & Heptane (spray) & 2200 & 2764 & 301 & 46 & 0.32 & 0.19 & 8.42 & 1.25 & 2.82 & 1.01 & 1.83 & 2.00 & 2.38 & 0.05 \\
\hline & & 2790 & 3169 & 377 & 58 & 0.02 & 0.08 & 7.00 & 1.08 & 3.96 & 0.80 & 2.91 & 1.35 & 4.58 & 0.09 \\
\hline & & 3390 & 3734 & 83 & 15 & 13.38 & 0.51 & 4.23 & 0.23 & 0.05 & 0.05 & 0.04 & 0.03 & & \\
\hline & & 545 & 649 & 358 & 42 & 0.14 & 0.10 & 10.32 & 0.54 & 3.13 & 0.39 & 0.05 & 0.03 & 7.17 & 0.14 \\
\hline 16 & Polystyrene & 715 & 769 & 309 & 35 & 0.26 & \begin{tabular}{|l|}
0.13 \\
\end{tabular} & 12.24 & 1.26 & 1.76 & 0.89 & 0.03 & 0.02 & 2.96 & 0.06 \\
\hline
\end{tabular}




\subsubsection{Gas Chromatography}

The results of the gas chromatography (GC) analysis are given in Table 17 below. All gas volume fraction values listed in this table and in the following figures are on a wet basis. The measurements listed in the table were multiplied by a factor of $10^{6}$. The GC was connected to the front probe gas sample line using the outlet of the bypass line on the total hydrocarbon analyzer. The front probe location is given in Table 2 and shown in Fig. 4.

The injection times were manually recorded relative to the fire ignition time. Because the turnaround time for the GC sampling was greater than $20 \mathrm{~min}$, a limited number of samples were acquired. For comparison with the GC results, the HRR, the total hydrocarbons (FID), and the carbon monoxide volume fraction were averaged over a $30 \mathrm{~s}$ window ending at the injection time. The total hydrocarbon volume fractions determined using the GC ("Total HC, from GC" in Table 17) were calculated for comparison with the total hydrocarbon analyzer results. This value was determined by summing each of the measured hydrocarbon volume fractions after converting to an equivalent methane basis. The results of this comparison are illustrated in Fig. 52.

For most of the GC samples acquired, the two methods agreed within experimental uncertainty. This confirms that the compounds occurring in significant amounts were correctly accounted for in the $\mathrm{GC}$ measurement. The most notable exception to this is the $\mathrm{GC}$ sample acquired during the natural gas test $\# 3$ at $\mathrm{t}=2140 \mathrm{~s}$, where the results differed by a factor of 5 for unknown reasons. For the polystyrene tests, the total hydrocarbons measurements from the GC were significantly lower than from the total $\mathrm{HC}$ analyzer. Since the GC method did not include compounds above $\mathrm{C}_{6}$, the presence of very large hydrocarbons could explain the differences, although this is an unlikely explanation. Future work will revisit this issue. The values in Table 17 that are in bold type are below the quantifiable detection limits of the method (the uncertainty was greater than the measured value), but were included to show that they were identified in trace amounts. The results of the uncertainty analysis of the GC measurements (described in Sec. 2.5.7) are show in Table 18. The values represent the combined expanded uncertainty with a coverage factor of 2 .

The GC results for the fire tests using natural gas showed, to a large degree, that the hydrocarbons measured at the sample location were simply unburned fuel. Figure 53 shows the composition of hydrocarbon species for a typical natural gas test. For the liquid and solid fuels included in this study, a large number of intermediate hydrocarbon species were quantified. In all cases, methane was the largest measured component of hydrocarbon species. Even though the GC measured species only as large as $\mathrm{C}_{6}$, the similarity between the total hydrocarbon results from the $\mathrm{GC}$ and the total hydrocarbon analyzer (see Fig. 52) provides evidence that there were no species of significant quantity missed by the GC analysis. These results imply that in the upper layer of these compartment fires methane was the most abundant hydrocarbon species, higher in concentration than the parent fuel in all cases. For example, Fig. 54 shows the GC measurements of the most abundant species (methane, ethyne plus ethene, and benzene) for several fire sizes, burning heptane as the fuel. Other species were below the GC detection limits (see blank spaces in Table 17). For the fires burning the two alcohol fuels, there is some uncertainty with regard to the total hydrocarbon and GC results, since the Nafion filter is known to absorb polar organic compounds such as alcohols. 
Table 17. Summary of GC sample results. Values in bold were identified as trace species. Blank spaces imply that the measurements were below the detection limits.

\begin{tabular}{|c|c|c|c|c|c|c|c|c|c|c|c|c|c|c|c|}
\hline $\begin{array}{l}\text { \# } \\
\stackrel{*}{*} \\
\stackrel{5}{*}\end{array}$ & $\underset{\Xi}{\Xi}$ & 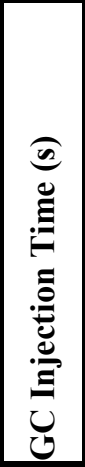 & 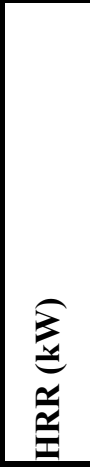 & 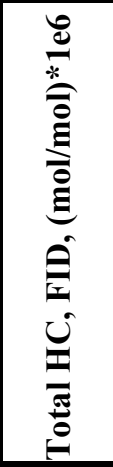 & 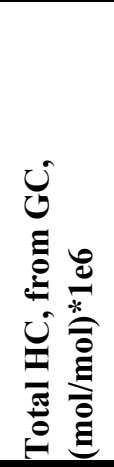 & 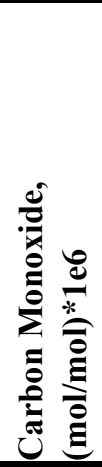 & 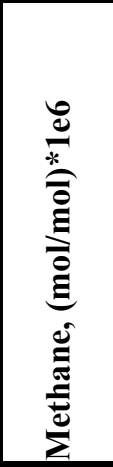 & 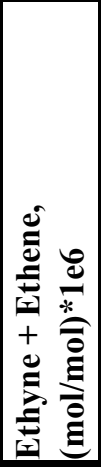 & 兽 & 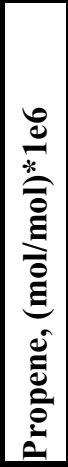 & 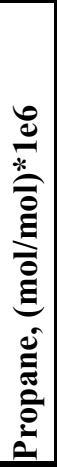 & 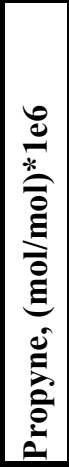 & 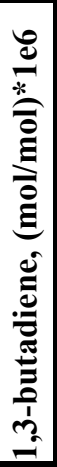 & 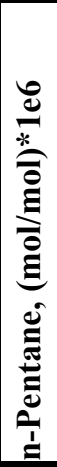 & 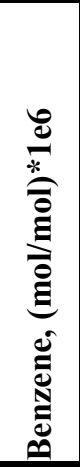 \\
\hline 1 & Natural Gas & 2940 & 184.3 & 11881 & 16590 & 7785 & 12058 & 397 & 1456 & & & & & & 138 \\
\hline \multirow{3}{*}{2} & \multirow{3}{*}{ Natural Gas } & 970 & 255.8 & & 21089 & 19687 & 16993 & 423 & 1164 & & & & & & 154 \\
\hline & & 3130 & 391.4 & & 51188 & 32685 & 42152 & 3330 & 58 & 37 & & 62 & 11 & & 320 \\
\hline & & 4330 & 175.7 & & 8642 & 9203 & 6685 & 734 & 29 & & & 12 & & & 66 \\
\hline \multirow{3}{*}{3} & \multirow{3}{*}{ Natural Gas } & 910 & 272.1 & 45673 & 30372 & 19356 & 23849 & 2432 & 83 & 19 & & 35 & 4 & & 219 \\
\hline & & 2140 & 405.5 & 116515 & 26511 & 32587 & 21920 & 1733 & 50 & 21 & & 32 & 6 & & 140 \\
\hline & & 3375 & 176.3 & 29487 & 11240 & 10055 & 8301 & 1121 & 35 & & & 18 & 8 & & 91 \\
\hline \multirow{2}{*}{6.5} & \multirow{2}{*}{ Natural Gas } & 1065 & 429.1 & 131001 & 137260 & 29794 & 134908 & 11770 & 905 & 216 & 51 & 365 & 64 & 10 & 752 \\
\hline & & 2310 & 272.5 & 60342 & 56684 & 24537 & 52668 & 6373 & 138 & 50 & & 184 & 20 & & 496 \\
\hline \multirow{3}{*}{7} & \multirow{3}{*}{ Heptane } & 1150 & 145.6 & 300 & 155 & 396 & -2 & 70 & & & & & & & 5 \\
\hline & & 2460 & 222.9 & 2967 & 2599 & 4363 & 793 & 756 & & & & 5 & 3 & & 100 \\
\hline & & 3675 & 341.5 & 5563 & 5064 & 20178 & 2944 & 1165 & & & & 6 & & & 89 \\
\hline \multirow{2}{*}{10} & \multirow{2}{*}{ Toluene } & 2840 & 131.5 & 580 & 469 & 2015 & 8 & 30 & & & & & & & 71 \\
\hline & & 4055 & 199.5 & 488 & 410 & 1257 & 53 & 34 & & & & & & & 53 \\
\hline \multirow{3}{*}{11} & \multirow{3}{*}{ Ethanol } & 1500 & 142.2 & 601 & 825 & 2054 & 270 & 252 & & & & & & & 9 \\
\hline & & 2740 & 268.5 & 20298 & 20618 & 33146 & 8332 & 5378 & 19 & 11 & & 48 & 5 & & 216 \\
\hline & & 3950 & 348.0 & 72784 & 80041 & 74807 & 33342 & 20725 & 156 & 76 & & 134 & 58 & 10 & 679 \\
\hline \multirow{2}{*}{12} & \multirow{2}{*}{ Methanol } & 2025 & 236.8 & 870 & 805 & 47196 & 706 & 50 & & & & & & & \\
\hline & & 3255 & 309.7 & 1923 & 2066 & 77652 & 1801 & 132 & & & & & & & \\
\hline 13 & Polystyrene & 1110 & 14.8 & 745 & 74 & 686 & -23 & 48 & & & & & & & \\
\hline 14 & Polystyrene & 1155 & 63.2 & 1351 & 748 & 1777 & -4 & 114 & & & & & 1 & & 86 \\
\hline \multirow{2}{*}{15} & \multirow{2}{*}{ Heptane } & 1565 & 228.1 & 4236 & 4021 & 7004 & 1744 & 995 & & & & 7 & & & 134 \\
\hline & & 3090 & 396.6 & 31937 & 26328 & 43786 & 13656 & 4954 & & 6 & & 43 & 12 & & 1044 \\
\hline 16 & Polystyrene & 620 & 355.4 & 502 & 309 & 32227 & 268 & 21 & & & & & & & \\
\hline
\end{tabular}

note: negative values listed in this table are a result of measurement uncertainty associated with the baseline drift correction of the quantification method and are not physically meaningful. 
Table 18. Summary of GC measurement uncertainty analysis results. Blank spaces imply that the measurements were below the detection limits.

\begin{tabular}{|c|c|c|c|c|c|c|c|c|c|c|c|}
\hline 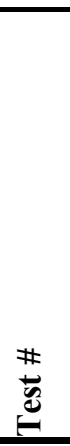 & $\begin{array}{l}\bar{\Phi} \\
\end{array}$ & 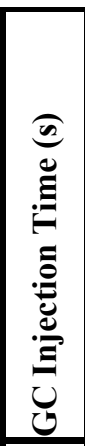 & 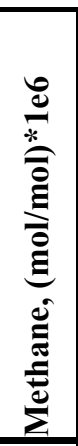 & 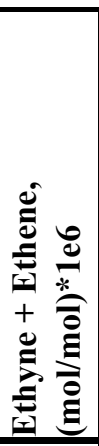 & 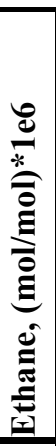 & 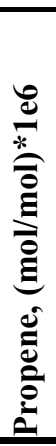 & 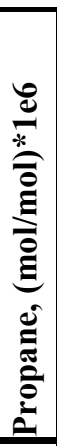 & 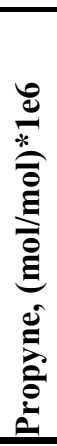 & 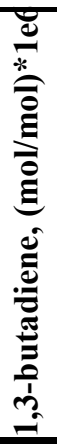 & 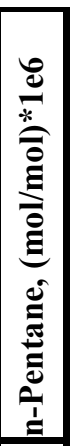 & 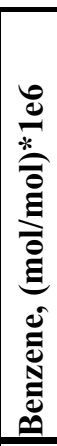 \\
\hline 1 & Natural Gas & 2940 & 123 & 16 & 64 & & & & & & 73 \\
\hline \multirow{3}{*}{2} & \multirow{3}{*}{ Natural Gas } & 970 & 152 & 16 & 57 & & & & & & 72 \\
\hline & & 3130 & 342 & 40 & 67 & 14 & & 14 & 36 & & 67 \\
\hline & & 4330 & 103 & 15 & 68 & & & 15 & & & 76 \\
\hline \multirow{3}{*}{3} & \multirow{3}{*}{ Natural Gas } & 910 & 199 & 28 & 66 & 15 & & 14 & 36 & & 70 \\
\hline & & 2140 & 185 & 20 & 67 & 15 & & 14 & 36 & & 73 \\
\hline & & 3375 & 108 & 15 & 67 & & & 15 & 36 & & 75 \\
\hline \multirow{2}{*}{6.5} & \multirow{2}{*}{ Natural Gas } & 1065 & 1114 & 162 & 53 & 13 & 65 & 12 & 35 & 75 & 61 \\
\hline & & 2310 & 427 & 83 & 64 & 14 & & 13 & 36 & & 63 \\
\hline \multirow{3}{*}{7} & \multirow{3}{*}{ Heptane } & 1150 & 104 & 18 & & & & & & & 78 \\
\hline & & 2460 & 102 & 14 & & & & 15 & 36 & & 74 \\
\hline & & 3675 & 100 & 15 & & & & 15 & & & 75 \\
\hline \multirow{2}{*}{10} & \multirow{2}{*}{ Toluene } & 2840 & 104 & 18 & & & & & & & 75 \\
\hline & & 4055 & 104 & 18 & & & & & & & 76 \\
\hline \multirow{3}{*}{11} & \multirow{3}{*}{ Ethanol } & 1500 & 103 & 17 & & & & & & & 78 \\
\hline & & 2740 & 108 & 69 & 68 & & 15 & 14 & 36 & & 70 \\
\hline & & 3950 & 271 & 293 & 64 & & 14 & 14 & 35 & 75 & 61 \\
\hline \multirow{2}{*}{12} & \multirow{2}{*}{ Methanol } & 2025 & 102 & 18 & & & & & & & \\
\hline & & 3255 & 100 & 18 & & & & & & & \\
\hline 13 & Polystyrene & 1110 & 104 & 18 & & & & & & & \\
\hline 14 & Polystyrene & 1155 & 104 & 18 & & & & & 36 & & 75 \\
\hline \multirow{2}{*}{15} & \multirow{2}{*}{ Heptane } & 1565 & 101 & 15 & & & & 15 & & & 73 \\
\hline & & 3090 & 132 & 63 & 68 & 15 & & 14 & 36 & & 62 \\
\hline 16 & Polystyrene & 620 & 103 & 18 & & & & & & & \\
\hline
\end{tabular}




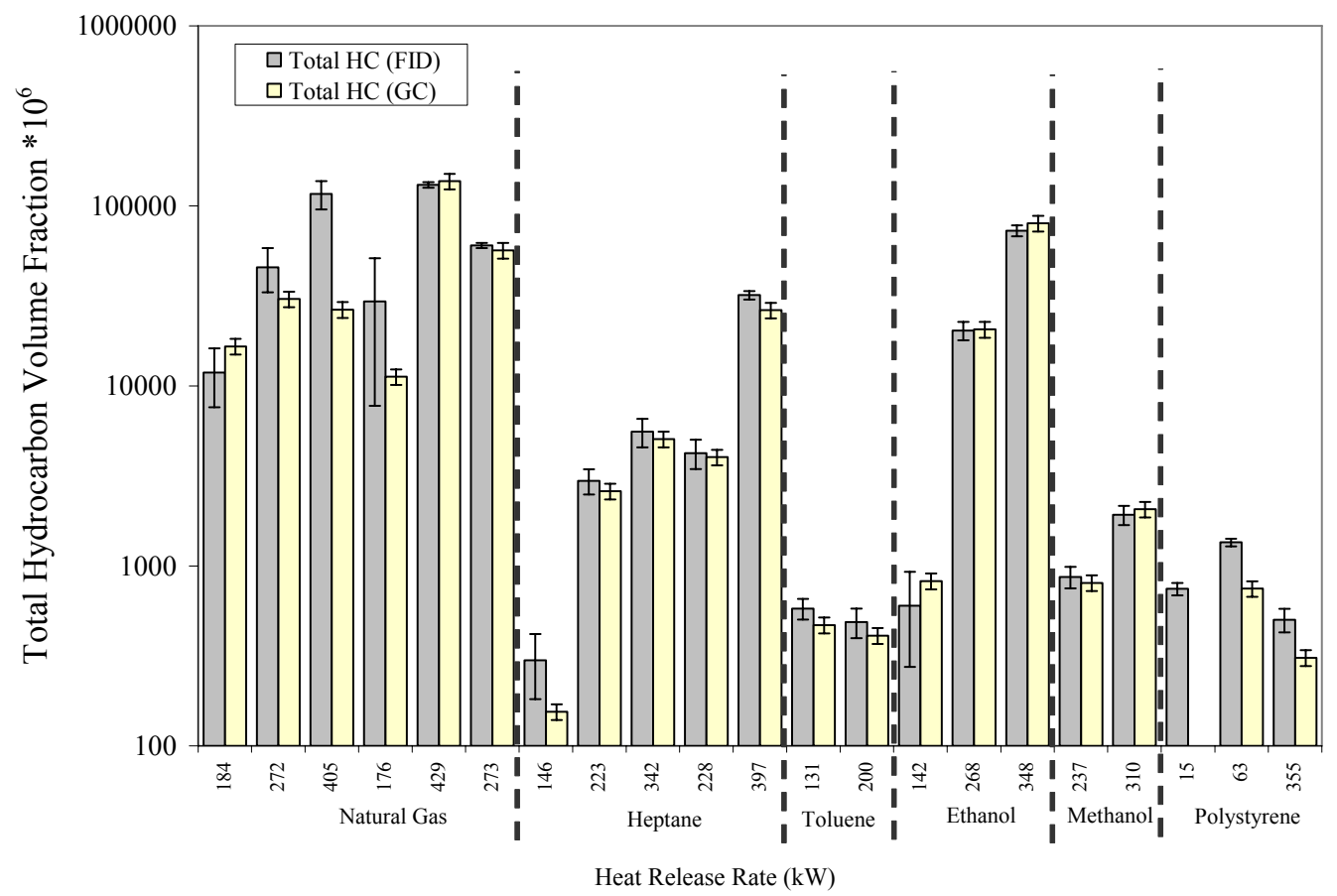

Figure 52. Comparison of total hydrocarbons measured using the GC and the total hydrocarbon analyzer (THC Front), both expressed on a $\mathrm{CH}_{4}$ basis.

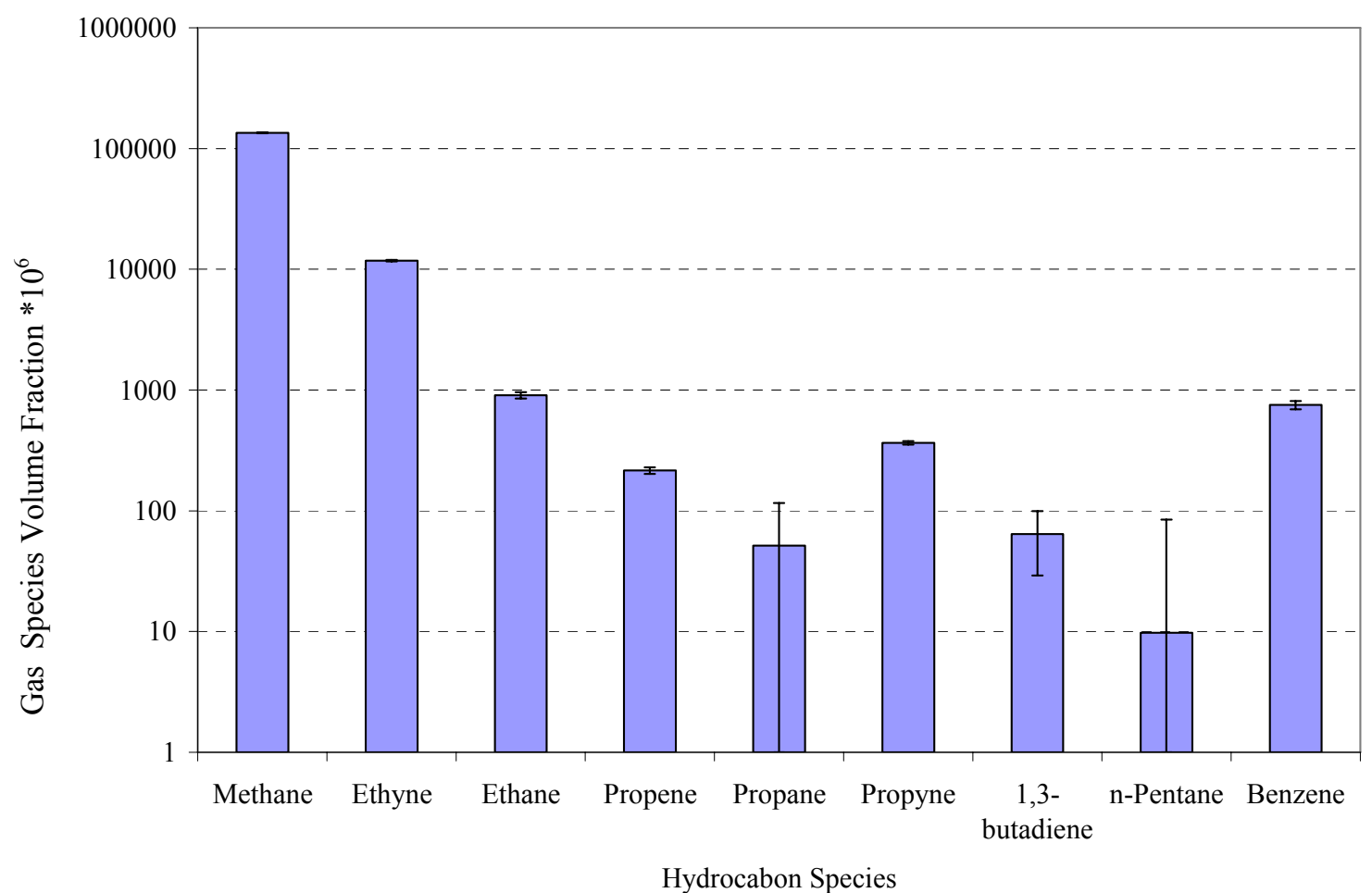

Figure 53. GC gas species composition measurements in the natural gas fire \#65, $\mathrm{HRR}=429 \mathrm{~kW}$. 


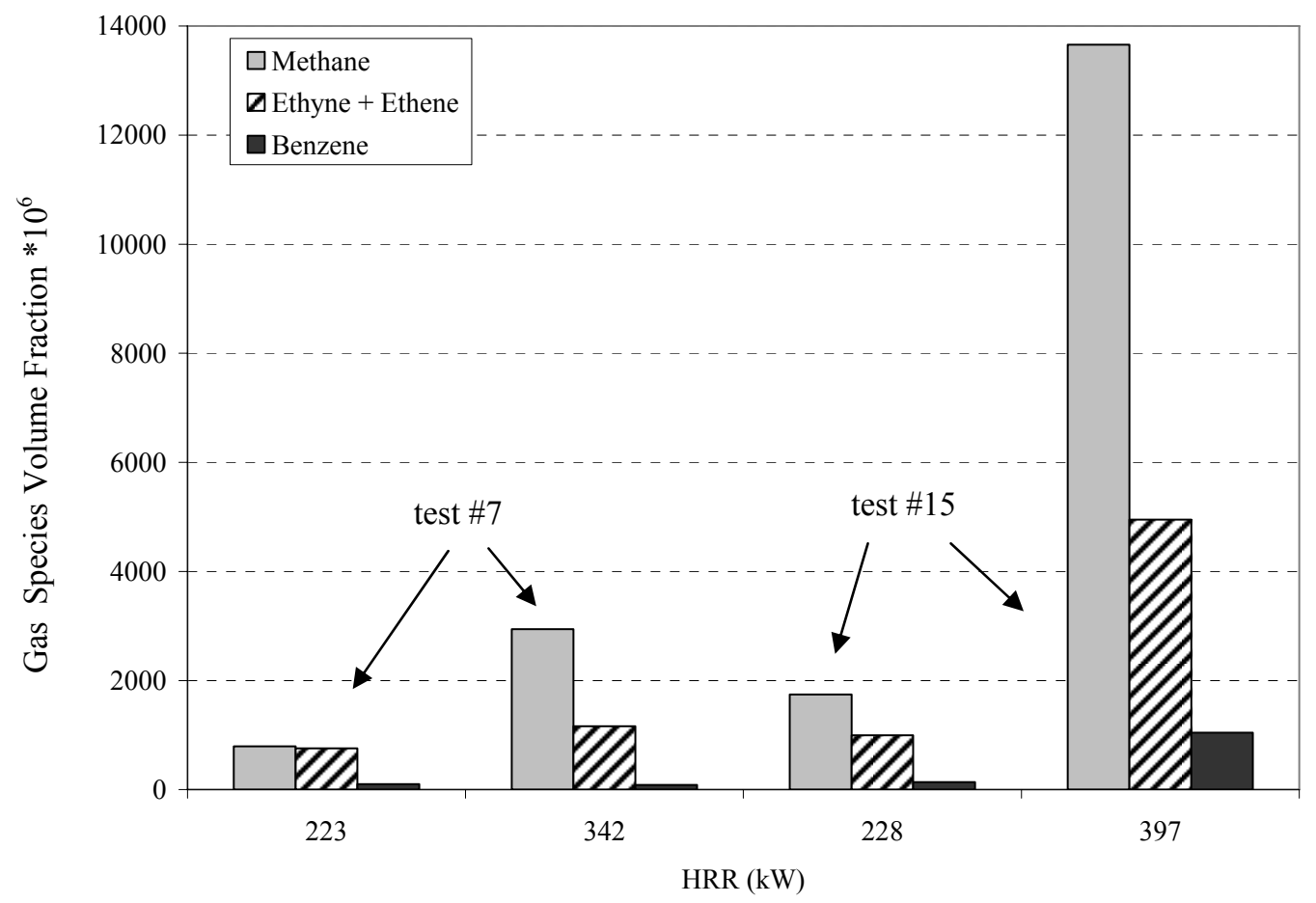

Figure 54 GC measurements of methane, ethyne plus ethene, and benzene in the heptane pool fire (test \#7) and heptane spray fire (test \#15), front gas sample probe.

\subsection{Optical Soot}

Figure 55 shows the time variation of the optical measurement of soot mass concentration for test \#6, a natural gas fire with a nominal heat release rate that varied from $75 \mathrm{~kW}$ to $400 \mathrm{~kW}$. Table 19 presents the average optically measured soot mass concentrations in the doorway for the four fire sizes considered in test \#6. The optical measurement averages were determined during the same time periods as the gravimetric measurements. Figure 56 shows the measured soot concentration varied from $47 \mathrm{mg} / \mathrm{m}^{3}$ to $380 \mathrm{mg} / \mathrm{m}^{3}$, following the trend in fire size.

Figure 57 shows the variation with time of the soot mass concentration for the $20 \mathrm{~cm}$ diameter polystyrene fire (test \#13). For the first 6 min after ignition, the soot mass concentration linearly increased as the fire size increased until a steady state was reached. At $500 \mathrm{~s}$ after ignition, the soot mass concentration was almost constant, with an average value of $(700 \pm 90) \mathrm{mg} / \mathrm{m}^{3}$ (between $600 \mathrm{~s}$ and $1200 \mathrm{~s}$ after ignition). As expected, the polystyrene fire was highly sooting, with the soot concentration significantly larger than that of natural gas.

Figure 58 shows the time variation of the soot mass concentration for the $40 \mathrm{~cm}$ diameter polystyrene fire (test \#14). The mass concentration of soot increased as the fire HRR increased. After ten minutes, the mass concentration of soot stopped increasing, and a near-steady value was reached. The soot mass concentration was approximately $(1500 \pm 400) \mathrm{mg} / \mathrm{m}^{3}$ (between $1115 \mathrm{~s}$ and $1230 \mathrm{~s}$ after ignition). As expected, the doorway of the $40 \mathrm{~cm}$ polystyrene pan fire (test \#14) had significantly higher soot concentrations than that of the natural gas fire (tests \#6) and the $22 \mathrm{~cm}$ polystyrene pan fire (test \#13). 
Table 19 also shows the gravimetric measurements made inside the compartment at the front and rear locations. Both sets of data show that as the fire became larger and the compartment became underventilated, higher soot mass concentrations were present. A comparison of the soot mass concentrations at the front and rear of the compartment with the doorway shows that the amount inside of the compartment was larger by a factor of 2 to 3 for all but the smallest fire sizes. As was true for the larger natural gas fires in test \#6, the observed soot mass concentrations inside of the compartment in tests $\# 13$ and $14\left(1140 \mathrm{mg} / \mathrm{m}^{3} \pm 140 \mathrm{mg} / \mathrm{m}^{3}\right.$ and $2700 \mathrm{mg} / \mathrm{m}^{3} \pm 140 \mathrm{mg} / \mathrm{m}^{3}$, respectively) were much (a factor of 1.6 to 1.8 ) larger than in the doorway $\left(700 \mathrm{mg} / \mathrm{m}^{3} \pm 90 \mathrm{mg} / \mathrm{m}^{3}\right.$ and $1500 \mathrm{mg} / \mathrm{m}^{3} \pm 400 \mathrm{mg} / \mathrm{m}^{3}$, respectively) during the same sampling periods in these tests. The larger concentrations within the compartment may be due to air entrainment in the doorway, leading to soot oxidation.

Table 19. Soot measurements during narrow doorway natural gas fire (test \#6).

\begin{tabular}{|c|c|c|c|}
\hline \multirow{2}{*}{$\begin{array}{c}\text { Gravimetric } \\
\text { Sampling } \\
\text { Location }\end{array}$} & \multirow{2}{*}{$\begin{array}{l}\text { HRR } \\
(\mathrm{kW})\end{array}$} & \multicolumn{2}{|c|}{$\operatorname{Soot}\left(\mathrm{mg} / \mathrm{m}^{3}\right)$} \\
\hline & & $\begin{array}{c}\text { Gravimetric } \\
\text { (Compartment) }\end{array}$ & $\begin{array}{c}\text { Optical } \\
\text { (Doorway) }\end{array}$ \\
\hline rear & \multirow{2}{*}{75} & $35 \pm 62 \%$ & \multirow{2}{*}{$47 \pm 13 \%$} \\
\hline front & & $31 \pm 62 \%$ & \\
\hline rear & \multirow{2}{*}{180} & $428 \pm 7 \%$ & \multirow{2}{*}{$147 \pm 17 \%$} \\
\hline front & & $390 \pm 7 \%$ & \\
\hline rear & \multirow{2}{*}{270} & $763 \pm 7 \%$ & \multirow{2}{*}{$270 \pm 18 \%$} \\
\hline front & & $702 \pm 7 \%$ & \\
\hline rear & \multirow{2}{*}{400} & $766 \pm 7 \%$ & \multirow{2}{*}{$380 \pm 17 \%$} \\
\hline front & & $582 \pm 7 \%$ & \\
\hline
\end{tabular}




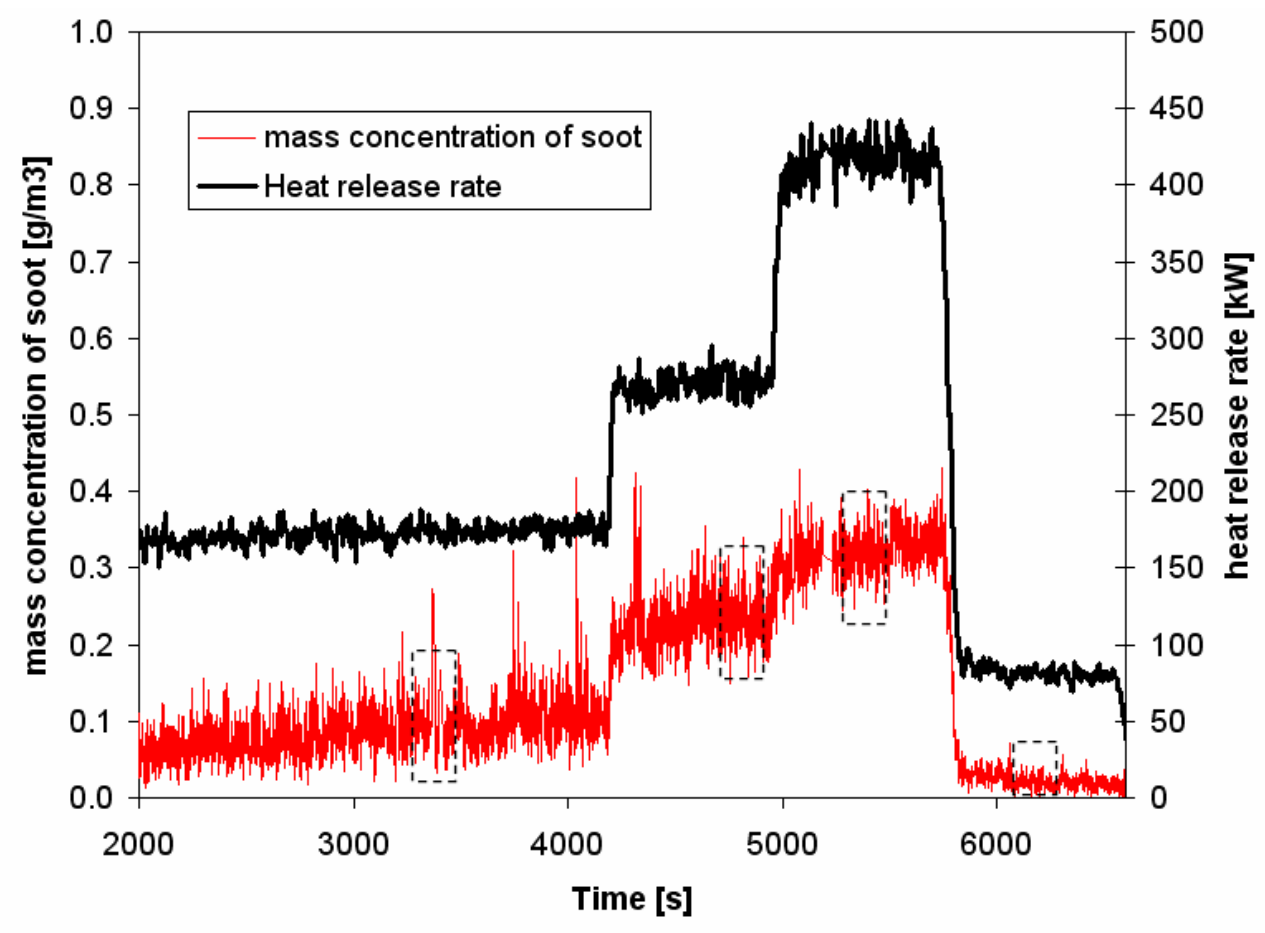

Figure 55. History of the soot mass concentration during natural gas fire (test \#6). Mean values of the soot mass concentration were determined over the same periods as the gravimetric measurements as indicated by the dotted boxes. The fire heat release rate is also shown.

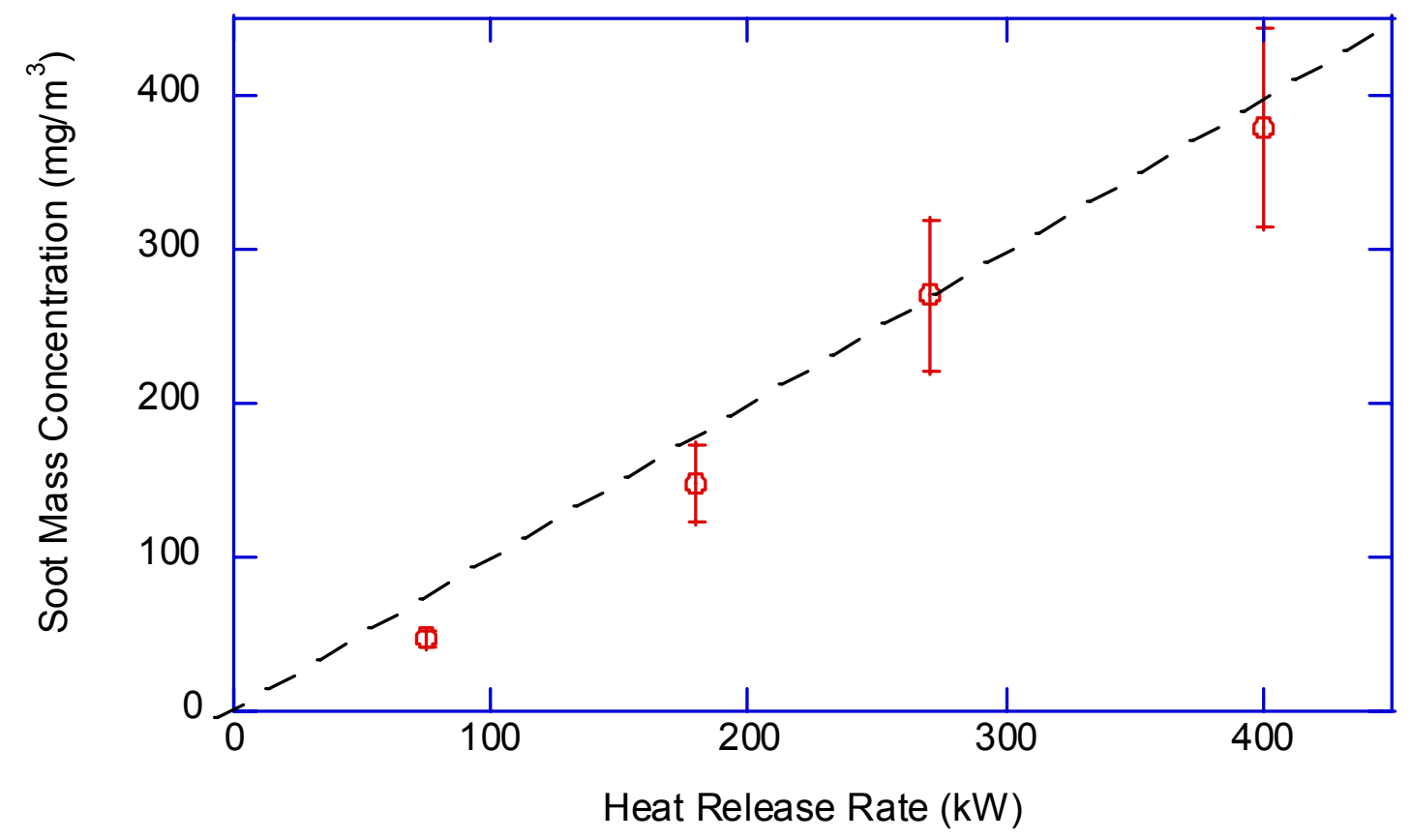

Figure 56. Soot mass concentration in the doorway during natural gas fire (test \#6) as a function of the HRR. 


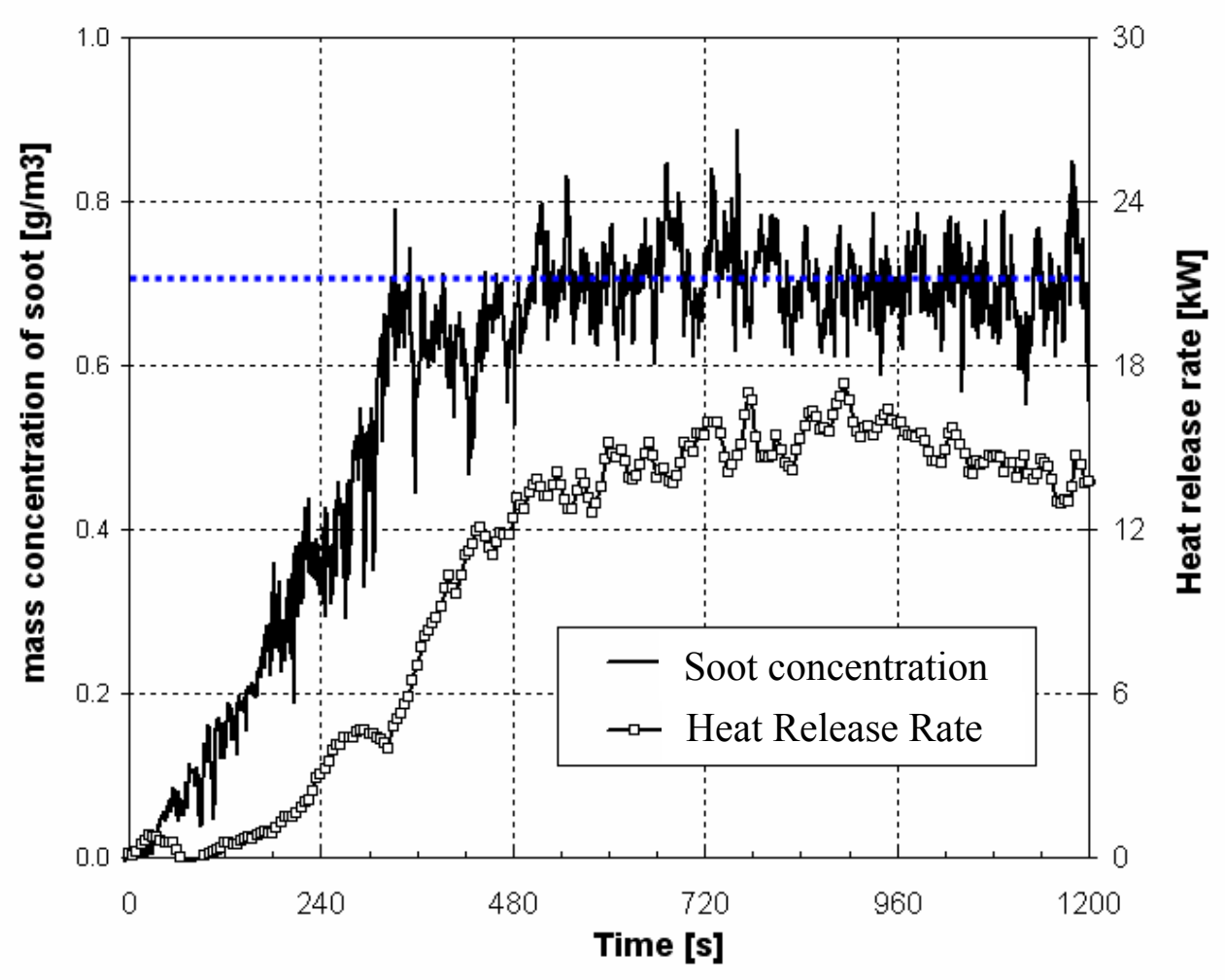

Figure 57. History of the particle mass fraction in the doorway during test \#13, polystyrene burning in the $20 \mathrm{~cm}$ diameter burner. The fire heat release rate is also shown.

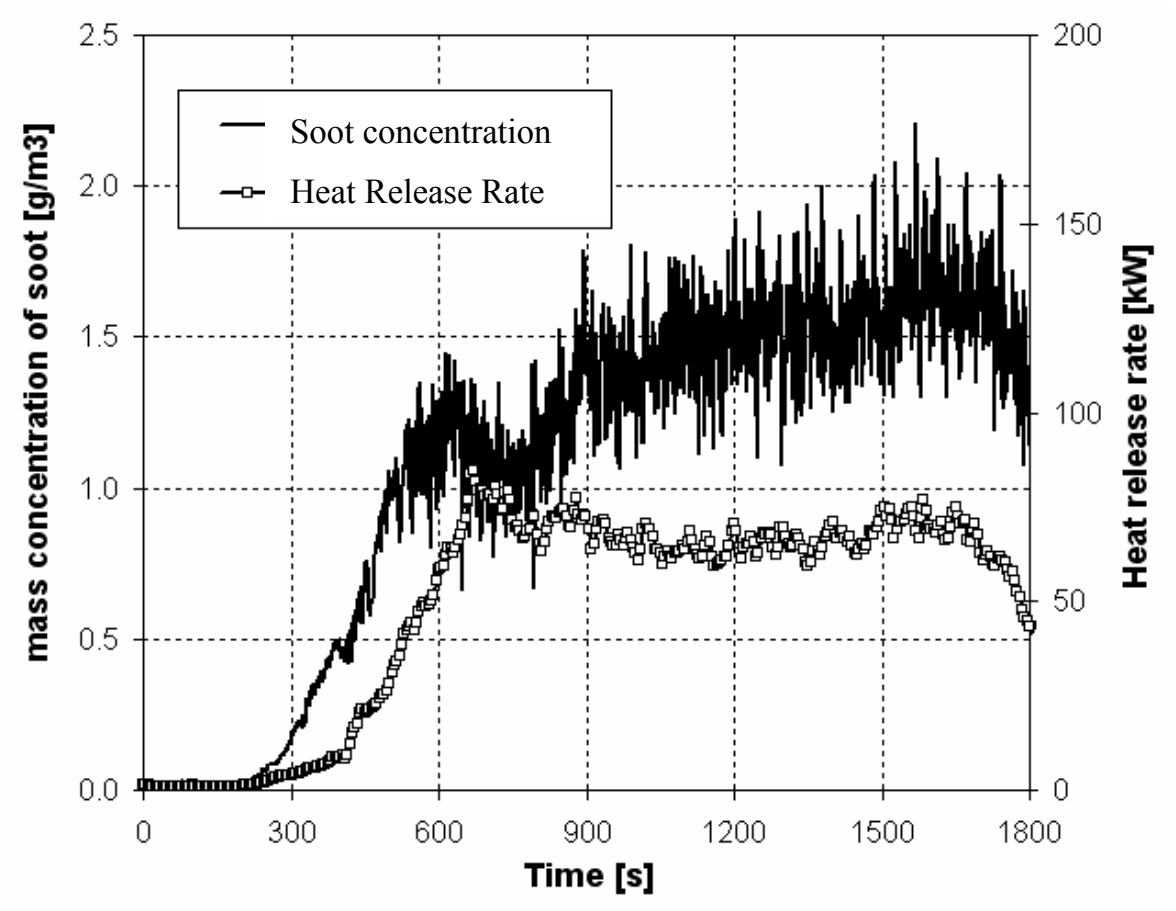

Figure 58. History of the soot mass concentration in the doorway during test \#14, polystyrene burning in a $40 \mathrm{~cm}$ diameter burner. The fire heat release rate is also shown. 


\subsection{Heat Fluxes}

The heat flux measurements to the floor of the enclosure help to characterize the thermal environment within the enclosure and the transient nature of the interior burning. In an enclosure with a distributed fuel source the heat flux to the floor can be used to predict the onset of flashover. The total heat flux measurement labels are described in Table 20 and their locations are listed in Table 2 of Sec. 2.4. Figure 59 shows the front and rear heat flux results for test \#15 with heptane fuel. The front and rear steady state average floor heat flux values for all of the tests are summarized in Table 12 and Table 13 and shown graphically in Fig. 60 and Fig. 61. In general the heat flux levels were significantly higher for the fuels with high soot yields. In addition, for the clean burning fuels the heat flux was fairly constant above heat release rates of $200 \mathrm{~kW}$. Heat flux levels in excess of $200 \mathrm{~kW} / \mathrm{m}^{2}$ were measured for heptane and toluene fires. Although these value are possible based on the measured temperature of the upper layer, they are well beyond the calibrated range of the transducer. Furthermore, all of the heat flux measurements are somewhat artificial since the gauge temperatures were held constant while the floor temperatures were observed to increase significantly. The actual net heat flux to the floor (that has been heated by the fire) would be significantly less than the measured heat flux to the water-cooled gauge.

Table 20. Description of interior total heat flux measurement labels.

\begin{tabular}{|l|l|}
\hline \multicolumn{1}{|c|}{ Measurement Label } & \multicolumn{1}{c|}{ Description } \\
\hline $12 \mathrm{HFR}(\mathrm{kW} / \mathrm{m} 2)$ & Total heat flux to floor at rear of enclosure \\
\hline $13 \mathrm{HFF}(\mathrm{kW} / \mathrm{m} 2)$ & Total heat flux to floor at front of enclosure \\
\hline
\end{tabular}

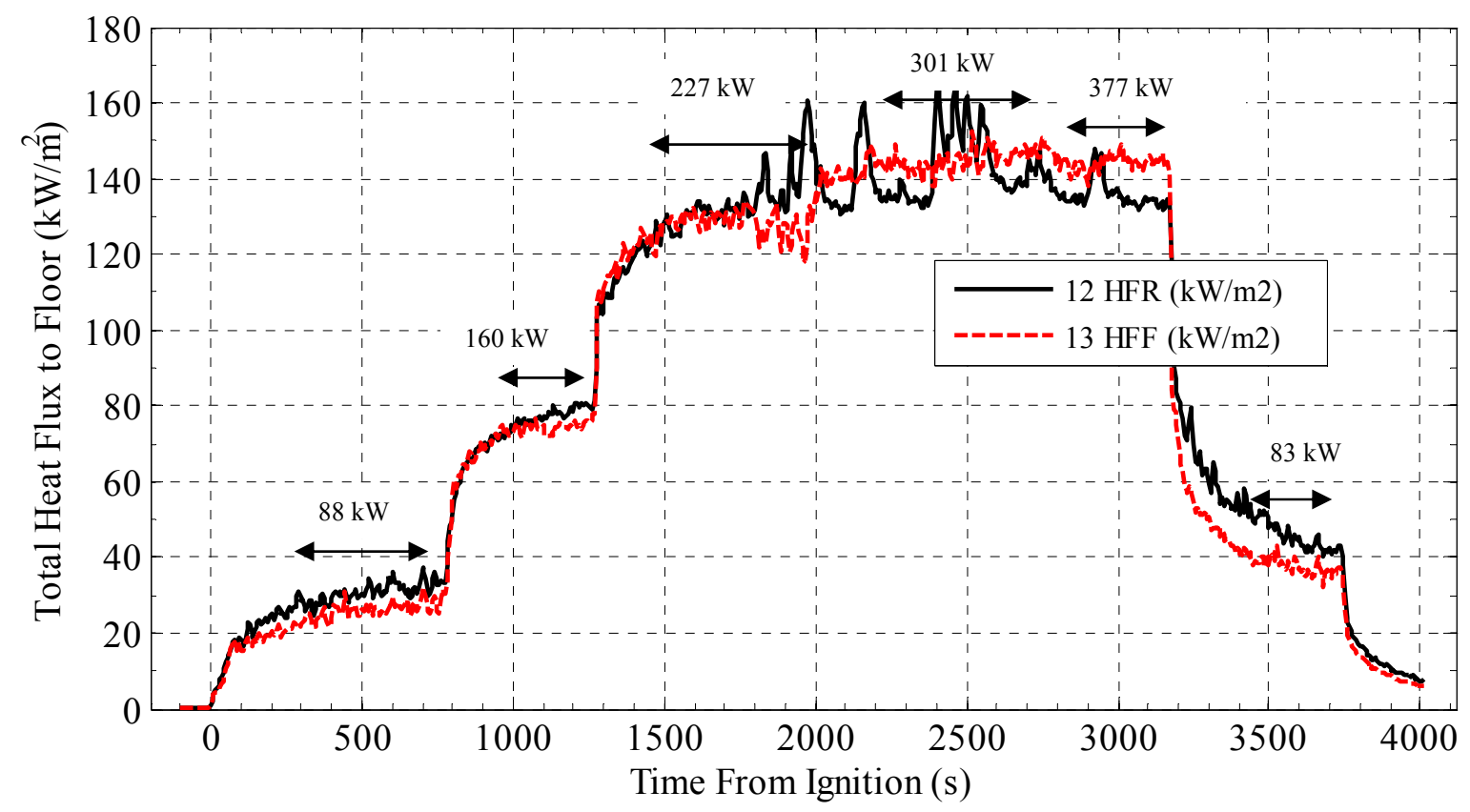

Figure 59. Total heat flux gauge measurements at two locations on the interior floor of the RSE for test \#15 using the spray burner with heptane fuel. 


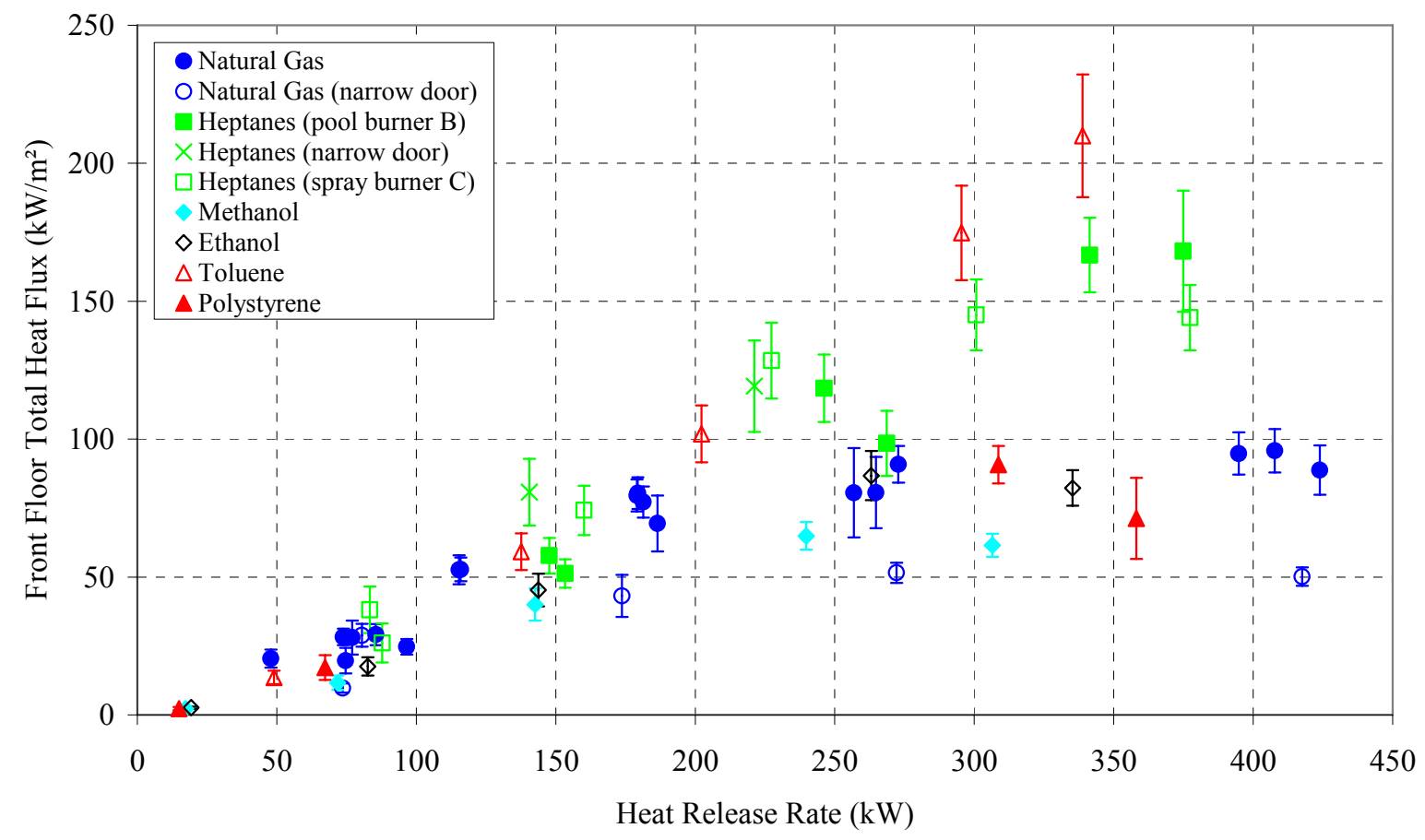

Figure 60 Steady state total heat flux measurement at front floor location. note: front heat flux gauge was partially blocked by debris for polystyrene test \#16.

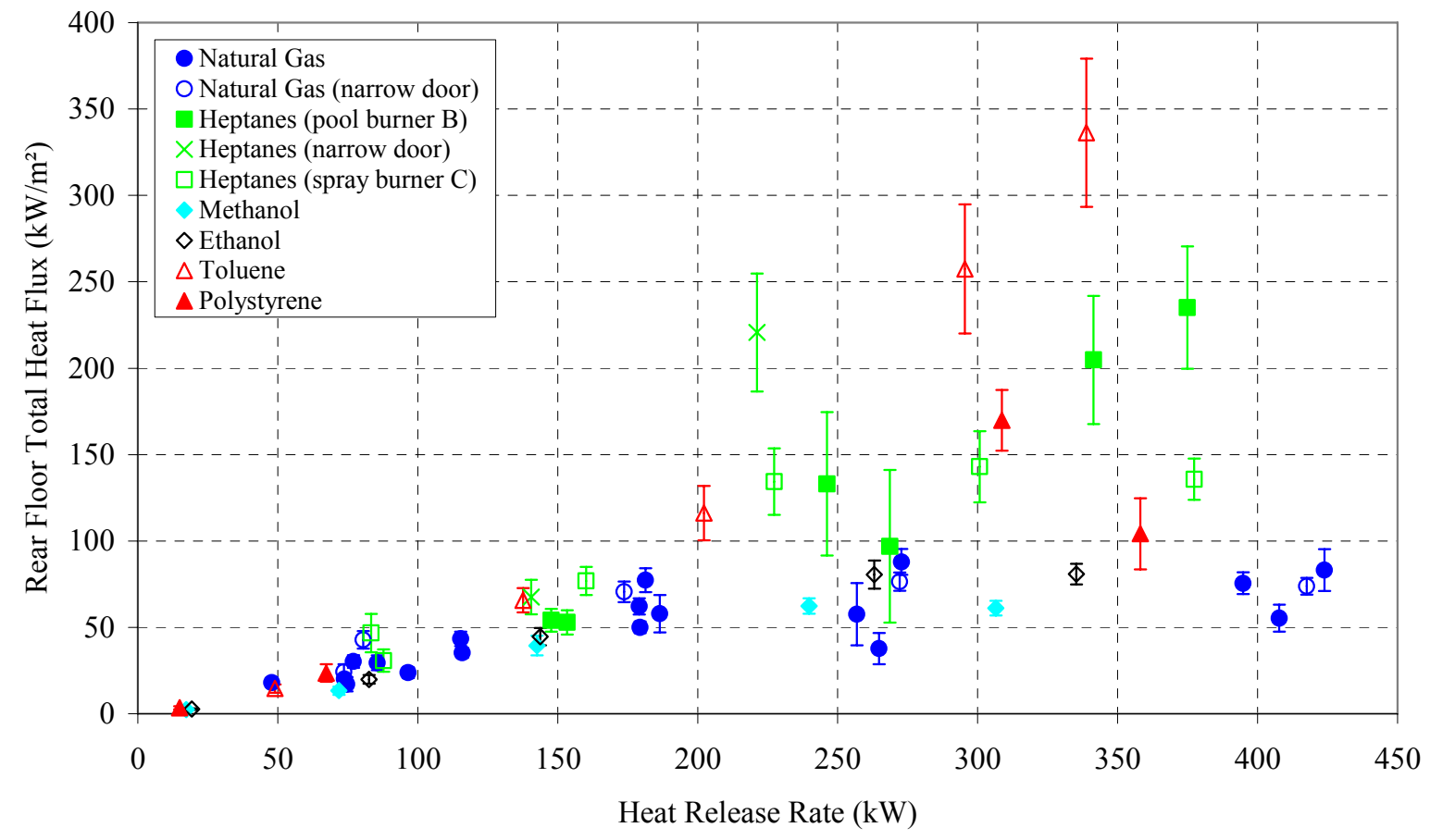

Figure 61. Steady state total heat flux measurement at rear floor location. 


\section{Discussion of Results}

\subsection{Fuel and Fire Size Comparisons}

Because of the precise metering used, natural gas was the most well controlled fuel used in this study. For these reasons, natural gas was used to observe the effects of changes in burner area, wall material construction, and doorway ventilation. Natural gas produced the highest quantities of total hydrocarbons in this test series. The transition to underventilated burning occurred at a lower HRR for natural gas than for other fuels in this study. Depletion of $\mathrm{O}_{2}$ and increased CO in the upper layer and flames exiting the doorway are indicators of underventilated burning. The reason for this transition occurring at a lower HRR for natural gas can be explained by differences in fuel stoichiometry (natural gas fuel requires $1 \%$ to $6 \%$ more oxygen for each unit of energy released than the condensed fuels studied) and differences in compartment fire structure.

Like natural gas, liquid heptane fuel was used to study the effects of different burners, door sizes and wall material configurations. Heptane $\left(\mathrm{C}_{7} \mathrm{H}_{16}\right)$ fuel (a blend of heptane isomers) was selected to represent a moderately sooting liquid alkane. The transition to underventilated burning occurred at a greater HRR for heptane than natural gas. Once the enclosure was underventilated, the $\mathrm{CO}$ and $\mathrm{THC}$ volume fractions were consistently lower for heptane than natural gas, but the soot concentrations were considerably higher. In general, the gas temperatures and floor heat fluxes were greater and more uniform from front to back for the heptane fires compared to natural gas fires.

Liquid toluene $\left(\mathrm{C}_{7} \mathrm{H}_{8}\right.$ - an aromatic hydrocarbon) was included to represent a fuel with a very high soot yield. The toluene fire produced very high temperatures, heat fluxes, and soot concentrations. Temperatures greater than $1500 \mathrm{~K}$ were measured, and some of the stainless steel wall pins and aspirated thermocouple probes were melted and destroyed during these tests. Test \#10 with toluene appeared to be slightly over-ventilated at the largest fire size, made evident by the presence of oxygen at the rear sample location. However, at the front sample location, oxygen was almost completely depleted and flames were observed outside the doorway. The toluene fires yielded relatively low THC and CO volume fractions compared to the other fuels. One feature that was unique to the toluene test was the formation of a large soot agglomerate $(\approx 10 \mathrm{~cm})$ on the water cooling inlet tube adjacent to the burner (see Fig. 62).

Liquid methanol $\left(\mathrm{CH}_{3} \mathrm{OH}\right)$ and liquid ethanol $\left(\mathrm{C}_{2} \mathrm{H}_{5} \mathrm{OH}\right)$ were chosen as clean burning fuels with high combustion efficiency, very low soot yields, and relatively low heats of combustion. The temperatures measured inside the enclosure during the tests with alcohol fuels were similar in magnitude to the tests with natural gas. As expected, there was no measurable amount of soot produced by the methanol fire and the ethanol fire produced soot concentrations similar to the natural gas fires. Extremely high volume fractions of $\mathrm{CO}$ were observed for the alcohol fuels after the fires reached ventilation-limited conditions. $\mathrm{CO}$ volume fractions greater than $8 \%$ were measured in the front of the enclosure for both of these fuels. 


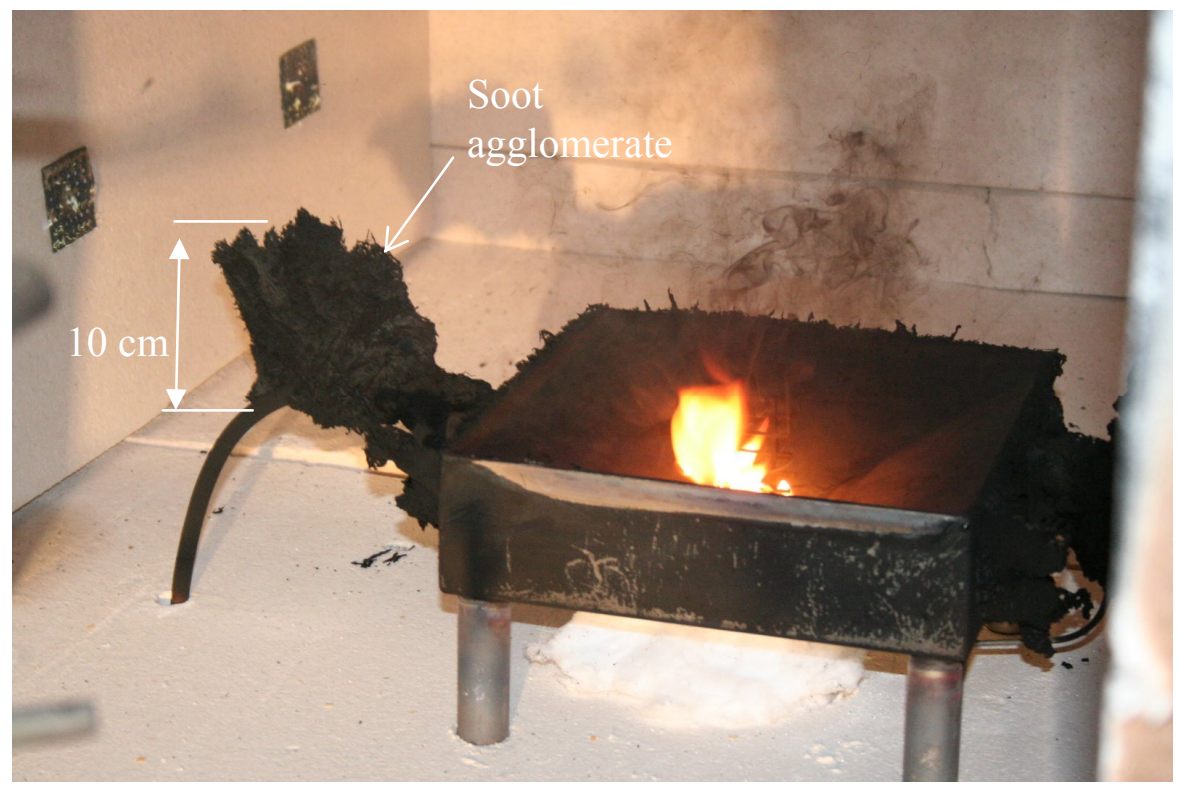

Figure 62. Photograph of soot agglomerate on the water inlet tube of the burner after toluene pool fire (test \#10).

Polystyrene pellets were burned in a $60 \mathrm{~cm}$ diameter pan (test \#16). This test differed from all of the other tests, as it involved a solid material in which natural feedback from the fire controlled the mass burning rate. A spray of heptane was ignited and was used to initiate burning of the polystyrene pellets.

The character of the measurements during Test 16 are highlighted in Fig. 63 which shows the measured $\mathrm{CO}$ volume fraction in the exhaust stack and at the front and rear of the upper layer in the compartment as a function of time. The data have been time shifted to account for transport delays in the exhaust and sample flows. The figure includes photographs at various times during the experiment which show the appearance of the fire as seen through the open doorway. At both sample locations within the compartment, the $\mathrm{CO}$ volume fractions increased as a function of time, reached a maximum, and then decreased to near-zero. In the stack, the $\mathrm{CO}$ volume fraction measurements show that the peak at $600 \mathrm{~s}$ which was observed inside of the compartment was also reflected in the stack. There were two additional peaks in the stack that were not as pronounced within the compartment.

The photo evidence provides some insight into the $\mathrm{CO}$ measurements in the compartment. At $380 \mathrm{~s}$ after ignition, the fire was rather small and flames were restricted to locations immediately above the pan. This began to change by $430 \mathrm{~s}$, when the glow of hot gases can be seen in the upper reaches of the compartment until at $600 \mathrm{~s}$, the entire doorway appeared to be filled with flame and smoke rolled out from the top of the doorway. While the doorway was still luminous at $825 \mathrm{~s}$, there were few flames rolling from the doorway. Instead, there was a general glow that was observed. This suddenly changed and by $866 \mathrm{~s}$, the fire had become rather small and the flames were observed to exist only immediately over the pan. At the same time, a steady flow of smoke was transported out from the top part of the compartment. 
Observation of the video record does not provide insight into the various extra peaks in the $\mathrm{CO}$ measurements in the stack. The reasons for the extra peaks are unclear, but the CO measurements are not an anomaly since the measured soot mass concentration in the exhaust stack tracks the CO peaks observed in the stack. Interestingly, the total hydrocarbon volume fraction has a large peak at $350 \mathrm{~s}$ that precedes the first large $\mathrm{CO}$ and soot peaks at $380 \mathrm{~s}$. The simultaneous occurrence of the $\mathrm{CO}$ and soot peaks is not unexpected. The timing of these concentration peaks are likely related to the compartment fire dynamics. Additional experiments are being planned to investigate this further.

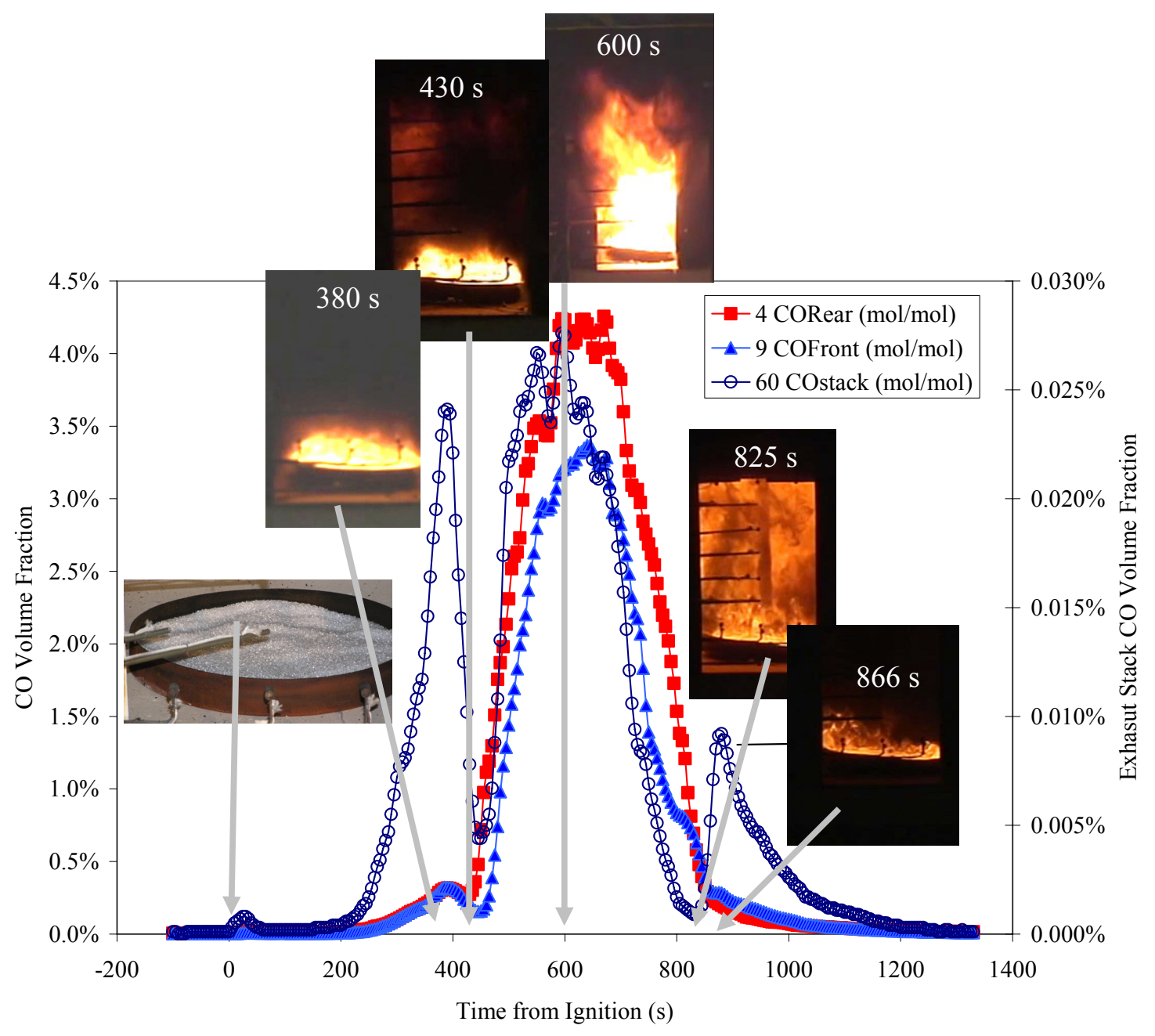

Figure 63 The $\mathrm{CO}$ volume fraction measured in the stack and at the front and rear of the compartment as a function of time during the burning of $6.0 \mathrm{~kg}$ of polystyrene pellets (Test 16). Photographs at various times show the fire appearance through the open doorway.

\subsection{Doorway Ventilation Comparisons}

Most of the tests conducted during this series used a $48 \mathrm{~cm}$ wide by $81 \mathrm{~cm}$ high door vent. Test \#5 (heptane) and test \#6 (natural gas) were performed using a $24 \mathrm{~cm}$ wide by $81 \mathrm{~cm}$ high door vent. The most obvious effect of the narrow doorway configuration was that the transition to ventilation limited burning occurred at a lower HRR than the full doorway configuration. This 
transition is evident by the reduced oxygen and increased carbon monoxide volume fractions as well as the appearance of flames outside the doorway. The magnitude and front to rear variation of the gas temperatures and species volume fractions were similar for the narrow (test \#6) and full door tests using natural gas. Test \#5 with heptane showed an interesting reversal of the internal structure of the fires. In contrast to the full door tests, the narrow doorway heptane test showed higher temperatures and $\mathrm{CO}$ volume fractions at the rear sample location. Because the narrow doorway testing was limited to only two fuels, further work is needed to generalize the effects of doorway geometry on the compartment fire structure.

\subsection{Construction Material Comparisons}

In Section 2.1.1, the two different construction materials, Marinite I and Kaowool M-board, were discussed along with the variation in the techniques used to line the enclosure with each material. There were concerns that the different composition of the materials as well as the possibility of leaks through additional seams (M-board) would cause differences in fire behavior. It was conceivable that the higher organic fraction of the Marinite could lead to additional heat release rate and gaseous products of combustion and pyrolysis. It was already known that Marinite experiences significant shrinkage when exposed to $1000{ }^{\circ} \mathrm{C}$ temperatures for tens of minutes due to baking off of organics and water.

In order to allay any concerns and reveal any noteworthy effects, experiments with the same fuels and HRRs were repeated for the enclosure lined with each of the two construction materials. For natural gas, the experiments with Marinite were test \#1, test \#2, and test \#3 while test \#6.5 used M-board. For heptane (using the same burner), the experiment with Marinite was test \#4 and that with M-board was test \#7.

One potential impact of construction material was the evolution of combustible organic components. Kaowool M-board has from $3 \%$ to $6 \%$ organic components. Taking into account the $0.23 \mathrm{~m}^{3}$ volume of the board used to construct the innermost lining, the reported density of $272 \mathrm{~kg} / \mathrm{m}^{3}$, a generic heat of combustion of $35 \mathrm{MJ} / \mathrm{kg}$, and estimating the organic component at $4.5 \%$, there was about $100 \mathrm{MJ}$ of energy available in the M-board layer. In order for this to impact the calorimetry, the organic material would have to vaporize and enter into the interior of the enclosure where it could be oxidized by enclosure air or by external entrained air as the doorway plume rose into the hood.

To see if the organic components of the M-board added to the HRR, the ratios of the calorimetrically measured HRRs to those estimated from metering of the fuel were calculated for test \#6.5 which was the first test conducted with M-board. This ratio was 1.27 for the initial fire size of $76 \mathrm{~kW}$. For the second fire size of $399 \mathrm{~kW}$, the ratio dropped to 1.06 . It's worth noting that $27 \%$ of $76 \mathrm{~kW}$ and $6 \%$ of $399 \mathrm{~kW}$ both result in $20 \mathrm{~kW}$ to $25 \mathrm{~kW}$ higher calorimeter HRRs than the HRRs calculated from the fuel. The third and fourth fire sizes, $269 \mathrm{~kW}$ and $179 \mathrm{~kW}$, respectively, resulted in ratios of about 1.01 . The last fire size of $74 \mathrm{~kW}$ had a ratio of 1.15 representing a calorimeter HRR $11 \mathrm{~kW}$ higher than the fuel metered HRR. Since the uncertainty on the $3 \mathrm{~m}$ calorimeter HRR is on the order of $15 \%$, these differences between calorimeter and fuel metered HRRs are significant, but not easily quantifiable. The conclusion from a review of this data is that there was likely additional heat release from evolved organic components of the construction material that may have been on the order of $20 \mathrm{~kW}$ to $25 \mathrm{~kW}$. The effect was more 
significant for early HRRs during the first "bake out" test and diminished by about half by the end of the test.

Another potential impact of the construction materials is on enclosure temperatures. Gas temperatures could be affected by additional HRR from bake-out of organics and by the thermal conductivity and emissivity of the wall material. Surface temperatures could also be affected by the insulating properties, heat capacities, and emissivities of the materials. Table 21 lists each material's properties including density, thermal conductivity, specific heat, and emissivity. The M-board had significantly lower thermal conductivity and density than Marinite I. Aspirated thermocouples were not deployed for long enough periods in test \#6.5 to be useful so only the gas temperatures from heptane fire tests \#4 and \#7 may be compared. Nominal upper layer gas temperatures in the rear were consistently about $25^{\circ} \mathrm{C}$ higher for the M-board than for the Marinite I. Nominal upper layer gas temperatures in the front varied from zero to about $80^{\circ} \mathrm{C}$ higher for the M-board. No measurable effect was observed on the lower layer gas temperatures. The observed correlation between upper layer gas temperature and wall material was relatively weak given the relatively large uncertainties in the temperature measurements.

Examination of the total heat flux to the floor for tests with natural gas and heptane showed the nominal heat fluxes for M-board construction were substantially higher $\left(20 \mathrm{~kW} / \mathrm{m}^{2}\right.$ to $30 \mathrm{~kW} / \mathrm{m}^{2}$ for HRRs greater than $200 \mathrm{~kW}$ ) than for Marinite I construction except for the front heat fluxes for the natural gas tests which were about the same. The larger heat fluxes and temperatures observed for the test using M-board are likely due to better insulating properties compared to Marinite I.

Finally, since mixing and reaction rates and products are influenced by the thermal environment, material differences have some potential to affect gas species measurements. However, an inspection of $\mathrm{O}_{2}, \mathrm{CO}, \mathrm{CO}_{2}$ did not reveal any consistent differences related to construction material.

While the impact of construction materials on the enclosure fire dynamics and measurements was of concern, the primary reasons for trying alternate materials were durability and ease of construction. Table 21 lists some differences between the two construction materials with regards to these and other issues. Of the many differences, the most important is that the Mboard survived longer than Marinite I with no cracking and a tolerable amount of warping when it was supported by a sufficient number of furnace pins, especially near the seams. The main differences in the materials are in shrinkage and water content.

Figure 64 through Fig. 69 photographically show some of the differences listed in the table. Figure 64 shows the Marinite I construction before test \#2 (natural gas) after experiencing just one fire with a max HRR of $180 \mathrm{~kW}$. The fit is still good, there is no apparent warping, and cracking is minimal with some appearing in the upper right corner. Figure 65 shows a similar view after test \#2, but significant cracking has occurred along with some sagging and warping. Figure 66 shows another view after test \#6 (natural gas) with even more severe cracking and sagging and a gap from a fallen piece of inner lining. 
Figure 67 through Fig. 69 show photographs of M-board construction. Figure 67 shows a closeup view of the furnace pins and tight seams before the enclosure was exposed to a fire.

Figure 68 shows a similar view after the first fire, test \#6.5. There is a small amount of warping at the wall seam. Figure 69 shows the whole enclosure interior with the back removed.

Extensive warping and sagging occurred, but not much cracking. The warping and sagging were remedied for the construction of the next enclosure lining by increasing the number of furnace pins, especially near the seams. Figure 70 depicts an aspirated thermocouple probe and furnace pins that have been highly degraded by extremely high heat fluxes and temperatures. The pins still held, but were extremely fragile and easily broken in this state.

Table 21. Comparison of thermal, physical and construction properties of wall lining materials.

\begin{tabular}{|c|c|c|}
\hline Propery & Marinite I & Kaowool M-board \\
\hline Sheet size & $1.2 \mathrm{~m} \times 2.4 \mathrm{~m}(4 \mathrm{ft} \times 8 \mathrm{ft})$ & $0.9 \mathrm{~m} \times 1.2 \mathrm{~m}(3 \mathrm{ft} \times 4 \mathrm{ft})$ \\
\hline $\begin{array}{l}\text { Number of } \\
\text { internal seams }\end{array}$ & 12 & 18 \\
\hline Fastener type & Screws, washers & Furnace pins \\
\hline Fastener durability & Survive well & Survive with some warping \\
\hline Cracking & $\begin{array}{l}\text { Some after first test, noticeable } \\
\text { increases with each test }\end{array}$ & No cracking \\
\hline Warping & $\begin{array}{l}\text { Increases with each test up to } \\
\text { sagging of several } \mathrm{cm}\end{array}$ & $\begin{array}{l}\text { Was significant near seams, not } \\
\text { significant with additional fasteners }\end{array}$ \\
\hline Fragility & $\begin{array}{l}\text { Still stiff and strong after multiple } \\
\text { tests although less securely attached } \\
\text { and susceptible to falling loose }\end{array}$ & $\begin{array}{l}\text { Fairly soft and fragile even when } \\
\text { new, should not be handled after } \\
\text { exposed to fires }\end{array}$ \\
\hline $\begin{array}{l}\text { Shrinkage@ } \\
982{ }^{\circ} \mathrm{C}\end{array}$ & $13.2 \%$ & $2.2 \%$ \\
\hline $\begin{array}{l}\text { Thermal } \\
\text { Conductivity, } \mathrm{k}\end{array}$ & $\begin{array}{l}0.11 \mathrm{~W} / \mathrm{m} \cdot \mathrm{K} \text { to } 0.13 \mathrm{~W} / \mathrm{m} \cdot \mathrm{K}\left(24^{\circ} \mathrm{C}\right. \\
\left.\text { to } 538^{\circ} \mathrm{C}\right)\end{array}$ & $\begin{array}{l}0.06 \mathrm{~W} / \mathrm{m} \cdot \mathrm{K} \text { to } 0.22 \mathrm{~W} / \mathrm{m} \cdot \mathrm{K} \\
\left(0.20 \mathrm{~W} / \mathrm{m} \cdot \mathrm{K} \text { at } 1000^{\circ} \mathrm{C}\right)\end{array}$ \\
\hline Density, $\rho$ & $737 \mathrm{~kg} / \mathrm{m}^{3}$ & $272 \mathrm{~kg} / \mathrm{m}^{3}$ \\
\hline Specific Heat, $c_{p}$ & $\begin{array}{l}1172 \mathrm{~J} / \mathrm{kg} \cdot \mathrm{K} \text { to } 1424 \mathrm{~J} / \mathrm{kg} \cdot \mathrm{K}\left(93^{\circ} \mathrm{C} \text { to }\right. \\
\left.425^{\circ} \mathrm{C}\right)\end{array}$ & Not specified \\
\hline Emissivity, $\varepsilon$ & $0.74 \pm 0.4$ & 0.95 \\
\hline Organic Content & $4 \%$ to $8 \%$ & $3 \%$ to $6 \%$ \\
\hline Water Content & $3 \%$ of dry weight & $<0.5 \%$ \\
\hline Ease of Cutting & $\begin{array}{l}\text { Slow, requires saw, produces a lot of } \\
\text { dust }\end{array}$ & Can be cut with a utility knife. \\
\hline
\end{tabular}




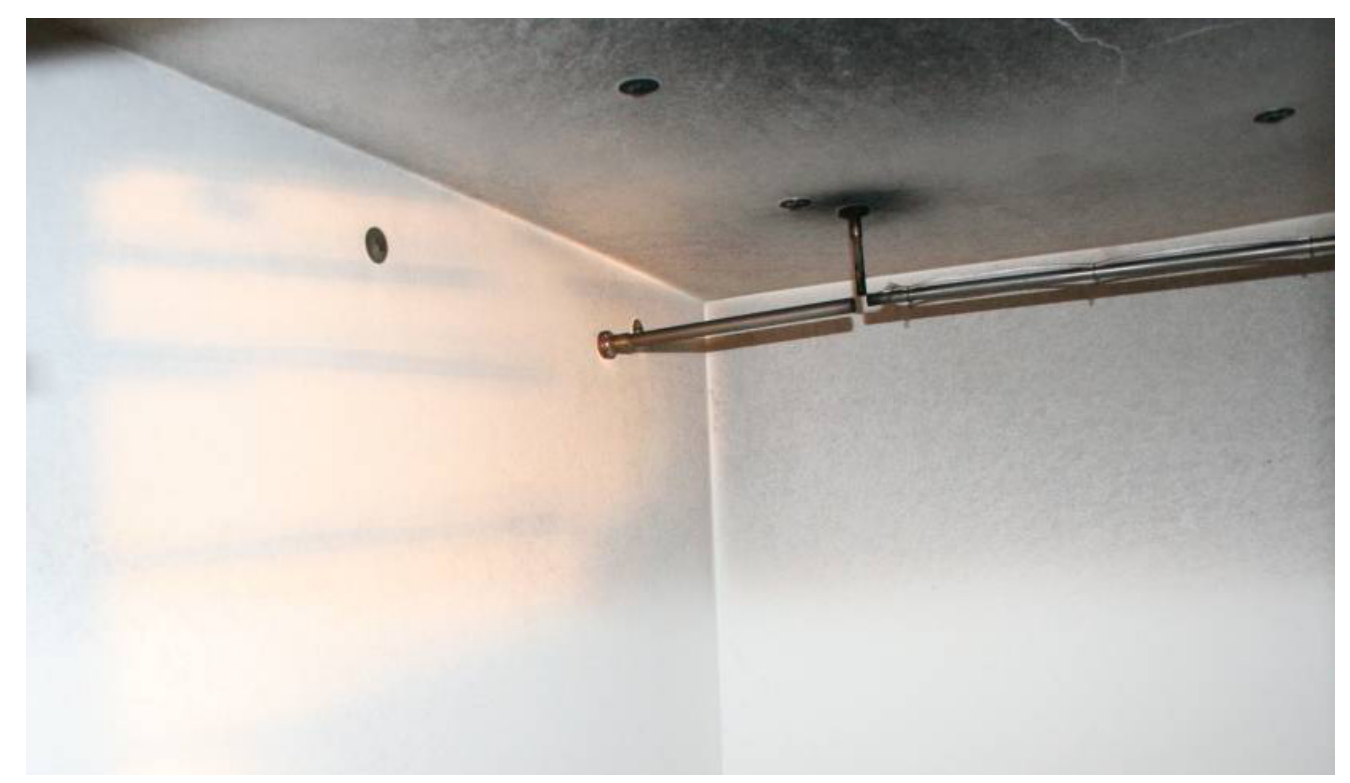

Figure 64. Photo of rear gas sample location and Marinite I construction before test $\# 2$.

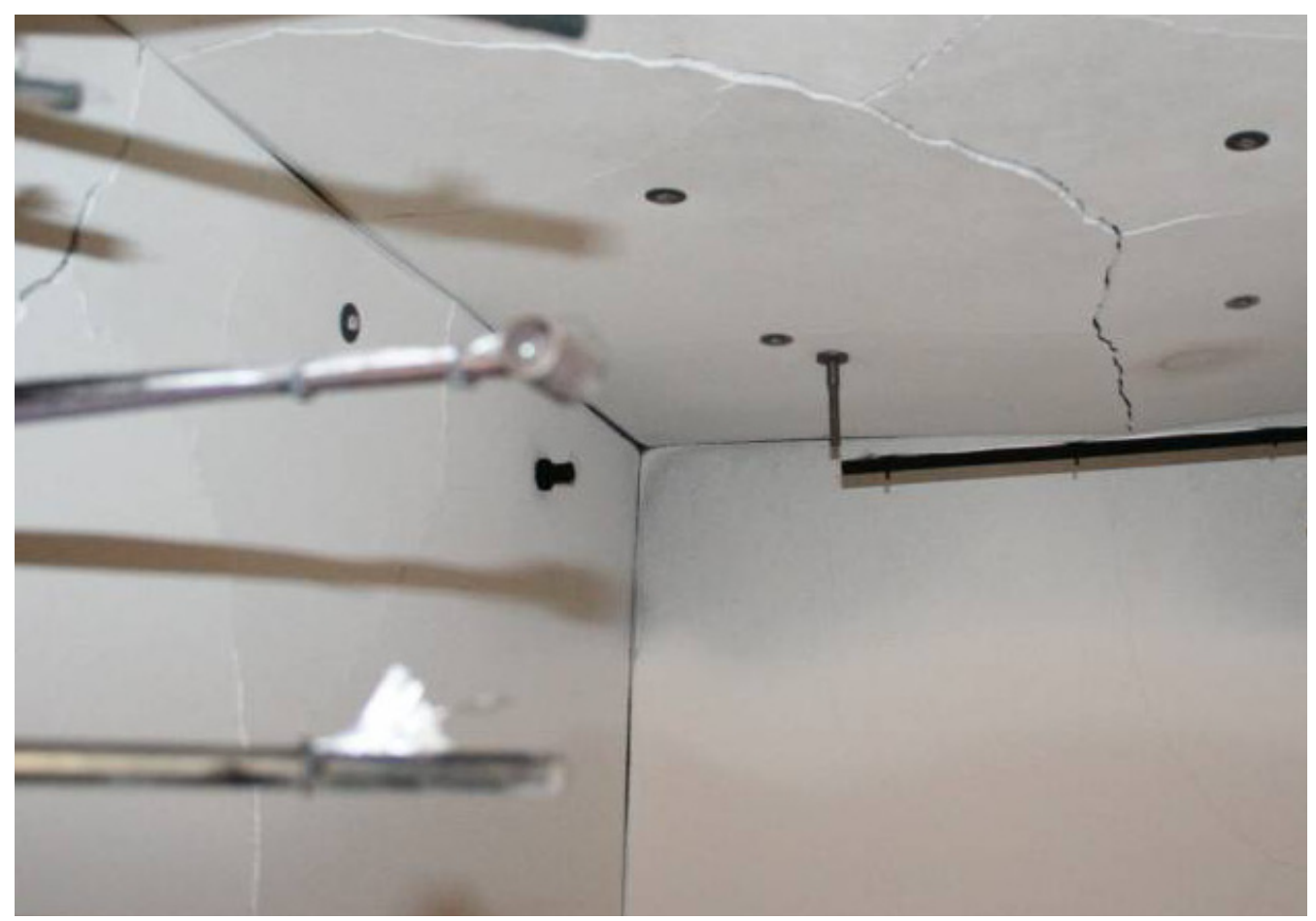

Figure 65. Photo of rear gas sample location and Marinite I construction after test $\# 2$ with natural gas. 


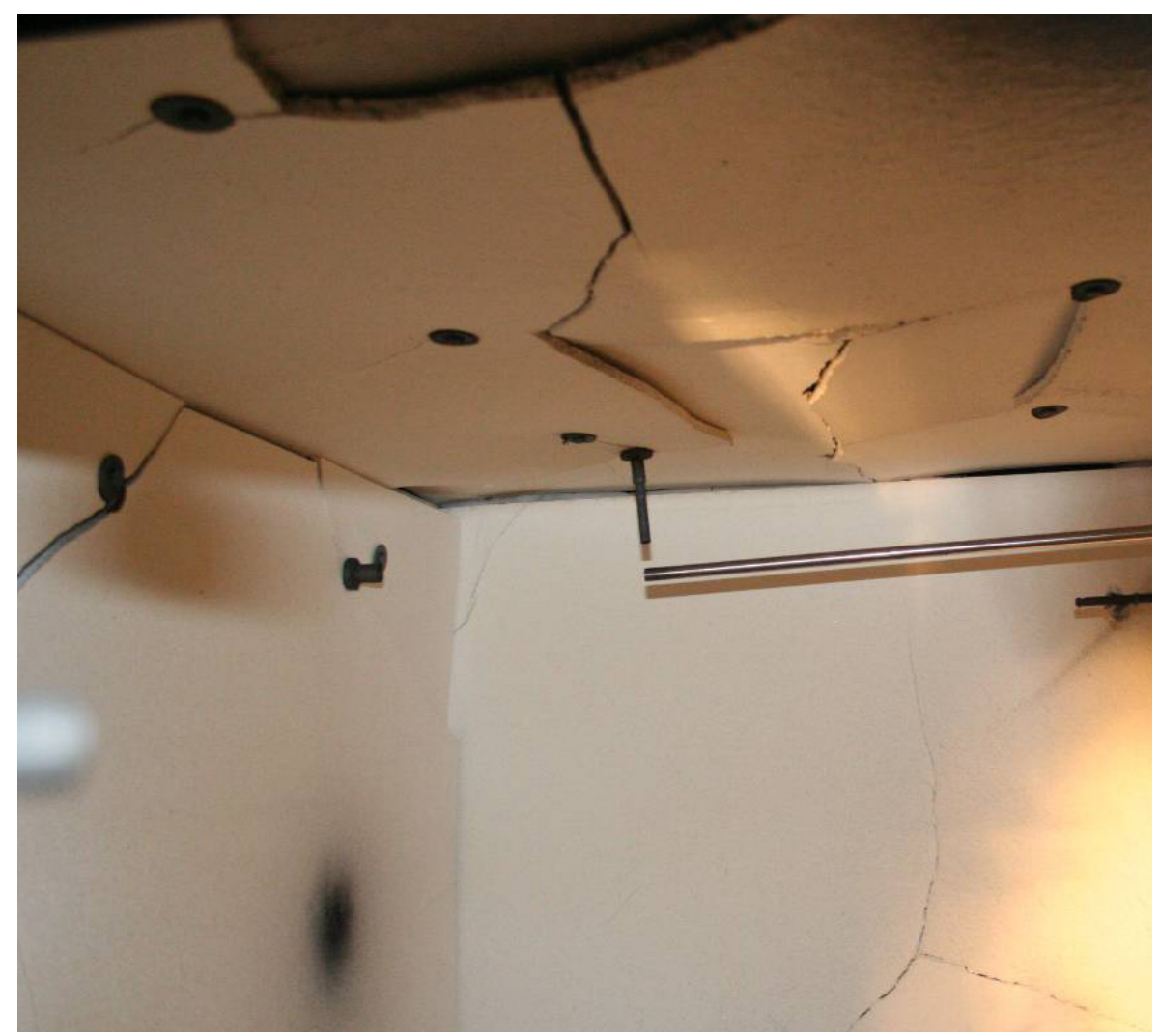

Figure 66. Photo inside enclosure after test \#6 showing Marinite I condition. Large chunks of ceiling fell to the floor during this test.

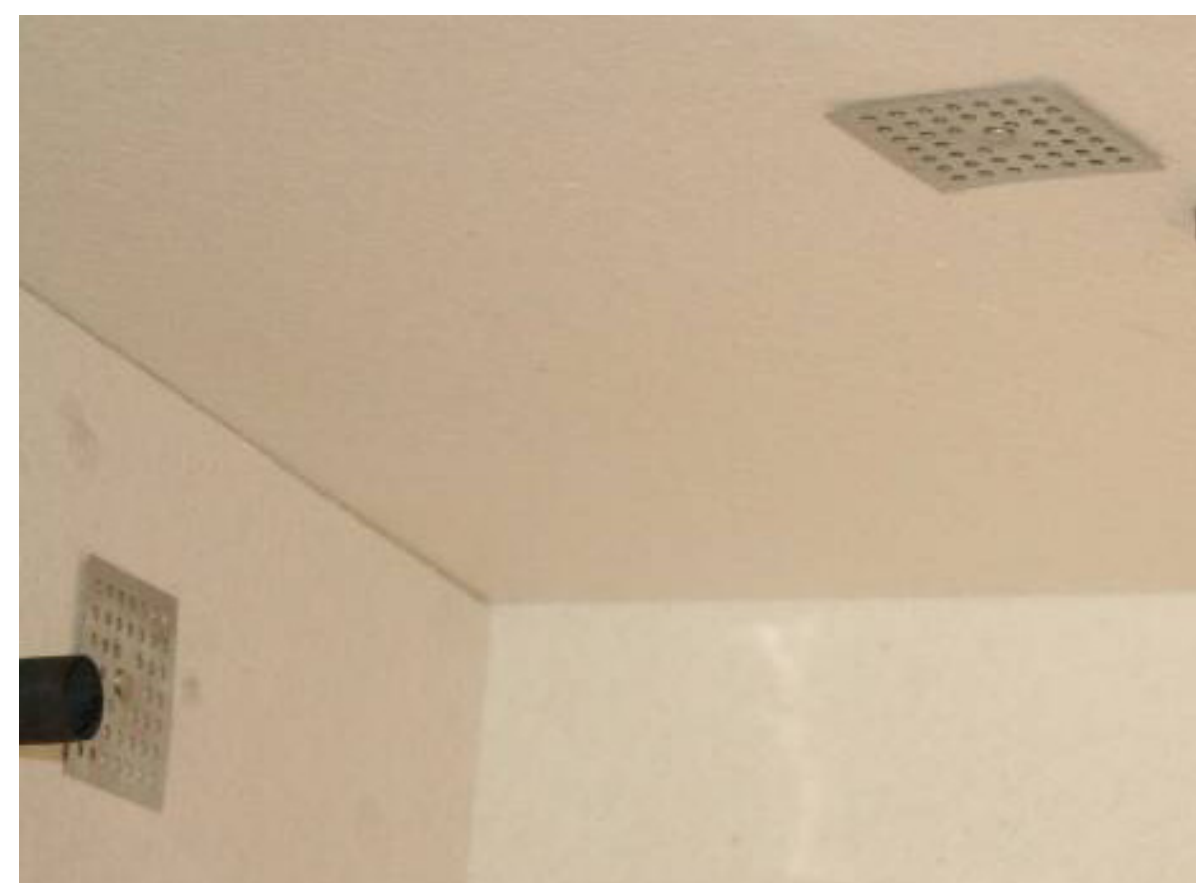

Figure 67. Photo of rear gas sample location showing Kaowool M-board and furnace pin construction prior to test \#6.5. 


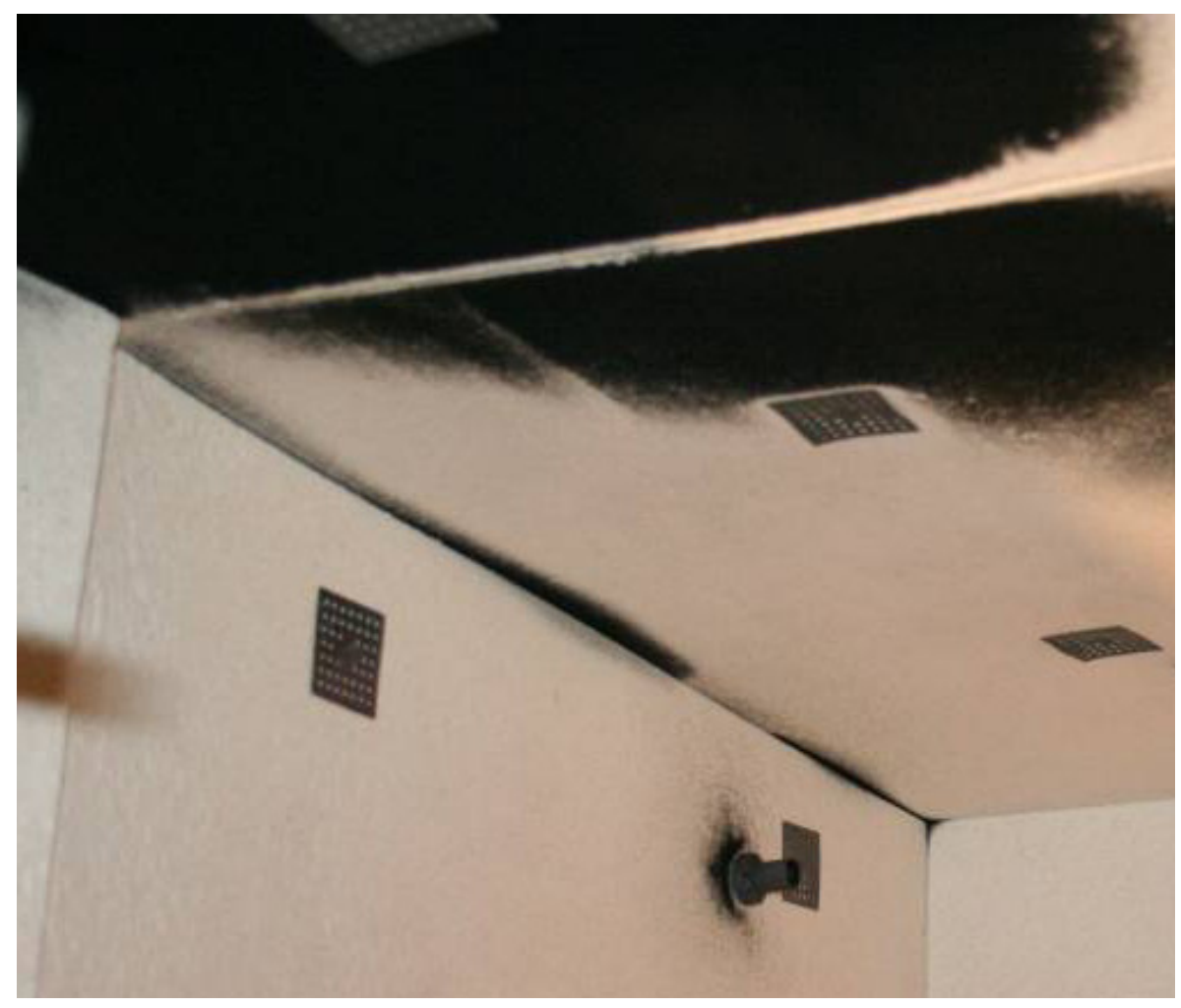

Figure 68. Photo of rear gas sample location after test \#6.5 with natural gas using Kaowool MBoard.

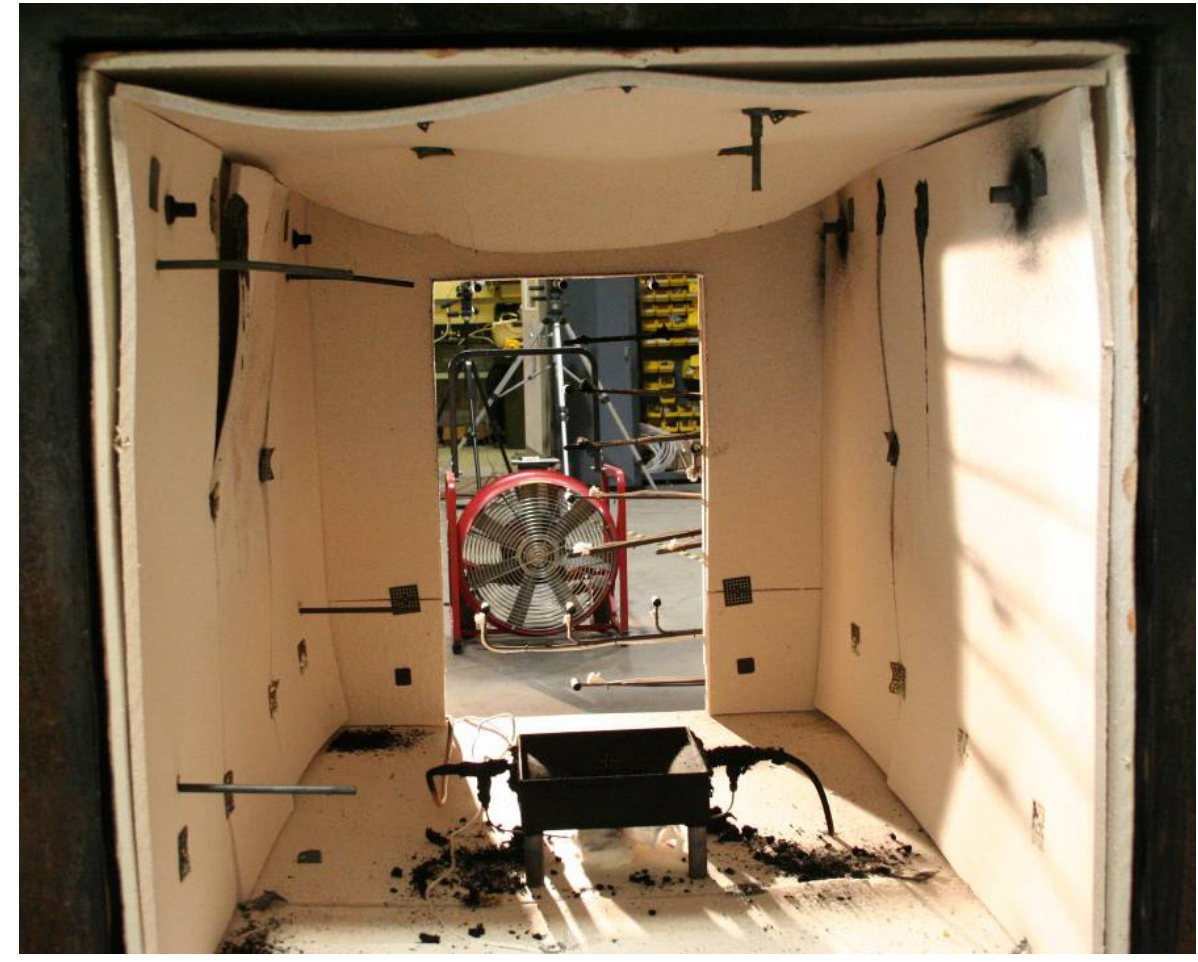

Figure 69. Photo of enclosure with rear wall removed after test \#10 using toluene. Notice melted stainless steel furnace pins and bowed M-board wall but very little cracking of walls. 


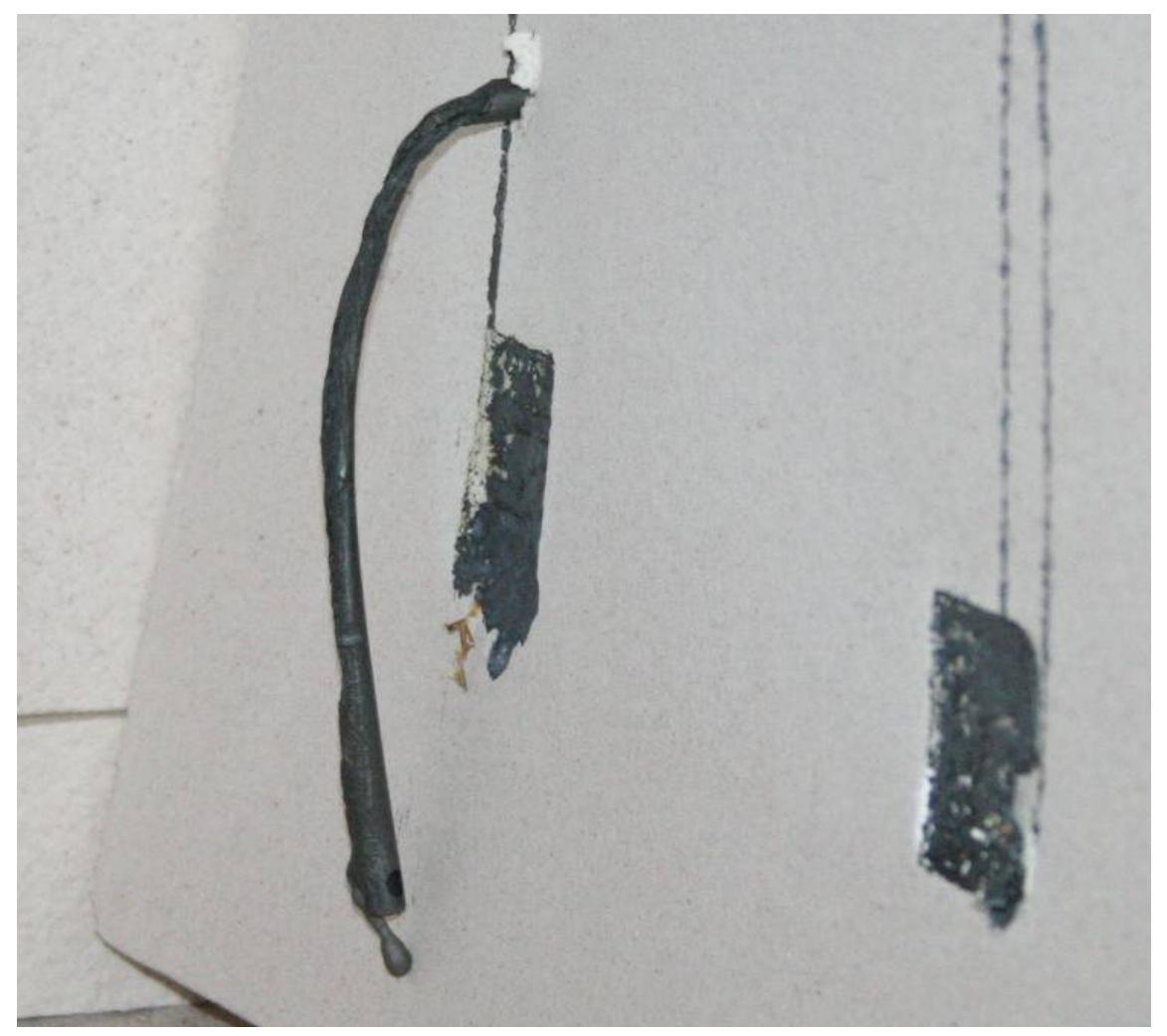

Figure 70. Photo of rear lower aspirated probe (TR24A) after test \#16 with polystyrene. Stainless steel furnace pins melted and dripped along the wall.

\subsection{Burner Type Comparisons}

A number of different burner designs were used during this test series for both practical and technical reasons. Natural gas was delivered using square gravel-filled burners (A and B), shown in Fig. 2. Although the surface areas of these two burners varied by almost a factor of 4 , and only burner B was water cooled, there was no measurable difference in the fire conditions inside the enclosure as a function of HRR.

During the original test series in the 1990s, heptane was burned in a round pan and the depth of the pool was controlled. It was found that steady underventilated burning could not easily be attained using this method. In the test described here, liquid fuels were delivered using a square water-cooled pool burner with inclined walls (burner B) and a spray nozzle directed into a round catch pan (burner C). Burner B performed well in attaining steady burning for the heptane and toluene fuels (test \#7 and test \#10). In these tests, a large amount of radiation from the upper layer was imposed on the fuel surface. This additional heat flux was necessary to reach underventilated conditions since open burning tests with heptane using burner B resulted in a maximum HRR of only about $80 \mathrm{~kW}$ (the fuel surface area was $625 \mathrm{~cm}^{2}$ ). During test \#8 and test $\# 9$ attempts were made to achieve underventilated fires using methanol and ethanol liquid fuels with burner B. These attempts failed because of lack of re-radiation from the upper layer to increase the burning rate necessary for ventilation limited conditions. This was due to the combined effect of low heat of combustion and lack of soot to act as a radiation source. The maximum HRR was $20 \mathrm{~kW}$ and the maximum heat flux to the floor was $3 \mathrm{~kW} / \mathrm{m}^{2}$ for the alcohol 
fuels using burner B. The spray burner (C) allowed a greater burning area, enabling the attainment of underventilated fire conditions for the alcohol fuels in test \#11 and test \#12.

Test \#15 was conducted with heptane fuel to compare the spray burner performance with the results of test \#4 and test \#7 using the heptane pool burner B. Significant differences were observed in the species volume fractions, temperatures and heat fluxes at the same HRR using different burners. The spray burner $\mathrm{C}$ appeared to be less efficient both locally at the interior sampling locations and globally in the exhaust stack. During the $375 \mathrm{~kW}$ steady heptane fire in test \#15, the rear sample location CO, THC and soot measurements were between 3 and 5 times greater than the same fire size using the pool burner in test \#4. The same trend was observed in the exhaust stack species measurements. The interior gas temperatures and heat flux to the floor were lower for the spray burner test. One possible explanation for the inefficiency of the spray burner is that the fuel was injected higher in the compartment where the differences in temperature and oxygen volume fraction could lead to differences in mixing, impacting the compartment fire dynamics. This effect should be considered when making comparisons of different fuel types in the results presented here. Specifically, the CO volume fractions observed in test \#11 and test \#12 using the alcohols fuels could have been enhanced by the configuration of the fuel delivery (burner C). 


\section{Analysis of Compartment Chemistry}

The dynamics and chemistry of the processes occurring in a compartment fire are very complex. In an attempt to better understand the chemistry of the compartment fire experiments, gas species and soot measurements were made at two locations in the hot upper layer of the compartment and far downstream in the exhaust stack, where the temperatures had cooled, typically to less than $200{ }^{\circ} \mathrm{C}$.

\subsection{Mixture Fraction}

It is useful to consider the compartment fire composition measurements in terms of the mixture fraction. The use of mixture fraction to analyze flame data was first used by Bilger [39] and later modified by Peters [40] and others. The mixture fraction approach has been widely used to represent the chemistry in turbulent flame models and fire field models, and has been used to analyze the structure of laminar counterflowing and coflowing hydrocarbon and alcohol flames $[41,42]$.

Pool fires and compartment fires differ from simple laminar flames, as they are typically transient and turbulent by nature. Yet, application of the mixture fraction concept to these complex combustion situations can provide additional insight into the structure of the fire. The mixture fraction approach allows evaluation of a set of species measurements in terms of selfconsistency, and at the same time facilitates rapid assessment of the overall behavior of a combustion system. Floyd et al [43] applied the mixture fraction approach to evaluate the species composition at various locations in compartment fires. Pitts [17] measured the local equivalence ratio at various locations in compartment fires, investigating the possibility of a correlation for $\mathrm{CO}$. Since there is a one-to-one correspondence between mixture fraction and equivalence ratio, the approach used here is similar to that used previously by Pitts [17] and other experimentalists, with the difference that soot is considered in the analysis of mixture fraction and local equivalence ratio.

Sivathanu and Faeth [44] considered the relationship between soot and mixture fraction in an effort to improve the understanding associated with radiative emissions from fires. Their measurements [44] clearly showed that soot did not correlate well with mixture fraction in laminar hydrocarbon diffusion flames. Their data suggest, however, a relationship between soot volume fraction and temperature in the fuel rich regions of turbulent hydrocarbon diffusion flames.

In this study, the mixture fraction was used to evaluate the species composition at various locations in the hot upper layer of the compartment for a number of reasons. First, the analysis provides a check on the quality of the data and provides insight into the chemistry of compartment fires. Second, the significance of the inclusion of soot as part of the mixture fraction analysis was investigated. The intent of this part of the study is to determine if the inclusion of soot adds coherence to the mixture fraction approach. Finally, the importance of measurement uncertainty is highlighted, and its value is quantified as part of the mixture fraction analysis. 


\section{Definition of Mixture Fraction}

The mixture fraction is a non-dimensional quantity representing the mass fraction of a species, at a particular location, that was originally part of the fuel stream. The mixture fraction based on carbon containing species is defined as follows:

$$
Z=Y_{F}+Y_{c o} \frac{M W_{F}}{x M W_{c o}}+Y_{c o_{2}} \frac{M W_{F}}{x M W_{c o_{2}}}+Y_{\text {Soot }} \frac{M W_{F}}{x M W_{\text {Soot }}}
$$

where $M W_{i}$ is the molecular mass of chemical species i, $Y_{i}$ is the mass fraction of that species, $\mathrm{x}$ is the number of carbon atoms in the parent fuel molecule $\left(C_{x} H_{y} O_{z}\right), M W_{F}$ is the molecular mass of the parent fuel, $M W_{C O}$ is $28 \mathrm{~g} / \mathrm{mol}, M W_{\text {Soot }}$ is taken as $12 \mathrm{~g} / \mathrm{mol}$ (assuming that soot can be approximated as pure carbon), and $M W_{C O 2}$ is $44 \mathrm{~g} / \mathrm{mol}$. Alternative definitions of mixture fraction yield results similar to those shown below.

In the experiments reported here, the measurement of total unburned hydrocarbons was made using the total hydrocarbon analyzer, reported on an equivalent methane basis. The subscript $\mathrm{F}$ in the first term of Eq. 15 can be thought of as referring to total hydrocarbons (THC).

In the fire literature, soot is typically not considered in Eq. 15. Here, it is included formally. But in the analysis given below, this term is initially neglected, because it is small. Its inclusion is important for highly sooting conditions, as will be shown in the results section below.

The mass fraction, $Y_{i}$, of each species $i$ is determined from the measured volume fraction, $X_{i}$, by the following expression:

$$
Y_{i}=X_{i} M W_{i} / M W_{t o t}
$$

$M W_{\text {tot }}$ represents the average molecular mass of all gas species and is a function of the local composition.

$$
M W_{\text {tot }}=\sum_{i} X_{i} M W_{i}
$$

The state relations can be derived by considering the idealized reaction of a hydrocarbon fuel, rewritten here in an expanded form of Eq. 9:

$$
\begin{aligned}
\mathrm{C}_{x} \mathrm{H}_{y} \mathrm{O}_{z}+\eta(x+y / 4-z / 2)\left(\mathrm{O}_{2}+3.76 \mathrm{~N}_{2}\right) \rightarrow \max (0,1-\eta) \mathrm{C}_{x} \mathrm{H}_{y} \mathrm{O}_{z}+\min (1, \eta) x \mathrm{CO}_{2} \\
+\min (1, \eta)(y / 2) \mathrm{H}_{2} \mathrm{O}+\max (0, \eta-1)(x+y / 4-z / 2) \mathrm{O}_{2}+\eta(x+y / 4) 3.76 \mathrm{~N}_{2}
\end{aligned}
$$

where the function $\max (\alpha, \beta)$ returns the larger of the two parameters, $\alpha$ or $\beta$, and the function $\min (\alpha, \beta)$ returns the smaller of the two parameters, $\alpha$ or $\beta$. Here, $\eta$ is a parameter ranging from zero (all fuel and zero oxygen) to infinity (all oxygen and zero fuel) and becomes unity for stoichiometric conditions. The definition of $\eta$ shows that it is the reciprocal of the local fuel equivalence ratio, $\phi$.

$$
\phi=\frac{(F / A)}{(F / A)_{s t}}=\frac{M W_{F} / \eta(x+y / 4-z / 2)\left(M W_{O_{2}}+3.76 M W_{N_{2}}\right)}{M W_{F} /(x+y / 4-z / 2)\left(M W_{O_{2}}+3.76 M W_{N_{2}}\right)}=\frac{1}{\eta}
$$


where $F / A$ is the fuel-air ratio and the subscript st refers to stoichiometric conditions. The idealized mass fractions of products are obtained from the right side of the Eq. 18. For stoichiometric conditions, $Y_{F}=Y_{C O}=0$, and Eq. 15 leads to:

$$
Z_{s t}=Y_{C O 2} \frac{M W_{F}}{x M W_{C O 2}}
$$

The value of the stoichiometric mixture fraction for the fuels considered in this report is shown in Table 22. Its value varied from about 0.0554 for natural gas to 0.1346 for methanol.

Table 22. Stoichiometric value of the mixture fraction $\left(Z_{s t}\right)$ for different fuels.

\begin{tabular}{|l|c|c|}
\hline Fuel & Chemical Formula & $Z_{s t}$ \\
\hline Methane & $\mathrm{CH}_{4}$ & 0.0552 \\
\hline Natural Gas & $0.93 \mathrm{CH}_{4}+0.04 \mathrm{C}_{2} \mathrm{H}_{6}+0.01 \mathrm{C}_{3} \mathrm{H}_{8}+0.01 \mathrm{CO}_{2}+\ldots{ }^{*}$ & $0.0554 \pm 0.0002$ \\
\hline n-Heptane & $\mathrm{C}_{7} \mathrm{H}_{16}$ & 0.0622 \\
\hline Toluene & $\mathrm{C}_{7} \mathrm{H}_{8}$ & 0.0694 \\
\hline Polystyrene & $\left(\mathrm{C}_{8} \mathrm{H}_{8}\right)_{\mathrm{n}}$ & 0.0705 \\
\hline Methanol & $\mathrm{CH}_{3} \mathrm{OH}$ & 0.1346 \\
\hline Ethanol & $\mathrm{C}_{2} \mathrm{H}_{5} \mathrm{OH}$ & 0.1006 \\
\hline $\begin{array}{l}* \\
* *\end{array}$ & \\
\hline
\end{tabular}

A mixture fraction calculation for a methane-air flame is presented here as an example. For methane, Eq. 18 becomes:

$$
\begin{aligned}
\mathrm{CH}_{4}+2 \eta\left(\mathrm{O}_{2}+3.76 \mathrm{~N}_{2}\right) \rightarrow & \max (0,1-\eta) \mathrm{CH}_{4}+\min (1, \eta) \mathrm{CO}_{2}+2 \min (1, \eta) \mathrm{H}_{2} \mathrm{O} \\
& +2 \max (0, \eta-1) \mathrm{O}_{2}+7.52 \eta \mathrm{N}_{2}
\end{aligned}
$$

The traditional mixture fraction model holds that the mass fraction, $Y_{i}$, of products can be determined through the right side of Eq. 21 as follows:

$$
\begin{aligned}
& Y_{\mathrm{CH}_{4}}=\max (0,1-\eta) M W_{\mathrm{CH}_{4}} / M W_{t o t} \\
& Y_{\mathrm{CO}_{2}}=\min (1, \eta) M W_{\mathrm{CO}_{2}} / M W_{t o t} \\
& Y_{\mathrm{H}_{2} \mathrm{O}}=2 \min (1, \eta) M W_{\mathrm{H}_{2} \mathrm{O}} / M W_{t o t} \\
& Y_{\mathrm{O}_{2}}=2 \max (0, \eta-1) M W_{\mathrm{O}_{2}} / M W_{t o t} \\
& Y_{\mathrm{N}_{2}}=7.52 \eta M W_{\mathrm{N}_{2}} / M W_{t o t}
\end{aligned}
$$

where $Y_{C O}$ and $Y_{\text {Soot }}$ in Eq. 18 were taken as zero for this mixture fraction model calculation. The molecular mass of the mixture is a function of the local composition and can be calculated from the reactant concentrations:

$$
M W_{t o t}=M W_{C_{4}}+2 \eta\left(M W_{O_{2}}+3.76 M W_{N_{2}}\right) .
$$

Since $Y_{C O}$ and $Y_{\text {Soot }}$ are assumed to be equal to zero and $Y_{F}=Y_{C_{4}}$ the mixture fraction defined in Eq. 15 can be rewritten as:

$$
Z=Y_{\mathrm{CH}_{4}}+Y_{\mathrm{CO}_{2}} \frac{M W_{\mathrm{CH}_{4}}}{x M W_{\mathrm{CO}_{2}}}
$$


Using Eqs. 22 and 23, Eq. 24 can be rewritten as:

$$
Z=\frac{M W_{C_{4}}}{M W_{t o t}}=\frac{M W_{C_{4}}}{M W_{C H_{4}}+2 \eta\left(M W_{O_{2}}+3.76 M W_{N_{2}}\right)},
$$

and

$$
\eta=\frac{(1-Z)}{Z} \frac{M W_{\mathrm{CH}_{4}}}{2\left(M W_{\mathrm{O}_{2}}+3.76 M W_{N_{2}}\right)}=\frac{(1-Z)}{Z}(F / A)_{s t} .
$$

Figure 71 presents the relationship between the mixture fraction and the equivalence ratio $(1 / \eta)$ as delineated in Eq. 26 for the methane-air system. Under stoichiometric conditions $(\eta=1)$, the mixture fraction is 0.0552 for a methane-air flame as listed in Table 22. In Fig. 71, natural gas is treated as if it were methane. The figure shows that the mixture fraction compresses a large range of equivalence ratio values. Figure 72 shows the relationship between the mass fraction and the mixture fraction for most of the major species in the methane-air system, when $Y_{C O}$ is taken as zero.

\section{Mixture Fraction Uncertainty}

The uncertainty in the mixture fraction is propagated through Eq. 15 and is based on the measurement uncertainty of the species concentrations. The positive square root of the estimated variance, $U_{Z}\left(Y_{i}\right)$, is obtained from

$$
U_{Z}^{2}\left(Y_{i}\right)=\sum_{i=1}^{N}\left[\frac{\partial Z}{\partial Y_{i}}\right]^{2} U_{Y_{i}}^{2}
$$

where $U_{Y_{i}}$ is an estimate of the combined expanded measurement uncertainty of the measured mass fraction, $Y_{i}$, of species i. 


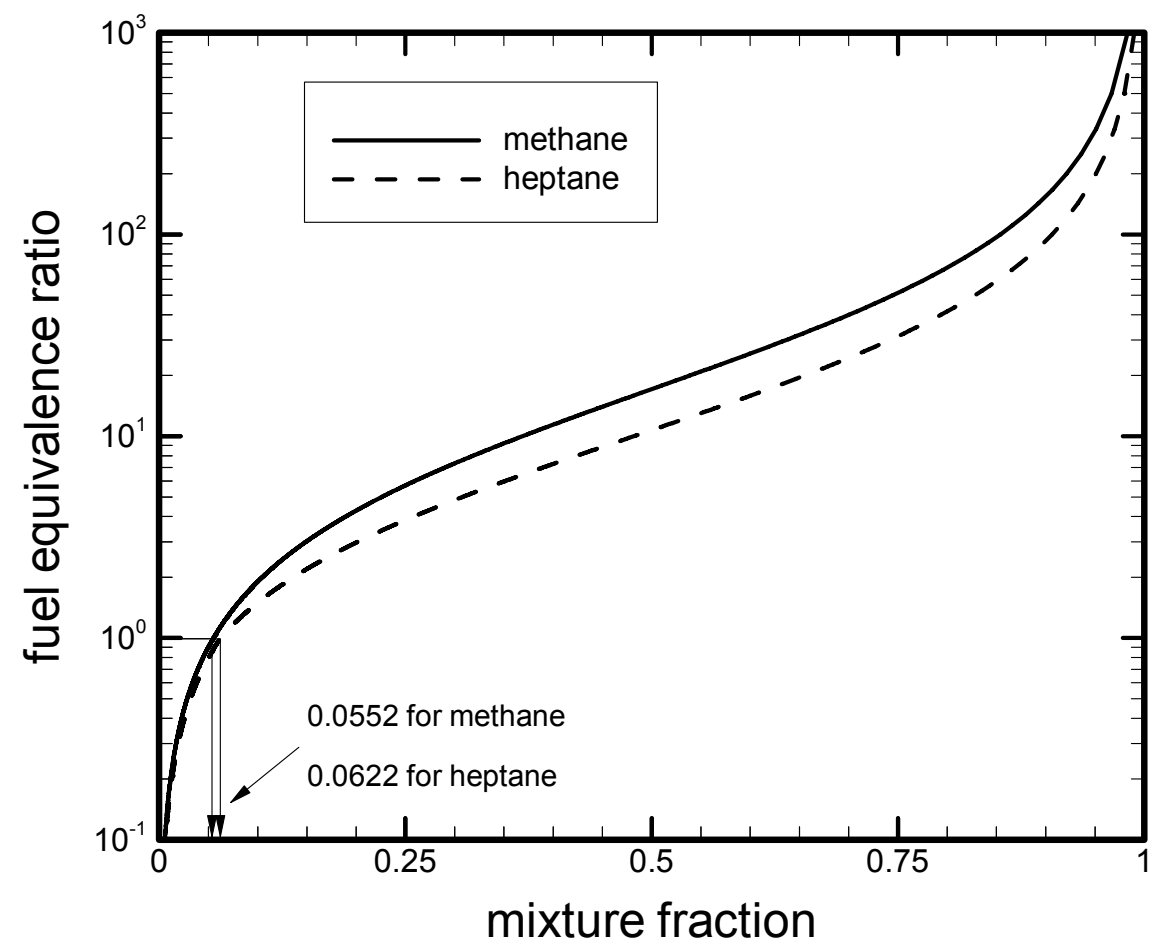

Figure 71 The equivalence ratio as a function of mixture fraction for nonpremixed flames burning methane and $\mathrm{n}$-heptane.

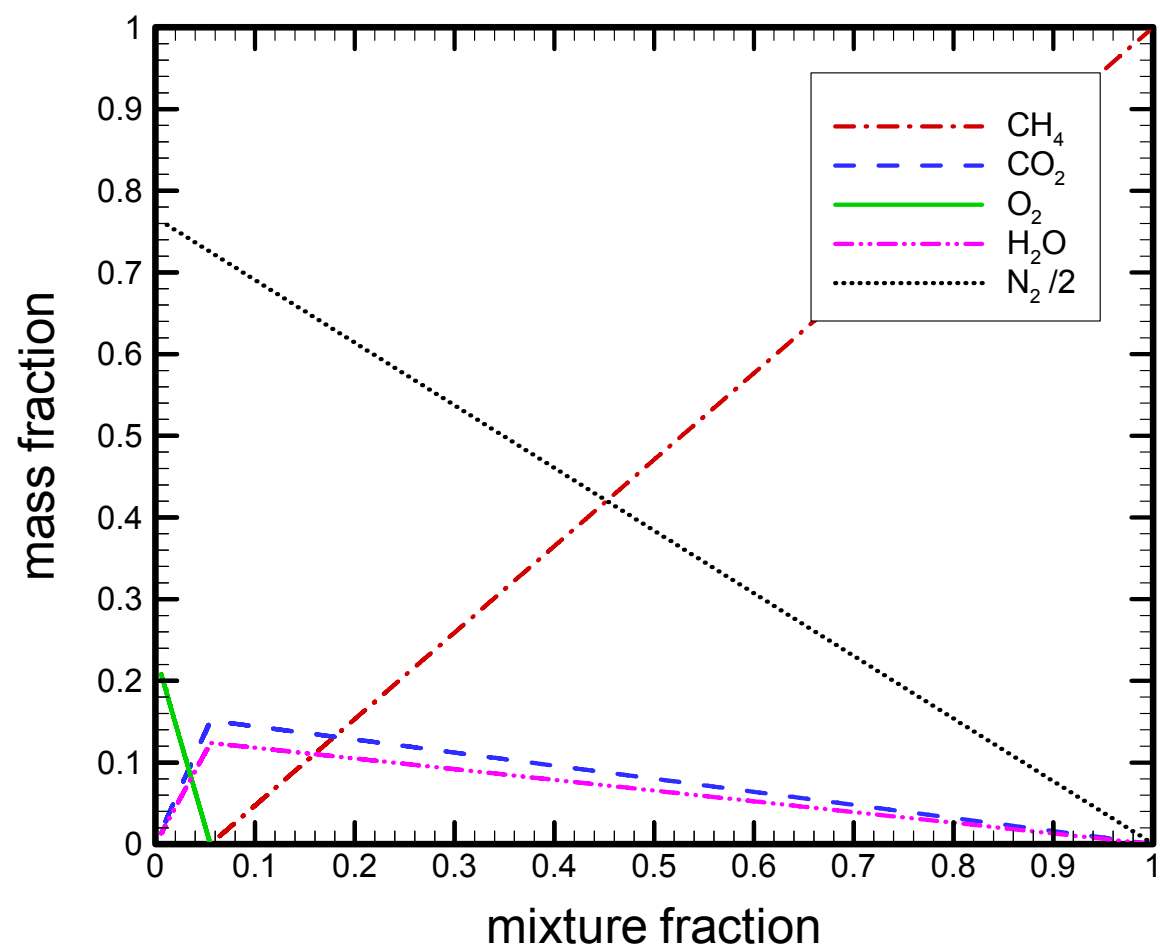

Figure 72 The mass fraction vs. the mixture fraction calculated by the single-parameter mixture fraction model. 


\section{Species Composition Results in terms of Mixture Fraction}

In this section, the time-varying species measurements are presented as a function of the mixture fraction. The results are organized in terms of fuel type, since the fuel type establishes the basis for the correlation (see Eqs. 9 and 15).

The species data are considered in terms of the species mass fraction $\left(Y_{i}\right)$, which is plotted as a function of the local mixture fraction $(\mathrm{Z})$, based on the fuel mass. Measurements from the front and rear of the compartment, for all fire conditions (i.e., heat release rate, burner type) and all times during the experiment are plotted on a single graph in terms of mixture fraction. The mass fractions of $\mathrm{H}_{2} \mathrm{O}$ and $\mathrm{N}_{2}$ were not measured in the experiments; the values of these species in this report (and shown in Fig. 73 through Fig. 96) are estimated from the stoichiometric relation (Eqs. 9-11). The mass fractions of the unburned hydrocarbons (THC) in each plot were taken from the hydrocarbon analyzer measurements. The total hydrocarbons (THC) results were normalized in terms of the equivalent fuel molecule for each fuel type.

The lines in Fig. 73 through Fig. 77, Fig. 80, and Fig. 81) represent, respectively, complete stoichiometric combustion and the hypothetical case when only $\mathrm{CO}_{2}$ is produced (no $\mathrm{CO}$ or soot; see Fig. 72). In some cases, because of the number of data points, the theoretical lines are somewhat obscured. The lines on the average steady-state measurement results are easier to distinguish as the plots are less crowded. In those plots, the propagated uncertainty is also presented. Soot was not measured at all times, but only during the periods when the fire heat release rate was quasi- steady. Thus, soot is shown only on the plots labeled "(b)" and is presented with the time-averaged gas species results only. The data labeled "THC" in the figures represents the total unburned hydrocarbons measured with the FID detector on the total hydrocarbon analyzer.

\section{Natural Gas}

Figure 73 presents all of the gas species measurements taken during all of the natural gas experiments (tests $\# 1$ - \#3, and \#6) in both the front and rear of the compartment as a function of mixture fraction. Figure 73a shows all of the transient measurements for all of the natural gas tests with the full-door configuration (tests \#1 - \#3 and \#6). Figure 73b shows the time-averaged steady-state measurements (and represents the same data as shown in Fig. 41). At any single location, the mixture fraction can vary from lean to rich, due to the dynamics of the fire. The stoichiometric mixture fraction $\left(Z_{\mathrm{st}}\right)$ is a useful reference point for consideration of fire chemistry (see Table 22; $\left.Z_{\mathrm{st}}=0.0544\right)$. For fuel lean conditions $\left(\mathrm{Z}<\mathrm{Z}_{\mathrm{st}}\right)$, the measured mass fractions of methane and carbon monoxide are near zero. As the mixture fraction increases, the mass fraction of oxygen decreases, and the carbon dioxide and water vapor mass fractions increase. For mixture fraction values greater than stoichiometric, the oxygen mass fraction approaches zero, whereas the fraction of unburned fuel increases approximately linearly. Under these conditions, the generation of carbon monoxide is observed and $Y_{C O}$ attains a maximum value of about $0.04 \mathrm{~g} / \mathrm{g}$.

As seen in the figure, the hypothetical lines show reasonable agreement with the measurements for fuel lean and near-stoichiometric conditions. As the mixture fraction increases beyond stoichiometric, however, the difference between the hypothetical lines and the measurements becomes considerable. The value of $Y_{C O}$ is not negligible for fuel rich conditions. As a result, the 
hypothetical lines over-predict the $\mathrm{CO}_{2}$ mass fraction by about $10 \%$ for mixture fraction values for $Z_{\text {st }}<Z<0.2$. As expected, the plots show that the simple traditional mixture faction approach does not correlate the experimental results for $\mathrm{CO}$. This behavior is also observed in laminar flames, which is attributed to finite rate chemistry effects associated with slow CO chemistry [41]. Other approaches to predict CO, possibly using variables that are functions of mixture fraction, will need to be considered to improve predictions of its concentration.

The vertical and horizontal error bars in Fig. $73 \mathrm{~b}$ represent the combined expanded uncertainty of the mass fractions of gas species and the mixture fraction, respectively. For $Z<0.2$, the uncertainties are relatively small, and the mixture fraction correlations show reasonable agreement with the experiments. For $Z>0.2$ (in Fig. 73b), the uncertainties in the mixture fraction and the mass fraction of gas species, especially unburned fuel and nitrogen, become large, and the maximum relative error of mixture fraction reaches values as large as $15 \%$. Typically, the mixture fraction model is within experimental uncertainty for the conditions considered in this study, when natural gas was the fuel. The results for $\mathrm{H}_{2} \mathrm{O}$ are the exception to this. Direct measurement of the $\mathrm{H}_{2} \mathrm{O}$ concentration would be helpful in this regard. Since the $\mathrm{H}_{2}$ concentration can be on the order of a few percent in a hydrocarbon diffusion flame [42], its measurement would also be of interest.. 


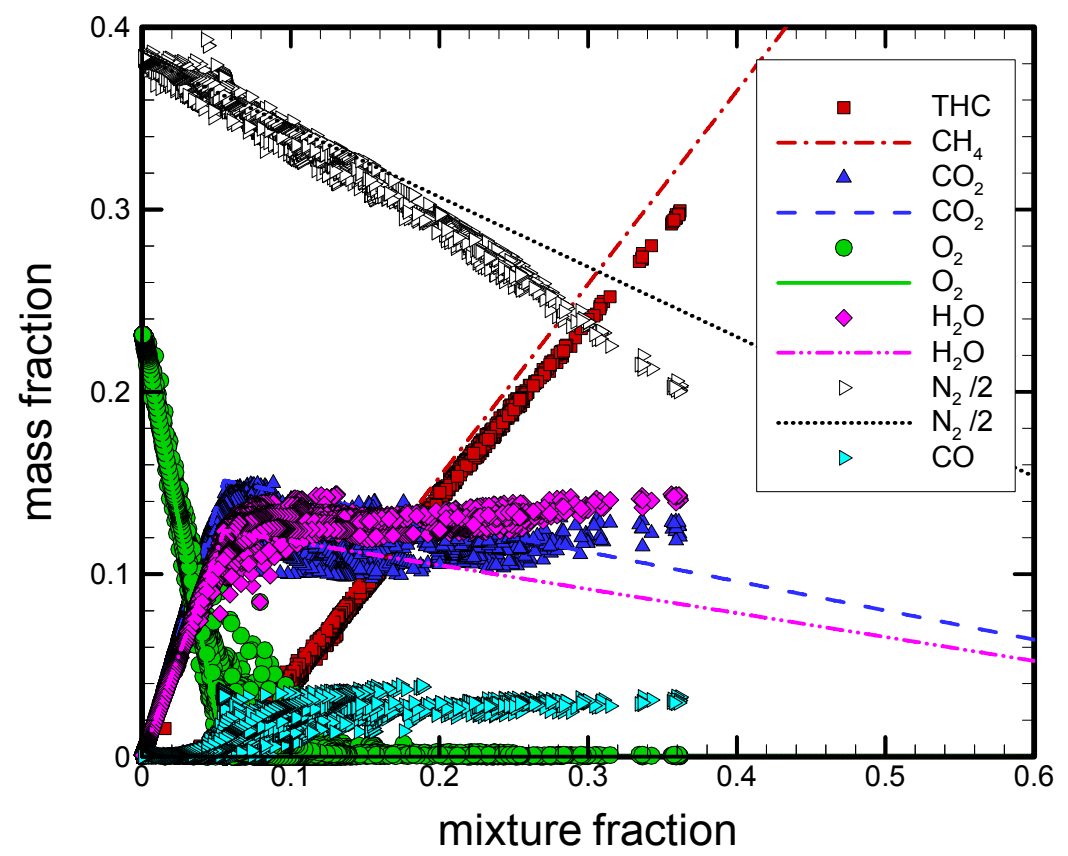

(a)

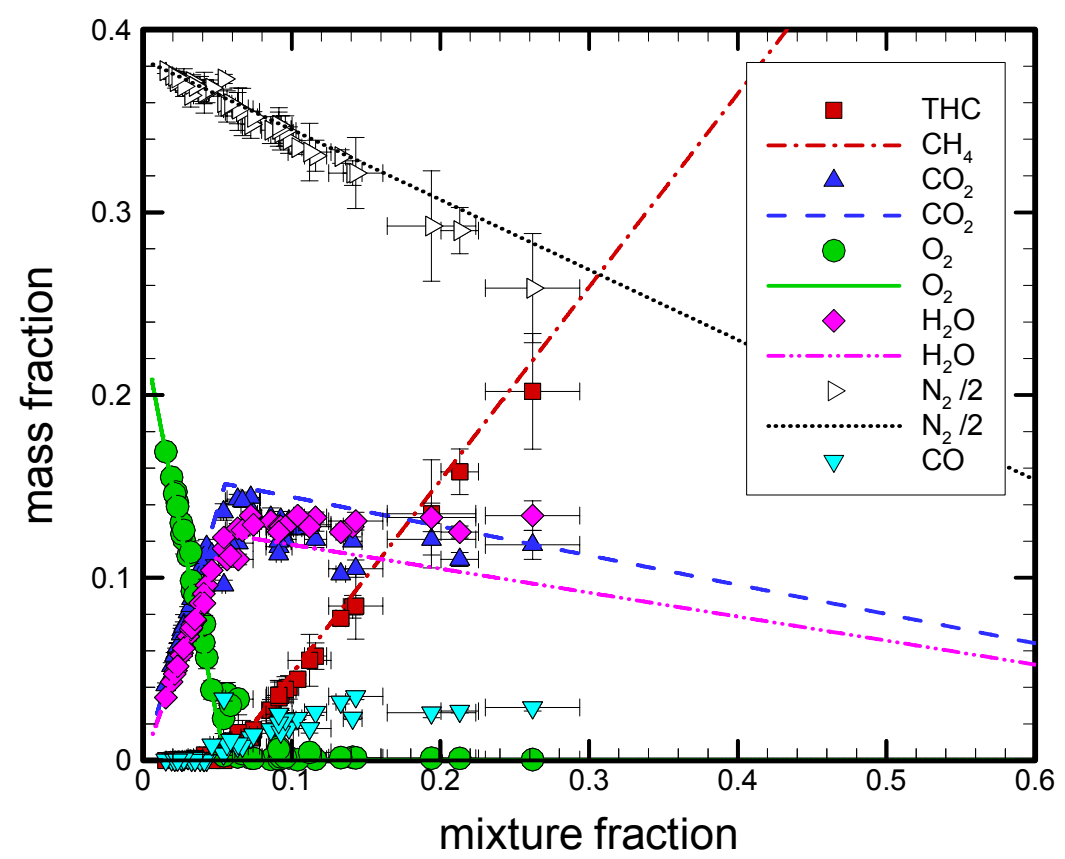

(b)

Figure 73 Mass fractions of front and rear compartment gas species as a function of mixture fraction for the natural gas fire tests \#1-\#3, and \#6: (a) transient measurements and (b) timeaveraged measurements during the period when the HRR was quasi-steady. 


\section{Condensed-Phase Hydrocarbon Fuels}

Figure 74 to Fig. 76 show the mass fraction as a function of mixture fraction for the fires burning heptane (tests $\# 4, \# 5, \# 7, \# 15$ ), toluene (test \#10) and polystyrene (tests \#13, \#14, \#16), respectively. For small values of mixture fraction $\left(\mathrm{Z}<<\mathrm{Z}_{\mathrm{st}}\right)$, the species mass fractions agree with the mixture fraction model for all three fuels. Figure 74 shows, however, for nearstoichiometric conditions, $Y_{\mathrm{CO}}$ is non-zero, which leads to $Y_{\mathrm{CO}_{2}}$ lower than predicted by the mixture fraction model. Figure $74 \mathrm{~b}$ and Fig. $75 \mathrm{~b}$ show that the measurement uncertainty was relatively small for lean mixture fractions. For large values of the mixture fraction, the variance of the species mass fraction results was relatively broad. This is particularly true for the transient results, but also for the time-averaged results. It is interesting to note that the figures show that the local conditions are not fuel-rich for any of the conditions investigated during the toluene and the polystyrene tests. Although there was a high concentration of mass fraction results about near-stoichiometric conditions, the negligible amounts of hydrocarbons measured during these tests led to mixture fraction values which were less than stoichiometric in value.

Species concentration results in the fire literature, such as those presented in Fig. 74 to Fig. 76, are typically reported without consideration of soot in the definition of mixture fraction. It is correct to include soot in Eq. 15 as the conserved scalar approach is based on the idea that elemental mass is neither created nor destroyed in a fire. The appearance of the plots qualitatively change when soot is considered. Figure 77a, Fig. 77b, and Fig. 77c replot the data shown in Fig. 74b, Fig. 75b, and Fig. 76b, respectively, and show that the inclusion of soot reduces the scatter in the mass fractions for large values of $Z$, while otherwise leaving the plots unchanged. Inclusion of soot stretches the value of $Z$ proportional to the measured soot mass fraction in a non-linear manner as illustrated in Fig. 78 using the heptane, toluene and polystyrene results. This is because $Y_{\text {Soot }}$ is negligible for lean conditions, whereas it is significant for large values of $Z$, taking on values as large as 0.1 . Neglecting soot for the fires burning natural gas and alcohol fuels is reasonable, whereas considering it for heavily sooting fires is necessary. The scatter in the mass fractions was reduced for these fuels when soot was considered in the definition of $Z$ (see Eq. 15). In Fig. 77a, Fig. 77b, and Fig. 77c, the sum of the soot and total hydrocarbons (THC) appears to closely follow the mixture fraction model results. The results plotted in this way are particularly convincing in Fig. 77a, where the independent results for soot and THC do not follow the state relationship model, but their sum does. Interestingly, Fig. 77 shows that there was no significant amount of THC measured in the upper layer of the compartment in the toluene or polystyrene fires. The carbon in the upper layer of these fires is primarily in the form of $\mathrm{CO}, \mathrm{CO}_{2}$ or soot. Examination of Fig. 52 presents the same data, which reaffirms that the total $\mathrm{HC}$ measurements were relatively small in the polystyrene and toluene fires, and that the unburned hydrocarbons did not represent a significant fraction of the carbon in the upper layer.

It is also of interest to examine the results in which soot was not used in the mixture fraction definition. This is the typical manner of representing the data in the combustion and fire literature. The value of neglecting soot in the mixture fraction definition is seen in the comparison of Fig. 74 to Fig. 76 with Fig. 77. For conditions when $Z<Z_{\text {st }}$, the results that neglect soot in the mixture fraction definition more closely track the state relationship model than the results that consider soot in the mixture fraction definition. The reasons for this are unclear, but this result may be important for understanding the success of mixture fraction 
correlations without consideration of soot. The comparison of Fig. 74 to Fig. 76 with Fig. 77 illustrates the importance of including soot in the mixture fraction definition, particularly for conditions when $Z>Z_{\text {st }}$. Further investigation of these results may prove useful in the development of predictive capabilities for compartment fire species.

Since CO chemistry is relatively slow compared to many flame processes, it may be reasonable to consider the effect of the local temperature on the state relationship model. Figure 79a and Fig. 79b shows the transient values of $Y_{\mathrm{CO}}$ and $Y_{\mathrm{CO}_{2}}$ in the front and rear of the compartment (same data as Fig. 74a) as a function of mixture fraction with symbols colored to represent the local temperature in the heptane experiments (tests \#4, \#5, and \#7). The results show that while there are some general trends associated with temperature, the values of $Y_{C O}$ are quite scattered and do not systematically correlate with temperature.

\section{Alcohol Fuels}

Figure 80 and Fig. 81 present the mass fractions of products for the methanol (tests \#8, \#12) and ethanol fires (tests \#9,\#11), respectively. Figure 80 shows the gas species mass fractions at the front and rear of the compartment as a function of mixture fraction for the methanol fire tests \#8 and \#12. Figure 80a and Fig. 81a shows all of the transient measurements for the methanol and ethanol tests, respectively and Fig. $80 \mathrm{~b}$ and Fig. $81 \mathrm{~b}$ shows the averaged quasi-steady measurements for the methanol and ethanol tests, respectively. The soot measurements are plotted with the quasi-steady results, but were not measured and are not shown as part of the transient results. Compared to the mixture fraction model, the concentrations of water vapor are too large, while the unburned fuel and carbon dioxide fall below the predictions. For fires burning both of the alcohol fuels, the value of $Y_{C O}$ is as high as $10 \%$, which is over two times its value in the natural gas and heptane fires. 


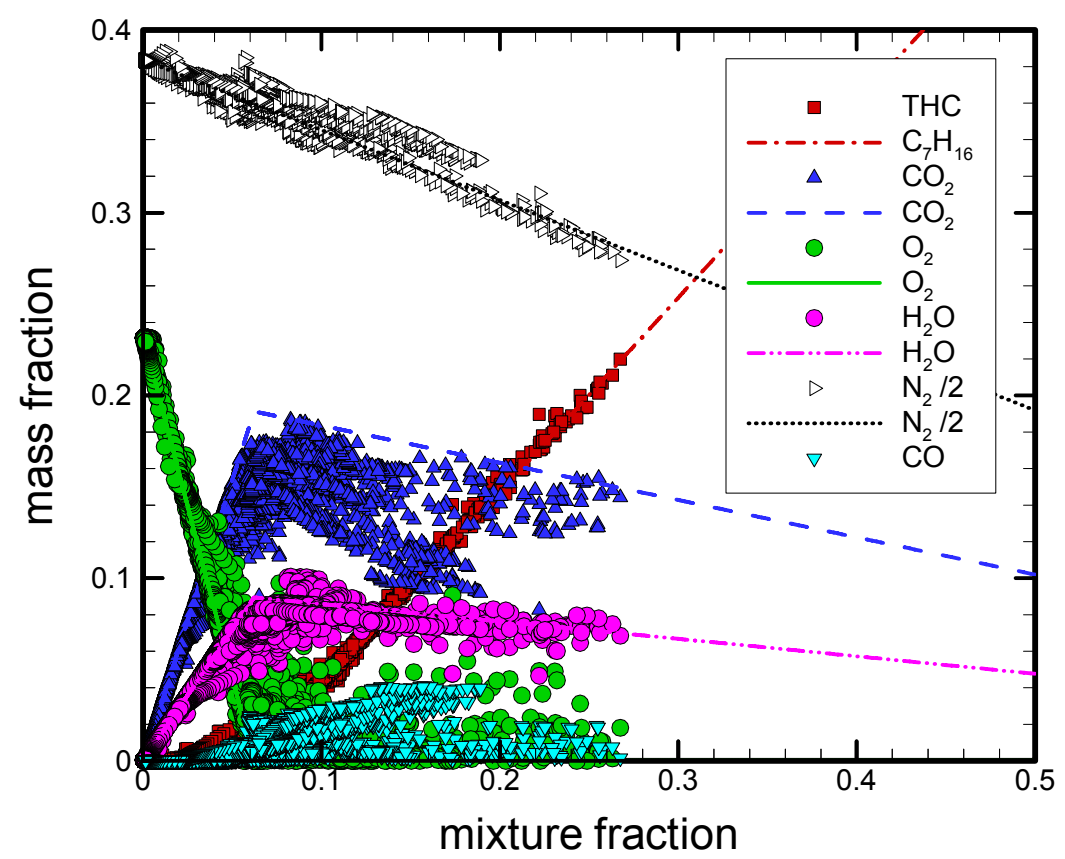

(a)

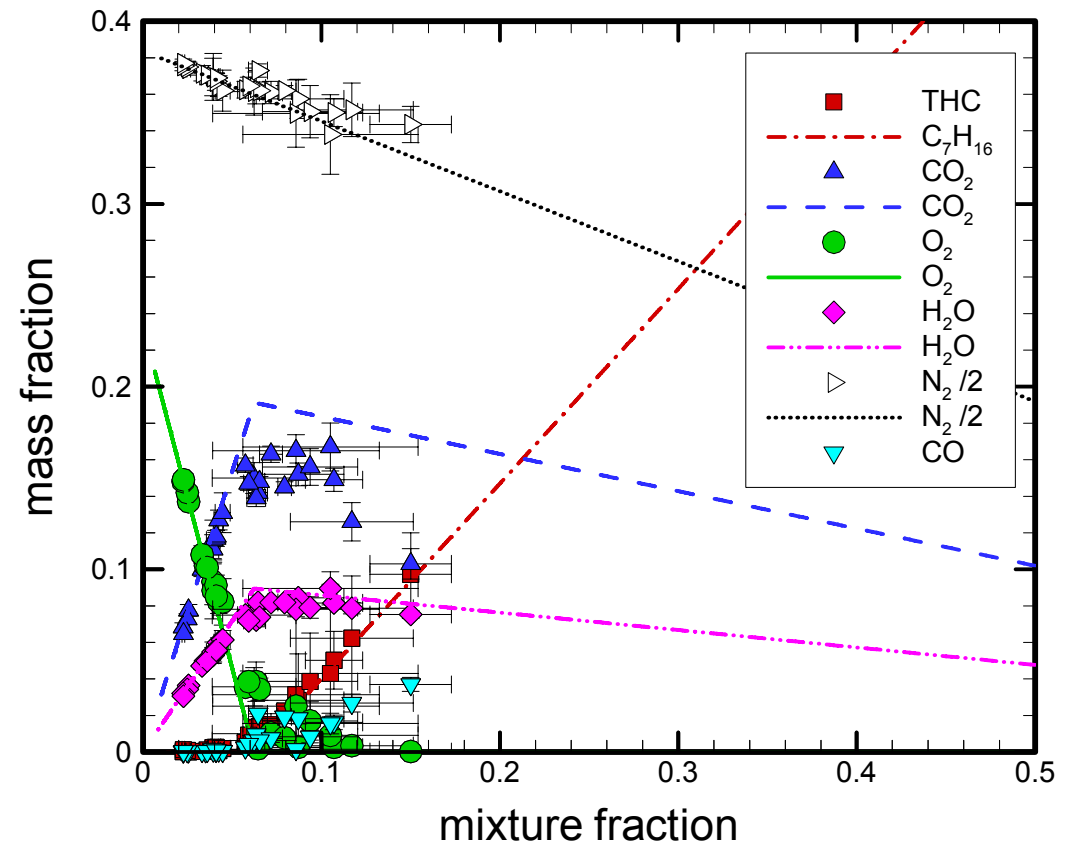

(b)

Figure 74 Mass fractions of front and rear compartment gas species as a function of mixture fraction for the heptane fire tests \#4, \#5, \#7 and \#15: (a) transient measurements and (b) timeaveraged measurements during the period when the HRR was quasi-steady. 


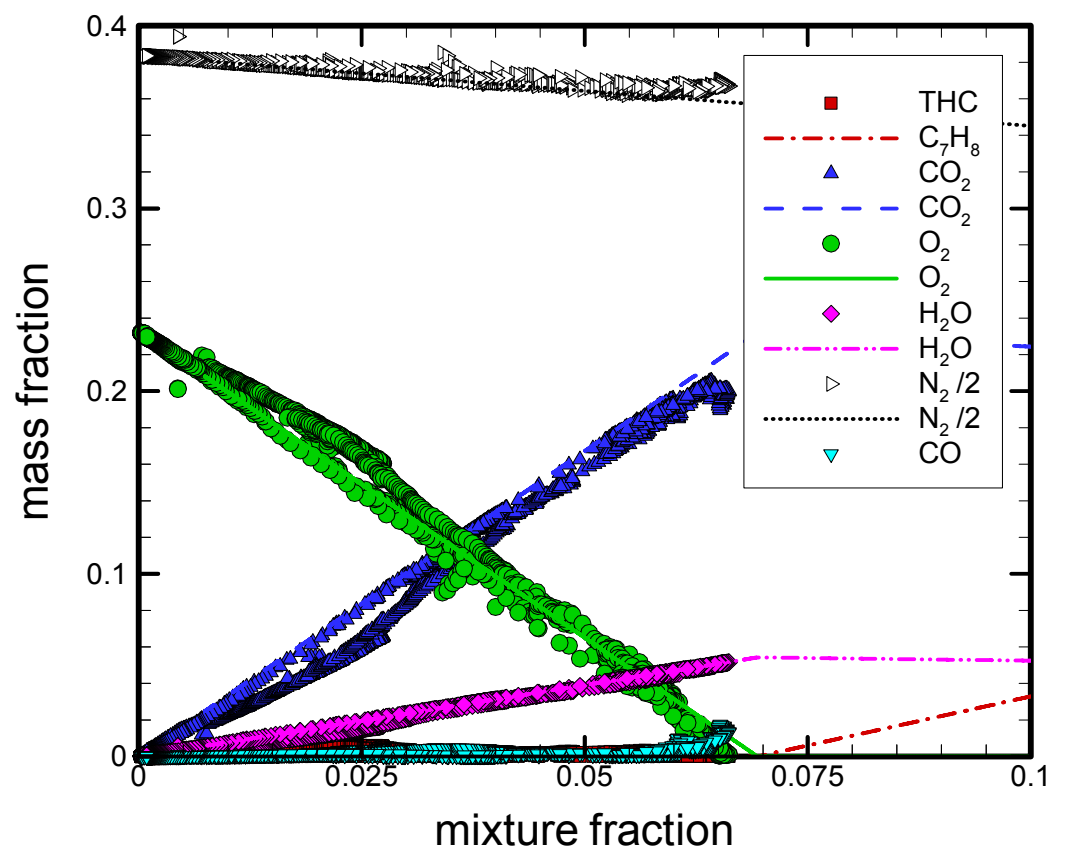

(a)

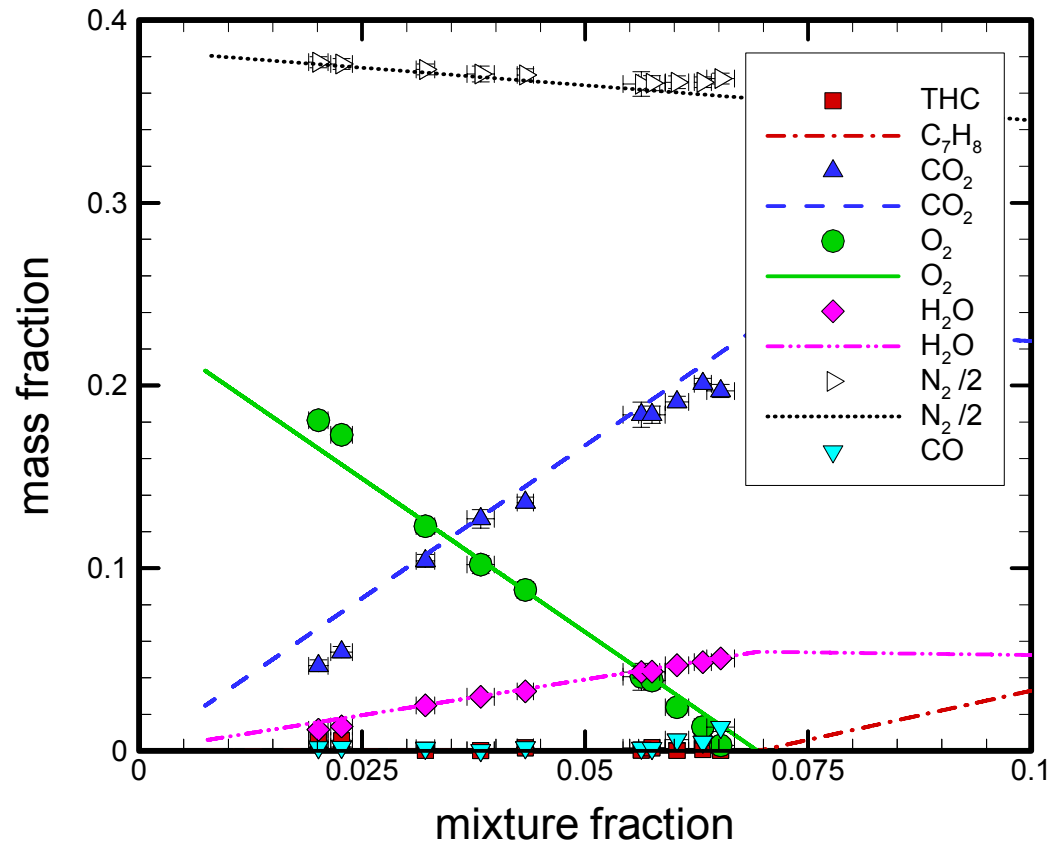

(b)

Figure 75 Mass fractions of front and rear compartment gas species as a function of mixture fraction for the toluene fire test \#10: (a) transient measurements and (b) time-averaged measurements during the period when the HRR was quasi-steady. 


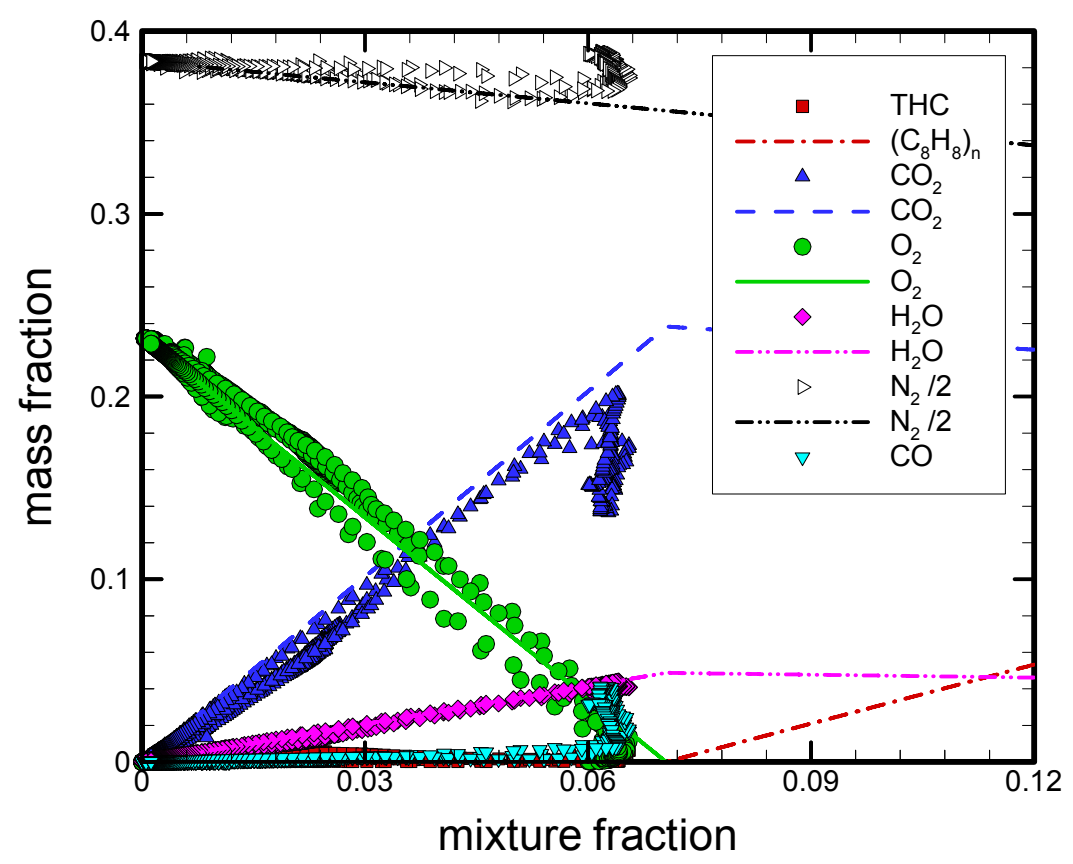

(a)

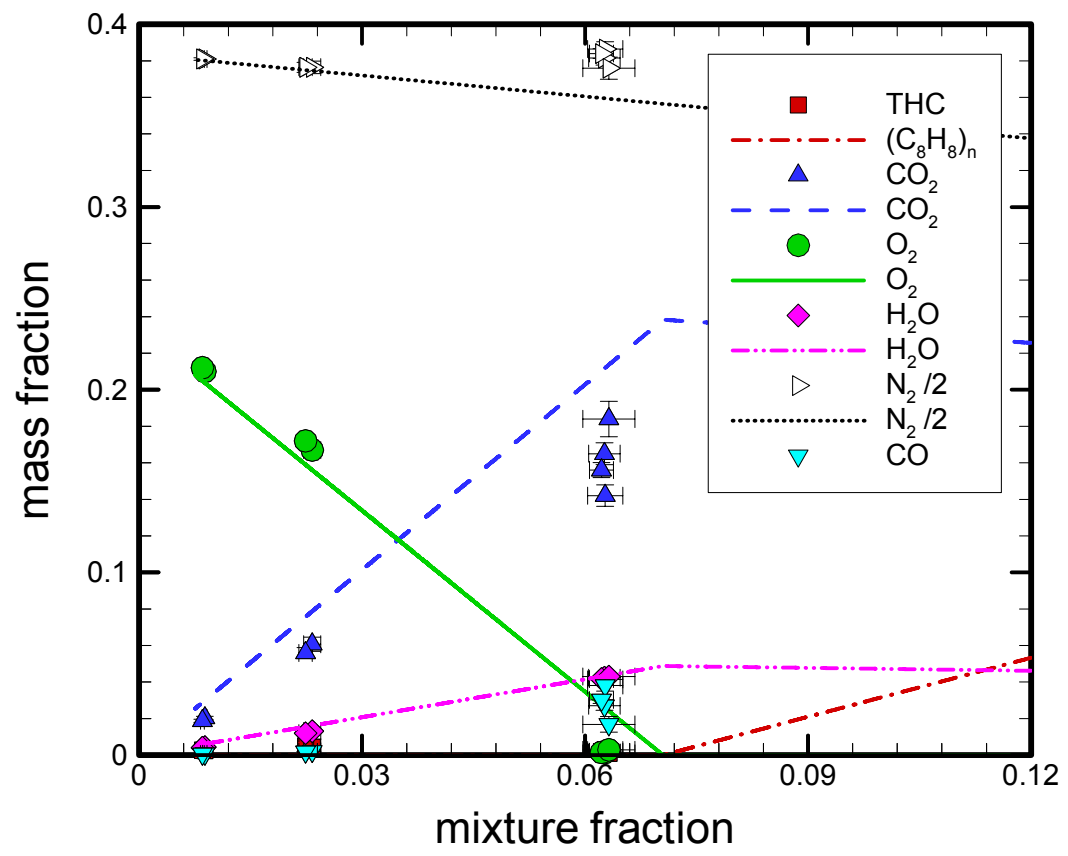

(b)

Figure 76 Mass fractions of front and rear compartment gas species as a function of mixture fraction for polystyrene fire tests \#13,\#14, and \#16: (a) transient measurements and (b) timeaveraged measurements during the period when the HRR was quasi-steady. 


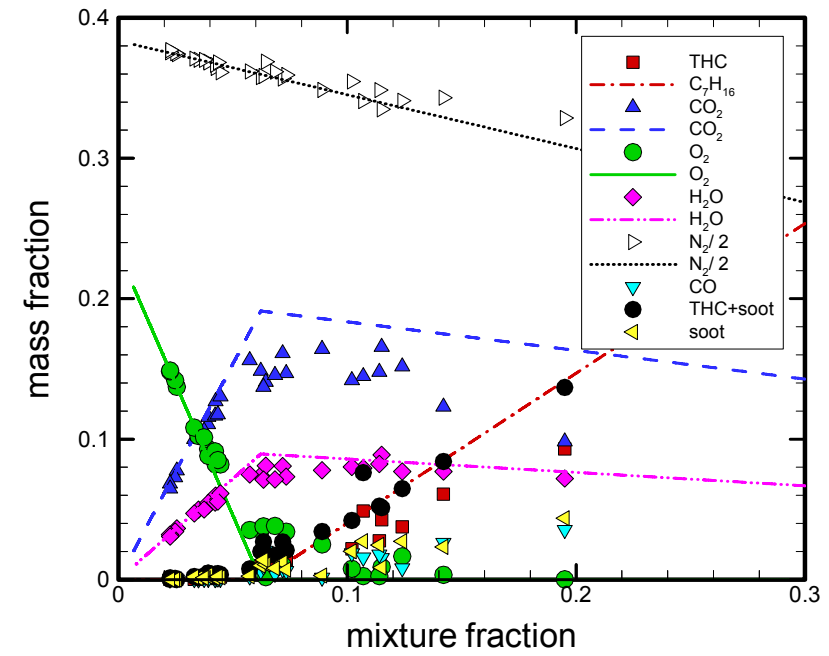

(a)

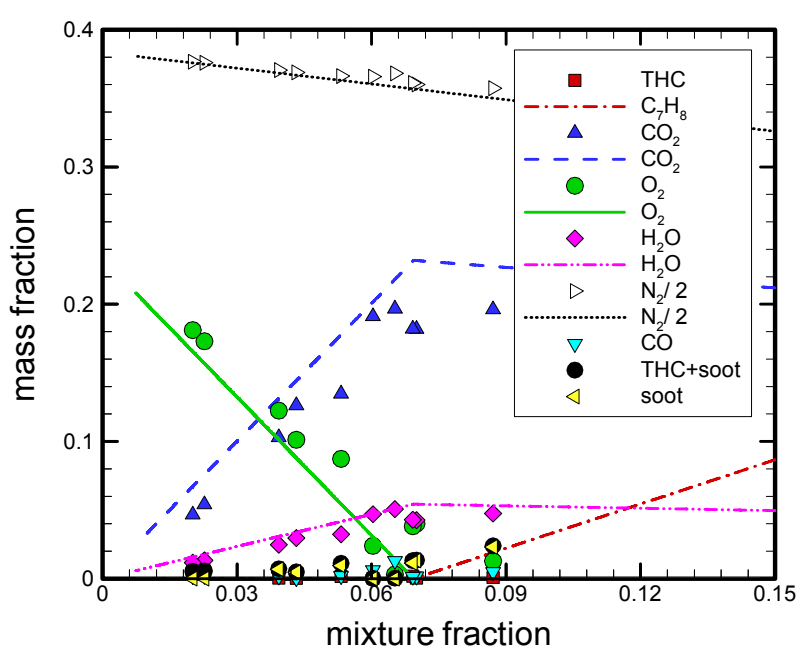

(b)

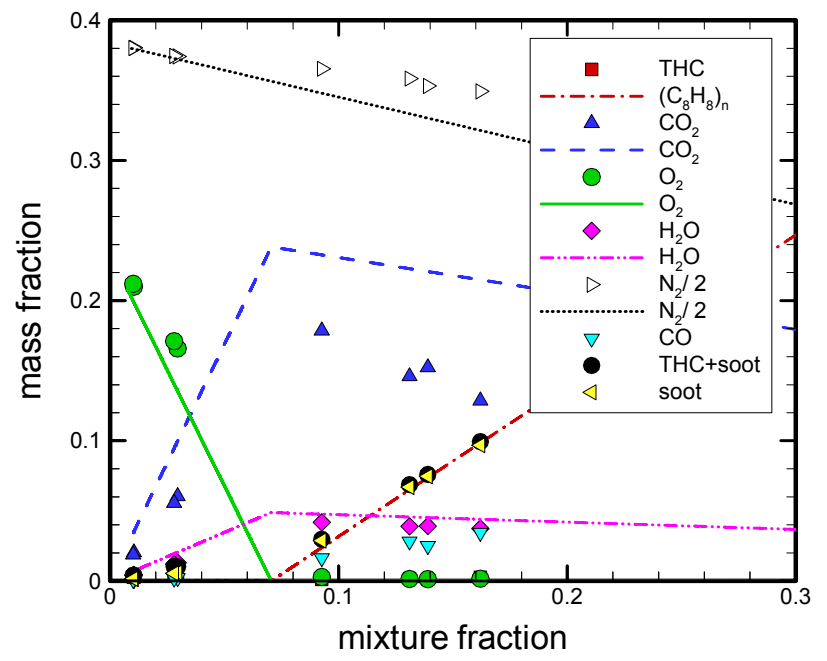

(c)

Figure 77 Mass fractions of front and rear compartment gas species as a function of mixture fraction (with soot included) for the time-averaged measurements when the HRR was quasisteady in the experiments burning (a) heptane, (b) toluene, and (c) polystyrene. 


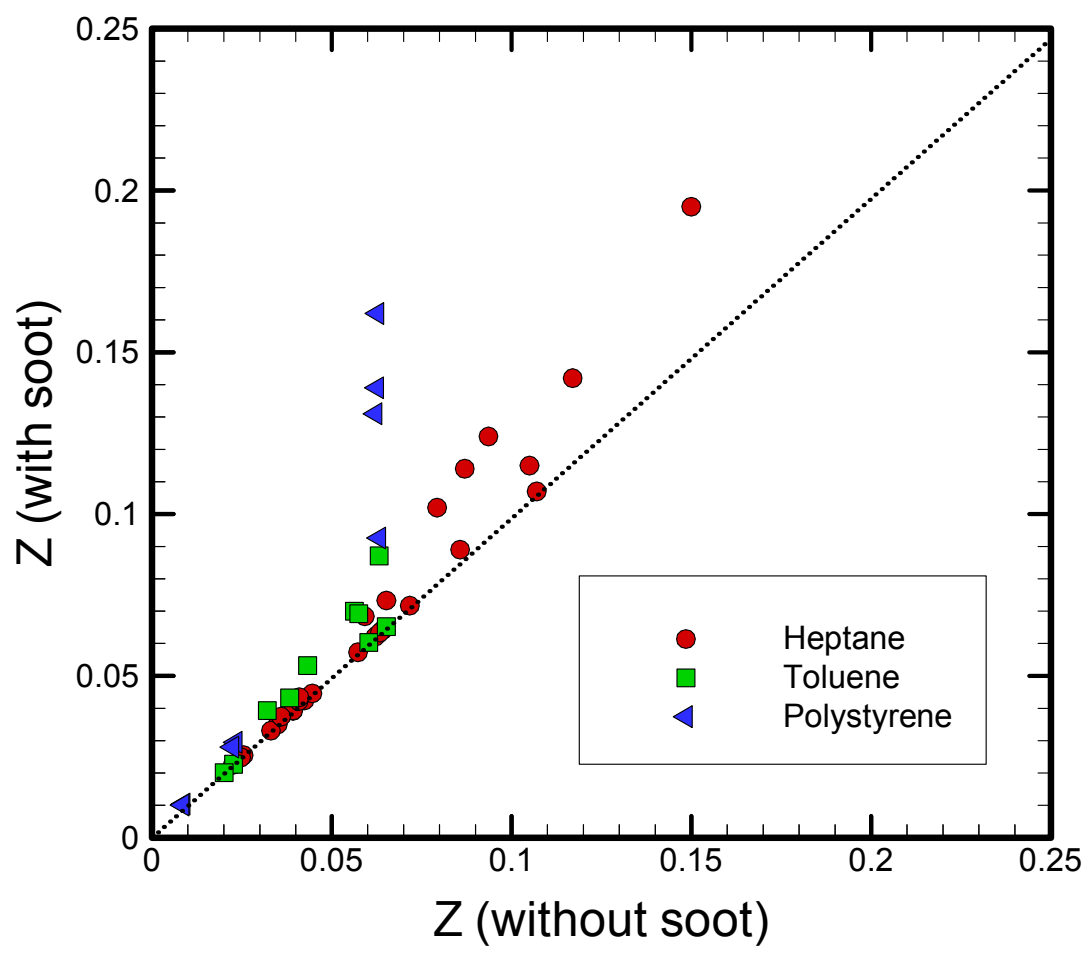

Figure 78 Comparison of mixture fractions calculated with and without soot using the timeaveraged species measurements when the HRR was quasi-steady in the experiments burning (a) heptane, (b) toluene, and (c) polystyrene. 


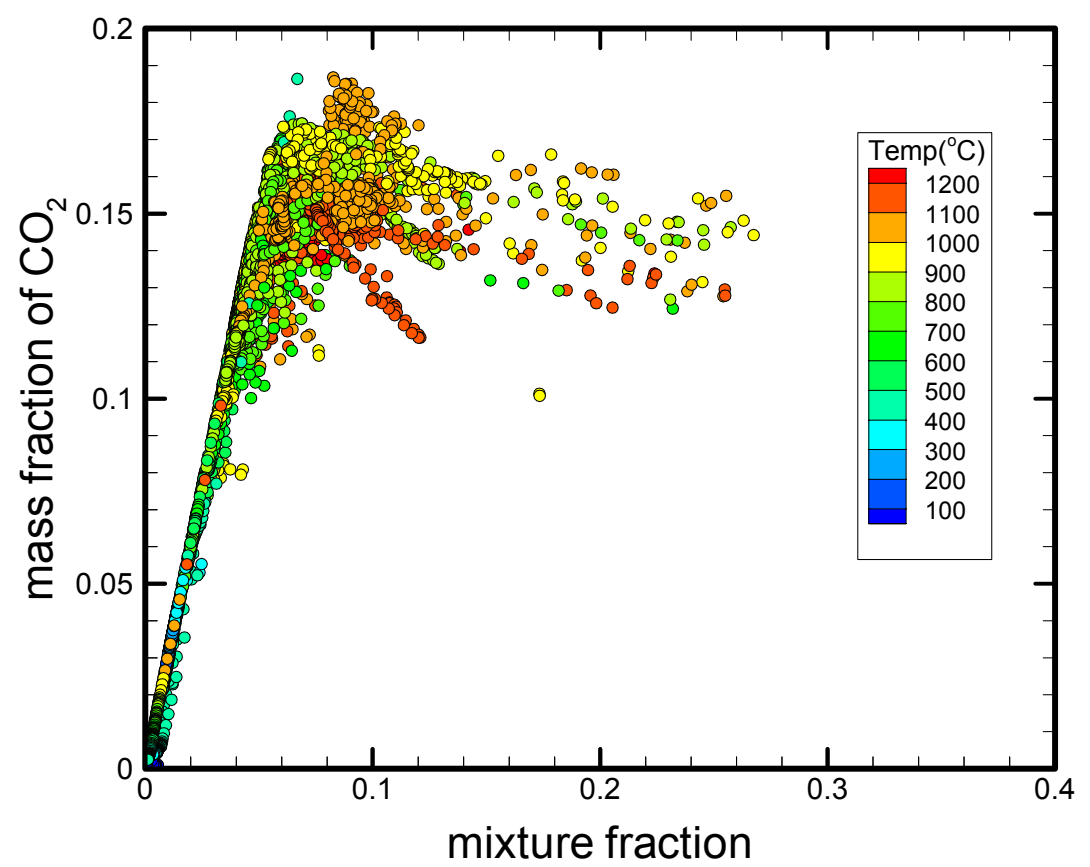

(a)

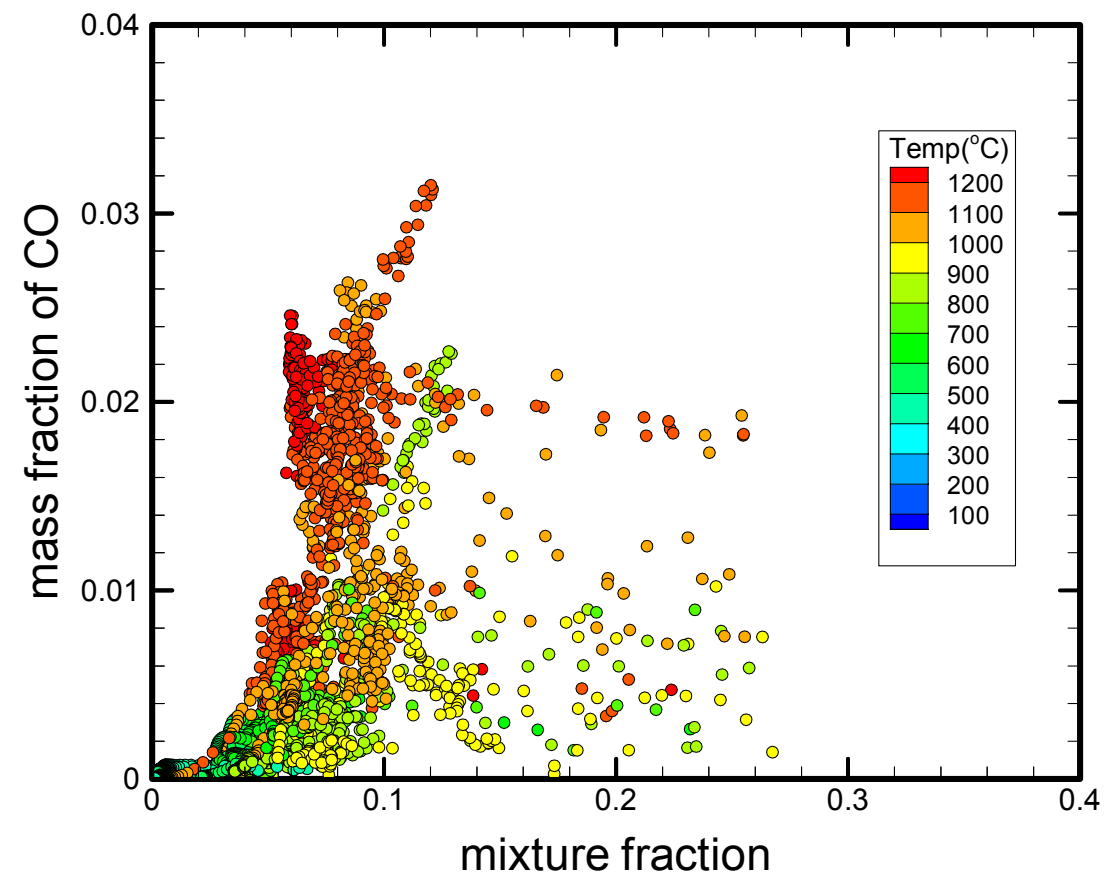

(b)

Figure 79 Transient values of (a) $Y_{\mathrm{CO} 2}$ and (b) $Y_{C O}$ in the front and rear of the compartment as a function of the mixture fraction (without soot) with symbols colored to represent the local temperature for the heptane fire tests $\# 4, \# 5$, and $\# 7$. 


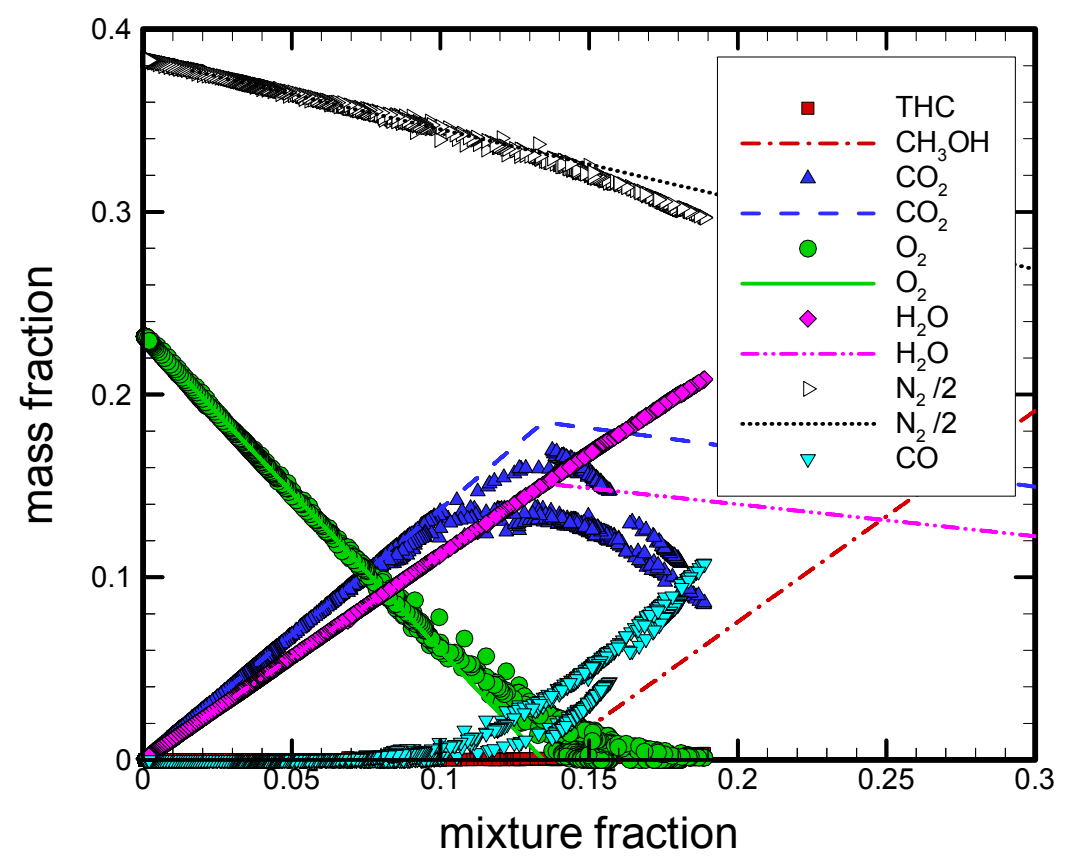

(a)

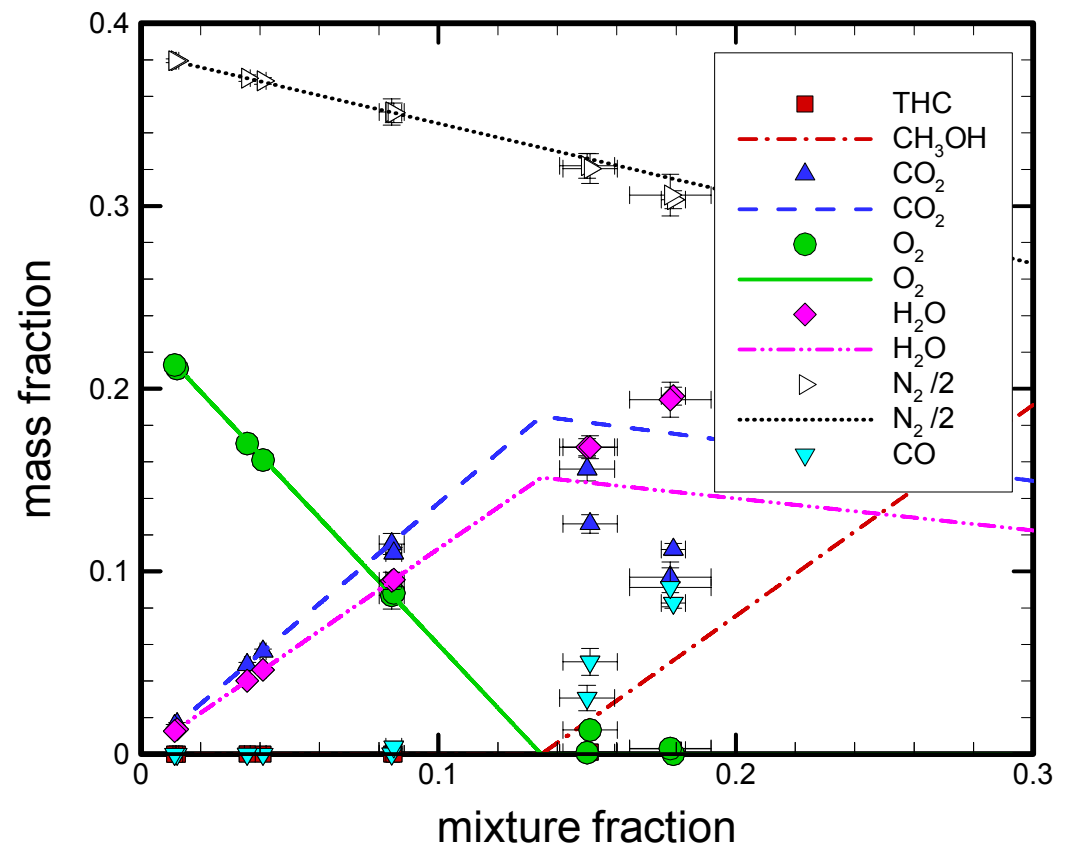

(b)

Figure 80 Mass fractions of front and rear compartment gas species as a function of mixture fraction for methanol fire tests \#8 and \#12: (a) transient measurements and (b) time-averaged measurements during the period when the HRR was quasi-steady. 


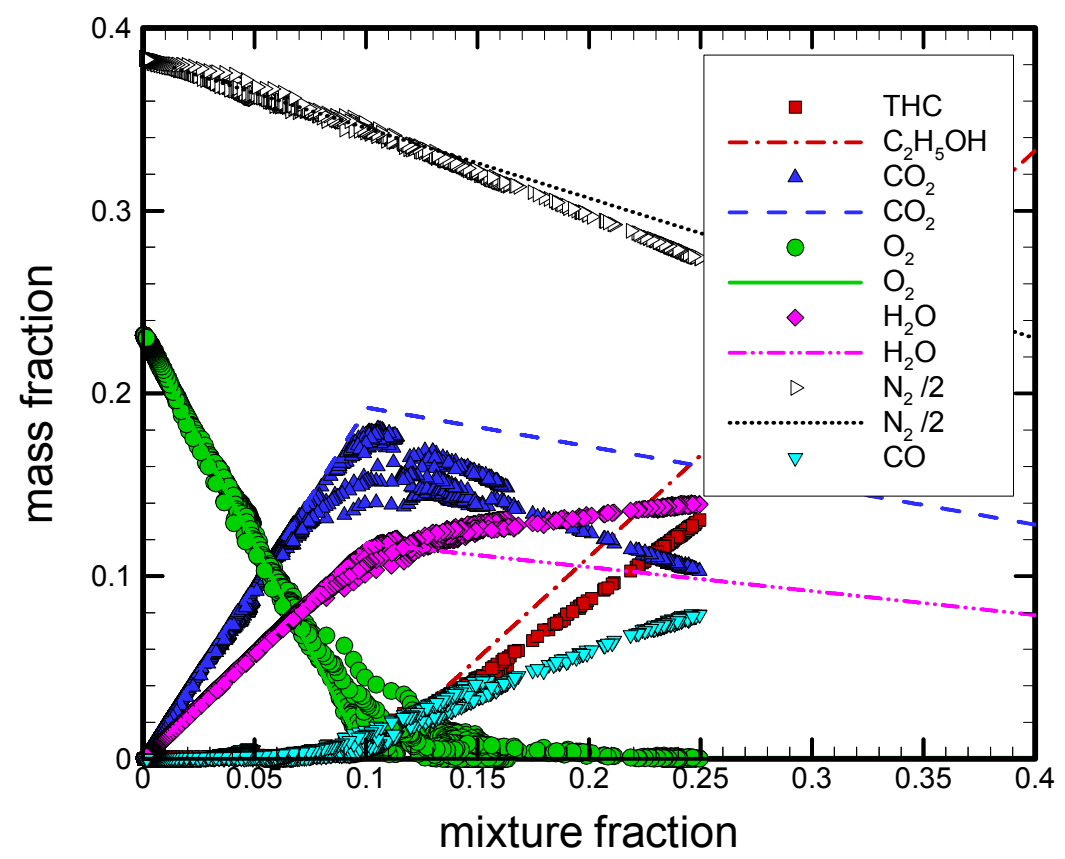

(a)

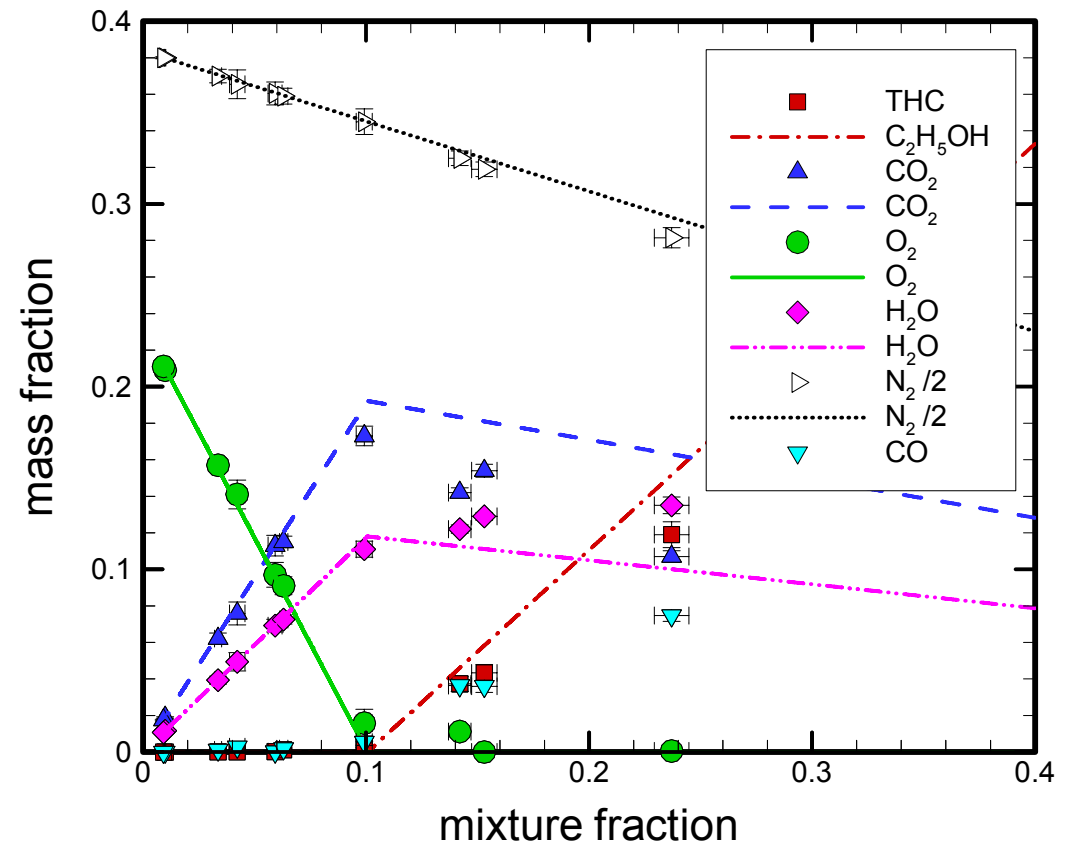

(b)

Figure 81 Mass fractions of front and rear compartment gas species as a function of mixture fraction for ethanol tests \#9 and \#11: (a) transient measurements and (b) time-averaged measurements during the period when the HRR was quasi-steady. 


\subsection{Chemical Equilibrium}

This section is complementary to the previous section, investigating aspects of the species concentrations in the compartment fire. Here, the measurements are used to test the hypothesis that local chemical equilibrium exists within the compartment. As an example, results are presented for natural gas. Although this type of analysis has been previously considered (e.g., Sivathanu and Faeth, [41] ), it is of interest to confirm that the measurements conducted in this study are consistent with previous results.

The time-averaged data taken during the period when the HRR was quasi-steady shown in Fig. 73 are considered in this analysis. Local chemical equilibrium was calculated using the measured species (unburned hydrocarbons, $\mathrm{CO}_{2}, \mathrm{CO}, \mathrm{O}_{2}, \mathrm{~N}_{2}, \mathrm{H}_{2} \mathrm{O}$, and soot) and temperature data as input. The STANJAN software [45] was used to calculate the products of local thermodynamic equilibrium. Product species that were considered included $\mathrm{CH}_{4}, \mathrm{C}_{2} \mathrm{H}_{6}, \mathrm{C}_{3} \mathrm{H}_{8}$, $\mathrm{CO}_{2}, \mathrm{CO}, \mathrm{O}_{2}, \mathrm{~N}_{2}, \mathrm{H}_{2} \mathrm{O}$, soot and $\mathrm{H}_{2}$. Figure $82 \mathrm{a}$ and Fig. $82 \mathrm{~b}$ compare the equilibrium results (filled symbols) with the measured mass fractions (open symbols) for the major species, e.g. $\mathrm{CH}_{4}, \mathrm{CO}_{2}, \mathrm{CO}, \mathrm{O}_{2}, \mathrm{H}_{2} \mathrm{O}$, and soot. Because of the dependency of equilibrium on temperature, the calculated results show significant scatter at larger mixture fractions. Like the mixture fraction correlation, the calculations show good agreement with the measurements for fuel lean conditions, but significant differences exist for fuel rich conditions - consistent with previous results [41]. In particular, predictions of $\mathrm{CO}$ are entirely inaccurate using this approach. In the following sections, compartment chemistry is investigated using other methods. 


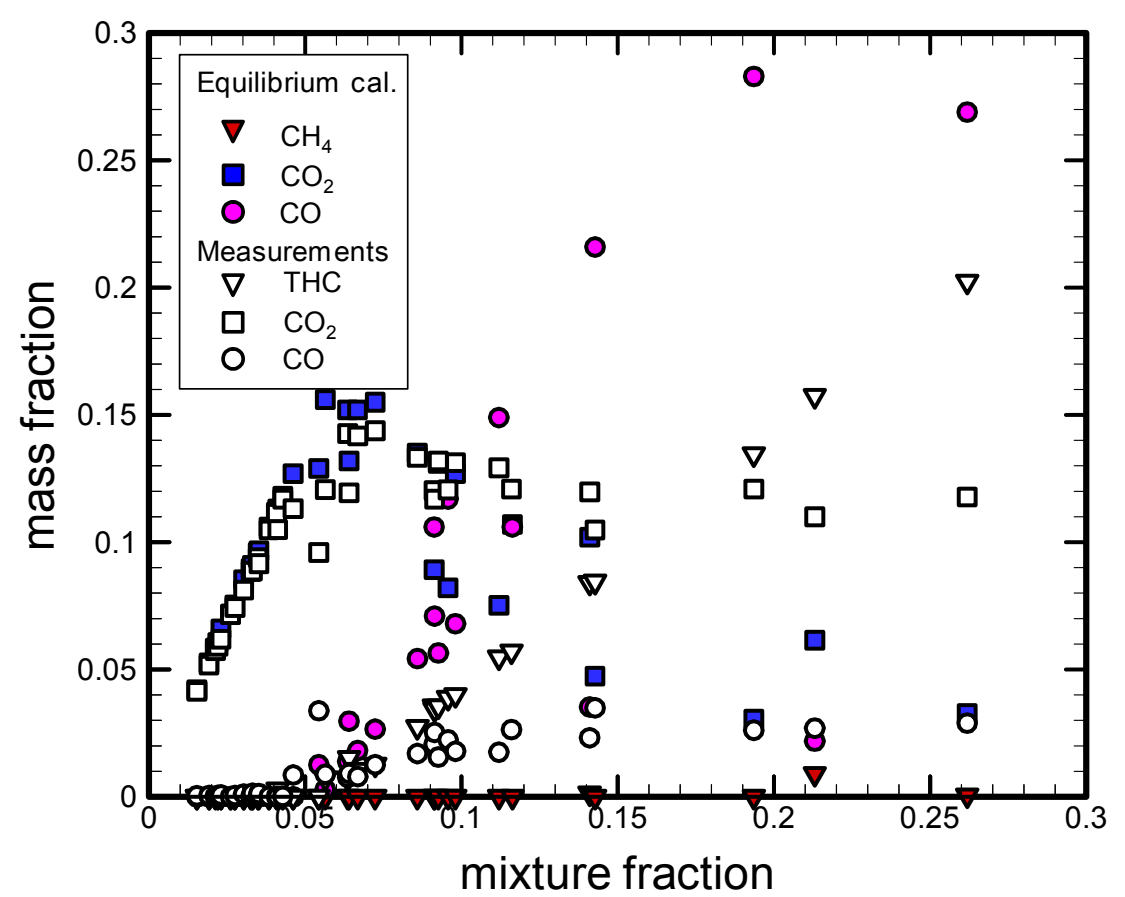

(a)

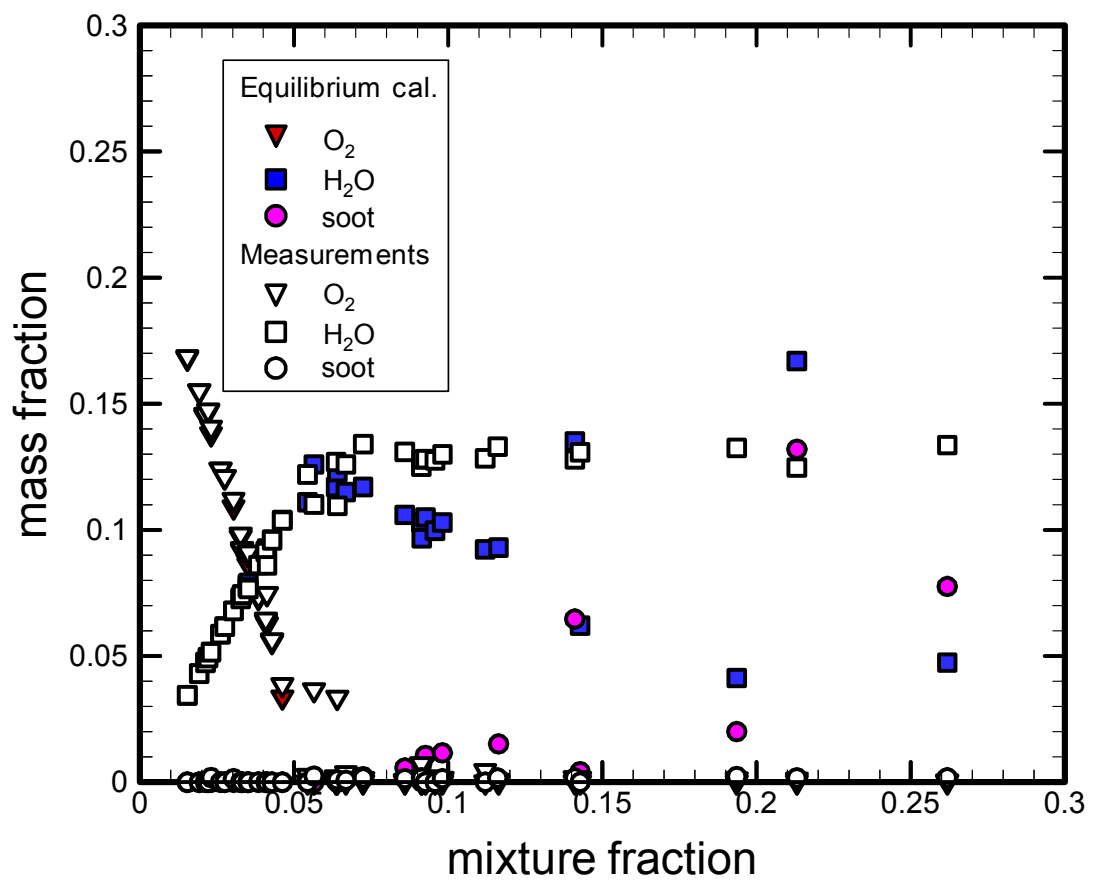

(b)

Figure 82 Comparison between the equilibrium calculations and the time-averaged species mass fractions measured in the front and rear of the compartment as a function of the mixture fraction during the period when the HRR was quasi-steady in the natural gas fire tests \#1-\#3, and \#6. 


\subsection{Carbon Balance}

The compartment measurements show that elemental carbon was partitioned among soot and three principal gaseous species $\left(\mathrm{CO}_{2}, \mathrm{CO}\right.$, and $\left.\mathrm{CH}_{4}\right)$ in the upper layer of the compartment. Other hydrocarbons were measured in only trace quantities compared to methane. The fractional mass-based amount of carbon that existed in the form of carbon monoxide $\left(\mathrm{F}_{\mathrm{CO}}\right)$ or carbonaceous soot $\left(\mathrm{F}_{\text {soot }}\right)$ is related to the mass fractions of carbon containing species at each measurement location as:

$$
F_{\text {soot }}=\frac{Y_{\text {soot }}}{\frac{12}{16} Y_{\mathrm{CH}_{4}}+\frac{12}{44} Y_{\mathrm{CO}_{2}}+\frac{12}{28} Y_{\mathrm{CO}}+Y_{\text {soot }}} ; \quad F_{C O}=\frac{\frac{12}{28} Y_{C O}}{\frac{12}{16} Y_{\mathrm{CH}_{4}}+\frac{12}{44} Y_{\mathrm{CO}_{2}}+\frac{12}{28} Y_{C O}+Y_{\text {soot }}}
$$

Typically, composition results are presented in the form of product yields or generation rates (defined below), rather than simply fractional mass-based amounts. There are some advantages, however, to examining the data in this form, as the values of $F_{i}$ are bounded from 0 to 1 . In the results presented for the compartment data, the value of $X_{s}$, which is a representation of the amount of carbonaceous soot is defined as:

$$
X_{s}=\frac{Y_{\text {soot }}}{M W_{c}} / \sum \frac{Y_{i}}{M W_{i}}
$$

which comes directly from algebraic manipulation of Eqs. 16 and 17, and the facts that $\sum X_{i} M W_{i}$ is a constant, and $\sum X_{i}=1$.

Table 23 lists $F_{\text {soot }}$ and $F_{C O}$ based on averages of the quasi-steady species measurements at the front and rear locations in the heptane, toluene and polystyrene fires. For convenience, the fire heat release rate (HRR), the local equivalence ratio $(\phi)$ and the ratio $\left(F_{C O} / F_{\text {soot }}\right)$ are also included in the table. The value of $F_{\text {soot }}$ was different for the different fuels, tending to increase with the local equivalence ratio (or mixture faction.) The $F_{\text {soot }}$ was largest for the polystyrene fires (see Table 23), reaching a value of 0.66 . The $F_{\text {soot }}$ in the other fires was also large, taking on values as large as 0.29 in one of the toluene fires and 0.45 in one of the heptane fires. The value of $F_{C O}$ was as large as 0.03 to 0.1 for the polystyrene fires, 0.03 to 0.04 for the toluene fires, and 0.02 to 0.14 for the heptane fires.

Table 23 lists value of $F_{C O} / F_{\text {soot }}$, which depends on fuel type, and physical location. Its value was less than 0.4 , except in one case.

Measurements by Koylu et al. [46] and Santoro and co-workers [47] showed that there is a linear relation in the emission of soot and $\mathrm{CO}$ from buoyant turbulent diffusion flames burning various hydrocarbon fuels (acetylene, propene, etc.). Measurements in the fuel lean (overfire) plume region of hydrocarbon fires showed that the soot and $\mathrm{CO}$ generation factors $\left(\eta_{\mathrm{S}}\right.$ and $\left.\eta_{\mathrm{CO}}\right)$ tended to increase with flame residence time, until a near-constant value was reached after long times (compared to the smoke point). Koylu et al. [46] reported that the ratio of the $\mathrm{CO}$ and soot generation factors for a range of fuel types was such that, $\eta_{C O} / \eta_{S}=0.34 \pm 0.09$. The generation rate was defined as the mass of soot (or gas species) produced per unit mass of fuel carbon consumed. This is slightly different than the soot (or gas species) yield ( $y_{\mathrm{CO}}$ and $y_{\mathrm{s}}$ ), which is based on the mass of all elements (not just carbon) in the fuel stream. The ratios of the yields 
and the generation rates, however, are equal, and their value can be determined at any location from the ratio of the mass fractions of $\mathrm{CO}$ and soot:

$$
\eta_{\mathrm{CO}} / \eta_{\mathrm{S}}=y_{C O} / y_{\text {soot }}=\mathrm{Y}_{\mathrm{CO}} / \mathrm{Y}_{\mathrm{soot}}=(7 / 3) F_{C O} / F_{\text {soot }}
$$

The constant value (7/3) in Eq. 30 is the ratio of the total CO mass to the mass of carbon.

Table 24 lists $y_{C O}, y_{\text {soot }}$, and the ratio $y_{C O} / y_{\text {soot }}$ based on the time-averaged species measurements at the front and rear compartment locations and the stack when the heat release rate was quasi-steady during each of the fires (natural gas, methanol, ethanol, heptane, toluene and polystyrene). The fire heat release rate (HRR) and the local equivalence ratio $(\phi)$ are also listed. Much of the same data was used as in Table 23.

Figure $83 \mathrm{a}$ and Fig. 83b show the yield of $\mathrm{CO}$ and soot as a function of the local equivalence ratio for the heptane, toluene and polystyrene fires. Straight lines seem to be reasonable fits to the data, intersecting the intercept at a non-zero value. Figure 84 is analogous to Fig. 83, with the parameters $F_{\text {soot }}$ and $F_{C O}$ considered in lieu of $y_{C O}$ and $y_{\text {soot }}$. The trends and values of the data shown in the graphs are very similar in appearance, consistent with the data presented in Table 23 and $F_{\text {soot }}$ and $F_{C O}$ is a reasonable way to represent the results and understand that in the toluene and polystyrene fires, almost twice as much carbon exists in the form of soot as compared to CO. The heptane data is much more scattered, making any sort of authoritative generality less convincing. In the richest polystyrene fire $(\phi \approx 2.5)$, almost $80 \%$ of the carbon exists in the form of $\mathrm{CO}$ or soot, with relatively little carbon in the form of $\mathrm{CO}_{2}$.

Figure $85 \mathrm{a}$ and $\mathrm{b}$ shows the yield of $\mathrm{CO}$ and soot as a function of the local equivalence ratio for the natural gas and ethanol fires. The values of $y_{C O}$ and $y_{\text {soot }}$ were relatively low, as compared to the results for the smoky fuels presented in Fig. 83.

Figure 86 shows the $\mathrm{CO}$ yield as a function of the soot yield for the same quasi-steady data shown in Fig. 83 for the heptane, toluene and polystyrene fires. Also shown is a line representing the results of Koylu et al [46]. Koylu reported about $30 \%$ scatter in the ratio of the yields of CO to soot, which is considerably smaller than that seen in the figure. Nevertheless, more data are needed to examine this relationship in the upper layer of compartment fires. It is interesting to note that Tewarson et al [48] reported that the ratio of the $\mathrm{CO}$ and soot generation efficiencies from small fires burning polymers varied, depending on the exact fuel type and the amount of ventilation.

Figure 87 shows the ratio of the $\mathrm{CO}$ yield to the soot yield as a function of the local equivalence ratio for the same quasi-steady data shown in Fig. 83 and Fig. 86 for the heptane, toluene and polystyrene fires. Best fit lines for each fuel type are different, and highlight the trends in the $y_{C O} / y_{\text {soot }}$ data.

Figure 88 shows the $\mathrm{CO}$ yield as a function of the soot yield for the same quasi-steady data shown in Fig. 85 for the natural gas and ethanol fires. Results for methanol are not shown, because the measured soot yield was zero. Also shown in the figure is a line representing the 
results reported by Koylu et al [46] for rather heavy hydrocarbons, including propane, and propylene. The Koylu results do not agree with the current set of data for these non-smoky fuels. Figure 89 shows the ratio of the $\mathrm{CO}$ yield to the soot yield as a function of the local equivalence ratio for the same quasi-steady data shown in Fig. 85 for the natural gas and ethanol fires. Both sets of data could be fit by straight lines. The figure shows that a horizontal line could adequately represent the natural gas results for rich conditions $(\phi>1)$. The ethanol results, however, show a finite slope, which is unique among the fuels tested (also see Fig. 87). Experiments over a range of ventilation conditions in full-scale are planned to further investigate the consistency and repeatability of the trends in the $\mathrm{CO}$ and soot measurement results.

Table 23. Average fractional soot, $\mathrm{CO}$ and $\mathrm{CO} / \mathrm{Soot}$ ratio at the front and rear compartment measurement locations.

\begin{tabular}{|c|c|c|c|c|c|c|c|c|c|}
\hline \multirow{2}{*}{ Fuel } & \multirow{2}{*}{ HRR } & \multicolumn{4}{|c|}{ Rear } & \multicolumn{4}{|c|}{ Front } \\
\hline & & $\phi_{\text {local }}$ & $F_{C O}$ & $F_{\text {soot }}$ & $F_{C O} / F_{\text {soot }}$ & $\phi_{\text {local }}$ & $F_{C O}$ & $F_{\text {soot }}$ & $F_{C O} / F_{\text {soot }}$ \\
\hline \multirow{12}{*}{ heptane } & 140 & 0.957 & 0.047 & 0.049 & 0.959 & 1.463 & 0.019 & 0.039 & 0.49 \\
\hline & 148 & 0.563 & 0.01 & 0.035 & 0.280 & 0.581 & 0.015 & 0.041 & 0.36 \\
\hline & 153 & 0.686 & 0.016 & 0.031 & 0.532 & 0.660 & 0.013 & 0.034 & 0.37 \\
\hline & 160 & 0.547 & 0.013 & 0.066 & 0.205 & 0.677 & 0.022 & 0.058 & 0.38 \\
\hline & 221 & 1.214 & 0.321 & 0.168 & 1.911 & 2.024 & 0.078 & 0.263 & 0.30 \\
\hline & 227 & 0.669 & 0.039 & 0.094 & 0.421 & 1.080 & 0.101 & 0.142 & 0.72 \\
\hline & 246 & 0.650 & 0.017 & 0.064 & 0.267 & 1.169 & 0.076 & 0.116 & 0.65 \\
\hline & 269 & 0.730 & 0.012 & 0.043 & 0.288 & 1.922 & 0.161 & 0.089 & 1.8 \\
\hline & 301 & 1.366 & 0.103 & 0.170 & 0.603 & 2.407 & 0.22 & 0.195 & 1.13 \\
\hline & 341 & 1.249 & 0.143 & 0.211 & 0.678 & 1.636 & 0.22 & 0.236 & 0.93 \\
\hline & 375 & 1.163 & 0.101 & 0.162 & 0.622 & 1.855 & 0.187 & 0.257 & 0.73 \\
\hline & 377 & 2.281 & 0.138 & 0.238 & 0.578 & 3.469 & 0.216 & 0.267 & 0.81 \\
\hline \multirow{3}{*}{ toluene } & 138 & 0.540 & 0.044 & 0.190 & 0.230 & 0.741 & 0.04 & 0.195 & 0.21 \\
\hline & 202 & 0.599 & 0.009 & 0.117 & 0.077 & 0.981 & 0.022 & 0.179 & 0.13 \\
\hline & 295 & 0.989 & 0.026 & 0.206 & 0.127 & 1.244 & 0.061 & 0.291 & 0.21 \\
\hline \multirow{4}{*}{ polystyrene } & 15 & 0.137 & 0.074 & 0.149 & 0.498 & 0.133 & 0.071 & 0.157 & 0.45 \\
\hline & 67 & 0.394 & 0.075 & 0.216 & 0.347 & 0.374 & 0.071 & 0.205 & 0.35 \\
\hline & 309 & 2.017 & 0.195 & 0.583 & 0.335 & 1.307 & 0.191 & 0.337 & 0.57 \\
\hline & 358 & 2.391 & 0.231 & 0.650 & 0.355 & 1.884 & 0.234 & 0.555 & 0.42 \\
\hline
\end{tabular}




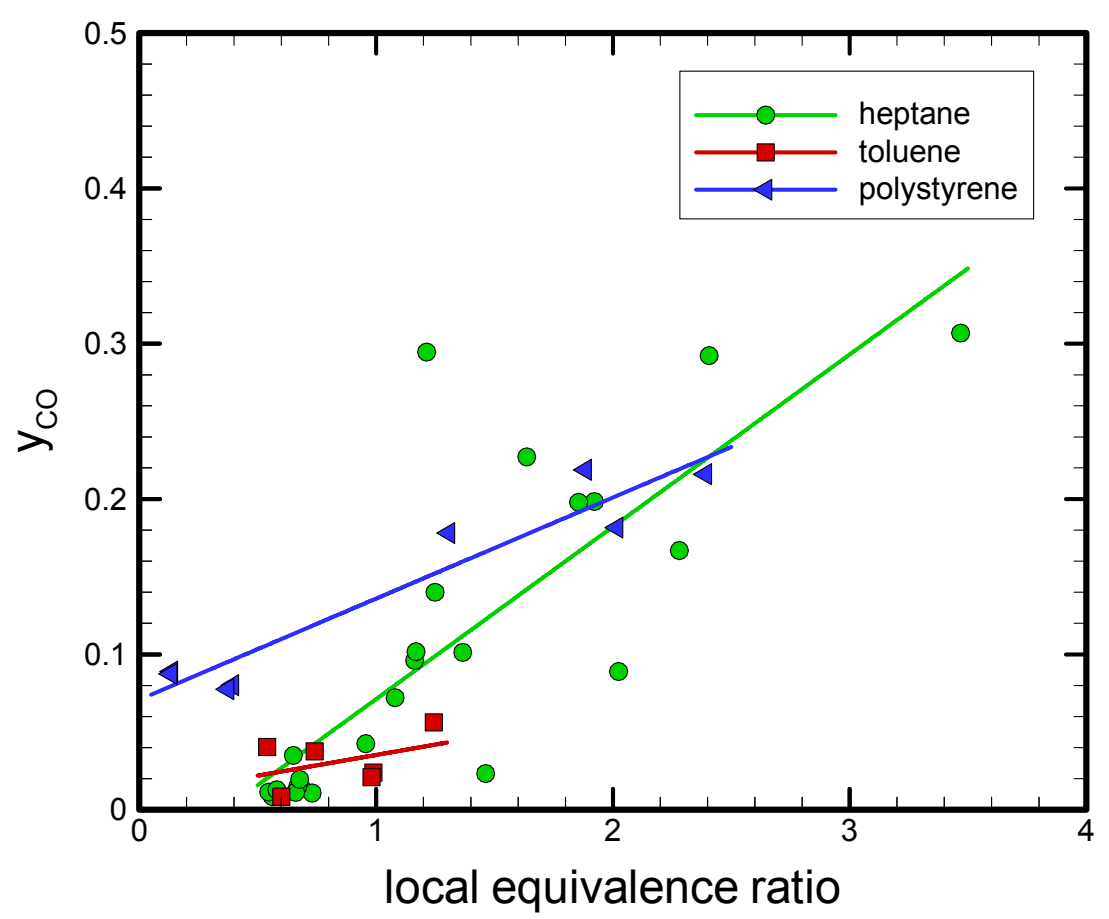

(a)

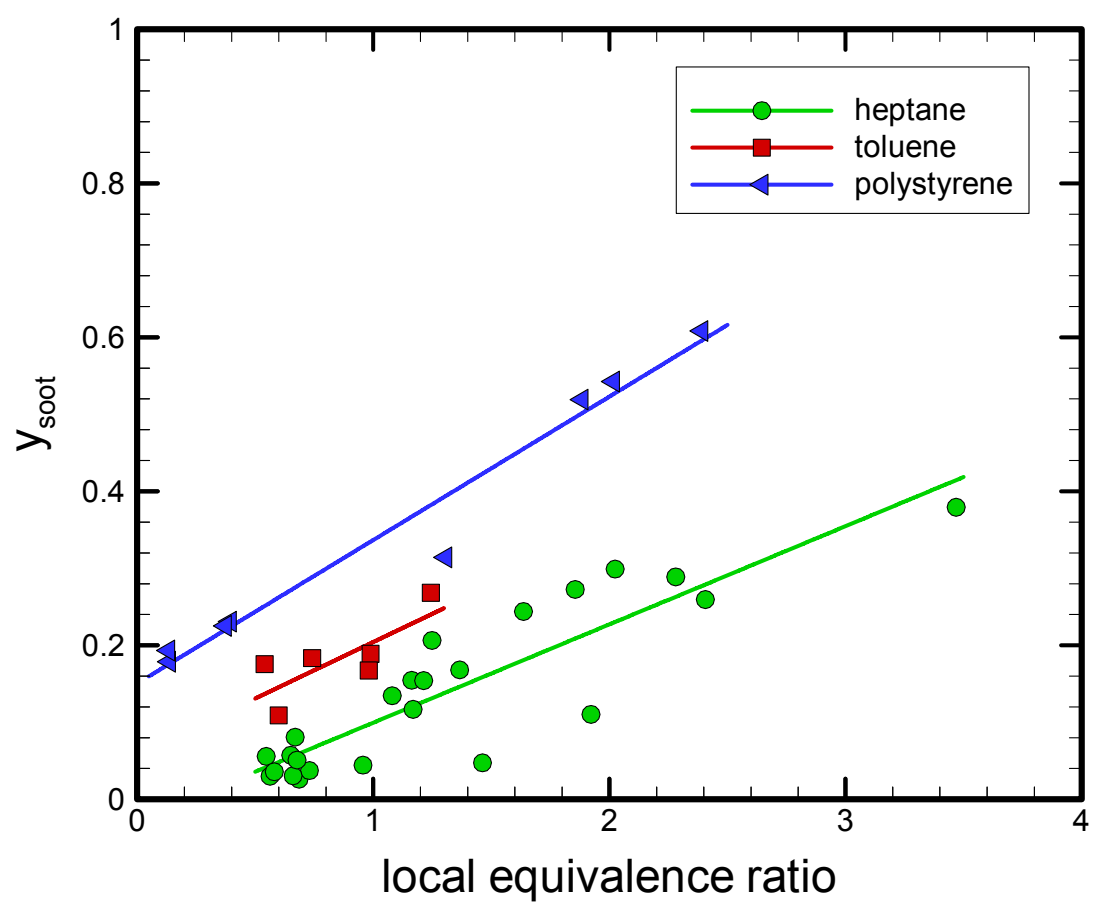

(b)

Figure 83 The $\mathrm{CO}$ and soot yields as a function of the local equivalence ratio for the timeaveraged measurements during the period when the HRR was quasi-steady in the heptane, toluene and polystyrene fires. 


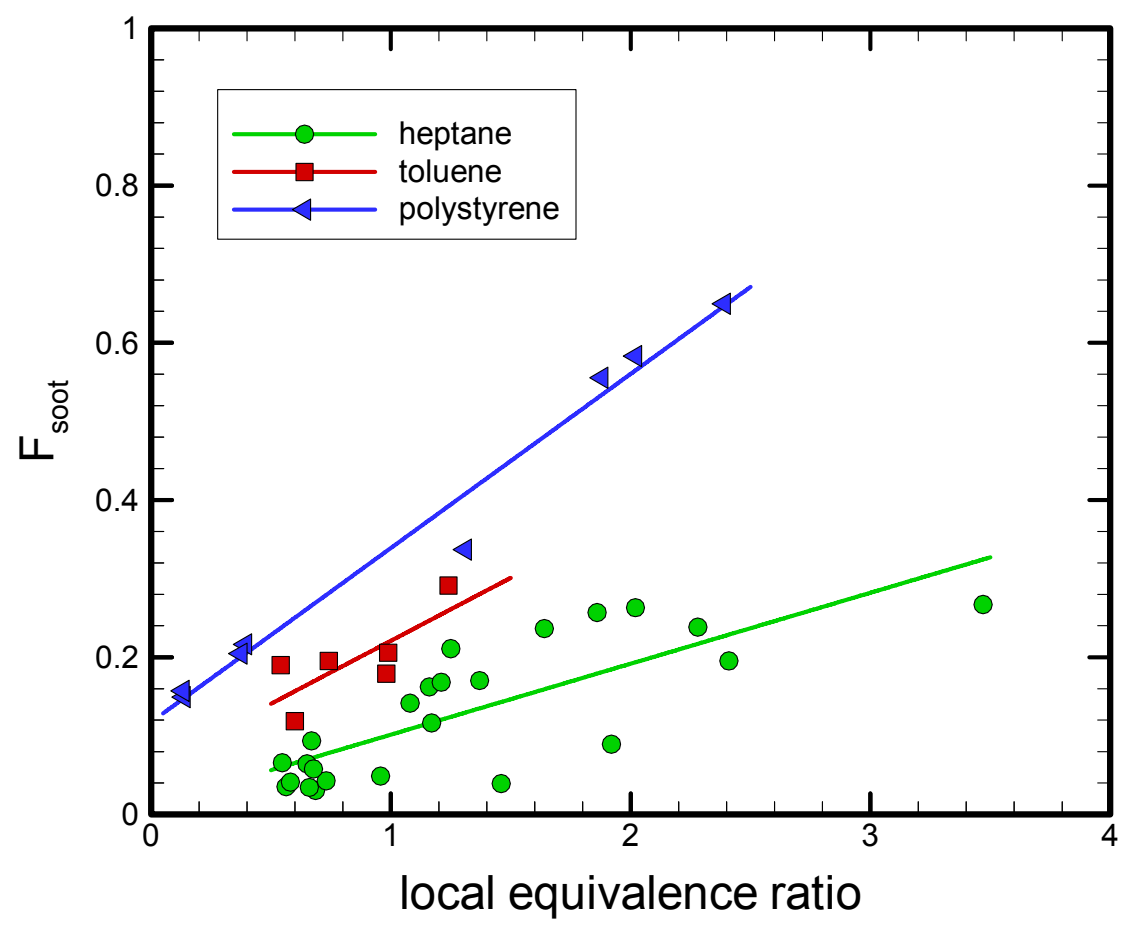

(a)

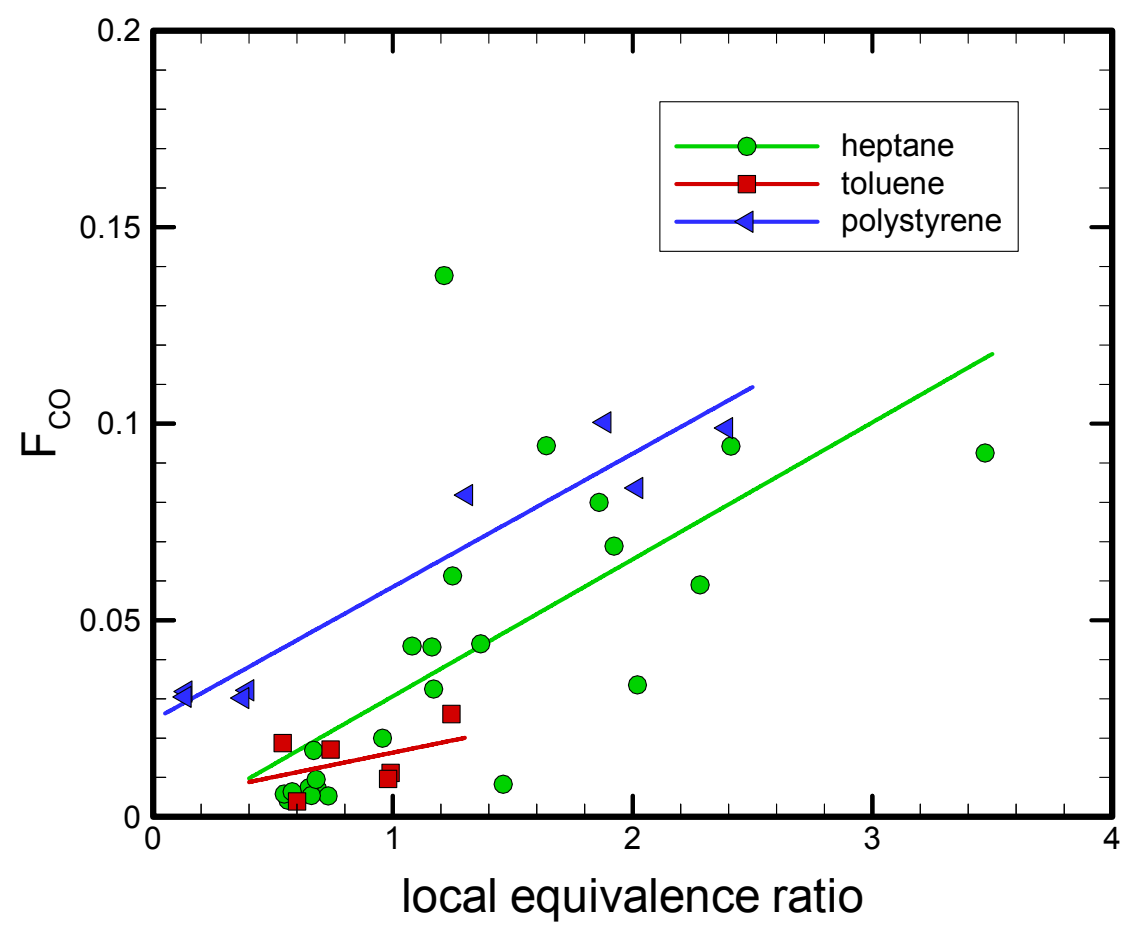

(b)

Figure 84. The values of $F_{C O}$ and $F_{S o o t}$ as a function of the local equivalence ratio during the period when the HRR was quasi-steady in the heptane, toluene and polystyrene fires. 


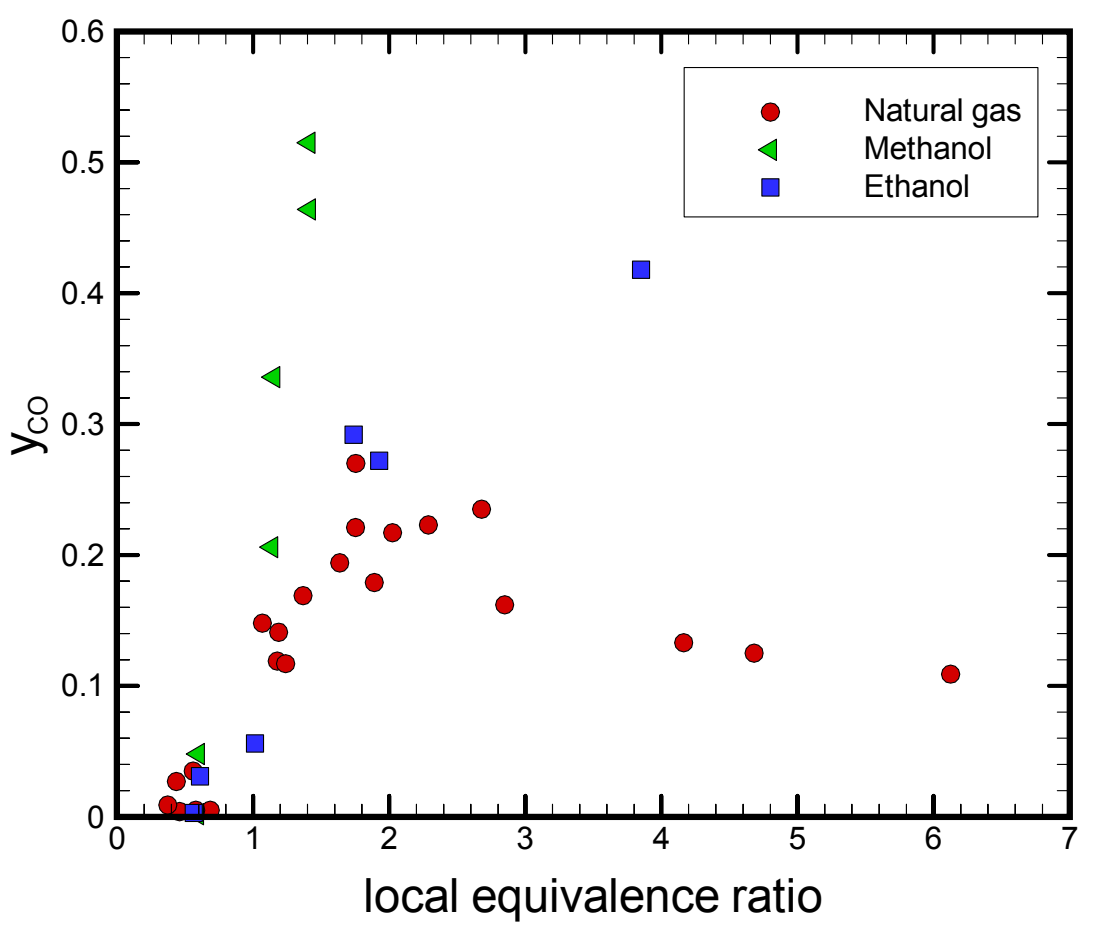

(a)

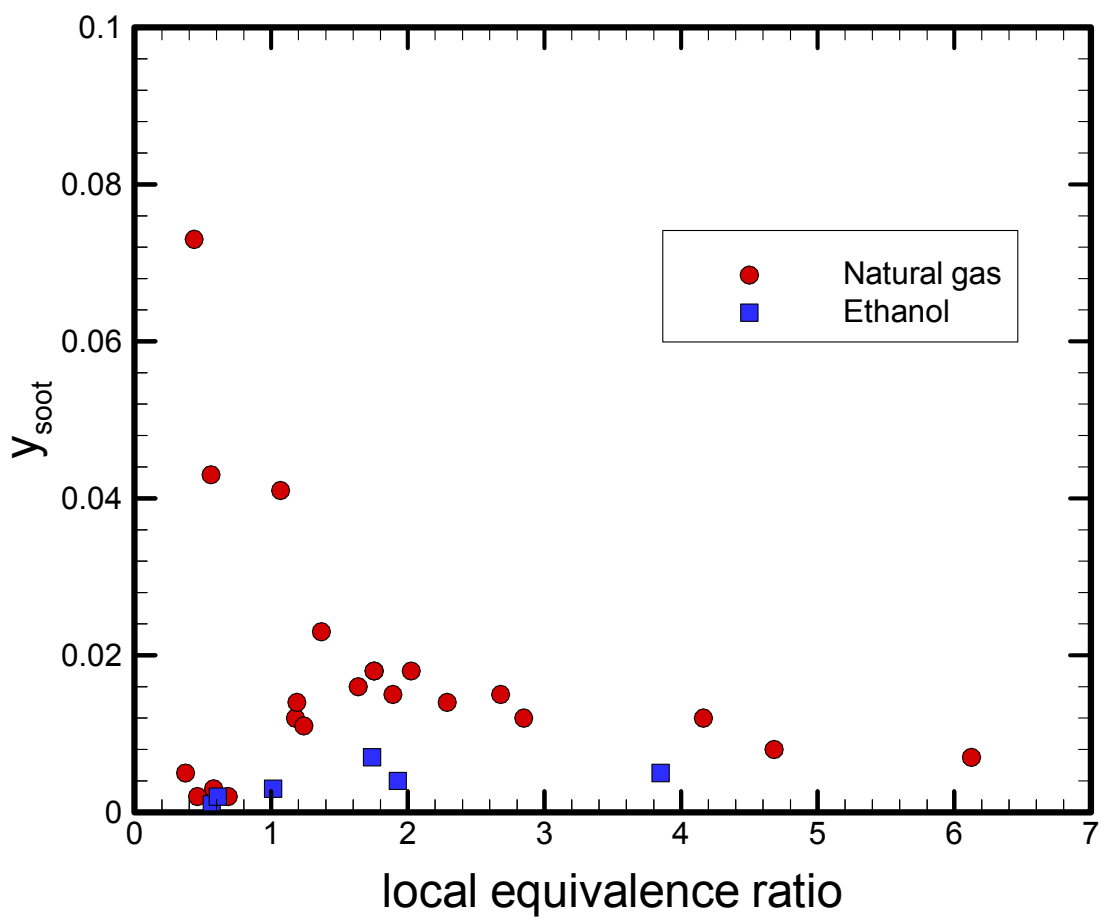

(b)

Figure 85 The $\mathrm{CO}$ and soot yields as a function of the local equivalence ratio during the period when the HRR was quasi-steady in the natural gas and ethanol fires. 


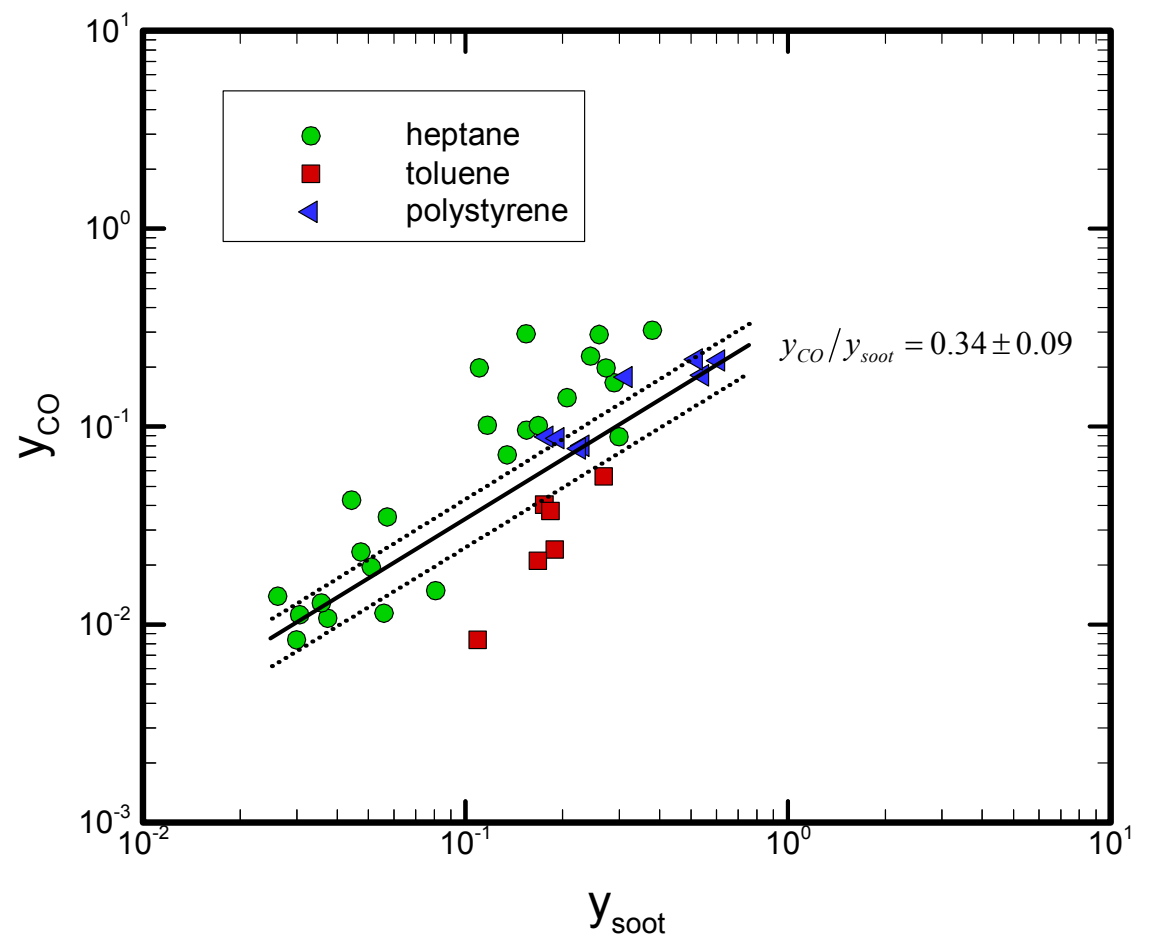

Figure 86. The $\mathrm{CO}$ yield as a function of the soot yield during the period when the HRR was quasi-steady in the heptane, toluene and polystyrene fires. Also shown is a line representing the results of Koylu [46].

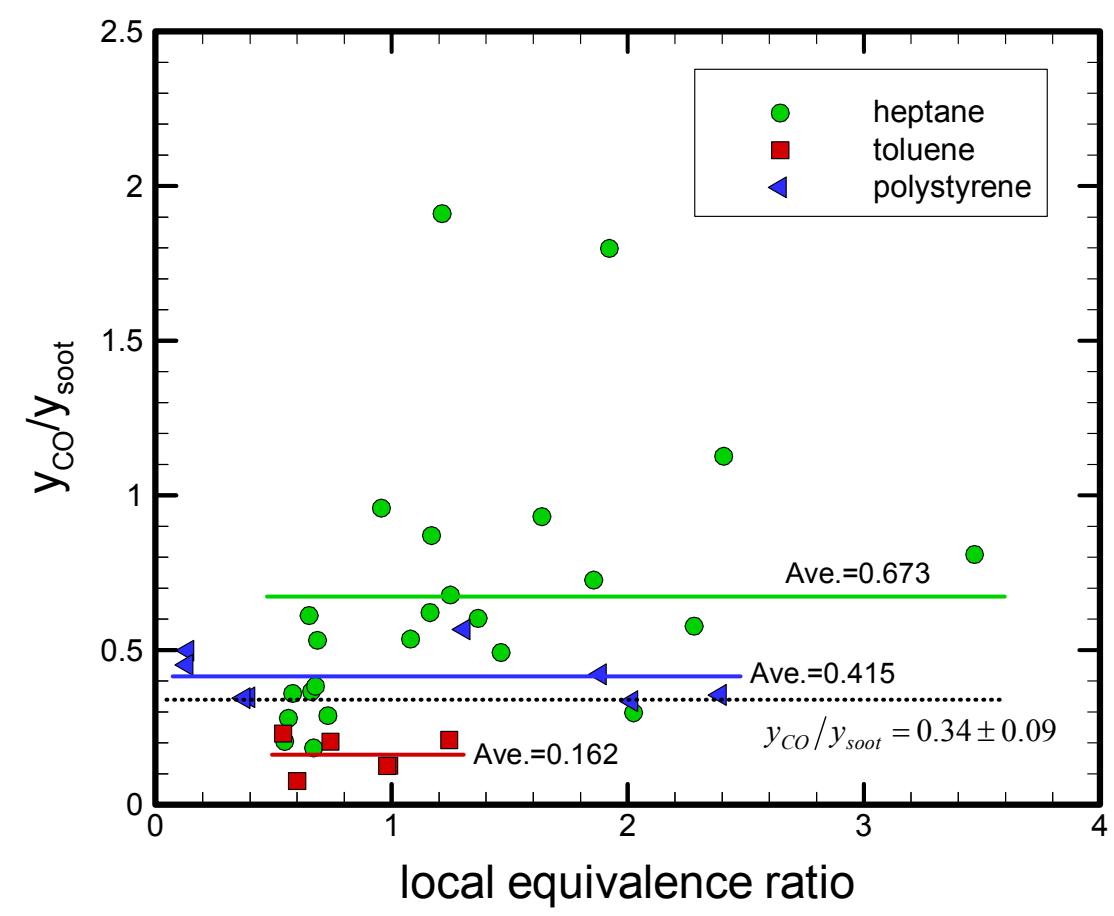

Figure 87. The ratio of the $\mathrm{CO}$ to soot yield as a function of the local equivalence ration during the period when the HRR was quasi-steady in the heptane, toluene and polystyrene fires. Best fit lines to the data and a line representing the results of Koylu [46] are also shown. 


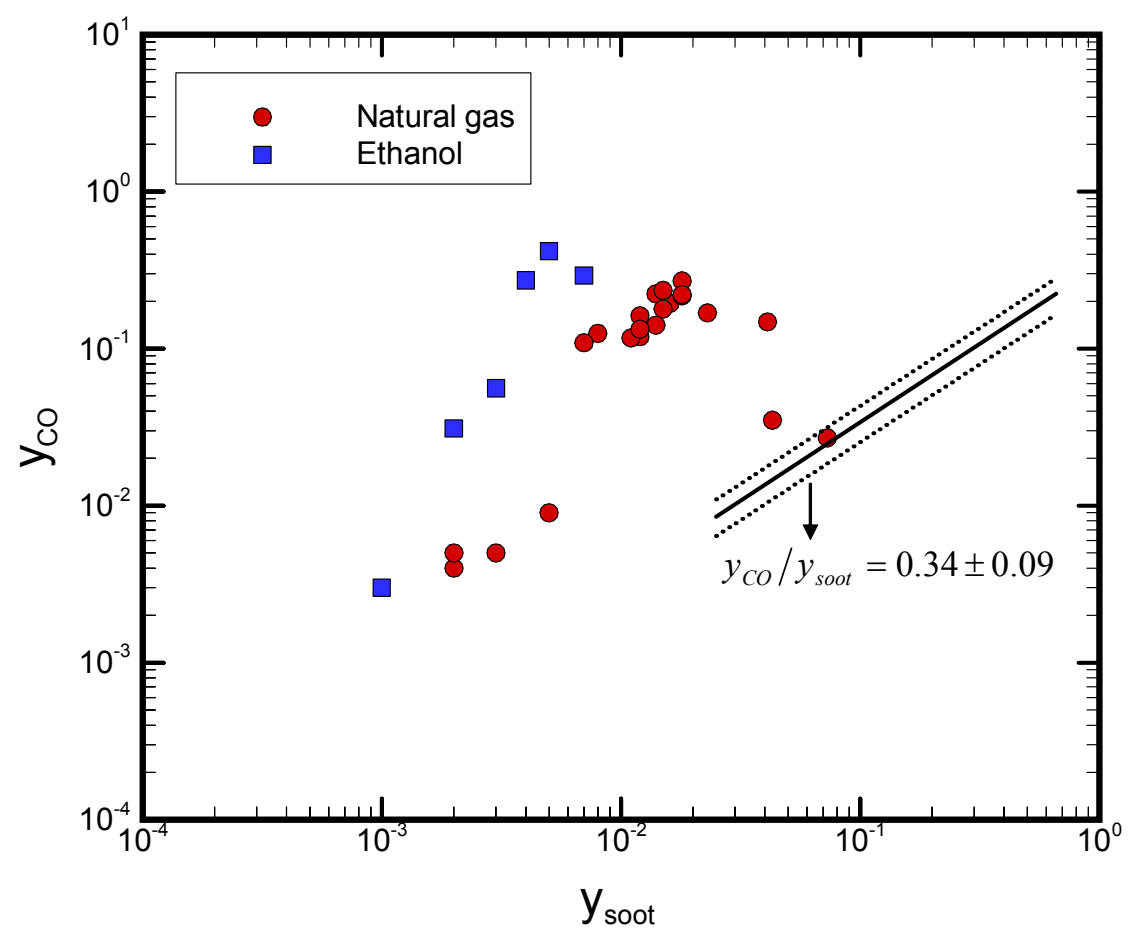

Figure 88 The $\mathrm{CO}$ yield as a function of the soot yield for the same data shown in Fig. 85 during the period when the HRR was quasi-steady in the natural gas and ethanol fires.

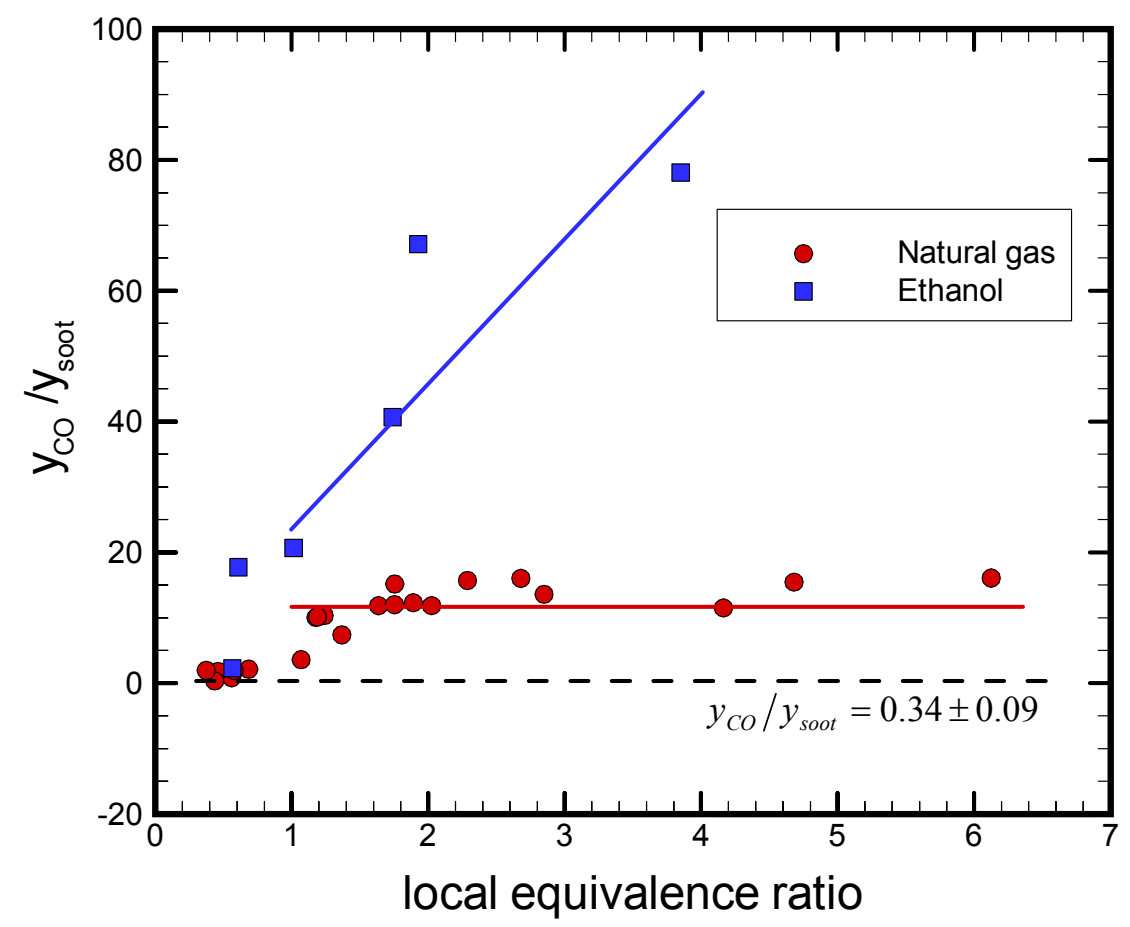

Figure 89 The ratio of the $\mathrm{CO}$ to soot yield as a function of the local equivalence ration for the same data shown in Fig. 85 during the period when the HRR was quasi-steady in the natural gas and ethanol fires. 
Table 24. Time-averaged yields of soot, $\mathrm{CO}$, and the ratio $\left(\mathrm{y}_{\mathrm{CO}} / \mathrm{y}_{\mathrm{s}}\right)$ at the front and rear compartment measurement locations and in the exhaust stack for all fuel types.

\begin{tabular}{|c|c|c|c|c|c|c|c|c|c|c|c|c|}
\hline \multirow{2}{*}{ Fuel } & \multirow{2}{*}{$\begin{array}{l}\text { HRR } \\
{[\mathrm{kW}]}\end{array}$} & \multicolumn{4}{|c|}{ Rear } & \multicolumn{4}{|c|}{ Front } & \multicolumn{3}{|c|}{ Stack } \\
\hline & & $\varphi_{\text {local }}$ & $\mathrm{y}_{\mathrm{co}}$ & $\mathrm{y}_{\mathrm{s}}$ & $\mathrm{y}_{\mathrm{co}} / \mathrm{y}_{\mathrm{s}}$ & $\varphi_{\text {local }}$ & $\mathrm{y}_{\mathrm{co}}$ & $\mathrm{y}_{\mathrm{s}}$ & $\mathrm{y}_{\mathrm{co}} / \mathrm{y}_{\mathrm{s}}$ & $\mathrm{y}_{\mathrm{co}}$ & $\mathrm{y}_{\mathrm{s}}$ & $\mathrm{y}_{\mathrm{co}} / \mathrm{y}_{\mathrm{s}}$ \\
\hline \multirow{13}{*}{ Natural gas } & 74 & 0.686 & 0.005 & 0.002 & 2.126 & 0.579 & 0.005 & 0.003 & 1.933 & - & - & - \\
\hline & 74 & 0.460 & 0.004 & 0.002 & 1.802 & 0.373 & 0.009 & 0.005 & 1.955 & - & - & - \\
\hline & 75 & 0.559 & 0.035 & 0.043 & 0.817 & 0.436 & 0.027 & 0.073 & 0.373 & - & - & - \\
\hline & 85 & 0.452 & 0.026 & - & - & 0.407 & 0.015 & - & - & 0.067 & 0.000 & - \\
\hline & 97 & 0.565 & 0.058 & - & - & 0.481 & 0.036 & - & - & 0.161 & 0.000 & - \\
\hline & 179 & 1.239 & 0.117 & 0.011 & 10.35 & 1.188 & 0.141 & 0.014 & 10.14 & - & - & - \\
\hline & 181 & 0.980 & 0.068 & - & - & 1.070 & 0.192 & - & - & 0.018 & 0.000 & \\
\hline & 186 & 1.368 & 0.169 & 0.023 & 7.396 & 1.069 & 0.148 & 0.041 & 3.588 & - & - & \\
\hline & 265 & 1.891 & 0.179 & 0.015 & 12.30 & 1.753 & 0.221 & 0.018 & 12.01 & - & - & - \\
\hline & 272 & 2.849 & 0.162 & 0.012 & 13.58 & 4.164 & 0.133 & 0.012 & 11.51 & - & - & - \\
\hline & 273 & 1.372 & 0.191 & - & - & 1.720 & 0.279 & - & - & 0.016 & 0.000 & - \\
\hline & 417 & 4.681 & 0.125 & 0.008 & 15.45 & 6.125 & 0.109 & 0.007 & 16.07 & - & - & - \\
\hline & 424 & 2.025 & 0.217 & 0.018 & 11.86 & 2.679 & 0.235 & 0.015 & 16.03 & 0.024 & 0.000 & \\
\hline \multirow{14}{*}{ Heptane } & 83 & 0.383 & 0.015 & - & - & 0.349 & 0.022 & - & - & 0.009 & 0.044 & 0.212 \\
\hline & 88 & 0.394 & 0.007 & - & - & 0.347 & 0.005 & - & - & 0.006 & 0.029 & 0.212 \\
\hline & 140 & 0.957 & 0.043 & 0.044 & 0.957 & 1.463 & 0.023 & 0.047 & 0.491 & - & - & - \\
\hline & 148 & 0.563 & 0.008 & 0.030 & 0.280 & 0.581 & 0.013 & 0.036 & 0.359 & 0.007 & 0.030 & 0.234 \\
\hline & 153 & 0.686 & 0.014 & 0.026 & 0.531 & 0.660 & 0.011 & 0.031 & 0.366 & - & - & - \\
\hline & 160 & 0.547 & 0.011 & 0.056 & 0.204 & 0.677 & 0.020 & 0.051 & 0.382 & 0.010 & 0.056 & 0.174 \\
\hline & 221 & 1.216 & 0.294 & 0.156 & 1.887 & 2.038 & 0.088 & 0.305 & 0.289 & - & - & - \\
\hline & 227 & 0.670 & 0.015 & 0.081 & 0.183 & 1.081 & 0.072 & 0.136 & 0.531 & 0.021 & 0.118 & 0.176 \\
\hline & 246 & 0.651 & 0.035 & 0.057 & 0.610 & 1.170 & 0.102 & 0.118 & 0.864 & 0.022 & 0.095 & 0.237 \\
\hline & 269 & 0.730 & 0.011 & 0.037 & 0.287 & 1.923 & 0.198 & 0.111 & 1.783 & - & - & - \\
\hline & 301 & 1.369 & 0.101 & 0.170 & 0.593 & 2.417 & 0.290 & 0.264 & 1.100 & 0.052 & 0.230 & 0.228 \\
\hline & 341 & 1.253 & 0.139 & 0.209 & 0.667 & 1.644 & 0.226 & 0.248 & 0.912 & 0.051 & 0.197 & 0.257 \\
\hline & 375 & 1.165 & 0.096 & 0.156 & 0.613 & 1.866 & 0.196 & 0.277 & 0.708 & - & - & - \\
\hline & 377 & 2.294 & 0.165 & 0.294 & 0.562 & 3.508 & 0.300 & 0.389 & 0.772 & 0.064 & 0.240 & 0.265 \\
\hline \multirow{5}{*}{ Toluene } & 49 & 0.312 & 0.115 & - & - & 0.275 & 0.124 & - & - & 0.098 & 0.148 & 0.662 \\
\hline & 138 & 0.541 & 0.040 & 0.176 & 0.229 & 0.742 & 0.037 & 0.185 & 0.203 & 0.045 & 0.146 & 0.305 \\
\hline & 202 & 0.600 & 0.008 & 0.110 & 0.076 & 0.983 & 0.021 & 0.169 & 0.124 & 0.013 & 0.154 & 0.084 \\
\hline & 295 & 0.991 & 0.024 & 0.191 & 0.125 & 1.252 & 0.056 & 0.273 & 0.204 & 0.011 & 0.127 & 0.084 \\
\hline & 339 & 0.861 & 0.104 & - & - & 0.936 & 0.200 & - & - & 0.023 & 0.171 & 0.136 \\
\hline \multirow{4}{*}{ Polystyrene } & 15 & 0.137 & 0.089 & 0.179 & 0.497 & 0.133 & 0.087 & 0.194 & 0.452 & 0.072 & 0.176 & 0.410 \\
\hline & 67 & 0.395 & 0.080 & 0.232 & 0.345 & 0.374 & 0.078 & 0.226 & 0.343 & 0.070 & 0.253 & 0.277 \\
\hline & 309 & 2.117 & 0.173 & 0.561 & 0.308 & 1.319 & 0.176 & 0.320 & 0.550 & 0.017 & 0.133 & 0.128 \\
\hline & 358 & 2.572 & 0.200 & 0.631 & 0.317 & 1.962 & 0.210 & 0.536 & 0.391 & 0.044 & 0.249 & 0.178 \\
\hline \multirow{3}{*}{ Methanol } & 143 & 0.592 & 0.002 & 0.000 & - & 0.598 & 0.048 & 0.000 & - & 0.000 & 0.000 & - \\
\hline & 240 & 1.137 & 0.206 & 0.000 & - & 1.151 & 0.336 & 0.000 & - & 0.006 & 0.000 & - \\
\hline & 306 & 1.414 & 0.464 & 0.000 & - & 1.411 & 0.515 & 0.000 & - & 0.011 & 0.000 & - \\
\hline \multirow{3}{*}{ Ethanol } & 144 & 0.565 & 0.003 & 0.001 & 2.288 & 0.610 & 0.031 & 0.002 & 17.71 & 0.004 & 0.000 & - \\
\hline & 263 & 1.014 & 0.056 & 0.003 & 20.68 & 1.739 & 0.292 & 0.007 & 40.68 & 0.004 & 0.000 & - \\
\hline & 335 & 1.927 & 0.272 & 0.004 & 67.13 & 3.850 & 0.418 & 0.005 & 78.05 & 0.008 & 0.000 & - \\
\hline
\end{tabular}




\subsection{Post-Compartment Product Yields}

It is useful to consider the product yields downstream from the fire compartment in the exhaust stack, and to compare these results to conditions in the compartment. These comparisons highlight the effects of a compartment on fire chemistry.

The yields of $\mathrm{CO}_{2}, \mathrm{CO}$, soot, and hydrocarbons determined from the measurements made in the exhaust hood during the quasi-steady burning periods for each of the fuels tested are shown in Figure 90 through Fig. 93 as a function of the fire heat release rate. The largest yield in the stack was for $\mathrm{CO}_{2}(125 \%$ to $300 \%)$, followed by soot $(<25 \%), \mathrm{CO}(<10 \%)$, and total hydrocarbons $(<3.5 \%)$. The $\mathrm{CO}_{2}$ yield in the stack shown in Fig. 90 was related to the stoichiometry (Eq. 9) and the combustion efficiency. The CO yield in the stack shown in Fig. 91 appeared to be a function of fuel type and fire size. Some fuels exhibited high CO yields for lower heat release rates (toluene, polystyrene, ethanol, natural gas) and other fuels exhibited relatively higher $\mathrm{CO}$ yields (heptane, methanol) for higher heat release rates. The results for the soot yield shown in Fig. 92 were also dependent on the fuel type and the HRR, whereas some fuels (natural gas and methanol) produced absolutely negligible amounts of soot. The soot yield was as large as $15 \%$ to $25 \%$ for the heptane, toluene and polystyrene fires.

The local product species yields in the rear and front of the compartment were discussed previously. Table 24 lists the $\mathrm{CO}$ and soot yields in the smoke-laden (heptane, toluene and polystyrene) and non-smoky fires (natural gas and ethanol) as a function of the fire size, both in the compartment and in the stack. The data in the Table are also plotted in Fig. 83 and Fig. 85. For the smoky fires, the yield of soot was almost always larger in the compartment than in the stack. For example, the yield of soot in the toluene fire varied from 0.15 to 0.17 in the stack as compared to values as high as 0.27 in the compartment. The polystyrene fire was the smokiest and the yield of soot varied from 0.13 to 0.25 in the stack as compared to 0.18 to 0.61 in the compartment. The yield of $\mathrm{CO}$ was generally, but not always larger in the compartment than in the stack, and typically a factor of 1.5 to 7 times larger depending on the fuel type. The yield of $\mathrm{CO}$ in the polystyrene fire varied from 0.02 to 0.07 in the stack as compared to 0.08 to 0.26 in the compartment. The yield of $\mathrm{CO}$ in the ethanol fire varied from approximately 0.004 to 0.07 in the stack as compared to 0.003 to 0.42 in the compartment. 


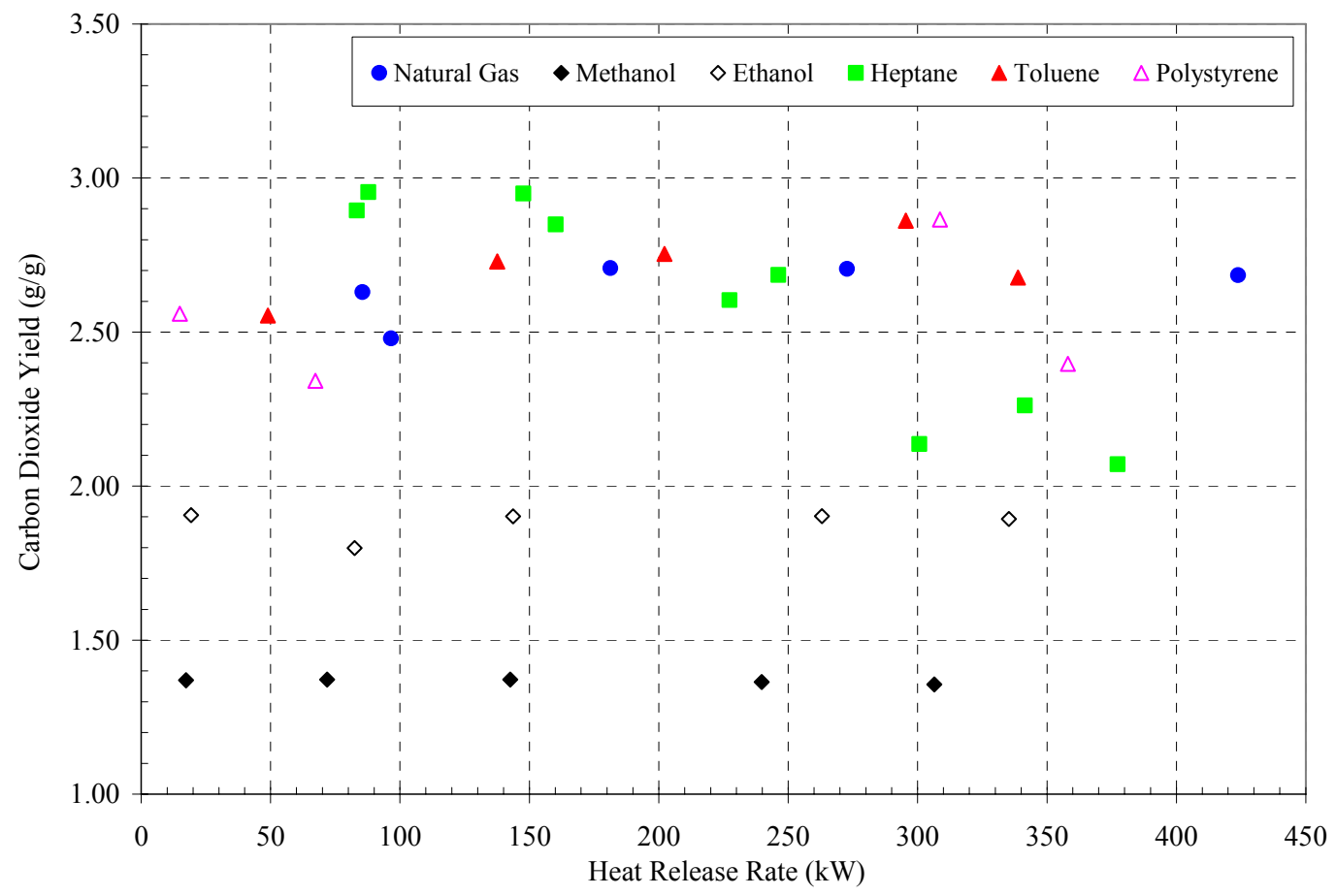

Figure 90 The $\mathrm{CO}_{2}$ yield in the exhaust stack as a function of the fire heat release rate during the periods when the HRR was quasi-steady for each of the fuels tested.

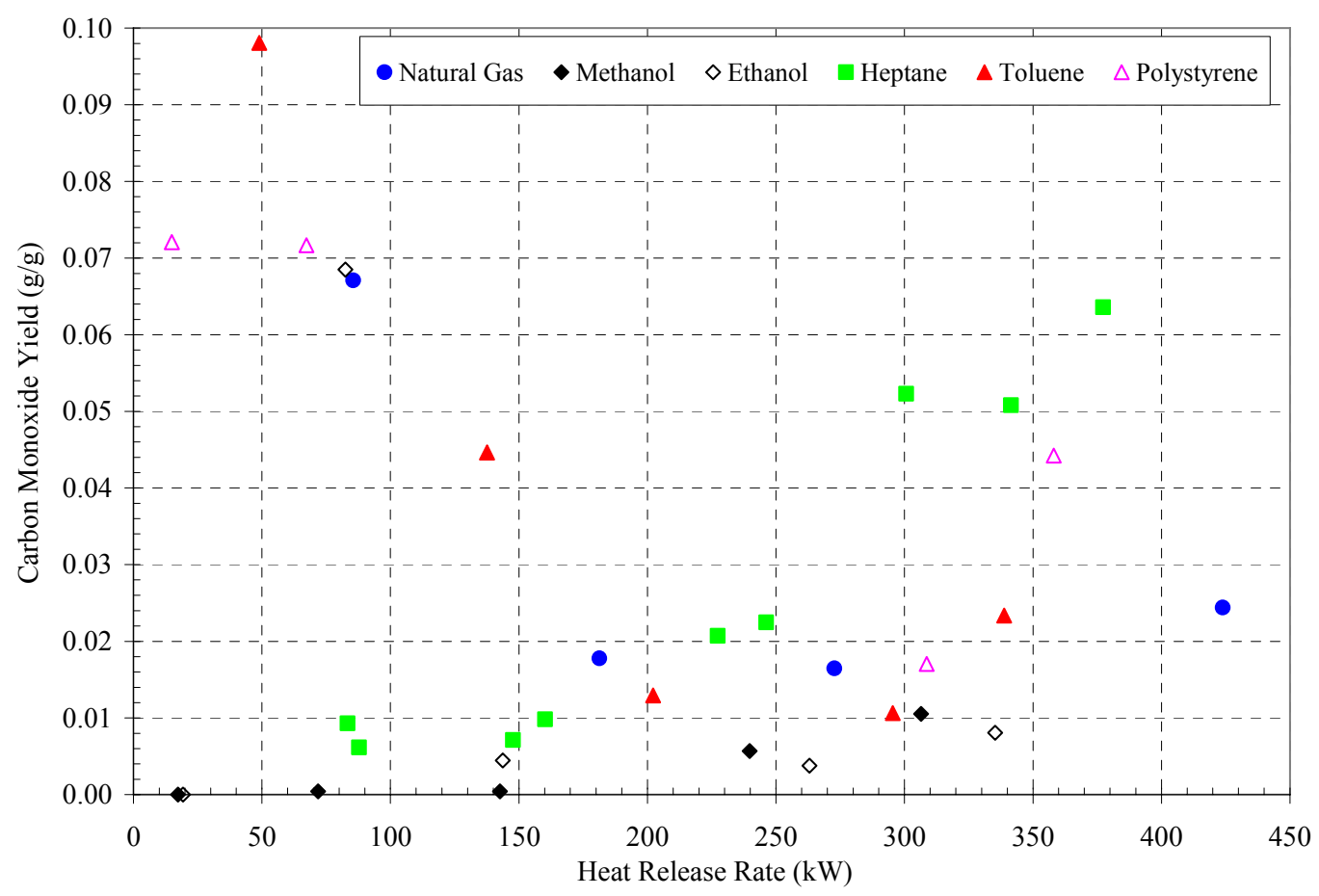

Figure 91. The $\mathrm{CO}$ yield in the exhaust stack as a function of the fire heat release rate during the periods when the HRR was quasi-steady for each of the fuels tested. 


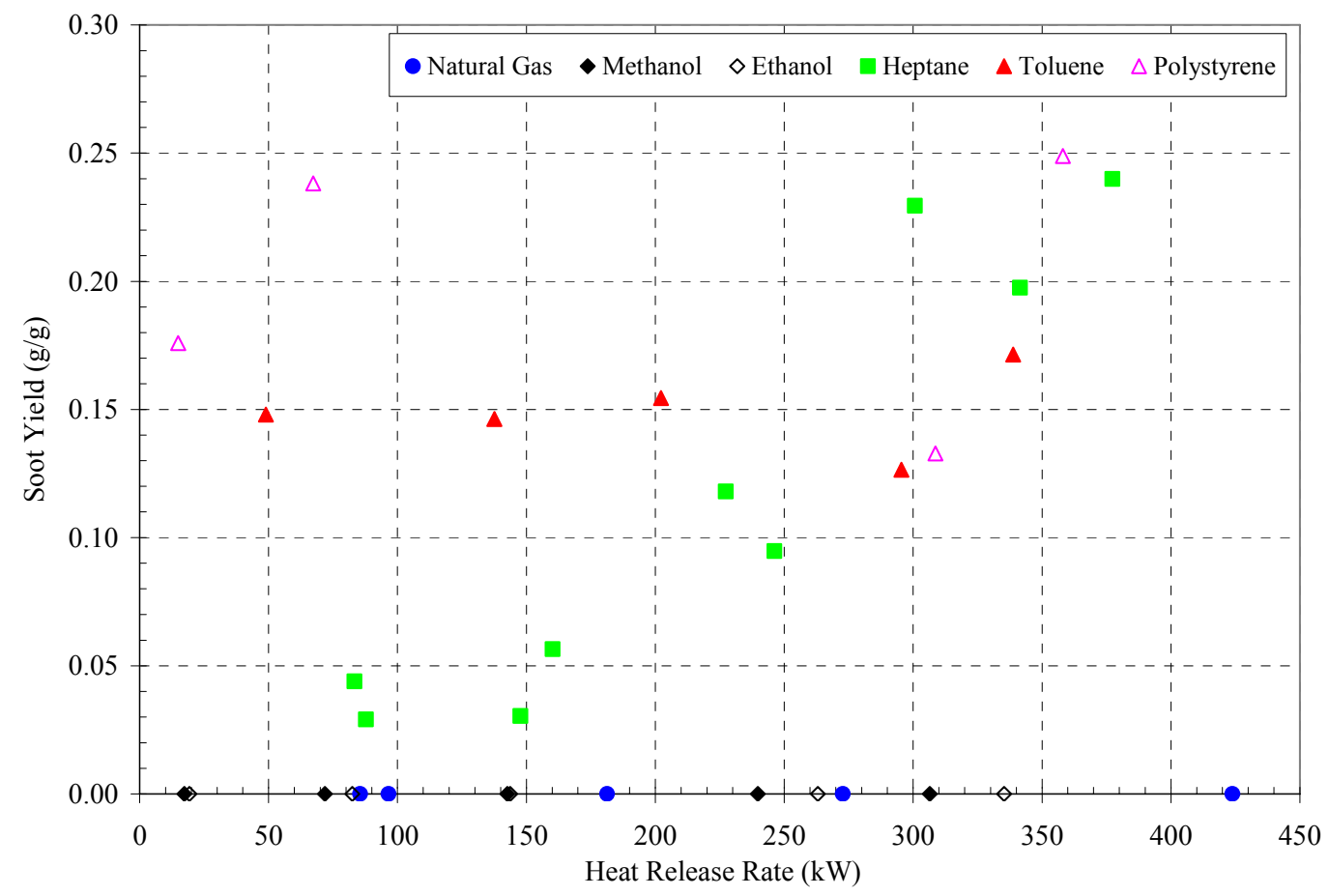

Figure 92. The soot yield in the exhaust stack as a function of the fire heat release rate during the periods when the HRR was quasi-steady for each of the fuels tested.

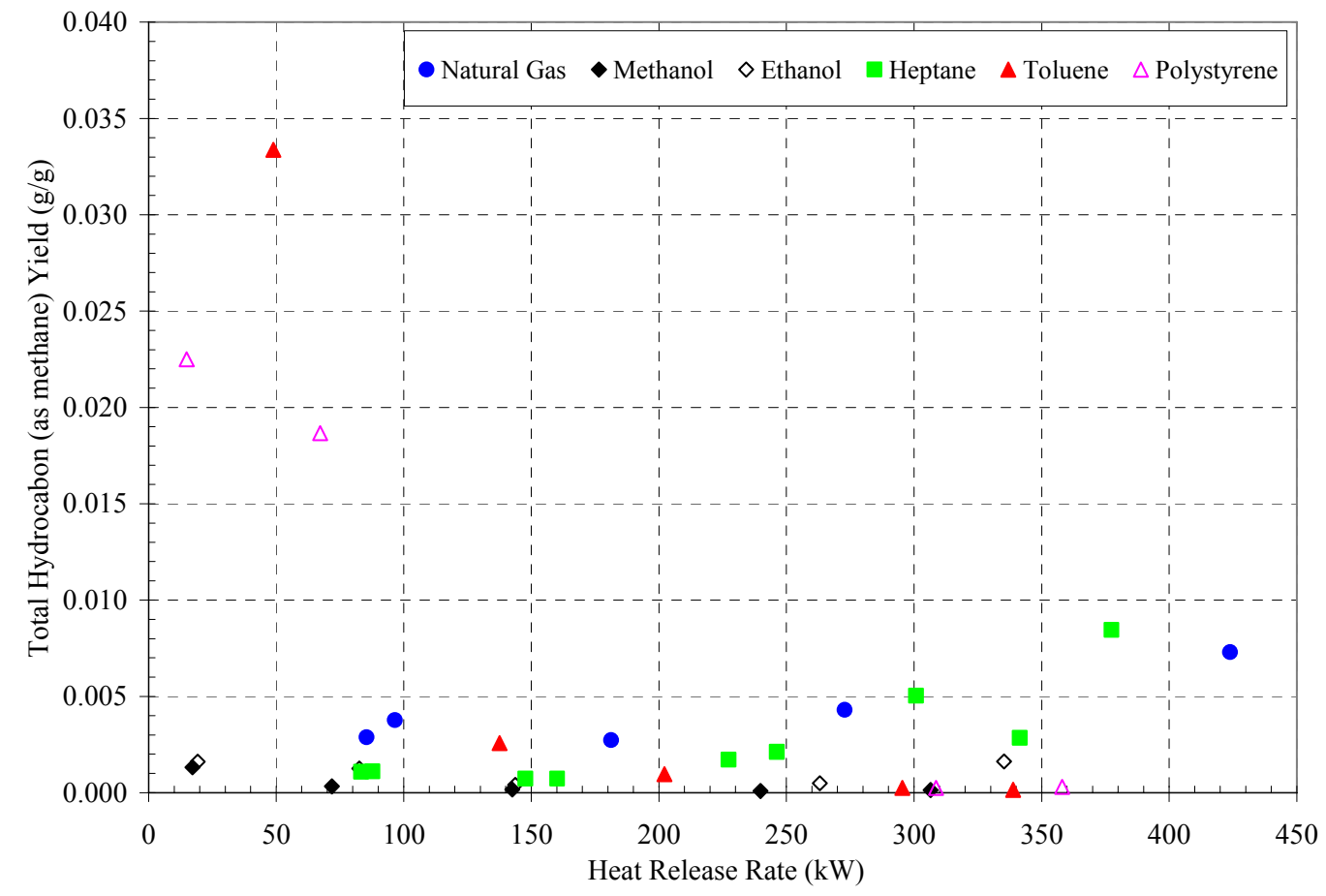

Figure 93. The total hydrocarbon yield in the exhaust stack as a function of the fire heat release rate during the periods when the HRR was quasi-steady for each of the fuels tested. 


\subsection{Combustion Efficiency}

To better understand the compartment chemistry, it is of interest to determine the combustion efficiency both in the exhaust stack and at various locations in the upper layer of the compartment. The combustion efficiency $\left(\chi_{\mathrm{a}}\right)$ is a global representation of the fractional amount of heat released by the fire as compared to complete combustion. It is defined as:

$$
\chi_{a}=\frac{\Delta \mathrm{H}_{\mathrm{c}}}{\Delta \mathrm{H}_{\mathrm{c}, \text { ideal }}}
$$

where $\Delta \mathrm{H}_{\mathrm{c}, \text { ideal }}$ is the net heat of complete combustion based on the conversion of all carbon and hydrogen in the fuel to $\mathrm{CO}_{2}$ and $\mathrm{H}_{2} \mathrm{O}$ (assumed to remain in the vapor phase) and $\Delta \mathrm{H}_{\mathrm{c}}$ is the net heat of combustion, which is the actual heat released in a chemical reaction. The value of $\chi_{a}$ is bounded by $0 \%$ and $100 \%$.

Using the nomenclature defined in Eq. 9 for the stoichiometry of the combustion reaction, the value of $\Delta \mathrm{H}_{\mathrm{c}, \text { ideal }}$ is:

$$
\Delta \mathrm{H}_{\mathrm{c}, \text { ideal }}=x \Delta_{\mathrm{f}} \mathrm{H}_{\mathrm{CO}_{2}, \text { gas }}^{\circ}+\frac{y}{2} \Delta_{\mathrm{f}} \mathrm{H}_{\mathrm{H}_{2} \mathrm{O}, \text { gas }}^{\circ}-\Delta_{\mathrm{f}} \mathrm{H}_{\text {fuel,(gas, liquid, solid })}^{\circ}
$$

where $\Delta_{\mathrm{f}} \mathrm{H}_{\mathrm{i}, \text { state }}^{\circ}$ is the heat of formation of species $\mathrm{i}$ at a given state. The heats of formation of $\mathrm{CO}_{2}$ and $\mathrm{H}_{2} \mathrm{O}$ are given in Ref. [49]. The value of $\Delta \mathrm{H}_{\mathrm{c}}$, the net heat of combustion is given by:

$$
\begin{aligned}
\Delta \mathrm{H}_{\mathrm{c}}=\mathrm{b} \Delta_{\mathrm{f}} \mathrm{H}_{\mathrm{CO}_{2}, \text { gas }}^{\circ}+ & \mathrm{c} \Delta_{\mathrm{f}} \mathrm{H}_{\mathrm{CO}, \text { gas }}^{\circ}+\mathrm{e} \Delta_{\mathrm{f}} \mathrm{H}_{\mathrm{C}, \text { solid }}^{\circ}+d \Delta_{\mathrm{f}} \mathrm{H}_{\mathrm{CH}_{4} \text {, gas }}^{\circ} \\
& +\mathrm{f} \Delta_{\mathrm{f}} \mathrm{H}_{\mathrm{H}_{2} \mathrm{O} \text {,gas }}^{\circ}-\Delta_{\mathrm{f}} \mathrm{H}_{\text {fuel, (gas, liquid, solid })}^{\circ}
\end{aligned}
$$

where the coefficients $\mathrm{b}-\mathrm{f}$ represent the amount of molecular products in the general combustion reaction defined in Eq. 9, and the heats of formation of $\mathrm{CO}$, soot, and $\mathrm{CH}_{4}$ are given by Ref. [49]. The molecular product yield coefficients are given in Eq. 34 below.

$$
\begin{aligned}
& \mathrm{b}=\frac{\mathrm{X}_{\mathrm{CO}_{2}} x}{\left(\mathrm{X}_{\mathrm{CO}_{2}}+\mathrm{X}_{\mathrm{CO}}+\mathrm{X}_{\mathrm{C}}+\mathrm{X}_{\mathrm{CH}_{4}}\right)}, \mathrm{c}=\frac{\mathrm{X}_{\mathrm{CO}} x}{\left(\mathrm{X}_{\mathrm{CO}_{2}}+\mathrm{X}_{\mathrm{CO}}+\mathrm{X}_{\mathrm{C}}+\mathrm{X}_{\mathrm{CH}_{4}}\right)} \\
& \mathrm{e}=\frac{\mathrm{X}_{\mathrm{C}} x}{\left(\mathrm{X}_{\mathrm{CO}_{2}}+\mathrm{X}_{\mathrm{CO}}+\mathrm{X}_{\mathrm{C}}+\mathrm{X}_{\mathrm{CH}_{4}}\right)}, \mathrm{d}=\frac{\mathrm{X}_{\mathrm{CH}_{4}} x}{\left(\mathrm{X}_{\mathrm{CO}_{2}}+\mathrm{X}_{\mathrm{CO}}+\mathrm{X}_{\mathrm{C}}+\mathrm{X}_{\mathrm{CH}_{4}}\right)}, \mathrm{f}=\frac{y}{2}-2 \mathrm{~d}
\end{aligned}
$$

Figure 94 shows the combustion efficiency and its uncertainty in the exhaust stack using measurements made during the steady burning periods as a function of the fire heat release rate for each of the fuels tested. The value of $\chi_{\mathrm{a}}$ was nearly $100 \%$ for all conditions in the methanol, ethanol and natural gas fires, whereas its value was smaller in the fires with the largest soot yields (heptane, toluene and polystyrene). The value of $\chi_{\mathrm{a}}$ in the exhaust stack was as low as $75 \%$ during the polystyrene fire. At the same time, the soot yield was nearly 0.25 . The expanded relative uncertainty of $\chi_{a}$ varied from $0.3 \%$ to $6 \%$. If $\chi_{a}$ was determined through the ratio of the measured heat release rate to the measured mass delivery rate, then the expanded relative uncertainty was larger than $15 \%$ and was not a function of the value of $\chi_{\mathrm{a}}$.

Figure 95 shows the combustion efficiency in the rear and front compartment sampling locations as a function of the measured fire heat release rate during the steady burning periods for the three 
smokiest fuels (heptane, toluene and polystyrene). There was a large amount of scatter in the results. In general, the value of $\chi_{\mathrm{a}}$ tended to decrease with increasing values of the HRR. During one of the larger polystyrene fires, the value of $\chi_{\mathrm{a}}$ was as low as $45 \%$ in the compartment. For the same fire, the value of $\chi_{\mathrm{a}}$ was much larger in the exhaust stack, reaching almost $80 \%$. The value of $\chi_{\mathrm{a}}$ for the heptane fires varied between $50 \%$ and $100 \%$. The scatter in the heptane results was rather large. As expected, the value of $\chi_{\mathrm{a}}$ tended to be higher when the oxygen volume fraction was larger as seen in Fig. 96. A comparison of Fig. 94 and Fig. 95 shows that the value of $\chi_{\mathrm{a}}$ inside the compartment was typically, but not always, equal to or smaller than the value of $\chi_{\mathrm{a}}$ in the stack, consistent with the idea that incomplete products of combustion continue to oxidize once they exit the compartment and are exposed to air.

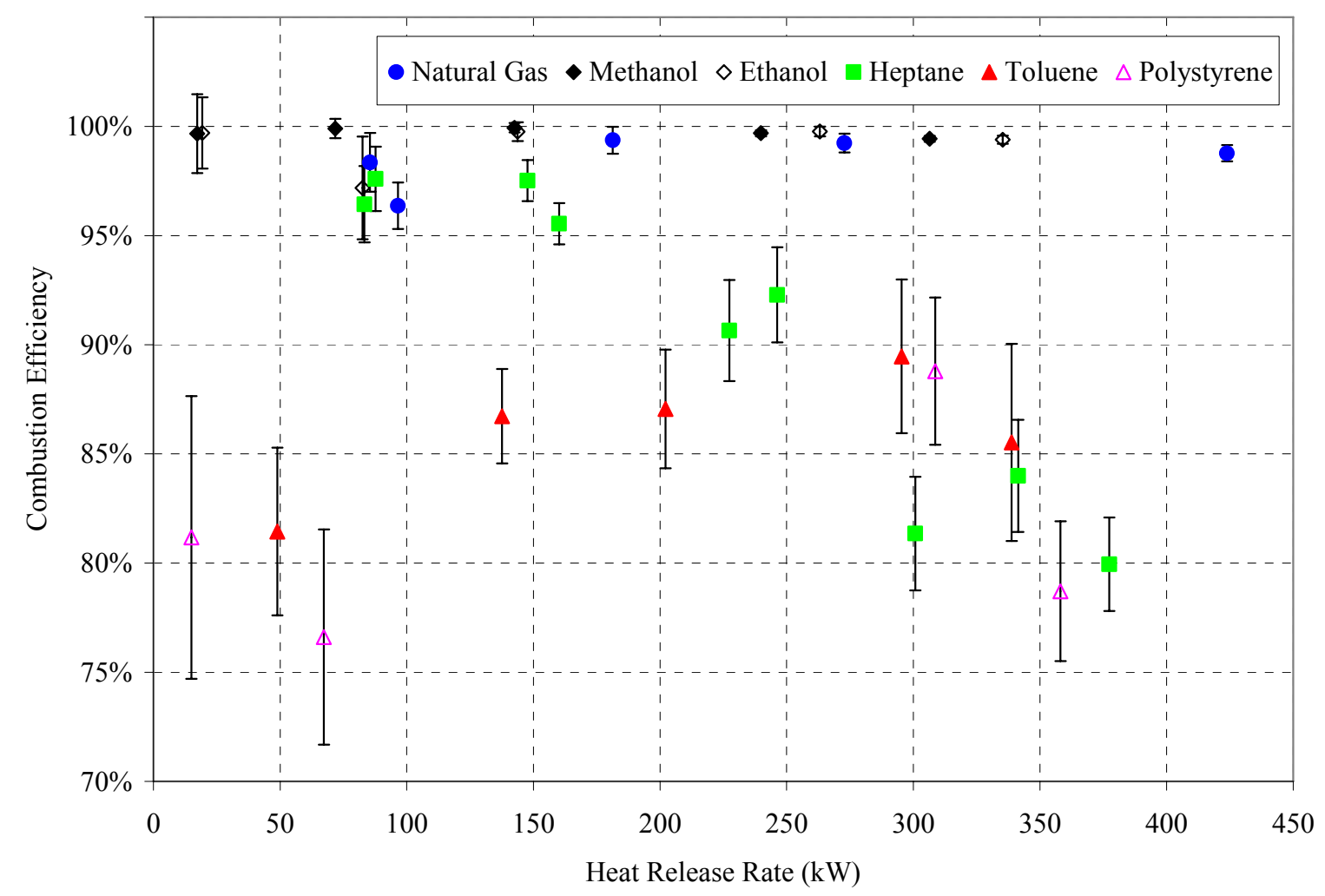

Figure 94. The combustion efficiency in the exhaust stack as a function of the fire HRR. 


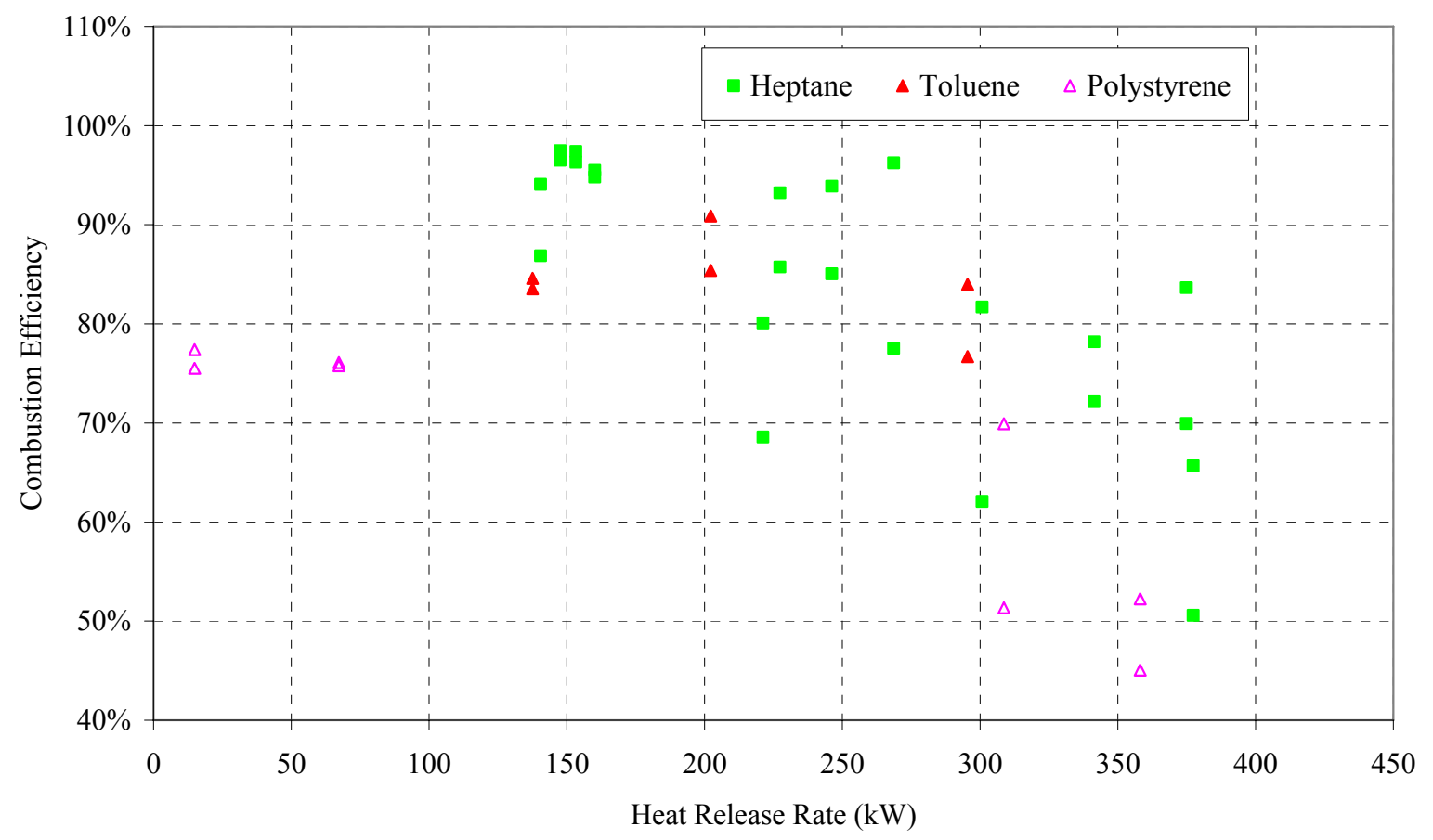

Figure 95. The local combustion efficiency at the rear and front compartment sampling locations as a function of the fire heat release rate during the periods when the HRR was quasi-steady for three fuels.

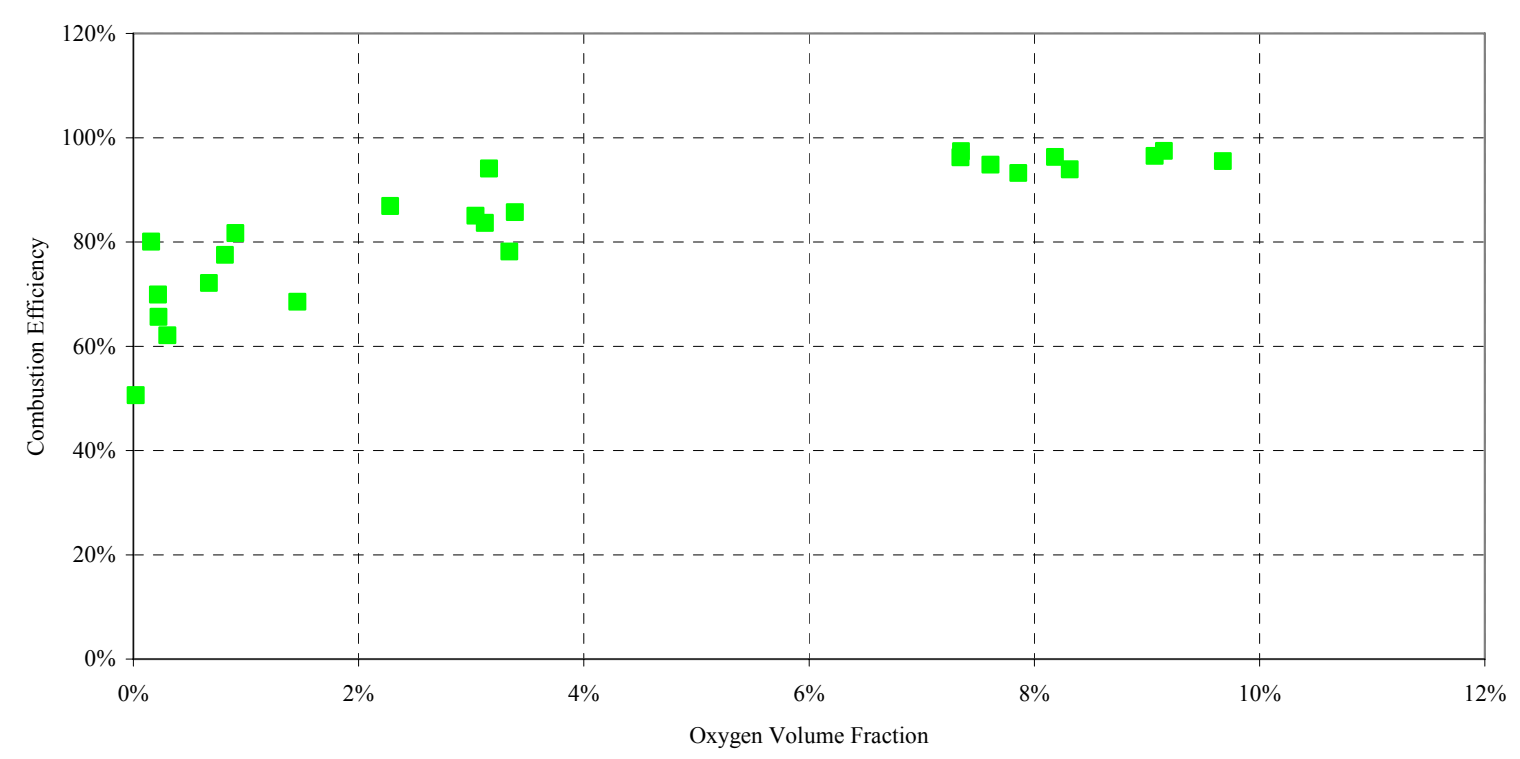

Figure 96. The local combustion efficiency at the rear and front compartment sampling locations as a function of the oxygen volume fraction during the periods when the HRR was quasi-steady in the heptane fire. 


\subsection{Summary of Chemical Analysis}

The mass fractions of gas species, such as hydrocarbons, carbon dioxide, carbon monoxide, oxygen, water vapor, and nitrogen, were considered as a function of the mixture fraction for each fuel type. The measurements were compared with the state relations based on the mixture fraction correlation model. Measurements in the upper layer of the compartment showed that the $\mathrm{CO}$ volume fraction was a function of fuel type, fire size, ventilation opening and specific sample location. In addition, the gas chromatographic results showed that hydrocarbons in the upper layer were composed mainly of $\mathrm{CH}_{4}$.

Consistent with previous studies, plotting the local composition as a function of the mixture fraction (or equivalence ratio) collapses hundreds of individual species measurements from an assortment of compartment conditions, with varying heat release rates, ventilation openings, and spatial locations, into a few coherent lines or bands. The results show that $\mathrm{CO}$ is not wellcorrelated with mixture fraction. Recognizing that $\mathrm{CO}$ kinetics are relatively slow, it was shown that consideration of temperature effects through analyses based on complete local thermal equilibrium and modification of the mixture fraction model to account for direct temperature correlation were not particularly fruitful. That these simple methods were not successful does not mean that improved accuracy cannot be achieved.

The results presented here demonstrate that it is important to consider soot as part of the mixture fraction analysis of compartment fires. This is particularly true in the upper layer of smoky fires in which about half (or more) of the fuel carbon may exist in the form of carbonaceous soot. Inclusion of soot in the analysis allows identification of fuel rich or underventilated conditions, conditions that otherwise would be considered lean or overventilated.

The combined mass of carbon in the form of soot and total hydrocarbons seem to be correlated by the soot-based mixture fraction for the conditions tested in this study. The $\mathrm{CO}$ and soot yields were found to be a function of fuel type and local equivalence ratio in the upper layer of the compartment for the smoky heptane, toluene and polystyrene fires. In addition, the ratio of $\mathrm{CO}$ yield to soot yield was found to be independent of local equivalence ratio for the smoky fuels. Additional experiments are needed to test this finding for other conditions and for full-scale compartment fires. In summary, mixture fraction is a useful initial way to describe the chemical structure of compartment fires. 


\section{Scaling Discussion}

The applicability of the experimental results reported here to other compartment fire scenarios can be considered in terms of a number of normalized parameters traditionally used in fire modeling applications. Use of normalized parameters facilitates comparison of results from scenarios of different scales by normalizing key physical characteristics of the scenario. A number of different forms of scaling may be considered, depending on the fire phenomena of interest [50]. Table 25 lists three normalized parameters that may be used to compare fire scenarios with the experiments reported here. The ranges of values for the normalized parameters examined in this study are listed in the table. The table is intended to provide guidance when evaluating the applicability of the data set reported here. For any given fire scenario, more than one normalized parameter may be necessary for determining applicability of the validation results, depending on the parameters of interest. In this sense, the Table should be considered illustrative, not exhaustive.

Table 25. List of non-dimensional scaling parameters for compartment fires and the range of values examined in this study.

\begin{tabular}{|c|c|c|c|}
\hline Parameter & Normalized Representation & Range of Values & Fuel Type \\
\hline $\begin{array}{l}\text { Heat Release } \\
\text { Rate }\end{array}$ & $Q_{\mathrm{d}}^{*}=\frac{\dot{Q}}{\rho_{\infty} c_{p} T_{\infty} \sqrt{g D D^{2}}}$ & $\begin{array}{l}1.6 \text { to } 44.2 \\
0.7 \text { to } 8.0 \\
1.0 \text { to } 7.2 \\
1.6 \text { to } 5.5 \\
1.5 \text { to } 5.5 \\
1.6 \text { to } 5.0\end{array}$ & $\begin{array}{l}\text { Natural Gas } \\
\text { Heptane } \\
\text { Toluene } \\
\text { Polystyrene } \\
\text { Methanol } \\
\text { Ethanol }\end{array}$ \\
\hline Ventilation & $\phi=\frac{\dot{m}_{F} / \dot{m}_{O_{2}}}{r}$, where $\dot{m}_{O_{2}}=\frac{0.23}{2} A_{o} \sqrt{h_{o}}$ & $\begin{array}{l}0.10 \text { to } 1.71 \\
0.16 \text { to } 0.83 \\
0.09 \text { to } 0.96 \\
0.03 \text { to } 0.69 \\
0.04 \text { to } 0.75 \\
0.01 \text { to } 0.77\end{array}$ & $\begin{array}{l}\text { Natural Gas } \\
\text { Heptane } \\
\text { Toluene } \\
\text { Polystyrene } \\
\text { Methanol } \\
\text { Ethanol }\end{array}$ \\
\hline $\begin{array}{l}\text { Compartment } \\
\text { height }\end{array}$ & $\frac{H}{D^{*}}$, where $D^{*}=\left(\frac{\dot{Q}}{\rho_{\infty} c_{p} T_{\infty} \sqrt{g}}\right)^{2 / 5}$ & $\begin{array}{l}1.4 \text { to } 3.5 \\
1.5 \text { to } 2.7 \\
1.6 \text { to } 3.4 \\
1.6 \text { to } 5.2 \\
1.6 \text { to } 5.0\end{array}$ & $\begin{array}{l}\text { Natural Gas } \\
\text { Heptane } \\
\text { Toluene } \\
\text { Polystyrene } \\
\text { Methanol } \\
\text { Ethanol }\end{array}$ \\
\hline
\end{tabular}

The most important parameter of any fire experiment is the heat release rate, as its magnitude drives changes in the thermal environment of the compartment or space of interest. A normalized quantity that relates the heat release rate to the diameter of the fire, $D$, is the first entry in Table 25 , commonly known as $Q_{d}^{*}$, where $\dot{Q}$ is the heat release rate $(\mathrm{kW}), \rho_{\infty}$ is the ambient density $\left(\mathrm{kg} / \mathrm{m}^{3}\right), T_{\infty}$ is the ambient temperature $(\mathrm{K}), c_{p}$ is the specific heat $(\mathrm{kJ} / \mathrm{kg}-\mathrm{K})$, and $g$ is the acceleration of gravity $\left(\mathrm{m} / \mathrm{s}^{2}\right)$. A large value of $Q_{d}^{*}$ represents a fire with a relatively large value of energy output power compared to its physical diameter, like an oil well blowout fire. A low value of $Q_{d}^{*}$ represents a fire with a relatively small value of energy output compared to its diameter, like a smoldering fire. Many typical accidental fire scenarios have $Q_{d}^{*}$ values on the order of 1 . The physical diameter of a realistic fire may not be well-defined and may not 
actually matter when assessing the "size" of a fire. Instead, a characteristic diameter, $D^{*}$ is considered in the definition of $Q_{d}^{*}$ as noted in the table. The range of values of $Q_{d}^{*}$ varied as a function of fuel type. In this study, $Q_{d}^{*}$ took on values as small as 0.7 and as large as 44 as seen in Table 25.

The second entry in the table is the global equivalence ratio $(\phi)$, which is associated with the overall fire-induced ventilation and compartment stoichiometry. An estimate of the maximum achievable steady-state oxygen supply is given by: $\dot{m}_{O_{2}}=\frac{0.23}{2} A_{o} \sqrt{h_{o}}$, where $\dot{m}_{O_{2}}$ is an empirical correlation for the mass flow rate of oxygen $(\mathrm{kg} / \mathrm{s}), A_{o}$ and $h_{o}$ are the area and height of the doorway opening $\left(\mathrm{m}^{2}\right), 0.23$ is the mass fraction of oxygen in air. The parameter $r$ in the table is the mass-based stoichiometric ratio of fuel to air required for complete combustion. The value of $\phi$ is useful in characterizing whether a given compartment fire is limited in size by its fuel supply or by its oxygen supply. The correlation for oxygen entrainment is valid for flashover conditions only, that is for values of $\phi>1$.

In all of the experiments performed as part of this study, the fuel mass flow rate was either controlled (for the gaseous fuels) or measured (for the condensed fuels), whereas the oxygen supply was naturally controlled by the size of the compartment doorway and the fire heat release rate. The range of values of $\phi$ varied as a function of fuel type, taking on values as small as 0.01 as seen in Table 25. The value of $\phi$ was less than 1.0 for almost all of the experimental conditions, except for natural gas when $\phi$ was as large as 1.7. This implies that conditions inside of the compartment were nearly always over-ventilated. There is strong evidence that the estimate for air mass flow is over-predicted using this approach. For each of the fuels listed in the table, flames were observed outside of the doorway (see photos in section 3 of this report), oxygen volume fractions were near zero and increased CO production was measured in the upper layer for the largest fires sizes. These are all strong indicators of underventilated burning. This may be due to an inaccurate assumption of the incoming air mass flow rate, or an invalid assumption in the GER model that all the incoming air enters the mixed upper layer. Pitts [51] proposed that a large fraction of the incoming air is entrained into the out-flowing gases and never reaches the reaction zone.

The third entry in the table is the compartment height, $\mathrm{H}$, normalized by $D^{*}$. The parameter $H / D^{*}$ relates $\dot{Q}$ to its physical dimensions and indicates the relative importance of the fire plume to other features of the fire-driven flow, such as the ceiling jet or doorway flow. The range of values of $H / D^{*}$ varied as a function of fuel type, taking on values as small as 1.4 and as large as 5.2 for conditions examined in this study, as seen in Table 25. 


\section{Conclusions}

This reports details the test methods and experimental results from a series of fire tests in the reduced scale enclosure. The following list describes the main findings of this work:

- New measurements of total hydrocarbons, and soot were successfully performed. These new measurement provide a more complete data set for validating and improving predictive fire models.

- The performance of various burner designs, wall materials and sample conditioning methods were evaluated in order to aid in the planning of future full-scale fire experiments.

- A detailed analysis of thermocouple temperature measurements provided an estimate of radiative error and response time in the thermal environment of a fully developed enclosure fire (see Appendix A).

- CFD modeling was successfully used to examine the effects of probe interactions (see Appendix B) and help design the experiments.

- The gas species composition measurements showed that methane was the most abundant hydrocarbon species in the upper layer for all of the fuels and fire conditions tested, and was higher in concentration than the parent fuel in all cases.

- No significant amount of hydrocarbons was measured in the upper layer of the compartment in the toluene or polystyrene fires.

- As much as $60 \%$ of the carbon in a polystyrene fire was present in the form of soot, which was more than twice the amount from any of the other hydrocarbons tested.

- The examination of compartment fire species data in terms of mixture fraction provided a rapid assessment of the overall chemical structure of the combustion environment. The measured data plotted as a function of mixture fraction confirmed the linear state relationship model for complete combustion when the fire was well ventilated.

- The results show that it is useful to consider soot as part of a mixture fraction analysis of compartment fires. The compartment gas species measurements showed that the $\mathrm{CO}$ concentration was a complex function of fuel type, fire size, ventilation and compartment sample location. The measured data plotted as a function of mixture fraction was consistent with previous studies that show the linear state relationship model is not valid for predicting $\mathrm{CO}$ in underventilated fires. In addition, a systematic correlation with temperature was not found. The results suggest that more research is needed to unravel the complexities of compartment fire chemistry.

- The species measurements showed that the soot yield was a function of fuel type and local equivalence ratio in the upper layer, whereas the ratio of the $\mathrm{CO}$ yield to the soot yield was independent of local equivalence ratio, and was not dissimilar to the results reported previously in Ref. [46].

- The mass fraction of CO in the upper layer of a reduced-scale compartment fire does not systematically correlate with the local temperature or mixture fraction, nor is it in local thermodynamic equilibrium. 
- The yields of CO and soot in the exhaust stack were usually, but not always, lower than the local yields in the upper layer of a compartment, for a wide range of fuels and heat release rates.

- The post-compartment conditions generally had larger combustion efficiency values than local conditions in the upper layer of the reduced-scale compartment fires, for a wide range of fuels and heat release rates.

- The ratio of the yields of CO to soot in the upper layer of the reduced-scale compartment were relatively constant for each of the fuels types, for the fires burning heptane, toluene and polystyrene; in addition, the values were comparable to previous measurements [46] in the plumes of over-ventilated turbulent hydrocarbon fires.

- The yields of CO and soot in the upper layer of the reduced-scale compartment fires were related to the local equivalence ratio for fires burning ethanol, heptane, toluene and polystyrene, over a wide range of fire sizes, but significant scatter precludes use of the data for $\mathrm{CO}$ prediction; the relationship was non-linear in fires burning methanol and natural gas.

\section{Future Work}

The experiments described in this report are part of an ongoing project to explore the thermal and chemical phenomena associated with, primarily, underventilated compartment fires. In the next phase of this project fire measurements will be conducted using a full-scale ISO 9705 compartment with quantified uncertainties. Based on the second scaling rule shown in Table 25 and the results shown in Fig. 42, oxygen depletion could be expected in the front of an ISO 9705 enclosure for fires larger than about $1800 \mathrm{~kW}$. Since investigation of underventilated burning is important, it may be advantageous to consider using a narrow doorway to reduce the fire size requirements to obtain conditions of interest in the experimental enclosure. The following tasks are planned to further this goal:

- Investigate the effects of distributed fuel sources on the structure of full-scale enclosure fires.

- Explore the effects of larger global equivalence ratios (primarily through decreased ventilation).

- Investigate scaling effects on the chemical and thermal structure of the fires.

- Explore the utility and durability of high-temperature-resistant blankets for full-scale enclosure construction.

- Improve the high temperature accuracy and time response of aspirated thermocouple probes through improved design.

- Extend gas species measurements to include quantification of hydrogen and water.

- Instrument the doorway to differentiate the heat release within and external to the compartment and to enable determination of the flows of enthalpy, mass and elemental carbon in and out of the compartment. 


\section{References}

[1] ISO 9705, Fire Tests - Full-Scale Room Test for Surface Products First Edition, International Organization for Standardization: Geneva, Switzerland (1993).

[2] K.B.McGrattan, Fire Dynamics Simulator (Version 4): Technical Reference Guide., NIST SP 1018 (2004).

[3] National Fire Protection Association and Society of Fire Protection Engineers, SFPE handbook of fire protection engineering, 3rd ed (2002).

[4] C.L.Beyler, Major Species Production by Diffusion Flames in A 2-Layer Compartment Fire Environment, Fire Safety Journal 10 (1), 47-56 (1986).

[5] E.E.Zukoski, J.H.Morehart, T.Kubota, and S.J.Toner, Species Production and Heat Release Rates in 2-Layered Natural-Gas Fires, Combustion and Flame 83 (3-4), 325-332 (1991).

[6] M.Cleary and Kent JH, Modeling of species in hood fires by conditional moment closure, Combustion and Flame 143 (4)357-368 (2005).

[7] S.Brohez, G.Marlair, and C.Delvosalle, Fire calorimetry relying on the use of the fire propagation apparatus. Part I: Early learning from use in Europe, Fire and Materials 30 (2), 131-149 (2006).

[8] S.Brohez, G.Marlair, and C.Delvosalle, Fire calorimetry relying on the use of the fire propagation apparatus. Part II: Burning characteristics of selected chemical substances under fuel rich conditions, Fire and Materials 30 (1), 35-50 (2006).

[9] N.P.Bryner, E.L.Johnson, and W.M.Pitts, Carbon Monoxide Production in Compartment Fires - Reduced-Scale Enclosure Test Facility, NIST IR 5568 (1994).

[10] W.M.Pitts, E.L.Johnsson, and N.P.Bryner, Carbon Monoxide Formation in Fires By HighTemperature Anaerobic Wood Pyrolysis, Twenty-Fifth Symposium (International) on Combustion1445-1462 (1994).

[11] B.Y.Lattimer and R.J.Roby, Carbon monoxide levels in structure fires: Effects of wood in the upper layer at a post-flashover compartment fire, Fire Technology 34 (4), 325-355 (1998).

[12] D.T.Gottuk, R.J.Roby, and C.L.Beyler, The role of temperature on carbon monoxide production in compartment fires, Fire Safety Journal 24 (4), 315-331 (1995).

[13] B.Y.Lattimer, U.Vandsburger, and R.J.Roby, Species transport from post-flashover fires, Fire Technology 41 (4), 235-254 (2005).

[14] R.G.Gann, J.D.Averill, E.L.Johnsson, M.R.Nyden, and R.D.Reacock, Smoke component yields from room-scale fire tests, NIST TN 1453 (2003). 
[15] M.M.Hirschler, Analysis of work on smoke component yields from room-scale fire tests, Fire and Materials 29 (5), 303-314 (2005).

[16] P.Blomqvist and A.Lonnermark, Characterization of the combustion products in large-scale fire tests: Comparison of three experimental configurations, Fire and Materials 25 (2), 7181 (2001).

[17] W.M.Pitts, The Global Equivalence Ratio Concept and the Formation Mechanisms of Carbon-Monoxide in Enclosure Fires, Progress in Energy and Combustion Science 21 (3), 197-237 (1995).

[18] G.Bertin, J.M.Most, and M.Coutin, Wall fire behavior in an under-ventilated room, Fire Safety Journal 37 (7), 615-630 (2002).

[19] A.Y.Snegirev, G.M.Makhviladze, V.A.Talalov, and A.V.Shamshin, Turbulent Diffusion Combustion under Conditions of Limited Ventilation: Flame Projection Through an Opening, Combustion, Explosion and Shock Waves 39 (1), 1-10 (2003).

[20] Y.Utiskul, J.G.Quintiere, A.S.Rangwala, B.A.Ringwelski, K.Wakatsuki, and T.Naruse, Compartment fire phenomena under limited ventilation, Fire Safety Journal 40 (4), 367-390 (2005).

[21] E.H.Yii, A.H.Buchanan, and C.M.Fleischmann, Simulating the effects of fuel type and geometry on post-flashover fire temperatures, Fire Safety Journal 41 (1), $62-75$ (2006).

[22] E.H.Yii, C.M.Fleischmann, and A.H.Buchanan, Experimental study of fire compartment with door opening and roof opening, Fire and Materials 29 (5), 315-334 (2005).

[23] NIST, Final report on the collapse of the World Trade Center towers, NIST NCSTAR (2005).

[24] W.L.Grosshandler, N.P.Bryner, D.Madrzykowski, and K.Kuntz, Report of the technical investigation of The Station nightclub fire, NIST NCSTAR 2 (2005).

[25] D.Madrzykowski and W.D.Walton, Cook County Administration Building fire, 69 West Washington, Chicago, Illinois, October 17, NIST SP1021 (2004).

[26] A.Hamins, A.Maranghides, E.L.Johnson, M.K.Donnelly, J.C.Yang, G.W.Mulholland, and R.Anleitner, Report of Experimental Results for the International Fire Model Benchmarking and Validation Exercise \#3, NIST SP1013-1 (2005).

[27] C.Huggett, Estimation of Rate of Heat Release by Means of Oxygen-Consumption Measurements, Fire and Materials 4 (2), 61-65 (1980).

[28] W.J.Parker, Calculations of the Heat Release Rate by Oxygen-Consumption for Various Applications, Journal of Fire Sciences 2 (5), 380-395 (1984). 
[29] R.A.Bryant, T.J.Ohlemiller, E.L.Johnsson, A.Hamins, B.S.Grove, A.Maranghides, G.W.Mulholland, and W.F.Guthrie, The NIST 3 Megawatt Quantitative Heat Release Rate Facility - Description and Proceedure, NIST IR 7052 (2004).

[30] ASTM D 1945-03, Standard Test Method for Analysis of Natural Gas by Gas Chromatography, (2003).

[31] ASTM D 3588 - 98, Standard Practice for Calculating Heat Value, Compressibility Factor, and Relative Density of Gaseous Fuels, (2003).

[32] ASTM E 603-06e1, Standard Guide for Room Fire Experiments, (2006).

[33] L.G.Blevins and W.M.Pitts, Modeling of bare and aspirated thermocouples in compartment fires, Fire Safety Journal 33 (4), 239-259 (1999).

[34] G.E.Glawe, F.S.Simmons, and T.M.Stickney, Radiation and Recovery Corrections and Time Constants of Several Chromel-Alumel Thermocouple Probe in High Temperature, High Velocity Gas Streams, NACA TN3766 (1953).

[35] The Temperature Handbook, Omega Engineering Inc. 5th Edition (2004).

[36] B.J.McCaffrey and G.Heskestad, Robust Bidirectional Low-Velocity Probe for Flame and Fire Applications, Combustion and Flame 1125-127 (1976).

[37] R.Bryant, C.Womeldorf, E.Johnsson, and T.Ohlemiller, Radiative heat flux measurement uncertainty, Fire and Materials 27 (5), 209-222 (2003).

[38] W.M.Pitts, A.V.Murthy, J.L.de Ris, J.R.Filtz, K.Nygard, D.Smith, and I.Wetterlund, Round robin study of total heat flux gauge calibration at fire laboratories, Fire Safety Journal 41 (6), 459-475 (2006).

[39] R.W.Bilger, Reaction-Rates in Diffusion Flames, Combustion and Flame 30 (3), 277-284 (1977).

[40] N.Peters, Laminar Diffusion Flamelet Models in Non-Premixed Turbulent Combustion, Progress in Energy and Combustion Science 10 (3), 319-339 (1984).

[41] Y.R.Sivathanu and G.M.Faeth, Generalized State Relationships for Scalar Properties in Nonpremixed Hydrocarbon Air Flames, Combustion and Flame 82 (2), 211-230 (1990).

[42] A.Hamins and K.Seshadri, The Structure of Diffusion Flames Burning Pure, Binary, and Ternary Solutions of Methanol, Heptane, and Toluene, Combustion and Flame 68 (3), 295307 (1987).

[43] J.E.Floyd, C.J.Wieczorek, and U.Vandsburger, Simulation of the Virginia Tech Fire Research Laboratory Using Large Eddy-Simulation With Mixture Fraction Chemistry and Finite Volume Radiative Heat Transfer, Proceedings of the 9th International Interflam Conference, Volume 1. September 17-19, 2001, Edinburgh, Scotland767-778 (2001). 
[44] Y.R.Sivathanu and G.M.Faeth, Temperature Soot Volume Fraction Correlations in the Fuel-Rich Region of Buoyant Turbulent-Diffusion Flames, Combustion and Flame 81 (2), 150-165 (1990).

[45] W.C.Reynolds, The Element Potential Method for Chemical Equilibrium Analysis: Implementation in the Interactive Program STANJAN, Department of Mechanical Engineering Stanford University available at: http://navier.engr.colostate.edu/tools/equil.html. (1986).

[46] U.O.Koylu and G.M.Faeth, Carbon-Monoxide and Soot Emissions from Liquid-Fueled Buoyant Turbulent-Diffusion Flames, Combustion and Flame 87 (1), 61-76 (1991).

[47] R.Puri and R.J.Santoro, Proc. 3rd Int. Sym. Fire Safety Science595-604 (1991).

[48] A.Tewarson, F.H.Jiang, and T.Morikawa, Ventilation-Controlled Combustion of Polymers, Combustion and Flame 95 (1-2), 151-169 (1993).

[49] NIST Standard Reference Database Number 69, NIST Chemistry WebBook available at: http://webbook.nist.gov/chemistry/. (2005).

[50] J.G.Quintiere, Scaling Applications in Fire Research, Fire Safety Journal 15 (1), 3-29 (1989).

[51] W.M.Pitts, Toxic Yield, Technical Basis for Performance Based Fire Regulations., A Discussion of Capabilities, Needs and Benefits of Fire Safety Engineering. United Engineering Foundation Conference. Proceedings.76-87 (2001).

\section{Acknowledgements}

A number of individuals were instrumental in the completion of this work. The fabrication work and execution of these tests would not have been possible without the expert assistance and enthusiasm of the LFL staff: Laurean DeLauter, Edward Hnetkovsky and Jack Lee. Mike Selepak did exemplary work in carefully performing the labor intensive extractive soot measurements. Jay McElroy performed the video documentation and instrument installation. The authors are grateful to the following NIST staff for extremely helpful discussions that were a significant contribution to this study: Kevin McGratten, Jason Floyd, Rodney Bryant, Bill Pitts, Alex Maranghides, Bill Grosshandler, and Andrew Lock.

This work is dedicated in memory of Jack Lee (1953-2007). Jack was a technician in the large fire laboratory and will be greatly missed. He provided 35 years of loyal service to NIST and countless contributions to fire safety research. 


\section{Appendices}

\section{A. Analysis of Thermocouple Temperature Measurement}

To estimate components of measurement uncertainty and instrument time response, the present study performed a series of detailed flow and heat transfer calculations, focusing on double shielded aspirated thermocouples and bare bead thermocouples. The character of the calculations is summarized in Table A1. There were two categories of calculations. The first category involved three-dimensional (3D) computational fluid dynamic (CFD) simulations, while the second involved an algebraic solution of the simplified energy balance equation. Two types of CFD modeling were performed. The first considered the realistic geometry in order to understand details of the flow field associated with the aspirated thermocouple. The second considered a simplified geometry, focusing on details of the heat transfer process. Ideally, the CFD simulation would be able to consider details of the flow and heat transfer in the actual geometry, including turbulence and conjugate heat transfer with conduction, convection and radiation for the real geometry, but this would be prohibitively expensive computationally. For this reason, the CFD calculations were split into detailed flow calculations for the actual geometry, and detailed conjugate heat transfer calculations for a simplified geometry. The 3D CFD calculation results are compared with algebraic solutions of a simplified energy balance model. The results predicted by the algebraic model were in agreement with the CFD model over a broad temperature range, despite its many assumptions and idealizations. A parametric study was conducted to quantify the thermocouple errors for various gas temperature and surrounding conditions. The CFD solutions were transient, allowing determination of instrument time response. This is in contrast to the analytical solution, which presented a steady-state solution only.

Table A1. Summary of the Numerical Simulations.

\begin{tabular}{|c|c|c|c|}
\hline & $\begin{array}{l}\text { Simple energy } \\
\text { balance model }\end{array}$ & $\begin{array}{l}\text { 3D CFD model for } \\
\text { Simple Geometry }\end{array}$ & $\begin{array}{l}\text { 3D CFD model for } \\
\text { Real Geometry }\end{array}$ \\
\hline Physics & $\begin{array}{l}\text { Heat transfer based } \\
\text { on specified } \\
\text { aspiration rate }\end{array}$ & $\begin{array}{l}\text { Flow and heat } \\
\text { transfer }\end{array}$ & $\begin{array}{l}\text { Turbulence } \\
\text { associated with } \\
\text { aspiration flow }\end{array}$ \\
\hline $\begin{array}{l}\text { Solid Phase Heat } \\
\text { Transfer }\end{array}$ & Thermally Thin & Considered & Not Considered \\
\hline $\begin{array}{l}\text { Radiative Heat } \\
\text { Transfer }\end{array}$ & Surface radiation & $\begin{array}{l}\text { Surface-Surface } \\
\text { Radiation }\end{array}$ & Not Considered \\
\hline $\begin{array}{l}\text { Convective Heat } \\
\text { Transfer }\end{array}$ & Empirical correlation & $\begin{array}{l}\text { Surface Energy } \\
\text { balance }\end{array}$ & $\begin{array}{l}\text { Surface Energy } \\
\text { Balance }\end{array}$ \\
\hline Surface Emissivity & 0.8 & 0.8 & Not considered \\
\hline $\begin{array}{l}\text { Surrounding } \\
\text { Temp. }\end{array}$ & $300 \mathrm{~K}$ to $1200 \mathrm{~K}$ & $300 \mathrm{~K}$ to $1200 \mathrm{~K}$ & Adiabatic \\
\hline Gas Temp. & $300 \mathrm{~K}$ to $1200 \mathrm{~K}$ & $300 \mathrm{~K}$ to $1200 \mathrm{~K}$ & $300 \mathrm{~K}, 1200 \mathrm{~K}$ \\
\hline Solution Type & Steady Solution & Transient solution & Transient Solution \\
\hline Turbulence & Empirical correlation & Standard K- $\varepsilon$ model & Standard K- $\varepsilon$ model \\
\hline $\begin{array}{l}\text { External Gas } \\
\text { Velocity }\end{array}$ & $1 \mathrm{~m} / \mathrm{s}$ & $1 \mathrm{~m} / \mathrm{s}$ & $1 \mathrm{~m} / \mathrm{s}$ \\
\hline No. Grids & None & 25000 & 1500000 \\
\hline
\end{tabular}




\section{D Flow Modeling for a Realistic Geometry}

The 3D flow modeling considered the realistic geometry of an open-ended double shielded aspirated thermocouple as seen in Fig. A1. The computational configuration included an inner and outer shields, a bare type $\mathrm{K}$ thermocouple taken to be cylindrical, and an extended domain. The computational domain was divided into approximately 1.5 million cells of a tetrahedral type mesh using the ICEM-CFD [2], which is a commercial CAD and grid generation program. Figures $\mathrm{A} 2$ and $\mathrm{A} 3$ show the computational grids for the open-end and open-side aspirated thermocouple geometries. Both types were used in the RSE compartment fire experiments. The flow fields were calculated using a commercially available CFD package to model the flow for given operating conditions [3]. The code is based on the finite volume method on a collocated grid. A non-staggered grid system was used for storage of discrete velocities and pressures. The standard k- $\varepsilon$ turbulence model and incompressible ideal gas assumption were applied to solve the Reynolds stress term and the density change, respectively. The governing equations were discretized by the $2^{\text {nd }}$ order upwind scheme in space and the SIMPLE algorithm (Semi-Implicit Method for Pressure Linked Equation) with under-relaxation used to iteratively solve the momentum equation in discretized form. The implicit solver was used to capture the main features of the unsteady motion around the aspirated thermocouples. In this study, CFD calculations investigated the flow field in the inner and outer aspiration tubes with an emphasis on characterizing any differences. That information was then used as boundary conditions for the CFD and analytic heat transfer analyses.

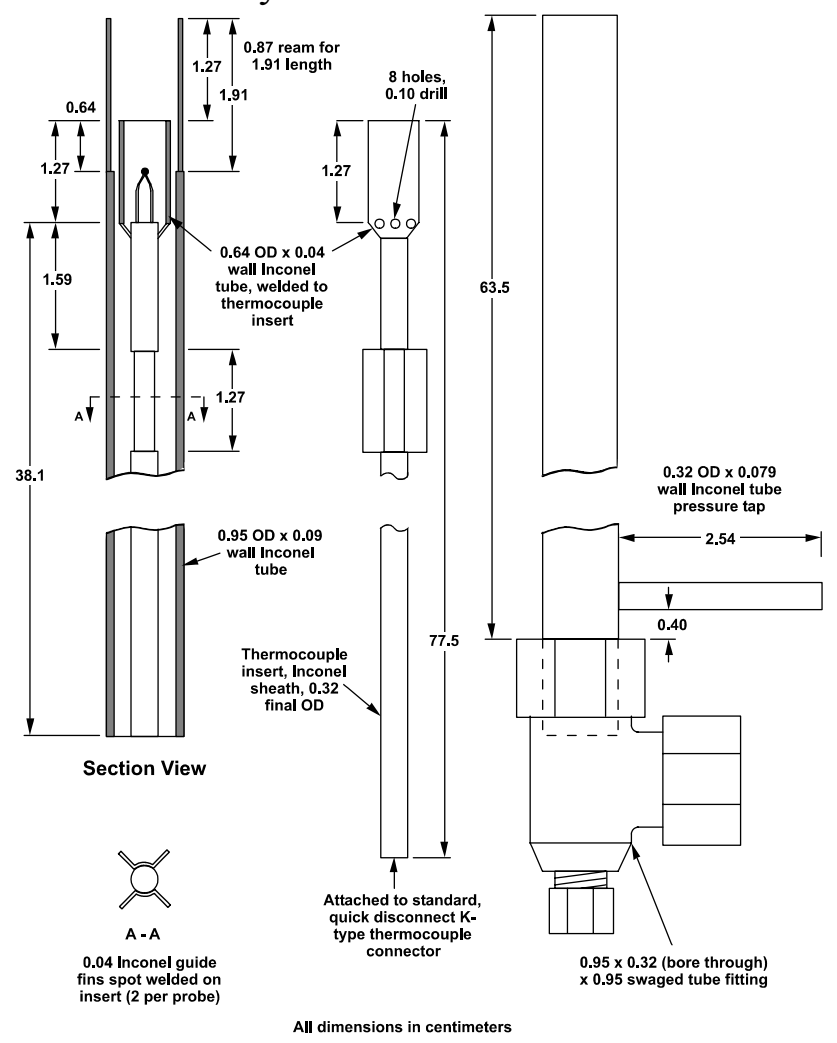

Figure A1. Schematic of a double shielded end-open aspirated thermocouple. 


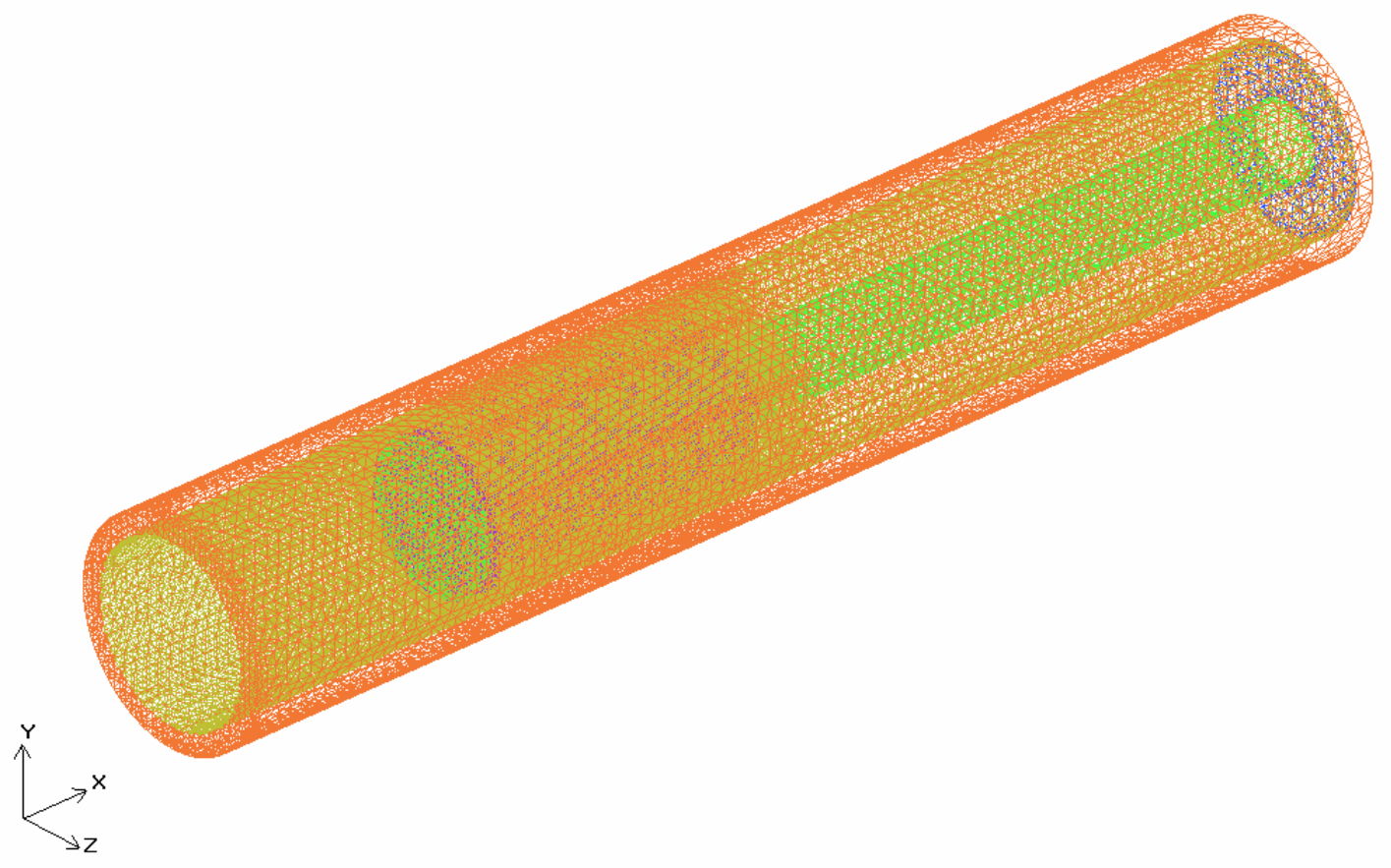

(a) Perspective view

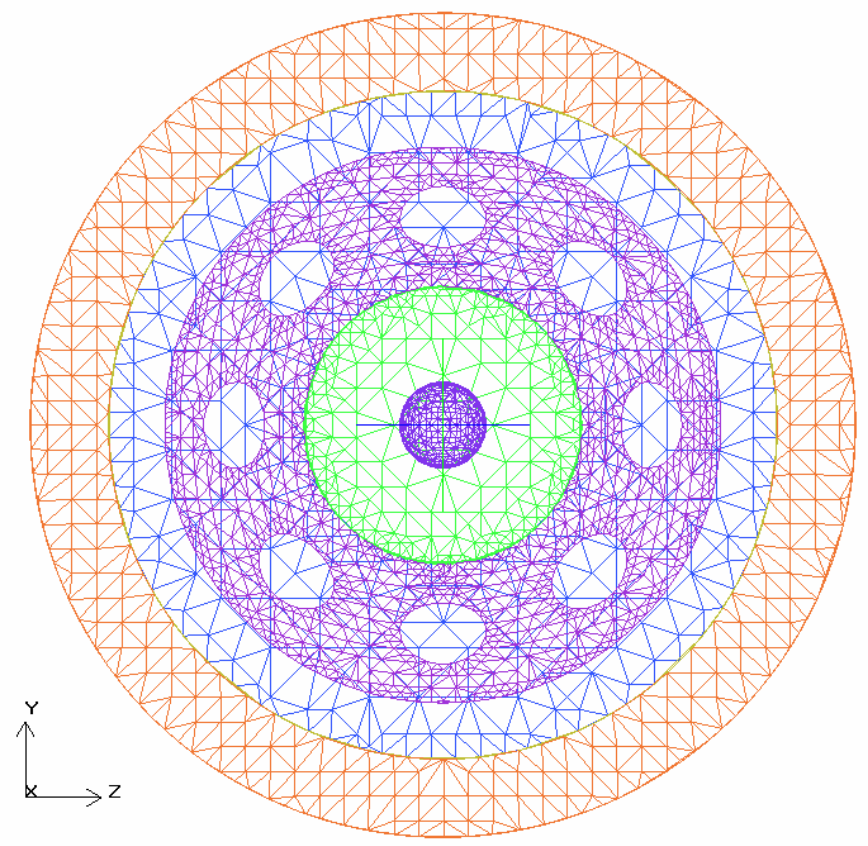

(b) Front view

Figure A2. Computational grids for end-open double shield aspirated thermocouples. 


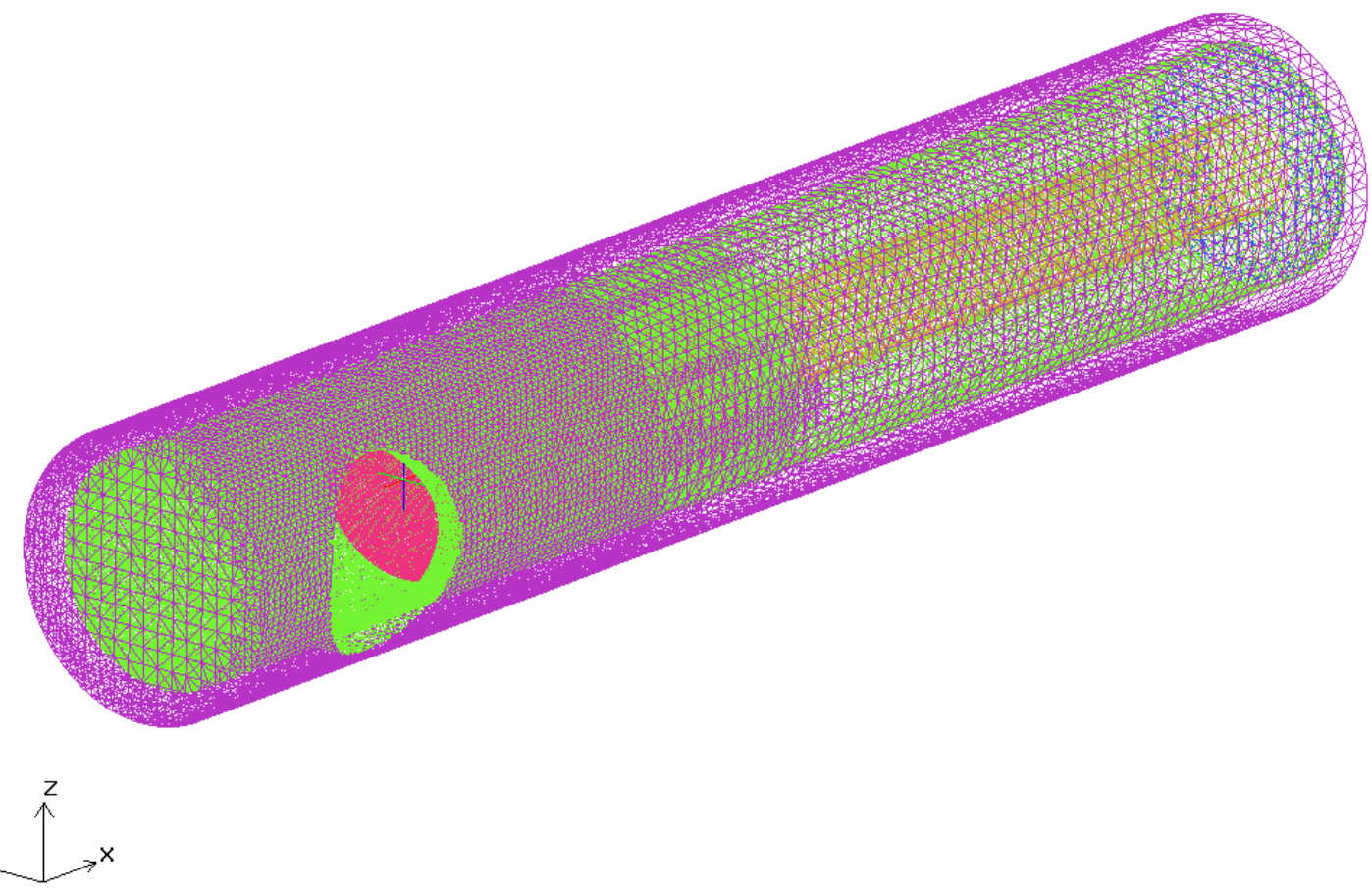

(a) Perspective view

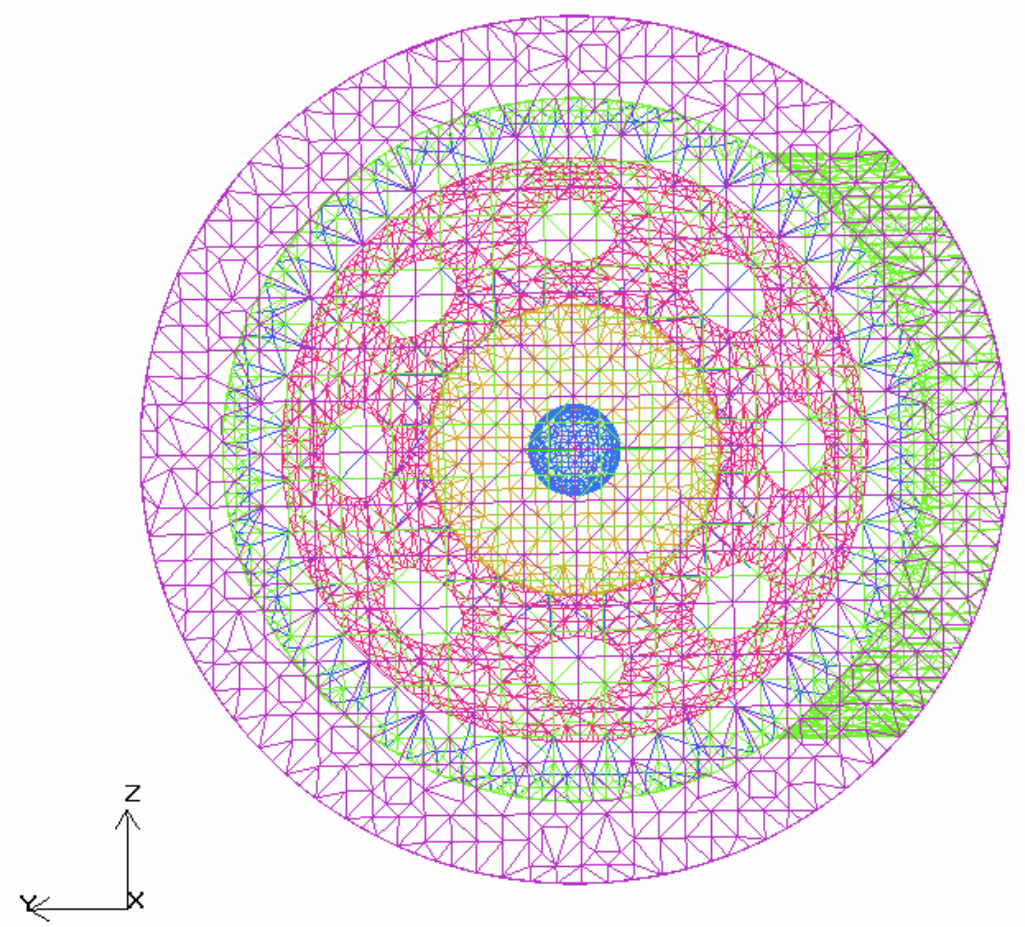

(b) Front view

Figure A3. Computational grids for side-open double shield aspirated thermocouples. 


\section{Conjugate Heat Transfer Modeling for a Simplified Geometry}

A detailed 3D heat transfer calculation (including conduction, convection, and radiation) was performed to estimate the effectiveness of bare-bead and double-shielded aspirated thermocouples for a simplified geometry. Figure A4 presents a schematic of the two configurations. The double-shielded calculation assumed that the flow domain consisted of an external flow, an annular flow between the outer and inner cylinders, and an inner flow within the inner cylinder. In the bare-bead calculation, the thermocouples were directly exposed to the external gas and the surroundings without a shield or an applied aspiration flow. The incoming gas temperature was assumed to be uniform. The incoming flow velocity induced by aspiration was imposed as a boundary condition, and was determined from the detailed flow calculations described above. The material properties of the shield and thermocouple bead were taken to be steel and nickel, respectively, and are listed in Table A2. This is a reasonable approximation as K-type thermocouples are composed of more than $90 \%$ nickel [4].

Table A2. Material Properties [5].

\begin{tabular}{|l|l|l|l|}
\hline Material & Density $\left(\mathrm{kg} / \mathrm{m}^{3}\right)$ & Specific heat $(\mathrm{J} / \mathrm{kg} \cdot \mathrm{K})$ & Thermal conductivity $(\mathrm{W} / \mathrm{m} \cdot \mathrm{K})$ \\
\hline Nickel & 8900 & 460 & 91.7 \\
\hline Steel & 8030 & 502 & 16.3 \\
\hline
\end{tabular}
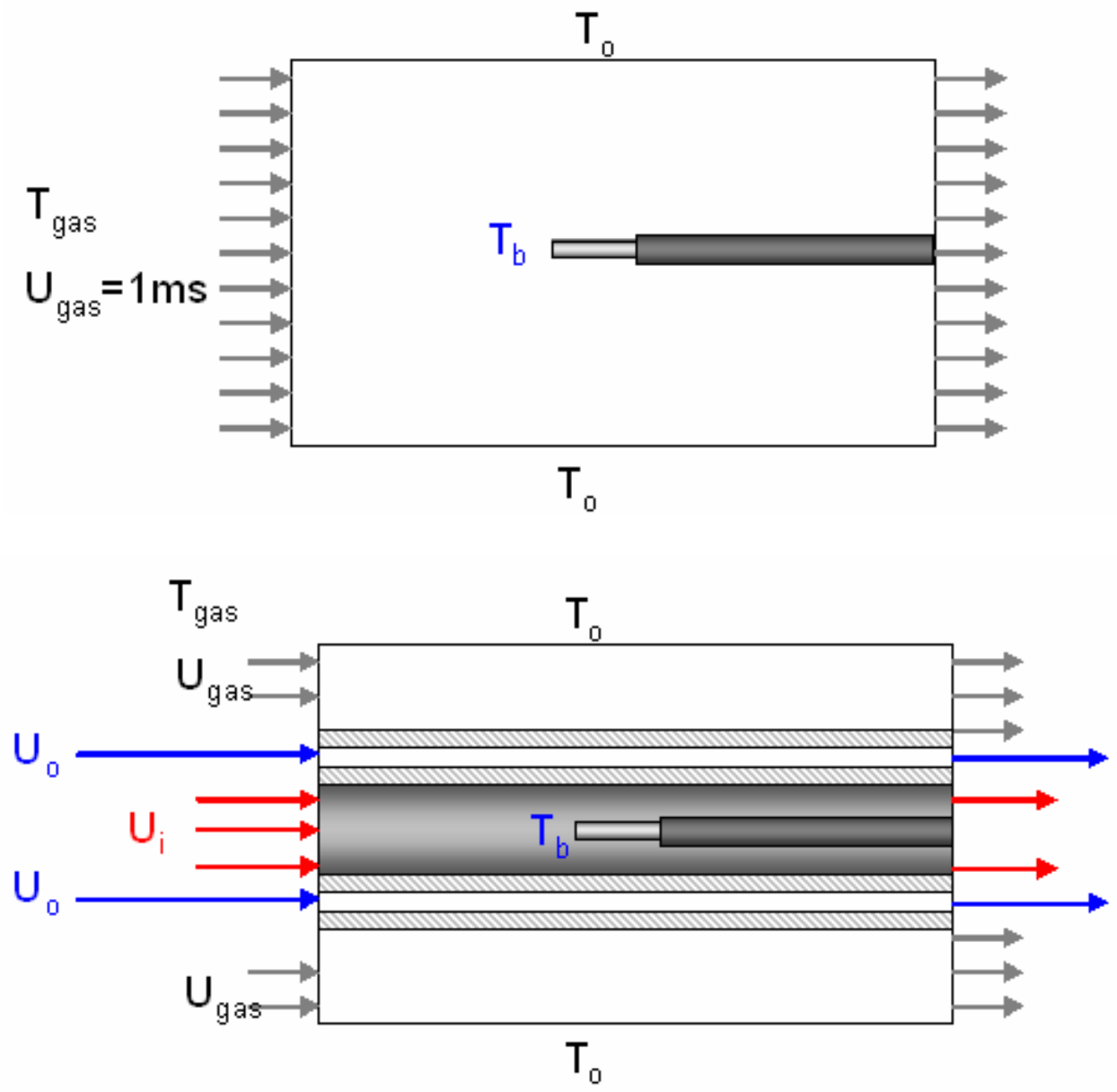

Figure A4. Schematic of bare bead and open-end double shielded aspirated thermocouples. 
Radiative heat transfer was computed using a surface to surface radiation model in which the energy exchange between the two surfaces depended on the view factor, which is a geometric function involving the size, distance, and orientation of surfaces. The surfaces were taken as gray and diffuse. The calculations were performed assuming a constant emissivity $(\varepsilon)$ of 0.8 for all metal surfaces, using the value recommended by Blevins [1]. The external flow velocity was assumed to be $1 \mathrm{~m} / \mathrm{s}$ in all cases.

The representative thermocouple temperature $\left(T_{b}\right)$ was calculated using a volume weighted average as follows:

$$
T_{b}=\frac{1}{V_{b}} \int T \cdot d v=\frac{1}{V_{b}} \sum_{i=1}^{N} T_{b, i} \cdot d V_{i}
$$

The thermocouple effectiveness was defined in terms of the percentage error $(\mathrm{E})$ between the incoming gas flow temperature ( $T_{g}$ in Fig. A4) and the representative temperature at the thermocouple bead ( $T_{b}$ in Fig. A4):

$$
E=100 \times\left(\frac{T_{b}-T_{g}}{T_{g}}\right)
$$

\section{Steady-State Solution of the Algebraic Energy Balance Equation}

An analytic solution of the steady state energy balance for aspirated thermocouples was previously reported [1]. That calculation, however, did not consider conductive heat transfer through the solid shield. Also, the temperature difference between the inner and outer surfaces

was assumed to be zero. In the case of the double shielded aspirated thermocouple, the inner and outer gas velocities were assumed to be equal and the external flow was assumed to be parallel to the probe axis.

\section{Results}

Figure A5 shows the calculated pressure and velocity fields of an end-open double shielded aspirated thermocouple at ambient temperature with an aspiration flow rate of $24 \mathrm{~L} / \mathrm{min}$. The entrance area of the inner cylinder of the aspirated thermocouple was larger than the exit area through its eight inner holes (see Figs. A1 and A2), causing a relatively high stagnation pressure inside the inner shield. This adverse pressure gradient forced the aspiration flow to pass through the outer passage with a differentially high velocity as compared to the inner cylinder. The flow blockage effect was characterized as a ratio of the average velocities between the inner and outer annular passages. It influenced the rate of convective heat transfer in the aspirated thermocouple, impacting the effectiveness of the aspirated thermocouple. Figure A6 presents the calculated maximum values of the velocity of the inner shield $\left(U_{i}\right)$, the outer annular passage $\left(U_{o}\right)$, and the maximum value of the ratio of these velocities $(\zeta)$ as a function of the total aspiration flow. The velocity ratio $(\zeta)$ is defined as:

$\varsigma=\frac{U_{o}}{U_{i}}$

For nominal operating conditions $(24 \mathrm{~L} / \mathrm{min}$ at STP), the maximum velocity in the inner shield was found to be about 3 times larger than that within the annular passage. Figure A6 shows that this ratio increased with aspiration flow. 


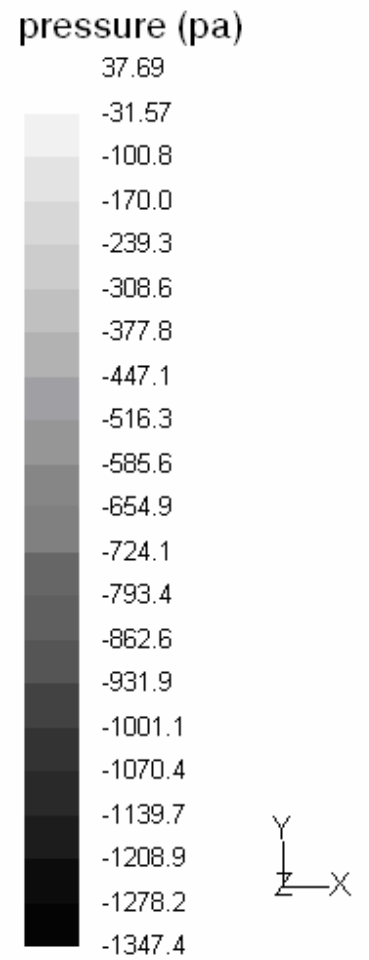

(a) Pressure field

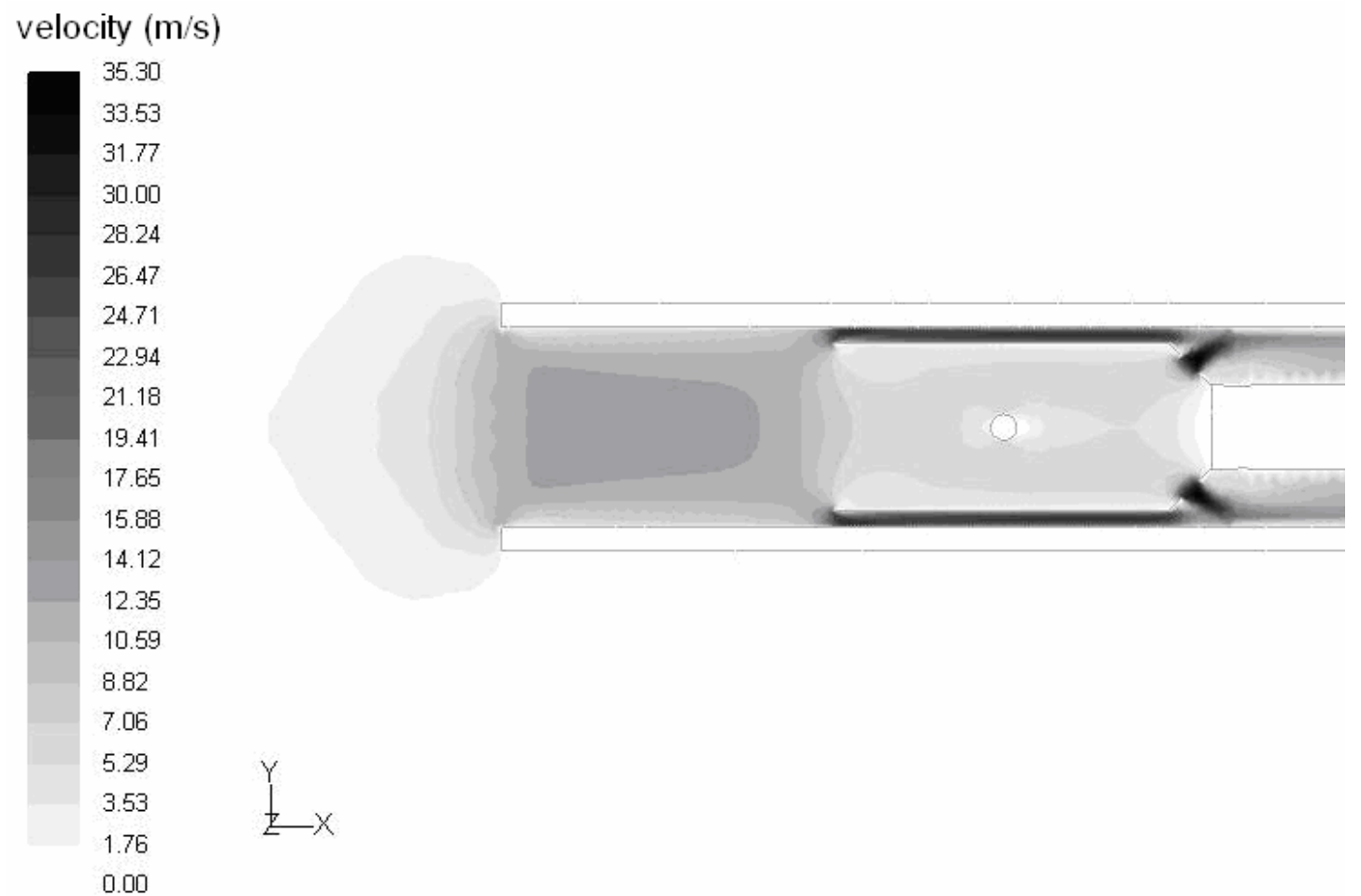

\section{(b) Velocity magnitude}

Figure A5. Calculated pressure and velocity fields in end-open double shielded aspirated thermocouples at ambient temperature with an aspiration flow rate of $24 \mathrm{~L} / \mathrm{min}$. 


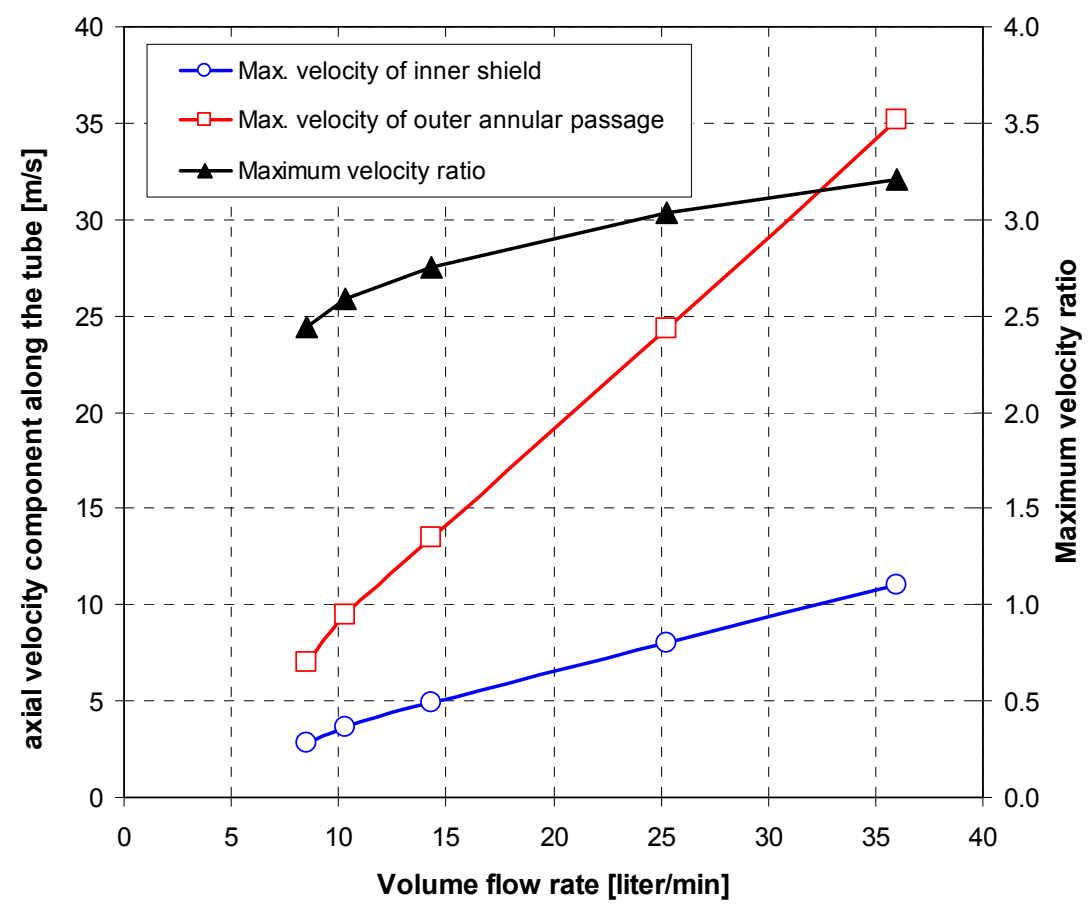

Figure A6. Comparison of the maximum axial velocity for end-open double shielded aspirated thermocouples $\left(\mathrm{T}_{\text {gas }}=300 \mathrm{~K}\right)$.

Figure A7 shows the calculated thermocouple error (see Eq. A2) for a bare bead thermocouple as a function of the surrounding ( $\mathrm{T}_{\mathrm{o}}$ in Fig. A4) temperatures for both the simple energy balance model and the 3D CFD model for an incoming gas temperature of either $300 \mathrm{~K}$ or $900 \mathrm{~K}$. The external gas velocity was taken as $1 \mathrm{~m} / \mathrm{s}$ directed toward the open end of the aspirated thermocouple. The results show one large error regime of thermocouple measurement associated with low values of the gas temperature and high surrounding temperatures. The results show that the error was relatively small for moderately-high gas temperatures, regardless of the surrounding temperature. Despite its many assumptions, the solution to the simple energy balance model was essentially in agreement with the 3D CFD calculation results for the bare bead thermocouple.

Figure A8 show maps of the calculated thermocouple error (Eq. A2) for an open-end doubleshielded aspirated thermocouple as a function of the thermocouple bead $\left(\mathrm{T}_{\mathrm{b}}\right)$ and the surrounding $\left(\mathrm{T}_{\mathrm{o}}\right)$ temperatures determined using the 3D CFD model. The map shows two regimes of significant error for the thermocouple temperature measurements. The first occurs for relatively low temperature surroundings in which the gas temperature is systematically under-predicted, notably for higher gas temperatures. The temperature error predicted by the CFD model in this regime varied with temperature, but was as large as $-280 \mathrm{~K}$ for gas temperatures of $1200 \mathrm{~K}$, corresponding to an error of about $25 \%$. The other significant-error regime occurs for large surrounding temperatures, in which the gas temperature is over-predicted. The maximum error in this regime was as large as $140 \mathrm{~K}$ for a high surrounding temperature $\left(\mathrm{T}_{\mathrm{o}}=1500 \mathrm{~K}\right)$ and a thermocouple temperature of about $900 \mathrm{~K}$. Calculations using the algebraic model show that similar trends result, but the magnitude of the differences was much smaller. There is less confidence in the algebraic model, due to its many assumptions. 
Figure A9 shows the calculated thermocouple response to a hypothetical step change in the gas temperature with an invariant surrounding temperature using the CFD model. The initial gas temperature and surrounding temperature were identical. Results are shown for initial temperatures of $1200 \mathrm{~K}$ and an aspiration rate of $24 \mathrm{~L} / \mathrm{min}$. The temperature rose or fell towards the final temperature over tens of seconds, the exact time depending on the relatively size of the step change. Results from several calculations similar to those presented in Fig. A9 are summarized in Fig. A10, which shows the time to reach a quasi-steady state condition after the hypothetical step change for various surrounding temperatures. Steady state was defined as the time when the thermocouple temperature variation was less than $1 \mathrm{~K} / \mathrm{s}$. Under this condition, the calculated results are within $10 \mathrm{~K}$ of the asymptotic calculation results.

The time to steady state varied with incoming gas temperatures, but was largest for high incoming gas temperatures. For example, for the case of a surrounding temperature of $300 \mathrm{~K}$, the time to steady state took a maximum value of about $50 \mathrm{~s}$ for an incoming gas temperature of $1100 \mathrm{~K}$.

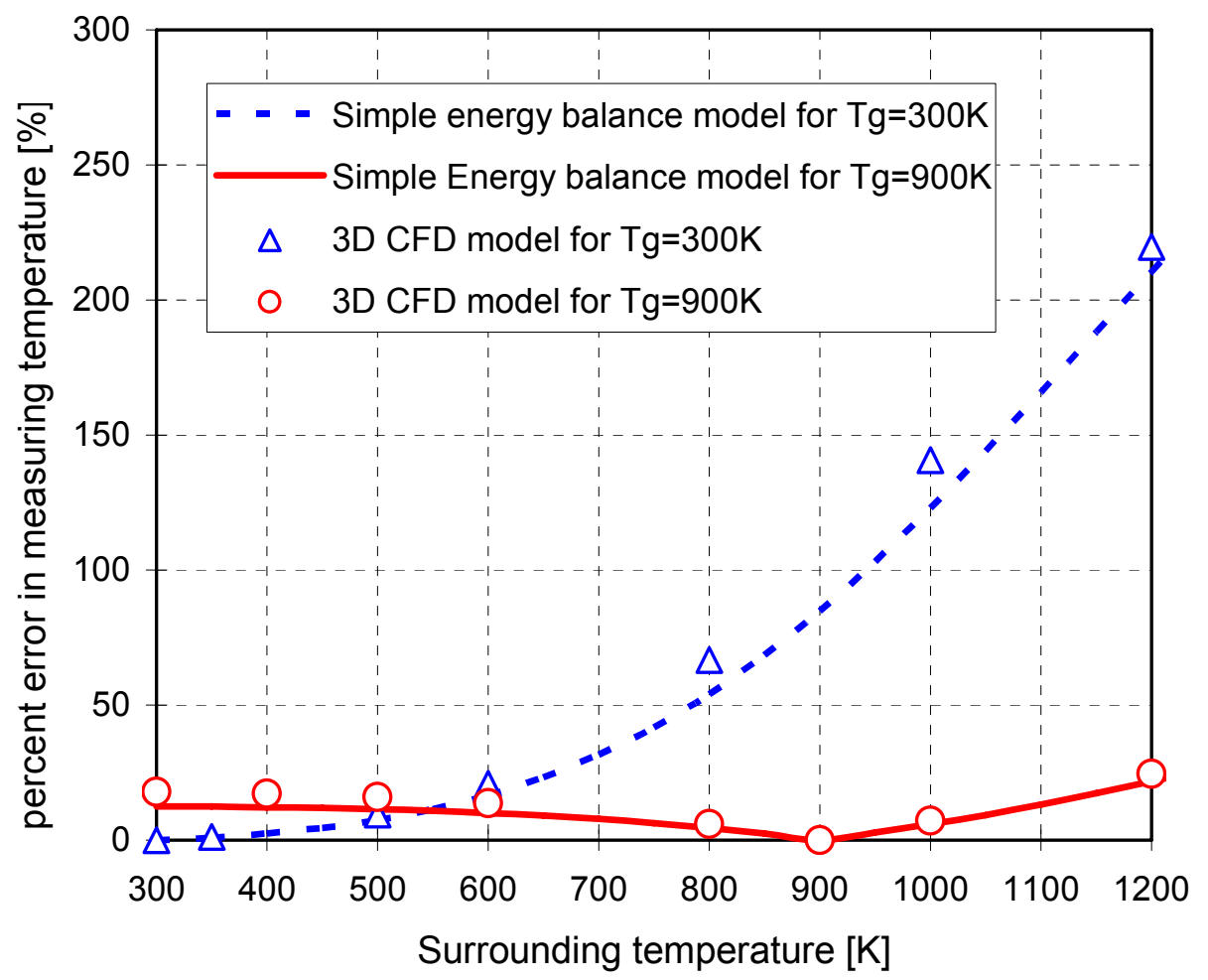

Figure A7. A comparison of the predicted percent error in measuring temperature between the simple energy balance model and the 3D CFD model for bare bead thermocouples with an external gas velocity of $1 \mathrm{~m} / \mathrm{s}$. 


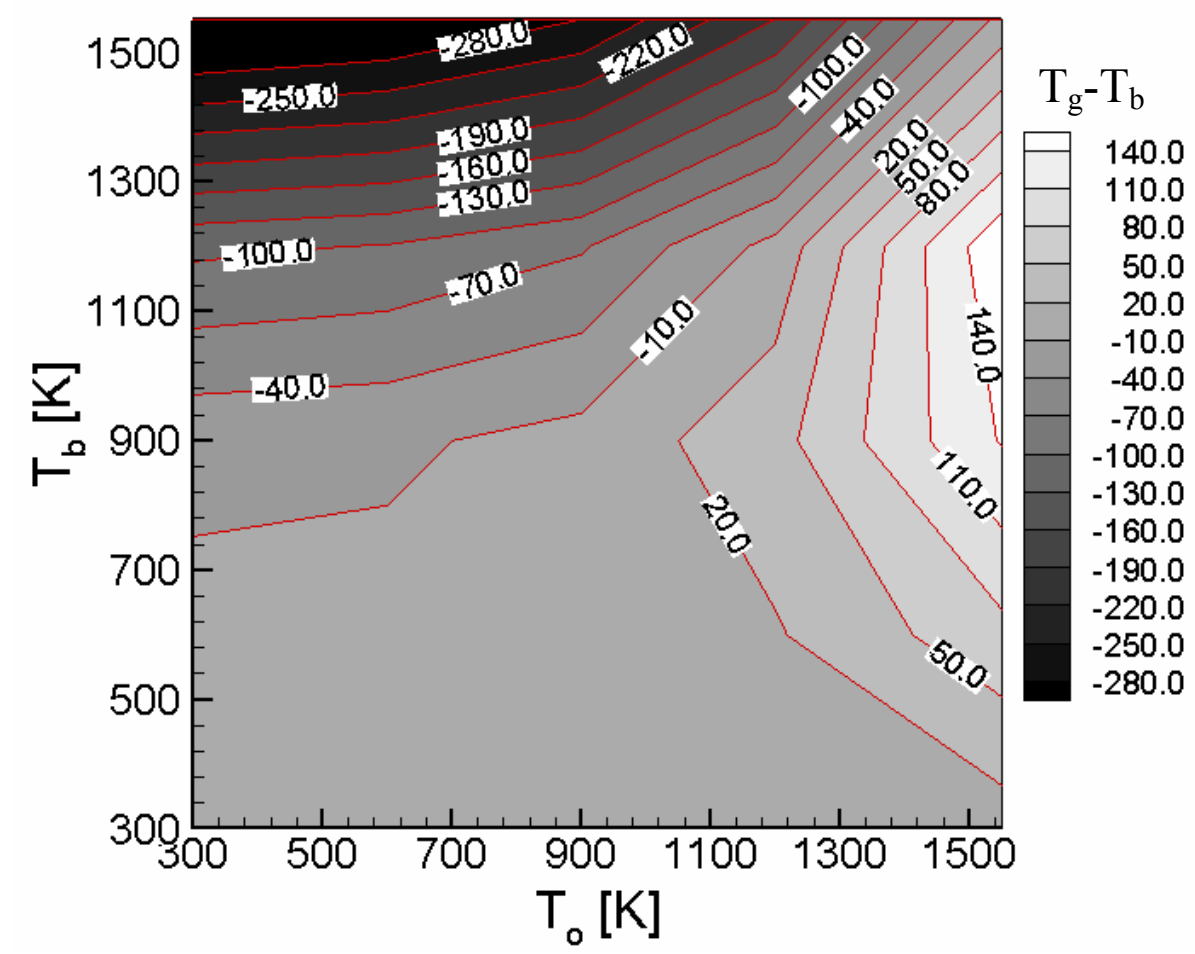

Figure A8. Map of the thermocouple uncertainty for a double shield aspirated thermocouple as a function of the measured $\left(T_{b}\right)$ and surrounding $\left(T_{0}\right)$ temperatures calculated using the CFD model.

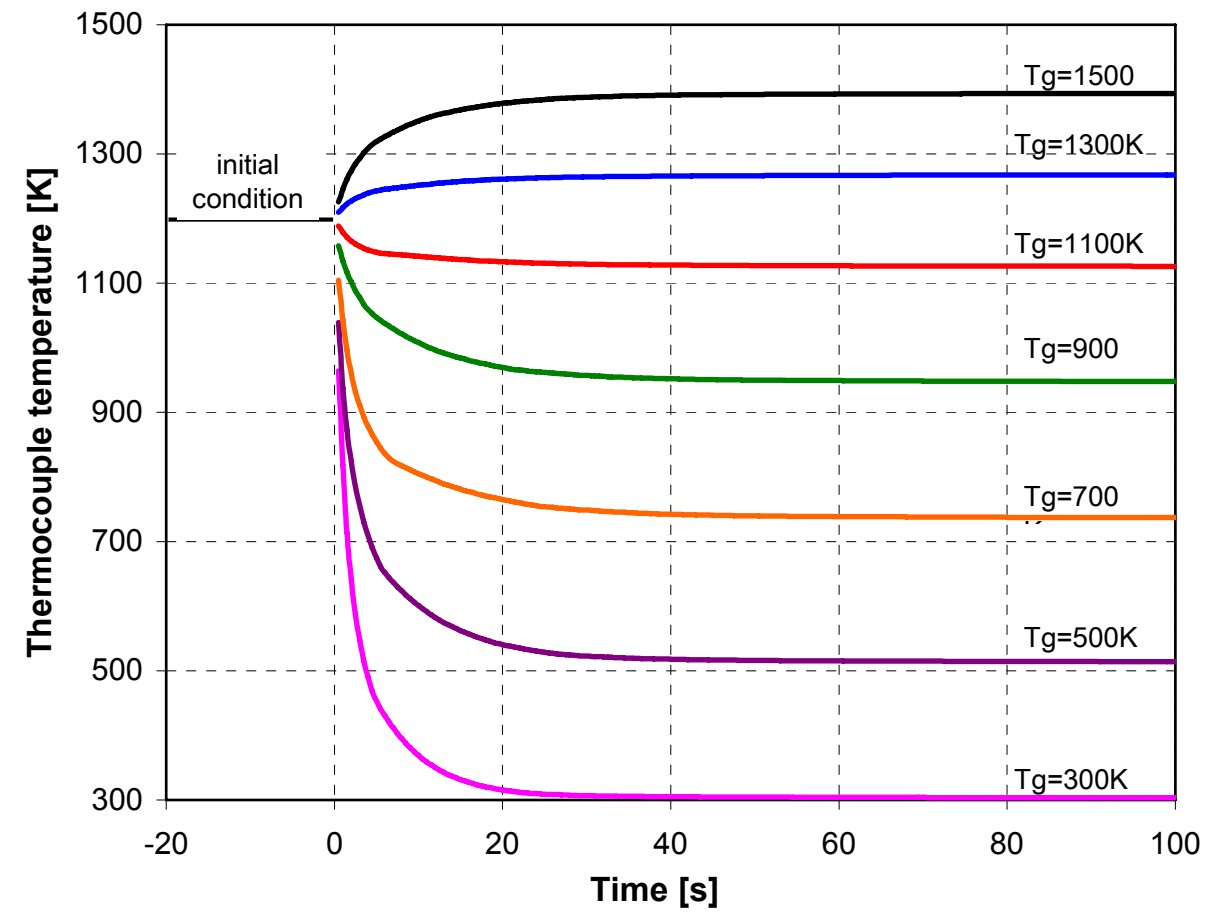

Figure A9. Calculated time history of the temperature of a double shielded aspirated thermocouple for various incoming gas temperatures $\left(\mathrm{T}_{\mathrm{g}}\right)$ with a surrounding temperature of $1200 \mathrm{~K}$ and an aspiration flow of $24 \mathrm{~L} / \mathrm{min}$ ). 


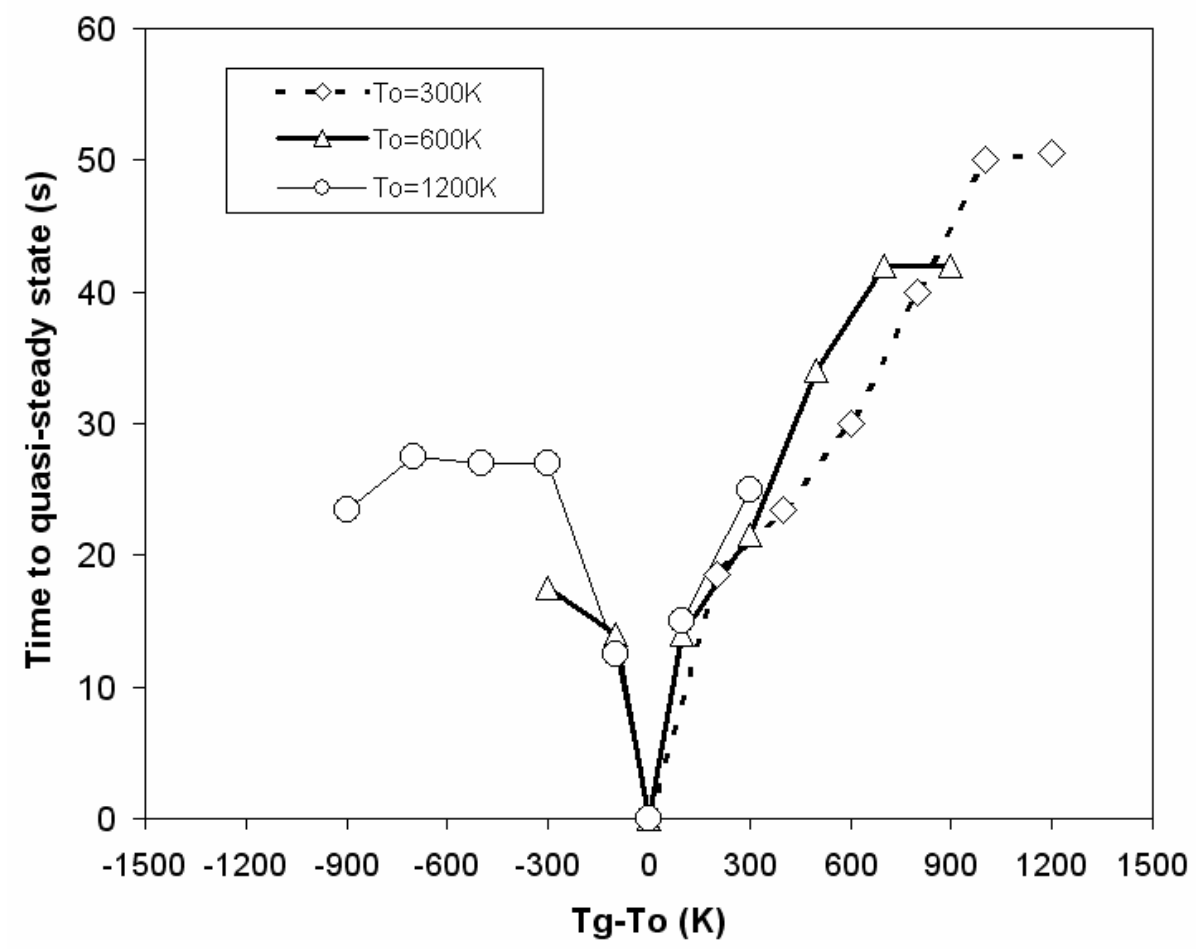

Figure A10. Comparison of calculated time to reach steady state for a double shielded aspirated thermocouple with a $24 \mathrm{~L} / \mathrm{min}$ aspiration flow rate as a function of the incoming gas temperature for surrounding temperatures of $300 \mathrm{~K}, 600 \mathrm{~K}$, and $1200 \mathrm{~K}$.

\section{Summary}

The present study investigated the flow and heat transfer characteristics of aspirated thermocouples using a simple energy balance model and a 3D CFD model. The calculations quantify the systematic measurement error, providing an estimate of the measurement uncertainty. At the same time, the model provides information on the time to achieve steadystate, which should be carefully considered in terms of the development of an experimental procedure and in the interpretation of the results.

Despite the application of additional assumptions and idealizations, calculations using the previously developed algebraic energy balance model generally showed good agreement with the results of the 3D CFD model. The algebraic model can be useful, particularly in parametric studies used to evaluate thermocouple measurement error. Consistent with previous findings, calculations show that use of the double shield aspirated thermocouple can greatly reduce the thermocouple error especially for low gas temperatures. The results, however, can still be biased by hundreds of degrees, depending on the conditions. Figure A8 provides information on the magnitude of the measurement error for a given value of the surrounding temperature. Since the surrounding temperature takes on multiple values and is a complex function of thermocouple location and fire conditions, a representation of the surrounding temperature can be made based on estimated temperature averages. Precise determination of the surrounding temperature is impossible, and engineering judgment is a key component of the uncertainty analysis. 
The results of the CFD model allow determination of the transient response of the double shield aspirated thermocouple, which is helpful in the interpretation of measurement results and possibly for design of the experiment itself. The calculated time response of the aspirated thermocouples suggests that while the measurements provide an adequate representation of the average local temperature, they do not provide an accurate representation of the magnitude of the temperature excursions. Turning the aspiration flow off during the experiment may bias the results if the time response is not taken into account. As a rule of thumb, for incoming gas temperatures less than $900 \mathrm{~K}$, an aspirated thermocouple should be in place for at least $1 / 2 \mathrm{~min}$ before the data should be considered acceptable. For incoming gas temperatures greater than $900 \mathrm{~K}$, an aspirated thermocouple should be in place for about $1 \mathrm{~min}$ before the data should be considered acceptable, unless the thermocouple is sampling from an optically thick upper layer, when $1 / 2$ min should be adequate.

\section{References}

[1] Blevins, L.G., Behavior of bare and aspirated thermocouples in compartment fires, Proc. $33^{\text {rd }}$ National Heat Transfer Conference, New Mexico, August 15-17, 1999.

[2] ICEM-CFD Version 4.0, User's Manual.

[3] FLUENT Inc., FLUENT Version 6.0 User's Guide.

[4] Burns, G. W. and Scroger, M. G., The calibration of thermocouples and thermocouple materials, NIST Special Publication 250-35, 1989.

[5] Incropera, F. P and DeWitt, D. P., Introduction to Heat Transfer, 2nd edition, Willy, 1993. 


\section{B. Analysis of Probe Interactions}

There were five different types of measurement probes at various positions in the fire compartment. They included bi-directional probes for velocity, bare-bead and aspirated thermocouples for temperature, gas sampling tubes for gas species and soot sampling probes for the gravimetric soot measurement. These probes affect the flow field through geometric obstructions and create a flow sink due to the extraction of combustion gas. The effects of the probes on the flow field were not avoidable in the measurement system, but should be minimized during the test. Among the measurement probes, the suction type probes, such as the aspirated thermocouples, gas and soot sampling probes could significantly influence the flow field. If the suction type probes are operated too close to each other, there could be an interaction associated with the suction flow rate.

Before the tests were conducted, numerical simulations were used to investigate the effect of the sampling probe on the flow field for various operating conditions. The interactions between the aspirated thermocouples and the gas sampling probes were investigated because of the high suction flow rate. The experimental suction flow rate of the soot probe was similar to the gas sampling probe $(\mathrm{Q} \approx 3 \mathrm{~L} / \mathrm{min} @ 300 \mathrm{~K})$.

Figure B1shows the configuration of the two sampling probes perpendicular to incoming gas flow. The flow field near the entrance of the sampling probe was examined for the typical operating conditions of the probes $\left(\mathrm{Q}_{1}=30 \mathrm{~L} / \mathrm{min}\right.$ for the aspirated thermocouple, $\mathrm{Q}_{2}=3 \mathrm{~L} / \mathrm{min}$ for the gas sampling). In the calculations the incoming gas had a constant velocity $\left(U_{g}\right)$ and gas temperature $\left(\mathrm{T}_{\mathrm{g}}\right)$. Figure $\mathrm{B} 2$ shows the velocity field near the sampling probe for an incoming gas velocity of $1 \mathrm{~m} / \mathrm{s}$, and a gas temperature of $900 \mathrm{~K}$. The influence of the sampling flow rate was restricted to the probe entrance. Generally, the gas velocities induced by the fire were much higher than the suction velocities of the sampling probes, and the effect of the probe suction on the flow field was negligible.

Figure B3 shows the streamlines at the center-plane of the probe. The distance from the probe entrance to the aspirated flow field disturbance was on the order of one diameter. Figure B4 and Fig. B5 represent the static pressure and stream-wise velocity $\left(\mathrm{U}_{\mathrm{x}}\right)$ profiles along the center axis of the probes for the $1 \mathrm{~m} / \mathrm{s}$ gas velocity and $900 \mathrm{~K}$ temperature. The static pressure and streamwise velocity do not vary significantly in this configuration. Also, the velocity profiles of the aspirated thermocouple and the gas sampling probe have nearly the same magnitude. If one probe affects the flow field of the other probe, the velocity profiles would not match. The incoming gas flow dominates the entire flow field except at the entrance of the probes because the flow rate of the sampling probes is relatively small compared to the main gas flow. Therefore, the probe interactions were negligible in the main plume of the fire induced flow, but in a low velocity region such as stagnation or recirculation zone, the suction from one probe can affect the flow field and the measurement volume being interrogated by other probes. 


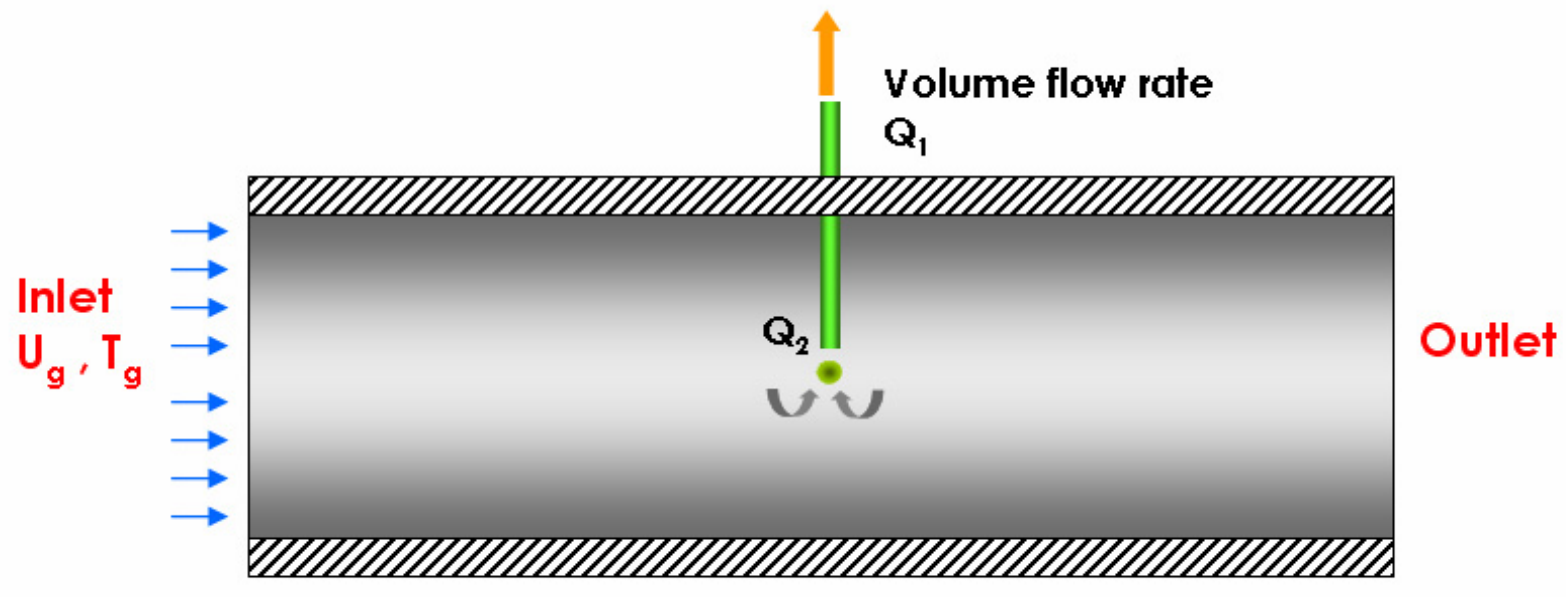

Figure B1. Schematic of the calculations of the sampling probes interaction.

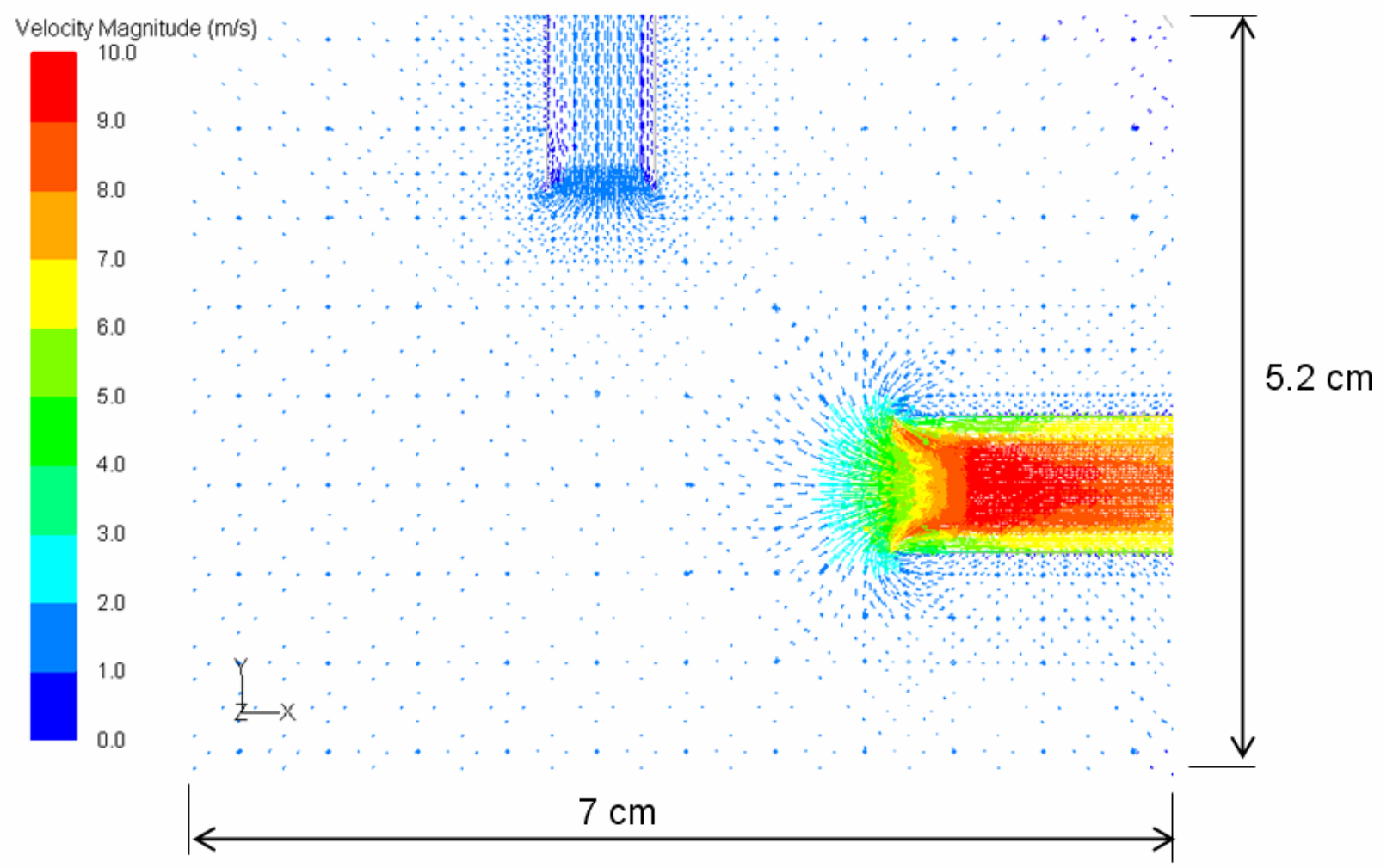

Figure B2. Velocity field across cross-section of the probes position. 


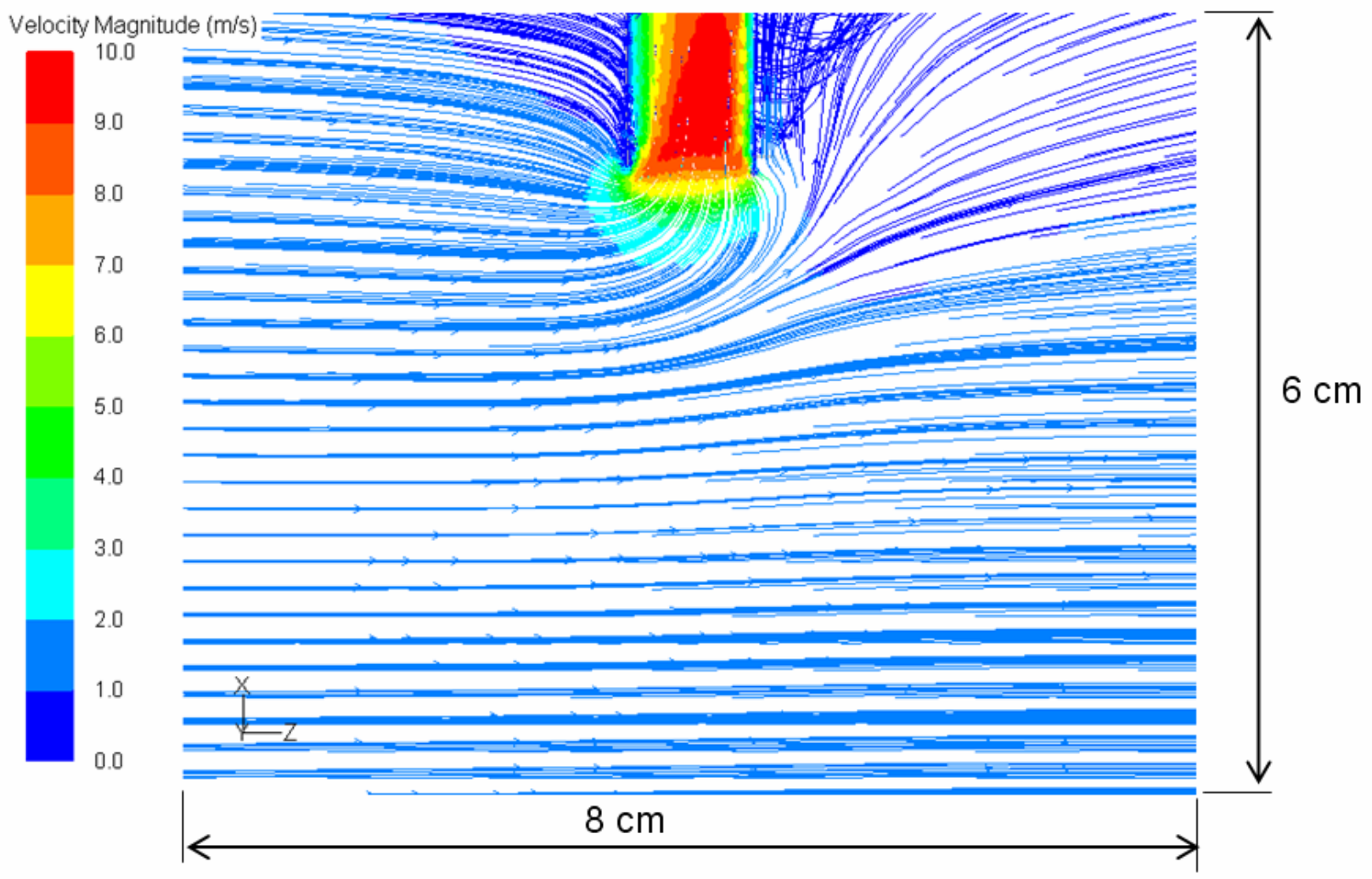

Figure B3. Streamlines near the aspirated thermocouple.

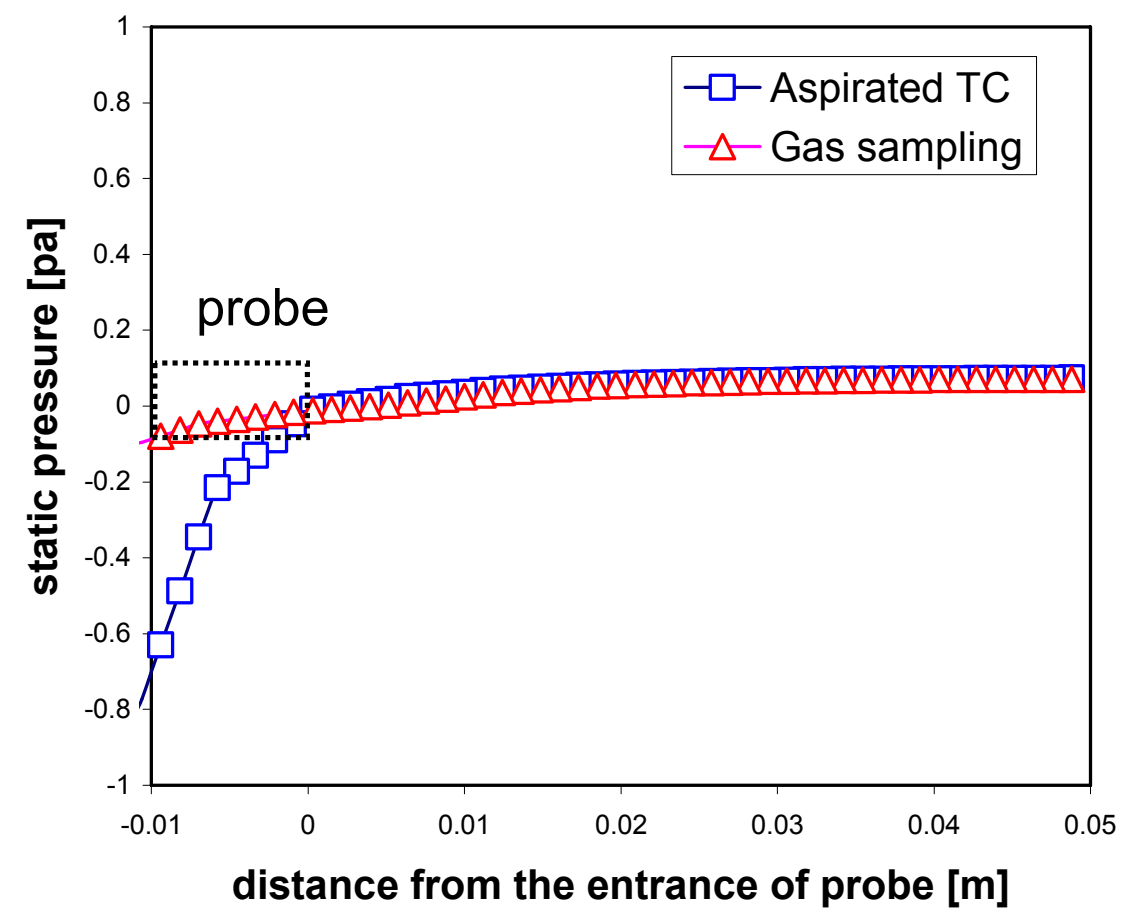

Figure B4. Static pressure profiles along the center axis of the probes. 


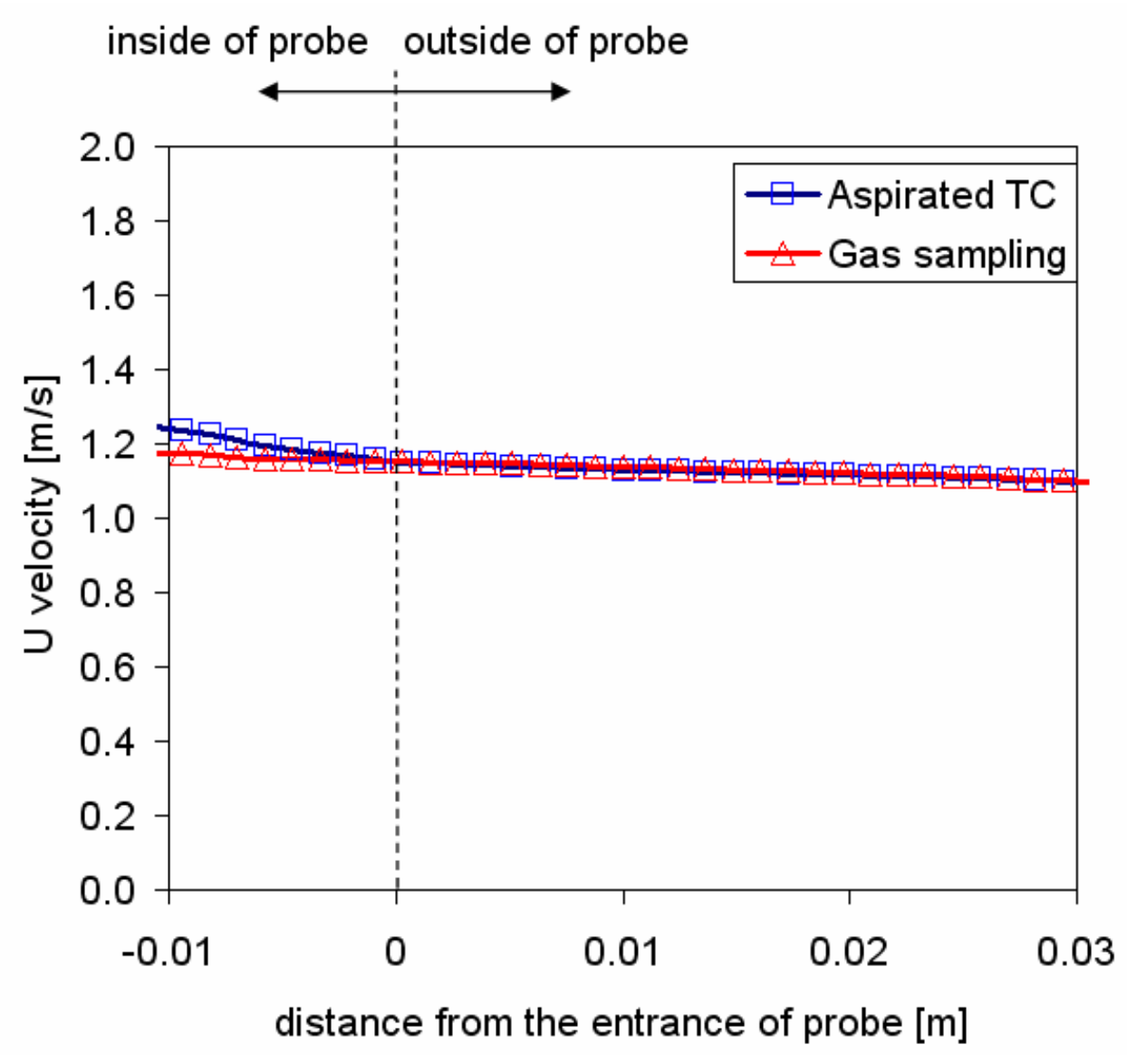

Figure B5. U-velocity profile along the center axis of the probes. 


\section{Channel Lists}

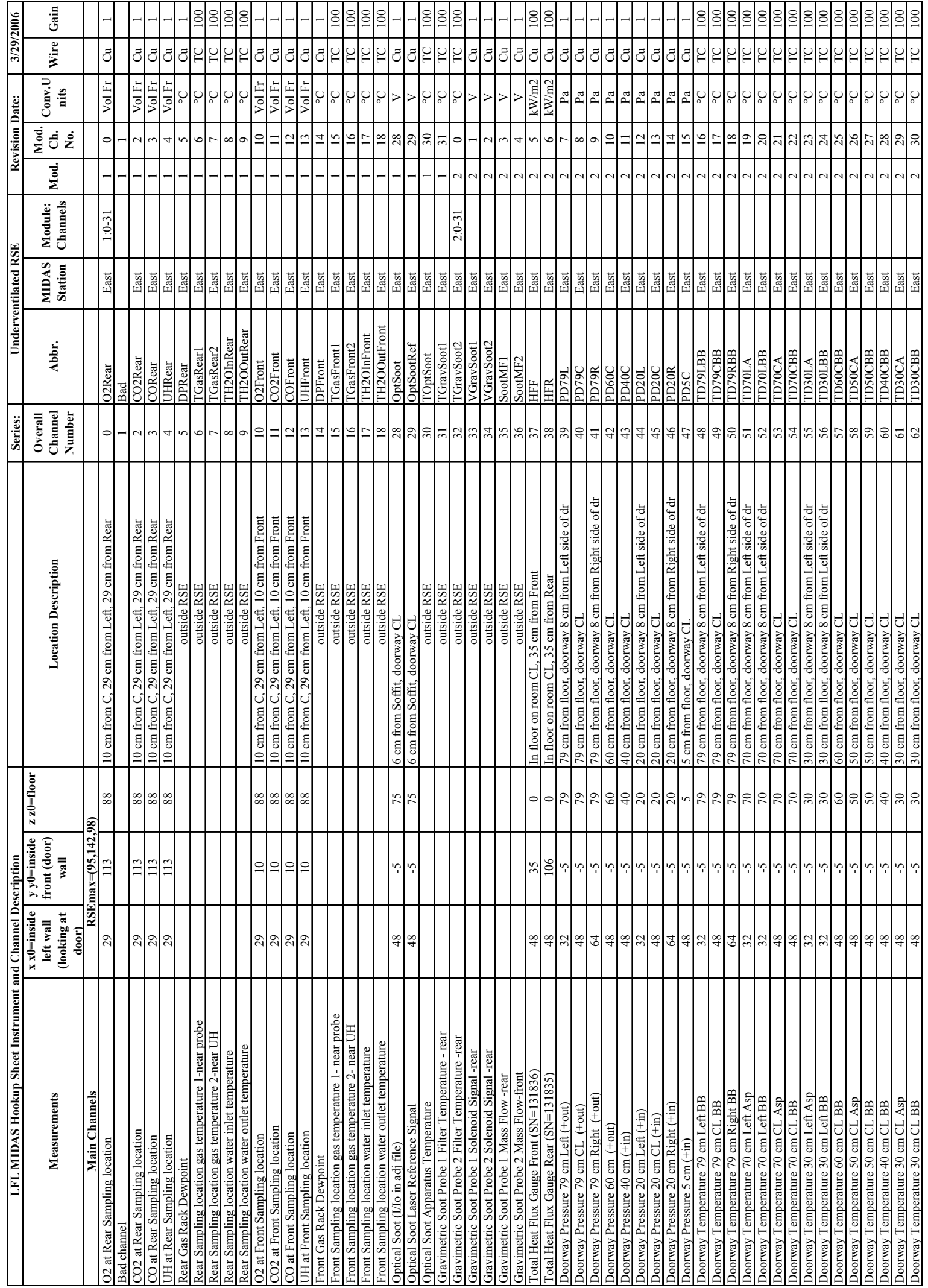




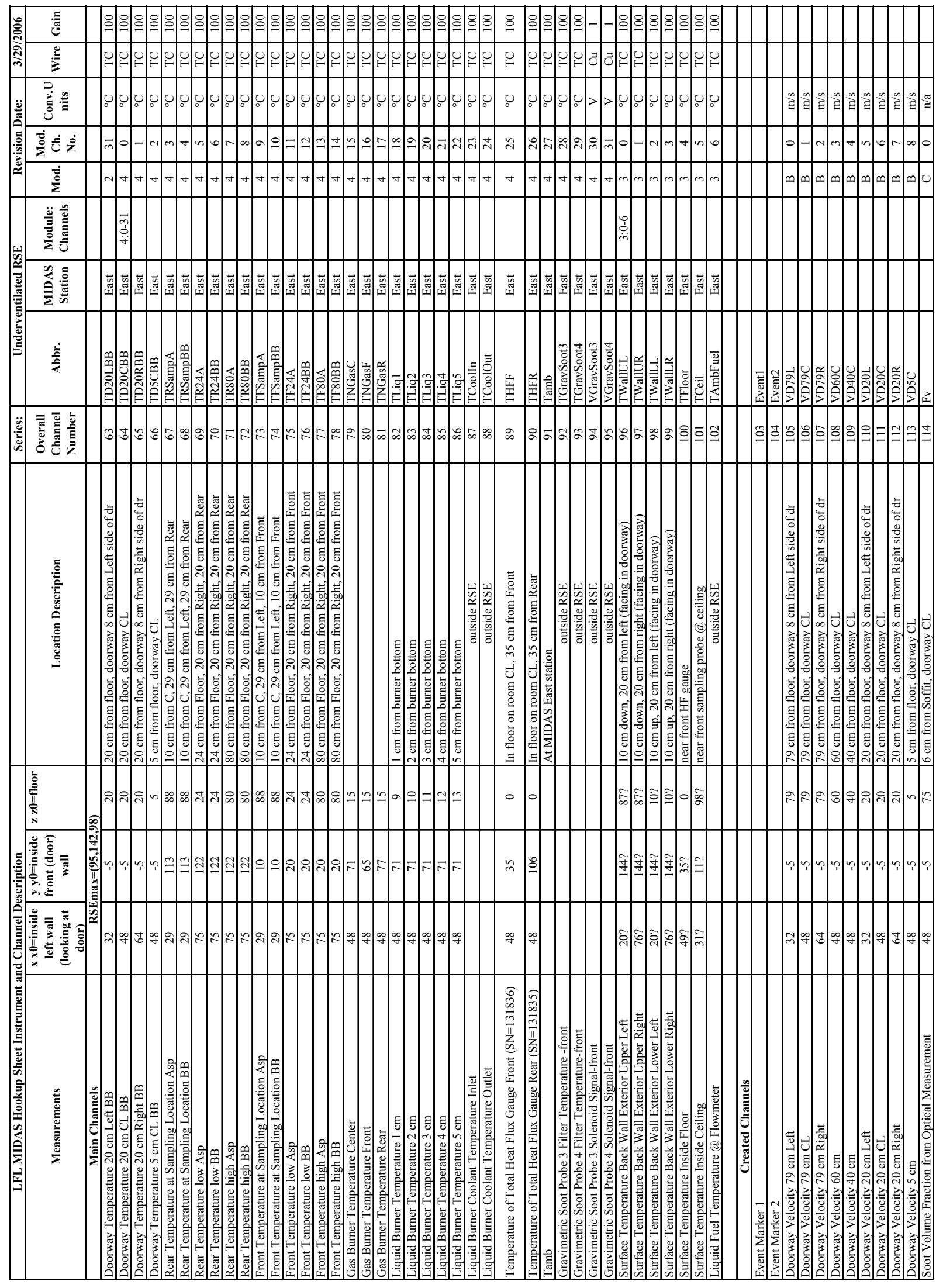




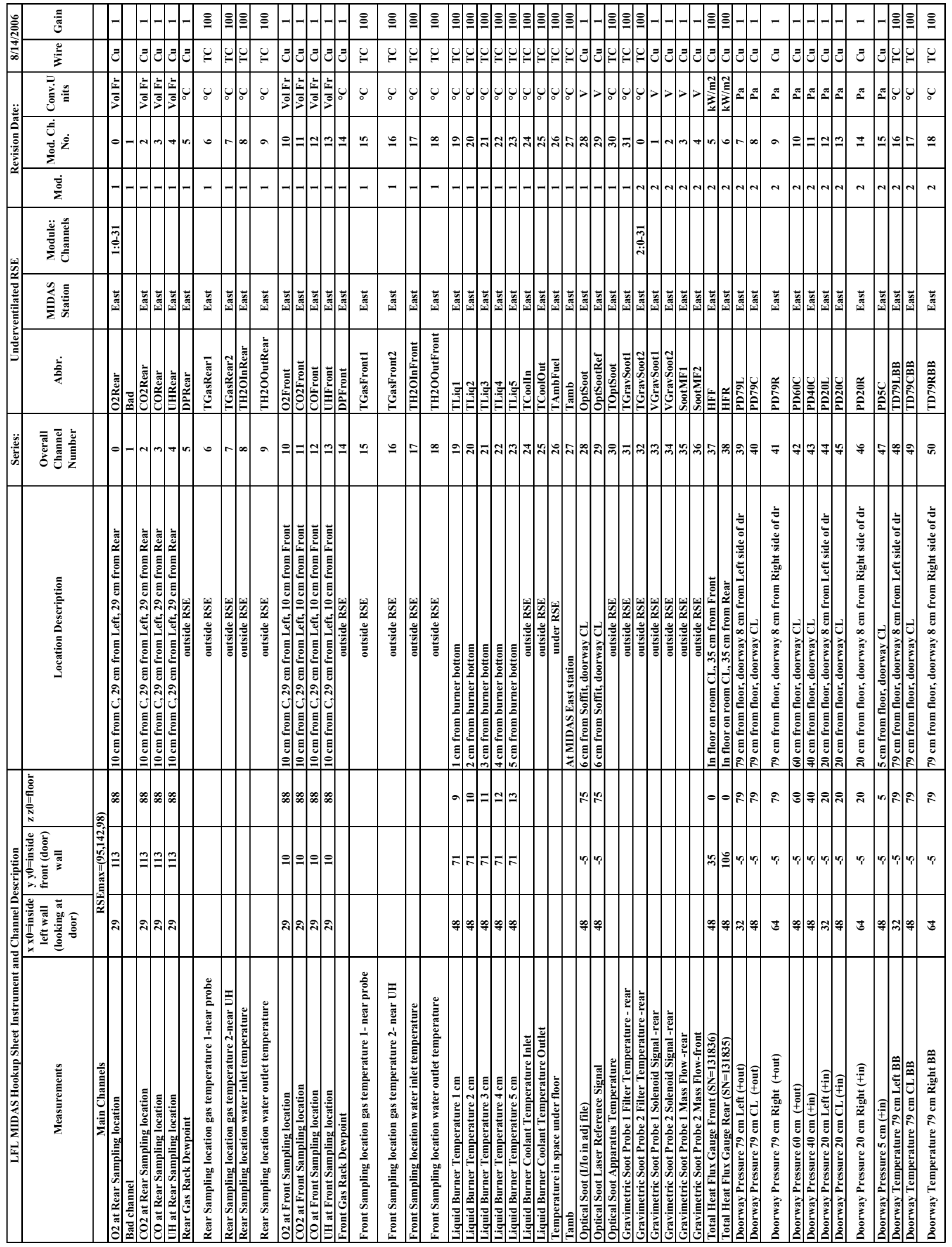




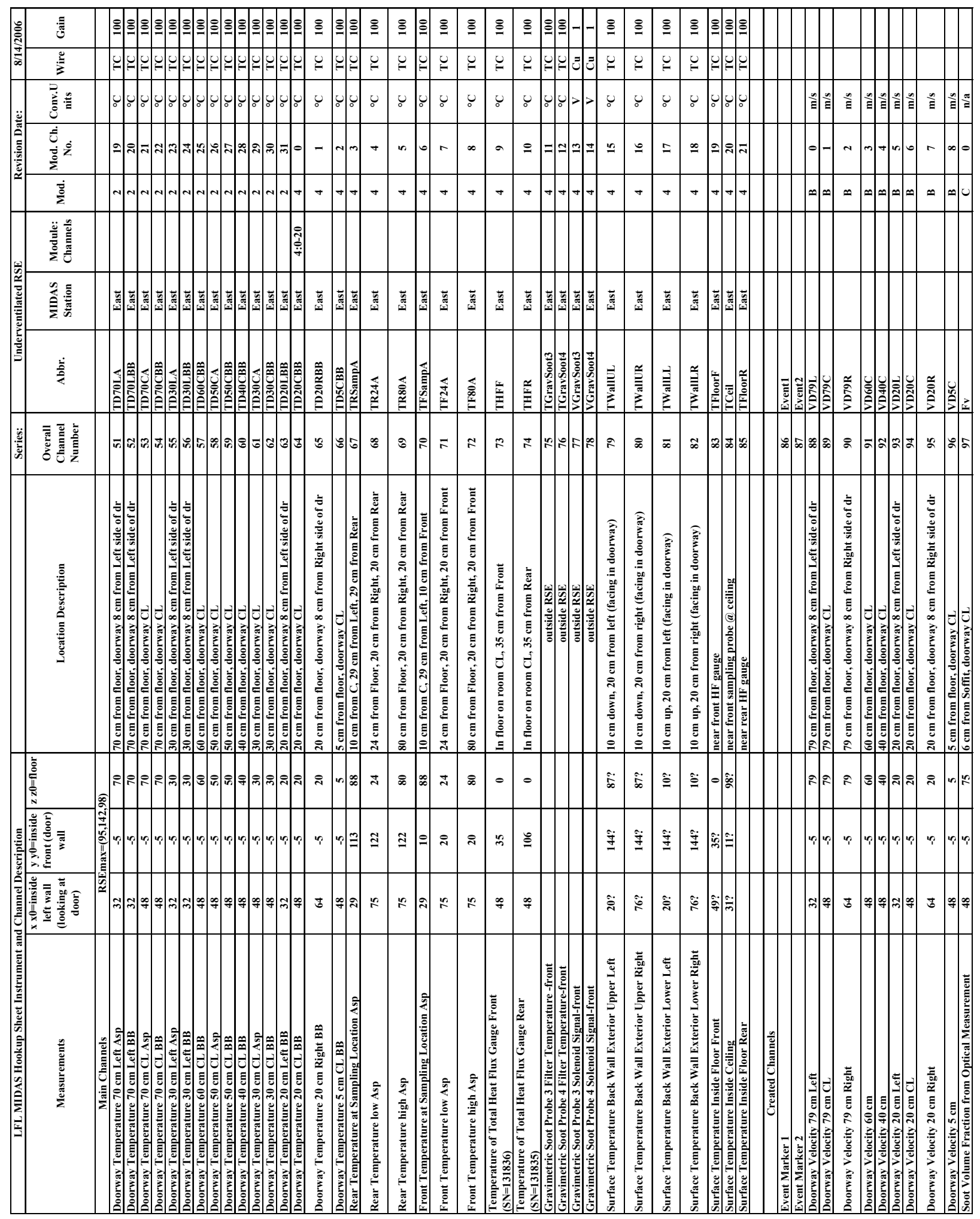




\section{Description of data columns (channels) in reduced ASCII data files.}

\begin{tabular}{|c|c|c|c|c|}
\hline \multirow{2}{*}{$\begin{array}{l}\text { Channel Name (units) } \\
1 \text { Time From Ignition (s) } \\
\end{array}$} & \multicolumn{3}{|c|}{$\begin{array}{c}\text { Position }(\mathrm{cm}) \\
\text { RSEmax }=(95,142,98)\end{array}$} & \multirow{2}{*}{\begin{tabular}{|l|} 
Description of Measurement \\
Time relative to ignition defined by Event 1 \\
\end{tabular}} \\
\hline & NA & NA & NA & \\
\hline 2 O2Rear $(\mathrm{mol} / \mathrm{mol})$ & 29 & 113 & 88 & Rear O2 volume fraction corrected for water (wet) \\
\hline 3 CO2Rear $(\mathrm{mol} / \mathrm{mol})$ & 29 & 113 & 88 & Rear $\mathrm{CO} 2$ volume fraction corrected for water (wet) \\
\hline 4 CORear $(\mathrm{mol} / \mathrm{mol})$ & 29 & 113 & 88 & Rear CO volume fraction corrected for water (wet) \\
\hline 5 THCRear $(\mathrm{mol} / \mathrm{mol})$ & 29 & 113 & 88 & Rear Total Hydrocarbons volume fraction corrected for water (wet) \\
\hline 6 SootRear $(\mathrm{g} / \mathrm{g})$ & 29 & 113 & 88 & Rear Soot Mass fraction corrected for water (wet) \\
\hline 7 O2Front $(\mathrm{mol} / \mathrm{mol})$ & 29 & 10 & 88 & Front $\mathrm{O} 2$ volume fraction corrected for water (wet) \\
\hline $8 \mathrm{CO} 2$ Front $(\mathrm{mol} / \mathrm{mol})$ & 29 & 10 & 88 & Front $\mathrm{CO} 2$ volume fraction corrected for water (wet) \\
\hline 9 COFront $(\mathrm{mol} / \mathrm{mol})$ & 29 & 10 & 88 & Front $\mathrm{CO}$ volume fraction corrected for water (wet) \\
\hline 10 THCFront $(\mathrm{mol} / \mathrm{mol})$ & 29 & 10 & 88 & Front Total Hydrocarbons volume fraction corrected for water (wet) \\
\hline 11 SootFront $(\mathrm{g} / \mathrm{g})$ & 29 & 10 & 88 & Front Soot Mass fraction corrected for water (wet) \\
\hline $12 \mathrm{HFR}(\mathrm{kW} / \mathrm{m} 2)$ & 48 & 106 & 0 & Total Heat Flux at Rear Floor \\
\hline $13 \mathrm{HFF}(\mathrm{kW} / \mathrm{m} 2)$ & 48 & 35 & 0 & Total Heat Flux at Front Floor \\
\hline 14 TambCal (C) & NA & NA & NA & Ambient Temperature in LFL \\
\hline 15 TRSampA (C) & 29 & 113 & 88 & Aspirated thermocouple at rear sample location \\
\hline 16 TFSampA (C) & 29 & 10 & 88 & Aspirated thermocouple at front sample location \\
\hline 17 TR24A (C) & 75 & 122 & 24 & Aspirated thermocouple in RSE \\
\hline 18 TR80A (C) & 75 & 122 & 80 & Aspirated thermocouple in RSE \\
\hline $19 \mathrm{TF} 24 \mathrm{~A}(\mathrm{C})$ & 75 & 20 & 24 & Aspirated thermocouple in RSE \\
\hline 20 TF80A (C) & 75 & 20 & 80 & Aspirated thermocouple in RSE \\
\hline 21 TFloorR (C) & 49 & 106 & 0 & Bare-bead thermocouple near heat flux gauge \\
\hline 22 TFloorF (C) & 49 & 35 & 0 & Bare-bead thermocouple near heat flux gauge \\
\hline 23 TCeilF $(C)$ & 31 & 11 & 98 & Bare-bead thermocouple on ceiling \\
\hline 24 TWallUR (C) & 19 & 144 & 87 & Bare-bead thermocouple on outside rear wall \\
\hline 25 TUFloor $(\mathrm{C})$ & & & & Bare-bead thermocouple in space below floor \\
\hline 26 TD79LBB (C) & 32 & -5 & 79 & Bare-bead thermocouple in doorway \\
\hline 27 TD79CBB (C) & 48 & -5 & 79 & Bare-bead thermocouple in doorway \\
\hline 28 TD79RBB (C) & 64 & -5 & 79 & Bare-bead thermocouple in doorway \\
\hline 29 TD70LA (C) & 32 & -5 & 70 & Aspirated thermocouple in doorway \\
\hline 30 TD70LBB (C) & 32 & -5 & 70 & Bare-bead thermocouple in doorway \\
\hline 31 TD70CA (C) & 48 & -5 & 70 & Aspirated thermocouple in doorway \\
\hline 32 TD70CBB (C) & 48 & -5 & 70 & Bare-bead thermocouple in doorway \\
\hline 33 TD30LA (C) & 32 & -5 & 30 & Aspirated thermocouple in doorway \\
\hline 34 TD30LBB (C) & 32 & -5 & 30 & Bare-bead thermocouple in doorway \\
\hline 35 TD60CBB (C) & 48 & -5 & 60 & Bare-bead thermocouple in doorway \\
\hline 36 TD50CA (C) & 48 & -5 & 50 & Aspirated thermocouple in doorway \\
\hline 37 TD50CBB (C) & 48 & -5 & 50 & Bare-bead thermocouple in doorway \\
\hline 38 TD40CBB $(\mathrm{C})$ & 48 & -5 & 40 & Bare-bead thermocouple in doorway \\
\hline 39 TD30CA (C) & 48 & -5 & 30 & Aspirated thermocouple in doorway \\
\hline 40 TD30CBB $(C)$ & 48 & -5 & 30 & Bare-bead thermocouple in doorway \\
\hline 41 TD20LBB (C) & 32 & -5 & 20 & Bare-bead thermocouple in doorway \\
\hline 42 TD20CBB (C) & 48 & -5 & 20 & Bare-bead thermocouple in doorway \\
\hline 43 TD20RBB (C) & 64 & -5 & 20 & Bare-bead thermocouple in doorway \\
\hline 44 TD5CBB $(\mathrm{C})$ & 48 & -5 & 5 & Bare-bead thermocouple in doorway \\
\hline $45 \mathrm{VD} 79 \mathrm{~L}(\mathrm{~m} / \mathrm{s})$ & 32 & -5 & 79 & Bi-directional probe velocity in doorway \\
\hline 46 VD79C $(\mathrm{m} / \mathrm{s})$ & 48 & -5 & 79 & Bi-directional probe velocity in doorway \\
\hline 47 VD79R $(\mathrm{m} / \mathrm{s})$ & 64 & -5 & 79 & Bi-directional probe velocity in doorway \\
\hline 48 VD60C $(\mathrm{m} / \mathrm{s})$ & 48 & -5 & 60 & Bi-directional probe velocity in doorway \\
\hline 49 VD $40 \mathrm{C}(\mathrm{m} / \mathrm{s})$ & 48 & -5 & 40 & Bi-directional probe velocity in doorway \\
\hline 50 VD20L $(\mathrm{m} / \mathrm{s})$ & 32 & -5 & 20 & Bi-directional probe velocity in doorway \\
\hline 51 VD20C $(\mathrm{m} / \mathrm{s})$ & 48 & -5 & 20 & Bi-directional probe velocity in doorway \\
\hline 52 VD20R $(\mathrm{m} / \mathrm{s})$ & 64 & -5 & 20 & Bi-directional probe velocity in doorway \\
\hline 53 VD5C $(\mathrm{m} / \mathrm{s})$ & 48 & -5 & 5 & Bi-directional probe velocity in doorway \\
\hline 54 HRRcal (kW) & & & & Heat Release Rate from Calorimeter \\
\hline 55 HRRburner (kW) & & & & Heat Release Rate from Burner (gas, pool or spray) \\
\hline 56 StackMFR $(\mathrm{kg} / \mathrm{s})$ & & & & Exhaust hood mass flow rate \\
\hline 57 Tstack $(\mathrm{C})$ & & & & Exhaust hood temperature (near bi-directional probe) \\
\hline 58 O2stack $(\mathrm{mol} / \mathrm{mol})$ & & & & Exhaust $\mathrm{O} 2$ volume fraction (dry) \\
\hline 59 CO2stack (mol/mol) & & & & Exhaust $\mathrm{CO} 2$ volume fraction (dry) \\
\hline 60 COstack $(\mathrm{mol} / \mathrm{mol})$ & & & & Exhaust CO volume fraction (dry) \\
\hline 61 THCstack $(\mathrm{mol} / \mathrm{mol})$ & & & & Exhaust total hydrocarbons volume fraction (dry) \\
\hline 62 MSstack $(\mathrm{mg} / \mathrm{m3})$ & & & & Exhaust soot mass concentration (wet) \\
\hline $63 \mathrm{H} 2 \mathrm{ORear}(\mathrm{mol} / \mathrm{mol})$ & 29 & 113 & 88 & Rear water volume fraction (calculated from $\mathrm{CO} / \mathrm{CO} 2$ ) \\
\hline 64 H2OFront (mol/mol) & 29 & 10 & 88 & Front water volume fraction (calculated from $\mathrm{CO} / \mathrm{CO} 2$ ) \\
\hline
\end{tabular}




\section{Equipment List}

\begin{tabular}{|c|c|c|c|c|}
\hline Description & Manufacturer & Model & Serial\# & NIST\# \\
\hline Oxygen analyzer for HRR & Servomex & $540 \mathrm{~A}$ & & 549709 \\
\hline $\mathrm{CO}_{2} / \mathrm{CO}$ analyzer for $\mathrm{HRR}$ & Seimens & Ultramat 6 & & 615207 \\
\hline Total HC analyzer for HRR & Rosemount & $400 \mathrm{~A}$ & & 569041 \\
\hline Mass flow controller for HRR & MKS & 1179A53C & 000346712 & \\
\hline Dew Point Transmitter for HRR & Vaisala & DMT242 & A4850006 & \\
\hline Sample dryer for HRR & PermaPure & PD-200T-72SS & $973-0905-6$ & \\
\hline Micro $\mathrm{GC}$ for natural gas & Agilent & $3000 \mathrm{~A}$ & & 623489 \\
\hline Sample pump for HRR & Gast & MOA-P122-AA & $4 Z 026$ & \\
\hline Liquid fuel turbine flow meter & Exact Flow & & & \\
\hline Natural gas flow meter & Instromet & IRMA 15M-125 & 319396 & 605032 \\
\hline Total heat flux gauge (HF Front) & Medtherm & $\begin{array}{l}16-0.75-10-4-12- \\
36-20679 k\end{array}$ & 131836 & \\
\hline Total heat flux gauge (HF Rear) & Medtherm & $\begin{array}{l}16-0.75-10-4-12- \\
36-20679 k\end{array}$ & 131835 & \\
\hline Oxygen Analyzer (O2Rear) & Servomex & 4100 & 393063 & 623487 \\
\hline Oxygen Analyzer (O2Front) & Servomex & 4100 & 393064 & 623488 \\
\hline $\mathrm{CO}_{2} / \mathrm{CO}$ Analyzer (Rear) & Seimens & Ultramat $6 \mathrm{E}$ & NI-L00197 & 600671 \\
\hline $\mathrm{CO}_{2} / \mathrm{CO}$ Analyzer (Front) & Seimens & Ultramat 6E & & 609425 \\
\hline Total HC analyzer (Rear) & Baseline-Mocon & $8800 \mathrm{H}$ & & 625764 \\
\hline Total HC analyzer (Front) & Baseline-Mocon & $8800 \mathrm{H}$ & & 623892 \\
\hline Dew point meter (Rear) & Vaisala & DMT242 & B074008 & \\
\hline Dew point meter (Front) & Vaisala & DMT242 & B074009 & \\
\hline Mass flow controller (Rear\&Front) & MKS & M100B53C & & \\
\hline MFC power supply & MKS & $247 \mathrm{D}$ & & \\
\hline Gas Chromatograph (Front) & $\mathrm{HP}$ & $5890 \mathrm{~A}$ & 2843A20868 & 541824 \\
\hline GC column & Restek & Rt-QPLOT & 19718 & \\
\hline Pressure Transducer for Velocity & MKS & $220 \mathrm{DD}$ & & \\
\hline Flow meter (spot check flows) & Bios Dry Cal & DCLT 20K & & \\
\hline $\begin{array}{l}\text { Sample pump for aspirated TCs } \\
\text { and gas sample tests } \# 1-6\end{array}$ & Gast & DOA-P703-FB & & \\
\hline $\begin{array}{l}\text { Gas conditioning system } \\
\text { (Rear\&Front) }\end{array}$ & PermaPure & MG-2812 & & rental \\
\hline Glass-lined stainless steel tubing & Grace Davison & 3149 & & \\
\hline Soot sample MFC & MKS & M100B53CCS1BV & 021407828 & \\
\hline Soot sample MFC & MKS & M100B53CCS1BV & 021407829 & \\
\hline MFC power supply & MKS & 247D & 000763015 & \\
\hline Soot sample filter & Pall & P5PJ047 & & \\
\hline Soot sample cleaning pad & Hoppe's & 1203 & & \\
\hline Soot sample filter holder & Gelman Sciences & 2220 & & \\
\hline $\begin{array}{l}\text { Soot sample 3-way solenoid } \\
\text { valves }\end{array}$ & Parker & $\begin{array}{l}\text { 04F30C2208AAF4 } \\
\text { C05 }\end{array}$ & & \\
\hline Soot sample pumps & Gast & MOA-P122-AA & & \\
\hline
\end{tabular}

